Florida International University FIU Digital Commons

6-1976

\title{
An operator's manual for the reservation and registration monitors of the Moby Data Hospitality System
}

\author{
Mark William Nemtzow \\ Florida International University
}

DOI: $10.25148 /$ etd.FI15092500

Follow this and additional works at: https://digitalcommons.fiu.edu/etd

Part of the Hospitality Administration and Management Commons

\section{Recommended Citation}

Nemtzow, Mark William, "An operator's manual for the reservation and registration monitors of the Moby Data Hospitality System" (1976). FIU Electronic Theses and Dissertations. 2067.

https://digitalcommons.fiu.edu/etd/2067 


\section{AN OPERATOR'S MANUAL \\ FOR THE \\ RESERVATION AND REGISTRATION MONITORS \\ OF THE \\ MOBY DATA HOSPITALITY SYSTEM \\ FOR \\ FLORIDA INTERNATIONAL UNIVERSITY}

\section{Presented to the Faculty of the Hotel School Florida International University for the Degree of \\ Master of Science}

by

Mark Wi11 iam Nemtzow

June 1976 


\section{ACKNOWLEDGMENTS}

The writer wishes to express his appreciation for the guidance given by Mr. George Conrade and thanks also to Mrs. Edward Genre in the preparation of this project. 


\section{PREFACE}

The hospitality industry has been one of the last major business segments in the United States to utilize the computer and its capabilities. Everyone associated with the industry and data processing has contributed to this delay: manufacturers have been very slow to identify and recognize the potential that exists in the hotel industry; data processors have often unwisely attempted to apply the successful solutions of other industries' problems to the hospitality industry; and lodging management has demonstrated little interest and contributed inadequate amounts of physical and economical resources.

The initial attempt by the hotel industry to utilize the computer now seems extremely primitive. The only systems being used were large, complex computers with software designed for other industries with minor changes. The major problem was one of cost justification. With the systems that were in existence a hotel had to have at least 500 rooms with an average rate of $\$ 50$ per room for it to be economically feasible.

The most important breakthrough for the hospitality industry has been the development of the mini-computer. It provided hotelmen with a system that has an acceptable price performance level and has opened doors for computerization in properties as small as 150 rooms. The mini-computer has provided the industry with the realistically-priced tools it 
needed to finally accomplish the goal of developing a powerful real-time hotel management information system.

One of the mini-computer systems that is now servicing

our industry is the Moby Data Hospitality System.

The Moby Data System is a complete hardware and software package that may be easily converted to almost any property. However, the training of the hotel employees in its usage, has been accomplished by personal instruction in the past.

The purpose of this paper is to develop a manual of instruction for the Moby Data Hospitality System at Florida International University. It is by no means a replacement for personal instruction on the system, but to be used as an aid for a better and more complete understanding of its capabilities and usage. 


\section{TABLE OF CONTENTS}

Page

Acknowledgment

Preface

Chapter I - Reservations 1

Reservation Monitor 1

1. Display Availability 2

2. Enter a Reservation 5

3. Change a Reservation 10

4. Display a Reservation 14

5. Deposit Received on A Reservation 17

6. Cancel a Reservation 19

7. Convention Monitor 22

a. Add a Master Record 23

b. Change a Master Record 27

c. Delete a Master Record 29

d. Display a Master Record 31

e. Convention Reports Monitor 33

1. Print Convention Reports 34

2. Print Room List 37

3. Print Convention
Transaction File

4. Exit 41

f. Exit 42

8. Reports Monitor 43

a. Print Today's Arrivals 44

b. Print House Forecast 46 
c. Print Today's Reservation Transactions

d. Print All Reservations With Deposit

e. Print Deposit Transactions

f. Print Reservations by offer Unti 1 Date

g. Print Confirmation of Today's Deposits

h. Print Deposit Request Letter

i. Print A11 Reservations

j. Order, Capacity, Financial Checks

k. End-of-Day Reservations

1. Return

9. Return to Do What

1. Check In

2. Update Room Records 87

3. Post Charges 92

4. Reports Monitor 97

a. Transaction by Key 98

b. Arrivals and Departures 99

c. Housekeeper's Report 102

d. Type of Payment 104

e. Print Auditt Trail by Time 105

f. Print Audit Trail by Type 107 
g. Print Guest Accounts 108

h. Shift Audit 110

i. Blank Registration Forms 113

j. Current House Status 114

5. Bill Listing - Check Out 117

6. Print Guest Message 123

7. Departed Guest Bill 125

8. Name Search 129

9. Change Room Status 131

10. Print/Display Available Rooms 133

11. Guest Room Transfer 137

12. Print/Display Registered Guests 139

13. Return to Systems 142

$\begin{array}{ll}\text { Appendix "A" } & 143\end{array}$

Appendix "B" Separate Volume 


\section{CHAPTER I}

\section{RESERVATION PROGRAM:}

A. The MOBYDATA HOSPITALITY SYSTEM enables any hotel employee to perform the job/function of a reservation clerk. All programs required to book, display, modify or cancel room reservations for dates up to one year in in advance are contained in the RESERVATION MONITOR. (Reservation records are stored on the rotating disc memory device and form the master reservation file.)

B. The reservationist need only select the job/function by number from the Reservation Monitor, display (1-A), XMIT, and receive the appropriate instructions and/or frame fills to accomplish the task, and print a variety of reports, forms and letters.

\section{$(1-\beta)$}

$$
\text { RESERVATION MONITOR } \quad 4 / 28 / 1976 \quad 10: 59
$$
1. DISPLAY AVAILABILITY
2. ENTER NEW RESERVATION
3. CHANGE RESERVATION
4. DISPLAY A RESERVATION
5. DEPOSIT RECEIVED ON RESERVATION
6. CANCEL A RESERVATION
7. CONVENTION MONITOR
8. REPORTS MONITOR
9. RETURN TO DO WHAT ENTER \#: 


\section{1, 1. DISPLAY AVAILABILITY}

A. This function enables the reservationist to observe how many rooms, by total and type are available during a 10 day time frame within the current 730 dayperiod.

B. The program is accessed by typing the number (1) on the Reservation Monitor (1-A), XMIT, and receive the first frame fil1, display $(1,1-1)$.

$$
(1,1-1)
$$

ARRIVAL DATE:

C. Type the arrival date desired, month/day for the present year or month/day/year, for any other year, ije. (4/28) or (4/28/1977), XMIT, and display the available rooms for 10 days from the date entered, display (1, 1-2).

$$
(1, x-2)
$$

\begin{tabular}{|c|c|c|c|c|c|c|c|c|c|c|}
\hline & $4 / 23$ & $40 \mathrm{ars}$ & 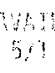 & 8014 & 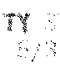 & 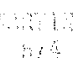 & 6 & $\begin{array}{l}29 \\
516\end{array}$ & $\begin{array}{l}176-7 \\
\therefore 7\end{array}$ & $5 / 8$ \\
\hline SAY & 68 & 68 & 67 & 67 & 68 & 69 & 69 & 68 & 68 & 85 \\
\hline Grit & $A$ & 8 & 44 & 44 & $4 !$ & 43 & 42 & A? & 15 & \\
\hline OCFAN & 70 & 70 & 70 & 71 & 71 & 71 & 71 & 70 & 70 & 63 \\
\hline Pool & 37 & 37 & 37 & 37 & 37 & 37 & 37 & 35 & 32 & 3 \\
\hline OELUX: & 6 & 3 & 9 & 8 & 8 & 8 & 8 & 7 & 7 & \\
\hline SUITE & 18 & 18 & 17 & 15 & 15 & 17 & 17 & 16 & 16 & 1 \\
\hline TOTAL & 243 & 244 & 244 & 242 & 240 & 243 & 244 & 238 & 238 & 23 \\
\hline & & & & - & SOLD & ROOHS & - & & & \\
\hline $\mathrm{INDT}$ & 1 & 1 & 2 & 3 & 4 & 3 & 2 & 3 & $\cdot 8$ & \\
\hline $\begin{array}{lll}2 N D & 0\end{array}$ & 6 & 5 & 4 & 5 & 6 & 4 & 4 & 9 & 4 & \\
\hline $\operatorname{coN} T$ & 0 & 0 & 0 & 0 & 0 & 0 & 0 & 0 & 0 & \\
\hline CON $D$ & 0 & 0 & 0 & 0 & 0 & 0 & 0 & 0 & 0 & \\
\hline TOTAL & 7 & 6 & 6 & 8 & 10 & 7 & 6 & 12 & 12 & 1 \\
\hline & 0 & 0 & 0 & 0 & 0 & 0 & 0 & 0 & 0 & \\
\hline
\end{tabular}

D. At the bottom of the display are five choices of action. The cursor is automatically placed to select one of the choices. Enter the number of the choice wanted and XMIT. 
D. 1. ENTER RESERVATION - This selection displays the

"Enter New Reservation" program, display $(1,2-1)$.

$$
(1,2-1)
$$

$\begin{array}{lc}\text { LAST NAME } & \vdots \\ \text { FIRST NAME } & \vdots \\ \text { STREET ADDRESS } & \vdots \\ \text { CITY } & \vdots \\ \text { STATE } & \vdots \\ \text { ZIP } & \vdots \\ \text { NUMBER OF ADULTS } & \vdots \\ \text { CHILDREN } & \vdots \\ \text { GROUP NAME } & \vdots \\ \text { ARRIVAL DATE } & \vdots \\ \text { NUMBER OF DAYS } & \vdots \\ \text { ROOM TYPE(S) } & \vdots \\ \text { NUMBER OF ROOMS } & \vdots \\ \text { ROOM RATE } & \vdots \\ \text { LATE ARRIVAL CODE: }\end{array}$

LATE ARRIVAL CODE:

SPECIAL REQUEST CODE:

SOURCE CODE

TRA.VEL AGENT \#

OFFER UNTIL DATE

DEPOSIT REG. LETTER

COMMENT LINE 1

COMMENT LINE 2

RESERVATION STATUS

CLERK NUMBER

ROOM TYPES

$\begin{array}{ll}1 \text { BAY } & 4 \text { POOL } \\ 2 \text { GOLF } & 5 \text { DELUXE } \\ 3 \text { OCEAN } & 6 \text { SUITE }\end{array}$

ARRIVAL CODES

1 NO DEP. $\quad 5$ DEPOSIT

2 TA NO DEP 6 TA W/DEP

3 LATE NO GUAR 7 LATE DEP

4 CONVENTION 8 AIRLINE

SPECIAL REQUESTS

1 CRIB 3 ROLLAWAY

2 FLOWERS 4 FRUIT/CHEESE

SOURCE CODES

1 PHONE

2 TELEX

3 FR. DESK

4 MAIL

5 TELEGRAM

RESERVATION STATUS

T TENTATIVE

D DEFINITE

1) EXIT 2) VERIFY 3) ENTER: ENTER 1 FOR CLERK \#

NOTE - For instructions in use of this frame fill, refer to the "New Reservation" section of this chapter.

2. PRINT - This selection prints the CRT display on the line printer. The operator must choose the number of days he wishes to print, display $(1,1-4)$.

$$
(1,1-4)
$$

\# DAYS (XMIT = 10):

AVAILABILITY PRINTING, PLEASE WAIT

3. NEW DATE - Repeats the display (1, 1-1) to enable the operator to select a different arrival date.

a. The same 5 choices are given on the bottom of the new display of availability. 
4. NEXT 10 DAYS - This selection displays the availability for the next 10 consecutive days.

a. The display will be the same as (1, 1-2) but with the dates of the next 10 days.

b. The same 5 choices are given to the operator at the bottom of the new display.

5. RETURN - Returns the system to the Reservation Monitor $(1-A)$. 


\section{1, 2. ENTER NEW RESERVATION}

A. This function enables the reservationist to enter a new reservation for any date in a 365 day timetperiod.

B. The program is accessed by typing the number (2) on the Reservation Monitor (1-A), XMIT or select the number (1) from the choices given on the bottom of the availability display $(1,102)$, XMIT and receive the frame fill for entering a new reservation, display (1,2-1).

$$
(1,2-1)
$$

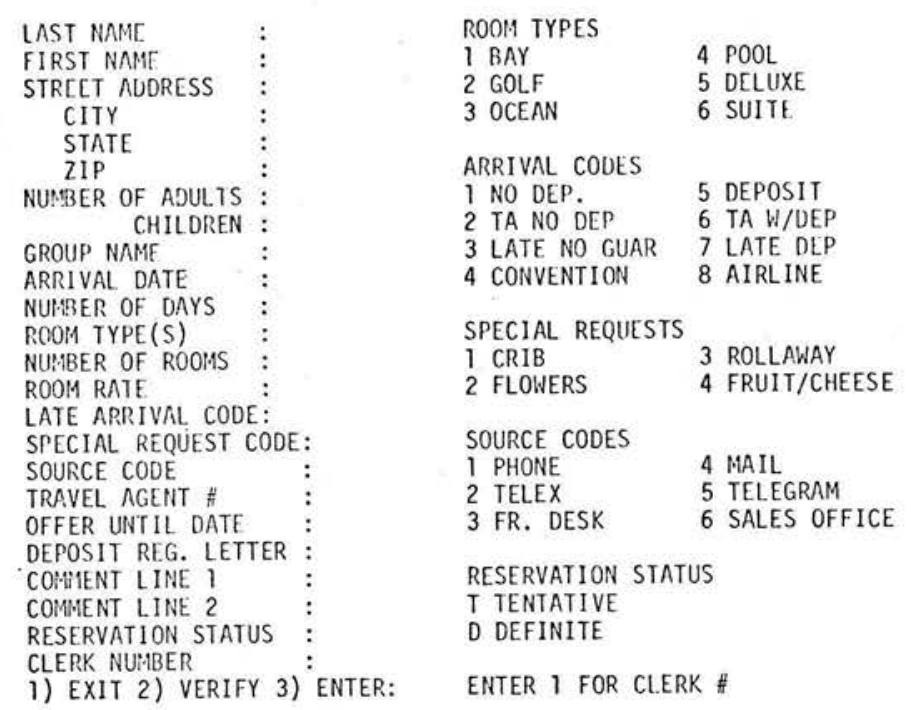

C. The cursor is automatically positioned to enter the first letter of the guest's last name. Begin typing the data as required.

1. If the operator places data on a line, he ends the line with CR (Carriage Return) which will automatically place the cursor in the proper position on the next 1 ine. 
C. 2. If the operator does not enter data on a line or the information is equal to $\emptyset$, depress $T A B$ to move the cursor to the next line.

D. Data input for display (1,2-1).

1. LAST NAME - Mandatory data. Enter last name of party and $C R$.

2. FIRST NAME - Optional data. Enter first name of party and CR. TAB if left blank.

3. STREET ADDRESS - Optional data. Enter data and CR. $T A B$ if left blank.

4. CITY: - Optional data. Enter data and CR. TAB if left blank.

5. STATE: - Optional data. Enter data and CR. TAB if left blank.

6. ZIP: - Optional data. Enter data and CR. TAB if left blank.

7. \# OF ADULTS: - Mandatory data. Enter the \# of adults that will occupy the room and CR.

8. \# of CHILDREN: - Optional data. Enter the \# of children that will occupy the room and CR. TAB if left blank.

9. GROUP NAME: - Optional data. Enter convention group name if party is with convention already in the convention master file so the computer may assign special rates if applied and CR. TAB if left blank. 
10. ARRIVAL DATE: - Mandatory data. Enter month/day and CR.

11. NUMBER OF DAYS: - Mandatory data. Enter the \# of days the guest will stay in the hotel and CR.

12. ROOM TYPE: - Mandatory data. Select the key number for the type of room from the list given on the right side of the format and CR.

13. \# OF ROOMS: - Mandatory data. Enter the \# of rooms the reservation is for and CR. At the present time this will always equal (1).

14. ROOM RATE: - Optional input data. If TAB the computer will assign room rate already programmed for the type of room selected. You may manually enter rate if you choose to change the given rate. Enter rate and $C R$.

15. LATE ARRIVAL CODE: - Mandatory data. Select the key number from 1 ist of arrival codes and CR.

16. SPECIAL REQUEST CODE: - Optional data. If one of the special requests is asked for select the key \# from list given and $C R$. TAB if left blank. 
17. SOURCE CODE: - Mandatory data. Select a key number from list provided and CR. This indicates how the reservation was received.

18. TRAVEL AGENT \#: - At present not functioning. TAB to next line.

19. OfFER UNTIL DATE: - Mandatory data. Enter date until which you wish the reservation held and CR. This may not be any later than arrival date.

20. DePOSit Reg. LetTer: - Mandatory data. This is a question. If you wish a letter printed, type (Y) and CR. If no letter is needed, type (N) and CR.

21. COMMENT LINE 1: - Optional data. Enter additional information on the reservation and CR. TAB if left blank.

22. COMMENT LINE 2: - Optional data. Enter additional information on reservation and $C R$. $T A B$ if left blank.

23. ReSERVATION STATUS: - Mandatory data. Select one of the two options listed by key letter and $C R$.

24. CLERK \#: - Mandatory data. Enter the clerk \# listed on the form and CR. 
E. At the end of the frame fill there are three choices the operator must make:

1. EXIT - This function will erase the information entered on the reservation format and return to the Reservation Monitor (1-A).

2. VERIFY - This function will redisplay the completed reservation erasing any corrections made.

3. ENTER - The purpose of this function is to enter the reservation to the master file. If the data input is correct, the reservation will be entered and a new reservation frame fill $(1,2-1)$ will be displayed on the screen to enter a new reservation if desired. If the information is wrong, the reservation will reappear on the screen with the cursor at the point of error for correction. 


\section{1, 3. CHANGE RESERVATION}

A. This function allows the reservationist to examine and modify any one reservation record contained within the Master Reservation File.

B. The program is accessed by typing the number (3) on the Reservation Monitor (1-A), XMIT and receive the frame fil1, display (1, 3-1).

$$
(1,3-1)
$$

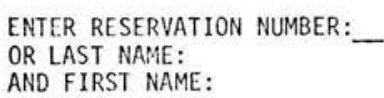

1. The reservationist has the option of entering the reservation number and XMIT. The system will display the reservation that is to be modified.

2. If the reservation number is not known, the operator depresses $T A B$ to move the cursor to the next line. Enter the last name and XMIT. The system will respond with 5 reservations, alpha-like the name being searched for, display (1,3-2).

$$
(1,3-2)
$$

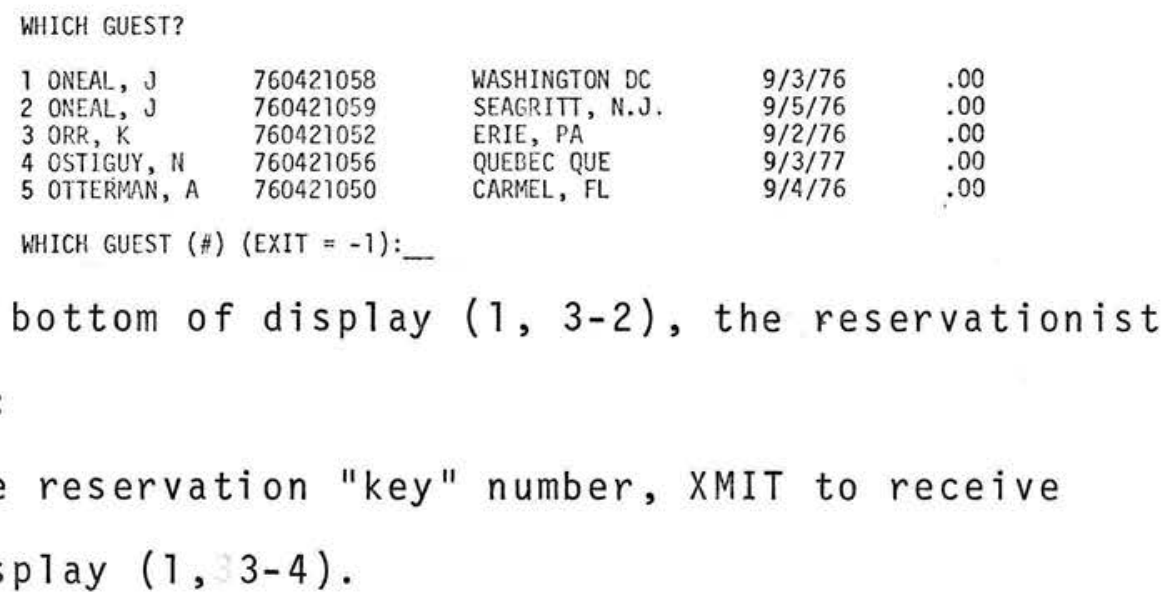


c. 2. If the reservation is not one of the selections, enter the number $(-1)$ and XMIT. The system will respond with "RESERVATION NOT FOUND. TRY AGAIN?", display $(1,3-3)$.

$$
(1,3-3)
$$

RESERVATION NOT FOUND DO YOU WISH TO TRY AGAIN?

a. The reservationist must answer Yes or No to this question.

1. If yes. Enter (Y), XMIT and the program will return to display $(1,3-1)$ for the entering of a new name.

2. If no. Enter (N), XMIT and the program will return to the Reservation Monitor (1-A).

D. Upon selection of the reservation you want to modify (sec. $3 / C / 1$ ) the program will respond with a display of the reservation for modification, display (1,3-4).

$$
(1,3-4)
$$

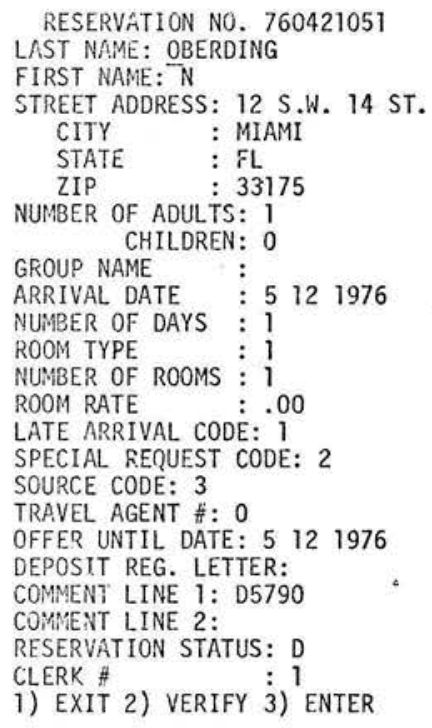


D. 1. CAUTION - Note that the cursor is positioned under the first letter of the guest's last name. ( $C R$ placed here will invalidate the reservation.)

2. To change data within a reservation record, move the cursor to the proper line position, either by the arrows or the $T A B$ key, and type the new information over the old, $C R$, and continue until all changes have been accomplished.

3. After making all the changes desired, the reservationist has a choice of action. Selects the key number for the action desired, XMIT.

a. EXIT - This selection is used to return to the Reservation Monitor (1-A) without modifying the reservation.

b. VERIFY - This selection will redisplay the modified reservation, erasing anyextra characters.

c. ENTER - The purpose of this function is to enter the modified reservation to the master file.

1. After entering the modified reservation the system will respond with display (1,3-5).

$$
(1,3-5)
$$

THE RESERVATION FOR D OBERDING HAS BEEN MODIFIED. DO YOU WANT TO MODIFY ANOTHER?: 
D. 1. C. 2. The reservationist must respond with a Yes or No answer.
a. If yes, enter ( $Y)$, XMIT and the system will return to display $(1,3-1)$.
b. If no, enter (N), XMIT and the system will return to the Reservation Monitor $(1-A)$ 


\section{1, 4. DISPLAY A RESERVATION}

A. This program allows the reservationist to examine, confirm or modify any one reservation record contained within the Master Reservation File.

B. This program is accessed by typing the number (4) on the Reservation Monitor (1-A). The system will respond with display $(1,4-1)$.

$$
(1,4-1)
$$

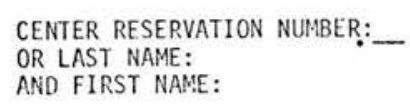

1. The reservationist has the option of entering the reservation number, XMIT. The system will display the reservation for examination, display (1, 4-3). OR;

The reservationist may depress $T A B$ to move the cursor to the next line and enter the last name of the party, XMIT. The system will respond with 5 reservations alpha-like the name being searched for, display $(1,4-2)$.

$$
(1,4-2)
$$

WHICH GUEST?

$\begin{array}{llllll}1 \text { OBERDING, D } & 760421051 & \text { MIAMI, FL, } & 5 / 12 / 76 & .00 \\ 2 \text { OBERHOLTZE, B } & 760421057 & \text { BALTIMORE MD } & 8 / 22 / 76 & .00 \\ 3 \text { OCONNER, A } & 760421054 & \text { DALIAS, TEX } & 7 / 04 / 76 & .00 \\ 4 \text { ODONNEL, A } & 760421059 & \text { ST. FLOP, FL } & 4 / 28 / 76 & .00 \\ 5 \text { OGRIN, K } & 760421055 & \text { PITTS, PA } & 4 / 10 / 76 & .00\end{array}$

C. At the bottom of display (1,4-2) the reservationist enters:

1. The reservation "key" number, XMIT, to receive display $(1,4-3)$. 
C. 2. If the reservation is not one of the selections, enter the number $(-1)$ and XMIT.

a. The system will respond with the question

"Reservation Not Found. Do You Wish To Try

Again?".

1. If yes, enter $(Y)$, XMIT, and the system will return to display $(1,4-1)$ to enter the new.

2. If no, enter (N), XMIT, the system will return to the Reservation Monitor (1-A). $(1,4-3)$

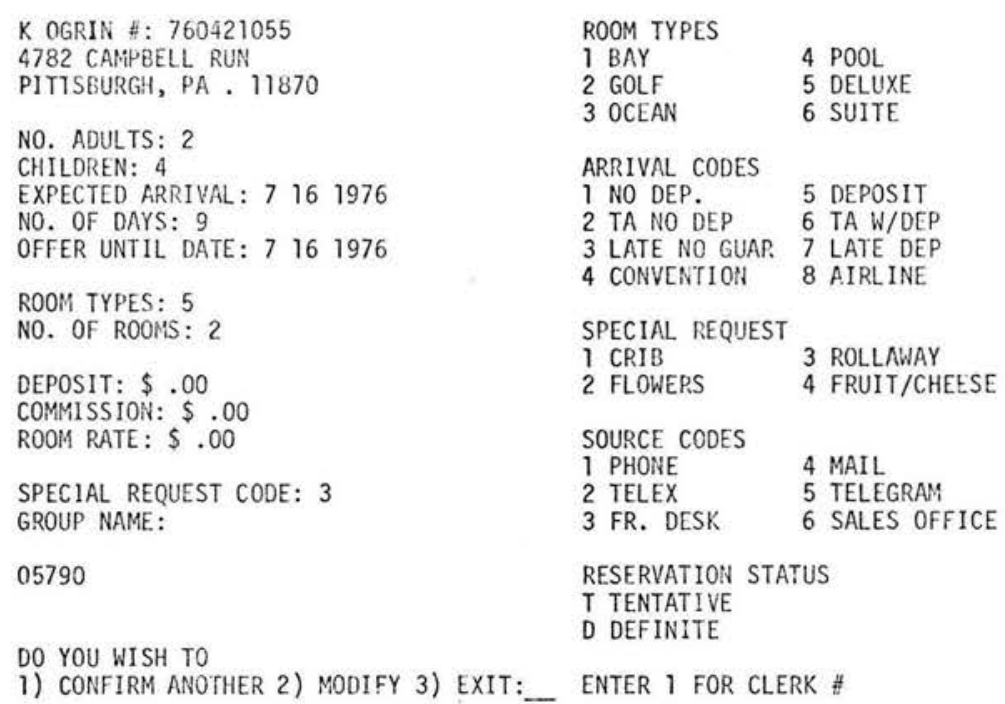

D. The cursor is automatically placed at the end of the display for the reservationist to decide the next step of action. Chooses from the three choices given by entering the \# of the choice and XMIT.

1. CONFIRM ANOTHER - This selection enables the reservationist to display another reservation from the master file. This is accomplished by entering (1) and XMIT. 
The system will return to display $(1,4-1)$.

2. MODIFY - This selection automatically transfers the reservation to program \#3, Change a Reservation, and resets the information in the format seen in display $(1,3-4)$. NOTE: The system will stay in the new program unless commanded otherwise.

3. EXIT - This selection will return the reservationist to the Reservation Monitor (1-A). 


\section{1, 5. DEPOSIT RECEIVED ON RESERVATION}

A. Deposits for reservations are entered on this separate program rather than on the (\#2) Enter New Reservation, or (\#3) Change Reservation, programs, because most deposits are received after the initial entry of the original reservation.

B. To enter a deposit. Type the number (5) on the Reservation Monitor (1-A) and receive the first frame fi11, display $(1,5-1)$.

$$
(1,5-1)
$$

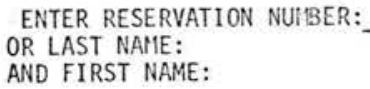

1. Enter the reservation number, XMIT. This will command the system to retrieve the reservation and place yourat frame fill $(1,5-3)$.

2. $T A B$ pass the reservation number and enter the first three letters of the guest's last name, CR and XMIT. The system will display a list of 5 alpha-like names, arrival dates, deposit amounts, and reservation number, display $(1,5-2)$.

$$
(1,5-2)
$$

WHICH GUEST?

$\begin{array}{lllll}1 \text { OBERDING, D } & 760421051 & \text { MIAMI, FL, } & 5 / 12 / 76 & .00 \\ 2 \text { OBERHOLTZE, B } & 760421057 & \text { BALTIMORE MD } & 8 / 22 / 76 & .00 \\ 3 \text { OCONNER, A } & 760421054 & \text { DALLAS, TEX } & 7 / 04 / 76 & .00 \\ 4 \text { ODONNEL, A } & 760421059 & \text { ST. FLOP, FL } & 4 / 28 / 76 & .00 \\ 5 \text { OGRIN, K } & 760421055 & \text { PITTS, PA } & 4 / 10 / 76 & .00\end{array}$


B. 2. a. Select the correct reservation by "key" number, XMIT, and the system will display a frame fill for entering the deposit, display (1, 5-3).

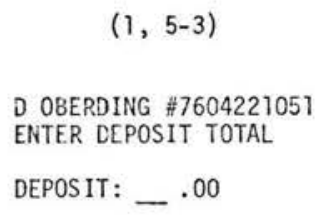

C. Enter the amount of deposit and XMIT. The amount of deposit should be the exact amount, inasmuch as all deposits entered through this program are recorded on the "Audit Trail" and "paid" key transactions register and become a part of the day's deposit.

D. After executing this selection of the program, the reservationist will receive the next frame fill, display $(1,5-4)$.

$$
(1,5-4)
$$

DEPOSIT FOR D OBERDING HAS BEEN ENTERED. DO YOU WISH TO ENTER ANOTHER?!

1. If no, enter (N), XMIT. The system will return to the Reservation Monitor (1-A).

2. If yes, enter (Y), XMIT. The system will return to frame fill $(1,5-1)$, allowing the operator to post another deposit.

TO CANCEL A RESERVATION WHICH CONTAINS A DEPOSIT, it is necessary to utilize this program. Display the frame fill (1, 5-3). Enter CR after deposit amount and XMIT to cancel the deposit. 


\section{1, 6. CANCEL A RESERVATION}

A. This program allows the reservationist to cancel any reservation that does not have a deposit.

B. The program is accessed by typing the number (6) on the Reservation Monitor (1-A), XMIT. The system will respond with a frame fill, display $(1,6-1)$.

$$
(1,6-1)
$$

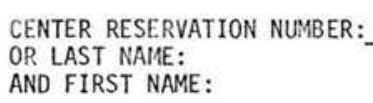

1. The reservationist has the option of entering the reservation number, XMIT. The system will display the reservation to be canceled, display (1,6-3). OR; If the operator does not know the reservation number, he may gain access to the reservation by executing a $T A B$ over the reservation number and typing the first three letters of the last name, XMIT. The system will respond with 5 reservations, alpha-1ike the reservation being searched for, display (1, 6-2).

$$
(1,6-2)
$$

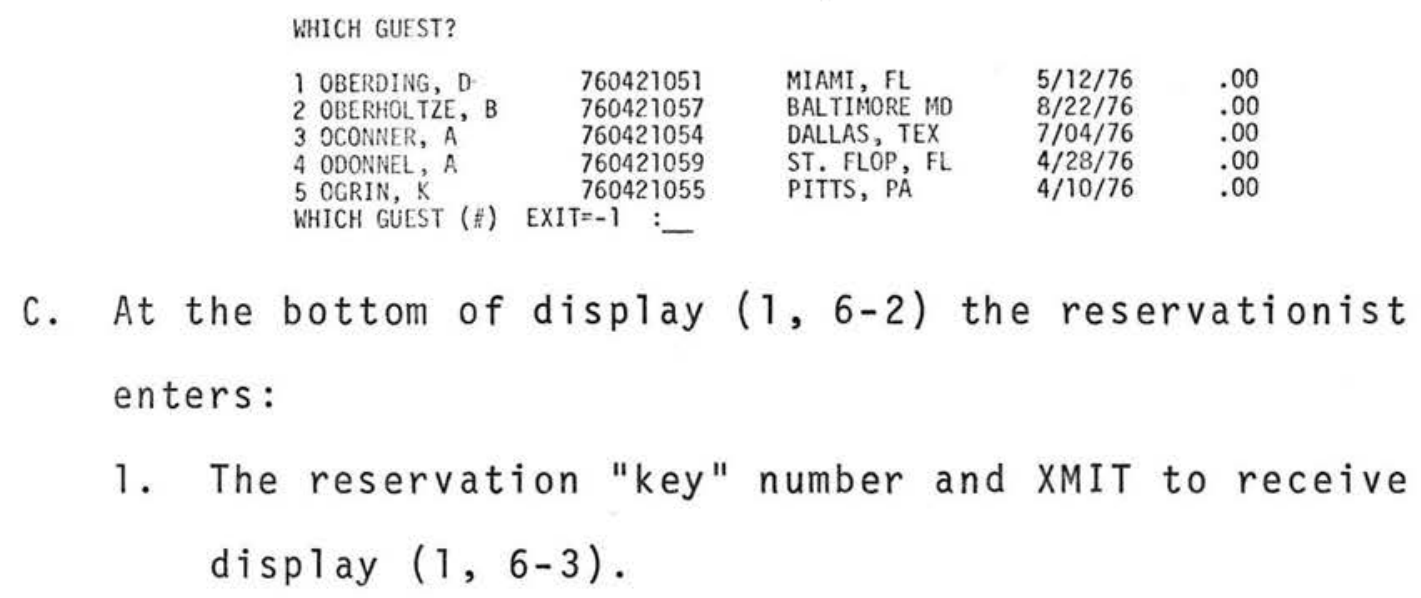


c. 2. If the reservation is not one of the ones listed in display $(1,6-2)$, enter number $(-1)$ and XMIT.

a. The system will respond with the question:

"RESERVATION NOT FOUND. DO YOU WISH TO TRY AGAIN?"

1. If yes, enter (Y), XMIT. The system will return to display $(1,6-1)$ to enter the new name.

2. If no, enter (N) and XMIT. The system will return to the Reservation Monitor (1-A). $(1,6-3)$

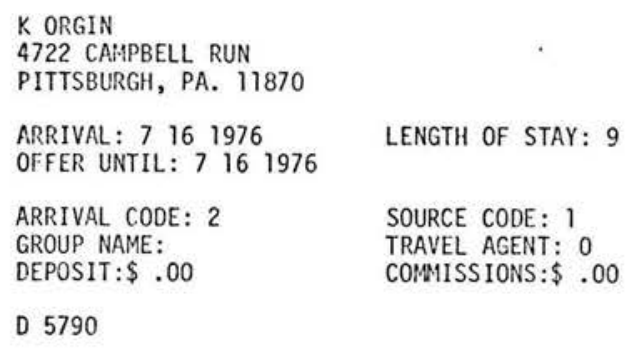

IS THIS THE RESERVATION YOU WANT TO CANCEL?:

D. Display (1, 6-3) shows the detail of the reservation and again asks if this is the correct reservation. The cursor is automatically positioned to answer the question with a yes or no answer.

1. If this is not the reservation wanted, enter (N) and XMIT. The system will stop the "Cancel" program and return to the Reservation Monitor (1-A).

2. If this is the reservation wanted, enter ( $Y$ ) and XMIT. The system will delete the reservation from the master reservation file and respond with display (1,6-4).

$$
(1,6-4)
$$


E. The cursor is automatically positioned to answer the question with a yes or no answer.

1. If no, enter (N) and XMIT. The system will return to the Reservation Monitor (1-A).

2. If yes, enter (Y) and XMIT. The system will return to display $(1,6-1)$ to start the "Cancel a Reservation" program again. NOTE: Reservations that have deposits already recorded cannot be canceled in this program. The system stops the program's action and sends the message to the operator.

RESERVATIONS CANNOT BE CANCELED DEPOSIT HAS NOT BEEN CLEARED XMIT:

In order to cancel the reservation the deposit must be removed in the "Deposit on a Reservation" program first. 


\section{1, 7. CONVENTION MONITOR}

A. The Convention Monitor enables the reservationist to create, change, delete, and display master files for convention reservations. It also enables the reservationist to generate reports for convention related activities.

B. The program is accessed by typing the number (7), XMIT on the Reservation Monitor (1-A). The system will respond with a sub-program 1ist, display (1, 7-1).

$$
(1,7-1)
$$

CONVENTION MONITOR 5/10/1976 14:17
1. ADD A MASTER RECORD
2. CHANGE A MASTER RECORD
3. DELETE A MASTER RECORD
4. DISPLAY A MASTER RECORO
5. CONVENTION REPORTS MONITOR
6. EXIT

ENTER HERE:

C. The reservationist need only select the job/function by number from the Convention Monitor (1, 7-1), XMIT and receive the appropriate instructions and/or frame fills to accomplish the task. 
1, 7A. ADD A MASTER RECORD

A. This function allows the reservationist to input all group records and assign a convention/group code name.

B. This program is accessed by typing the number (7) on the Reservation Monitor (1-A) and receiving the display (1, 7-1), the "Convention Monitor". Then type the number (1) on the Convention Monitor to receive the frame fill (1, 7A-1).

$$
\text { (1, 7A-1) }
$$

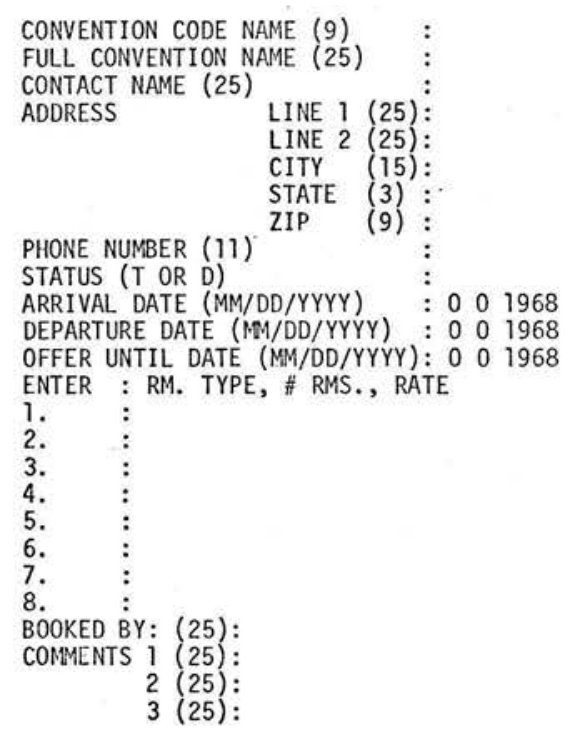

c. The cursor is automatically positioned to enter the first 1etter/number of the convention code name. Begin typing the data as required.

1. If the operator places data on a line, the line is ended with CR (Carriage Return) which will automatically place the cursor in the proper position on the next 1 ine. 
c. 2. If the operator does not enter data on a line or the information is equal to 0 , depress $T A B$ to move the cursor to the next line.

D. Data input for display $(1,7 A-1)$.

1. CONVENTION CODE NAME: - Mandatory data. Enter code name and $C R$.

2. FULl CONVENTION NAME: - Mandatory data. Enter the full name of the convention and CR.

3. CONTACT NAME: - Optional data. Enter contact name and CR. $T A B$ if left blank.

4. ADDRESS LINE 1:- Optional data. Enter address of the party information is to be sent to and $C R$. TAB if left blank.

5. ADDRESS LINE 2:- Optional data. Enter street address and CR. TAB if left blank.

6. ADDRESS CITY:- Optional data. Enter city and CR. $T A B$ if left blank.

7. ADDRESS STATE: - Optional data. Enter state and CR. $T A B$ if left blank.

8. ADDRESS ZIP:- Optional data. Enter Zip Code and CR. $T A B$ if left blank.

9. PHONE NUMBER:- Optional data. Enter contact's phone \# and CR. TAB if left blank.

10. STATUS ( $T O R$ D):- Mandatory data. Enter ( $T$ ) for tentative or (D) for definite and CR . 
11. ARRIVAL DATE: - Mandatory data. Enter month/day/year and CR.

12. DEPARTURE DATE:- Mandatory data. Enter month/day/ year and CR.

13. OFFER UNTIL DATE: - Optional data. Enter month/day/ year and CR. TAB if left blank.

14. ENTER: RM. TYPE, \#RMS, RATE:- Mandatory data. Enter Rm. type (by \#), \# of Rms. wanted for that type, and quoted Rm. Rate and $C R$. NOTE - Put comma between type and number and between \# and rate. Inputs for $8 \mathrm{rm}$. types a 11 owed.

15. BOOKED BY:- Optional data. Enter initials of operator and CR. TAB if left blank.

16. COMMENTS: - Optional data. Enter additional comments for the group and CR. TAB if left blank.

E. After inputing all the data for frame fill (1, 7A-1) TAB to the bottom of the frame and XMIT. The system enters the record to the master file and responds with display $(1,7 A-2)$.

$$
(1,7 A-2)
$$


F. The cursor is automatically positioned to answer the question with a yes or no answer.

1. If no, enter (N) and XMIT. The system will return to the Convention Monitor (1, 7-1).

2. If yes, enter (Y) and XMIT. The system will redisplay frame fill $(1,7 A-1)$ for entering a new master record. 


\section{1, 7B. CHANGE A MASTER RECORD}

A. This program enables the reservationist to modify/update information on any Master Record on file. NOTE - The code name cannot be modified.

B. The program is accessed by typing the number (7) on the Reservation Monitor (1-A) and receiving the display $(1,7-A)$, the "Convention Monitor". Then type the number (2) on the Convention Monitor to receive the frame fi11 (1, 7B-1).

$$
(1,7 B-1)
$$

ENTER CONVENTION CODE NAME BLANK = EXIT:

C. Enter the code name/number and XMIT. The system will respond with a display of the record requested, display $(1,7 \mathrm{~B}-2)$.

If the code name is unknown, XMIT. The system will return to the Convention Monitor (1, 7-1).

$$
(1,7 \mathrm{~B}-2)
$$

CONVENTION CODE NAME: 1

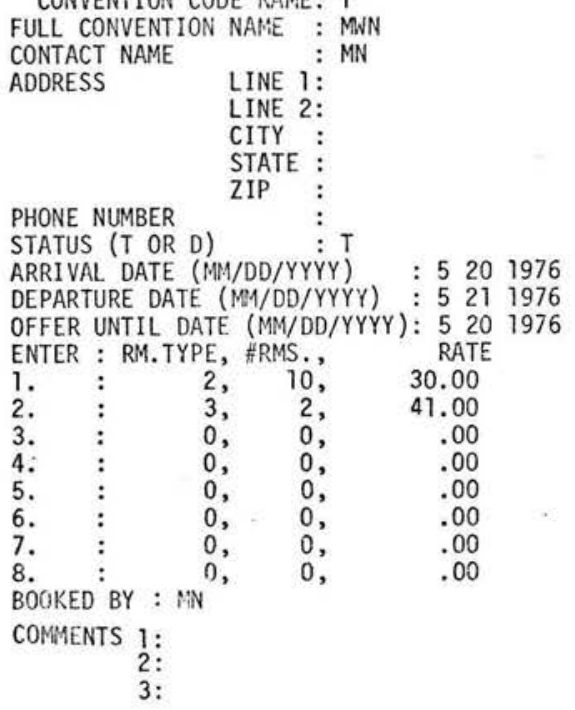


D. The cursor is automatically positioned on the Full Convention name for modification:

1. To make modifications type the correct information on the proper line and $C R$ at the end of the line.

2. If the line is correct or no changes are to be made $T A B$.

3. Position the cursor at the bottom frame fill and XMIT after all modifications are complete. The system will respond with display (1,7B-3).

$$
\text { (1, 7B-3) }
$$

E. The operator may answer this with a Yes or No answer on $1 y$.

1. If yes, enter (Y) and XMIT. The system will redisplay display $(1,7 B-1)$ to enter a new master code name.

2. If no, enter (N) and XMIT. The system will return to the Convention Monitor (1, 7-1). 


\section{1, 7C. DELETE A MASTER RECORD}

A. This program enables the reservationist to delete a Master Record.

B. The program is accessed by typing the number (7) on the Reservation Monitor (1-A) and receiving the display (1, 7-1), the Convention Monitor. Then type the number (3) on the Convention Monitor to receive the frame fil1 $(1,7 C-1)$.

$$
(1,7 c-1) \cdot
$$

\section{ENTER CONVENTION CODE NAME} BLANK = EXIT:

C. Enter the code name/number and XMIT. The system will respond with a display of the record to be deleted, display $(1,7 \mathrm{C}-2)$.

If the code name is unknown, XMIT. The system will return to the Convention Monitor $(1,7-1)$.

$$
(1,7 C-2)
$$

$$
\begin{aligned}
& \text { CONVENTION CODE NAME: I } \\
& \text { FULL CONVENTION NAME: MUN } \\
& \text { CONTACT NAME : MN } \\
& \text { ARRIVAL DATE } \quad: 5201976
\end{aligned}
$$

D. The cursor is automatically positioned at the end of the display for the operator to answer the question with a yes or no answer.

1. If no, enter (N) and XMIT. The system will return to display $(1,7 C-1)$ to reenter the information. 
2. If yes, enter (Y) and XMIT. The system will delete the record and respond with display $(1,7 C-3)$.

$(1,7 c-3)$

CONVENTION CODE NAME: 1
CONVENTION FULL NAME: MWN
COHTACT NAME
ARRIVAL DATE
IS THIS THE CONVENTION RECOR
YOU WISH TO DELETE? ( $Y$ OR N)
THE RECORD HAS BEEN DELETED
HIT XMIT

E. Transmit as stated on the display, the system will return to $(1,7 C-1)$ to enter a new code name. 


\section{1, 7D. DISPLAY A MASTER RECORD}

A. This program enables the reservationist to examine a Master Record from the Reservation file.

B. The program is accessed by typing the number (7) on the Reservation Monitor (1-A) and receiving the display (1, 7-1), the Convention Monitor. Then type the number (4) on the Convention Monitor to receive the frame fill $(1,7 D-1)$.

$$
(1,70-1)
$$

ENTER CONVENTION CODE MAME $B L A N K=E X I T$.

C. Enter the code name/number and XMIT. The system will respond with a display of the record requested, display (1, 7D-2). If the code name is unknown XMIT. The system will return to the Convention Monitor (1, 7-1).

$$
(1,7 D-2)
$$

CONVENTION CODE NAME: 1

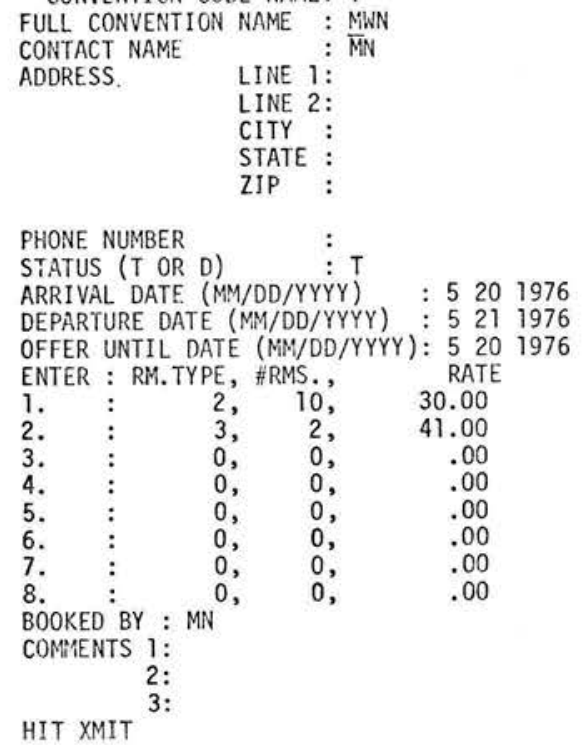


D. XMIT as stated on the display. The system responds by returning to display $(1,7 D-1)$ for entering a new code name for display. 


\section{1, 7E. CONVENTION REPORTS MONITOR}

A. This program enables the reservationist to retrieve reservation reports generated on convention activity by the system.

B. The program is accessed by typing the number (7) on the Reservation Monitor (1-A) and receiving the Convention Monitor $(1,7-1)$. Then type the number (5) on the Convention Monitor to receive a list of reports that can be generated, display $(1,7 E-1)$.

$$
(1,7 E-1)
$$

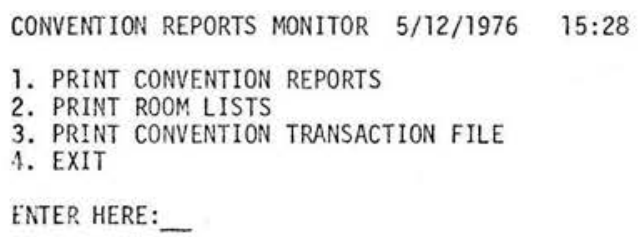

C. The operator need only to select the report(s) by number from the Convention Report Monitor (1, 7E-1), XMIT and receive the appropriate instruction and/or frame fills to accomplish the task. 


\section{1, 7E1. PRINT CONVENTION REPORTS}

A. This program will generate summary or detailed reports on any one or all conventions.

B. The program is accessed by typing the number (7) on the Reservation Monitor (1-A) and receiving the Convention Monitor (1, 7-1). Then type the number (5) on the Convention Monitor to receive the Convention Reports Monitor $(1,7 \mathrm{E}-1)$. Finally type the number (1) on the Convention Report Monitor to receive the frame fill $(1,7 E 1-1)$.

$$
(1,7 \varepsilon .1-1)
$$

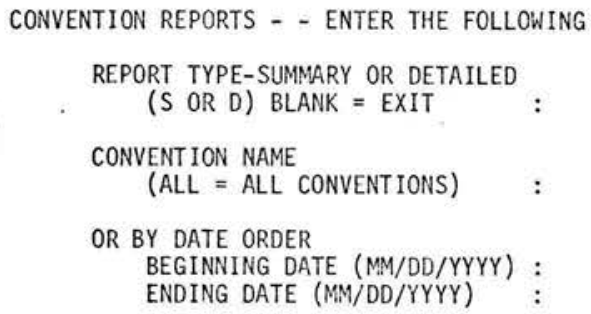

c. To print the operator selects the answers from the display to complete the frame fill and XMIT.

1. Report type -
a. If summary, enter (S) and Cr.
b. If detailed, enter (D) and $\mathrm{Cr}$.
c. If no report wanted, leave blank and XMIT. The system will return to the Convention Report Monitor, $(1,7 E-1)$.


c. 2. Convention name -

a. Select the code name/number wanted and CR.

b. If all conventions are wanted, enter $A L L$ and CR.

3. Date Order -

a. If the report is for a certain time period, enter month/day/year and CR.

4. If this is not requested $T A B$ to the end of the frame fi11 and XMIT.

D. Display (1,7E1-2) and (1,7E1-3) are examples of Summary and Betailed reports respectively. See page 36.

E. The system, after printing the report, returns to display (1, 7E1-1) for the generation of more reports or exit to the Convention Reports Monitor (1, 7-1). 


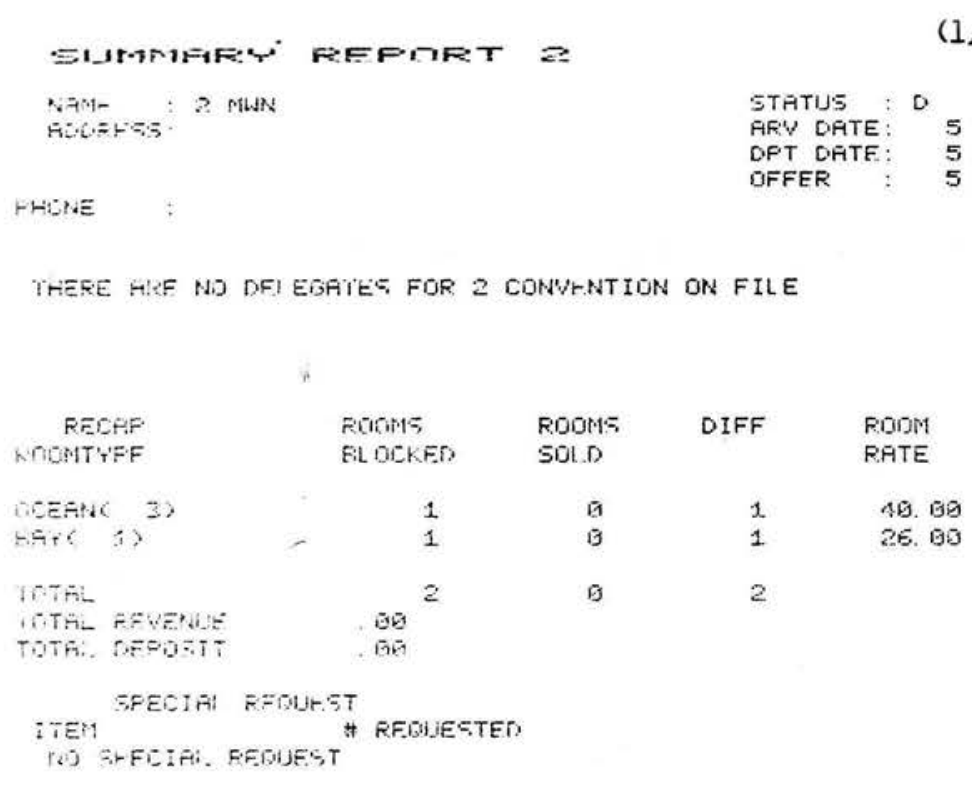

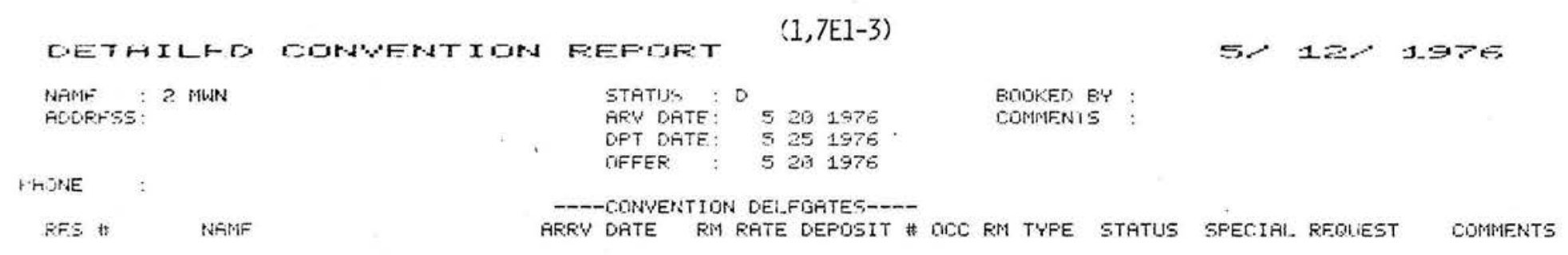

THERF PRF, MO DELEISATES FDR a CONWENTION ON FII.E

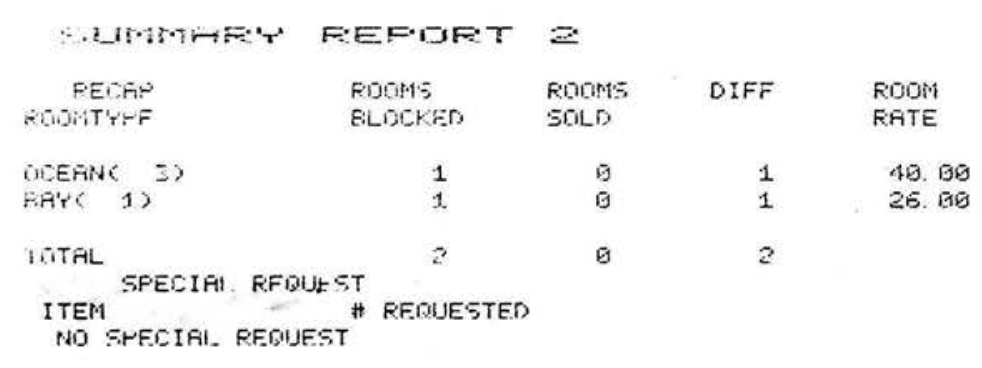




\section{1, 7E2. PRINT ROOMING LIST}

A. This program will generate a room list for each convention found on the master reservation file.

B. The program is accessed by typing the number (7) on the Reservation Monitor (1-a) and receiving the Convention Monitor (1, 7-1). Then type the number (5) on the Convention Monitor to receive the Convention Reports Monitor $(1,7 E-1)$. Finally type the number (2) on the Convention Reports Monitor to receive the display $(1,7 \mathrm{E} 2-1)$.

$$
(1,7 E 2-1)
$$

ENTER CONVENTION CODE NAME BL.ANK $=$ EXIT:

C. Enter the code name/number and XMIT. The system will respond with a 1 ist of ways the system can generate the reports display $(1,7$ E2-2).

$$
(1,7 \mathrm{E} 2-2)
$$

ROOM LIST WILL BE PRODUCED FOR: 2

YOU MAY LIST IN:

1. ROON NUMBER ORDER

2. ALPHA ORDER

3. EXIT

ENTER NUMBER:

D. To select the type report to be generated enter the "key" number and XMIT. The system will produce the report type requested. If no report is wanted enter number (3) for exit. The system will return to display (1, 7E2-1) for exit to the Convention Report Monitor or to generate a new report. 
E. Display (1,7E2-3) and (1,7E2-4) are examples of Room list - room number report and room list - alpha order report respectively.

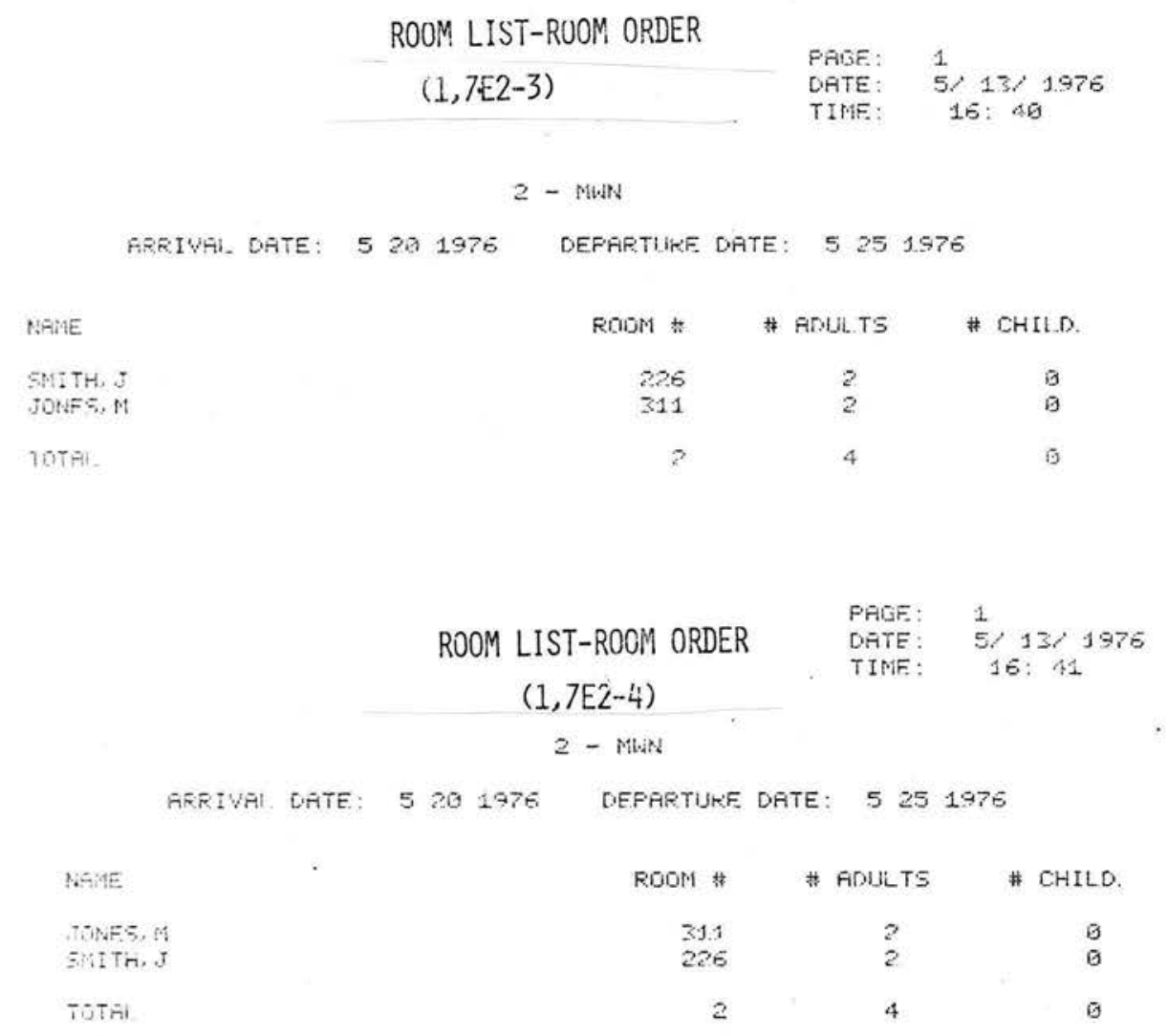

F. The system, after printing the report, returns to display (1, 7E2-1) for the generation of more reports or exit to the Convention Report Monitor (1, 7-1). 
A. This program will generate a list of all transactions that took place on the Convention Monitor.

B. The program is accessed by typing the number (7) on the Reservation Monitor (1-A) and receiving the Convention Monitor $(1,7-1)$. Then type the number (5) on the Convention Monitor to receive the Convention Reports Monitor $(1,7 \mathrm{E}-1)$. Finally type the number (3) on the Convention Reports Monitor to generate the report.

c. The system responds by printing the report, display (1, 7E3-1), and returning to the Convention Report Monitor $(1,7 \mathrm{E}-1)$ for the generation of more reports or exit to the Convention Monitor. (See Page 40.) 
(1,7E3-1)

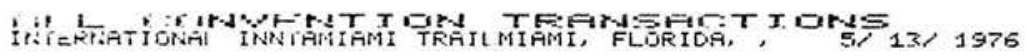
CONVENTION ADORESTS

CONRACT

EOOKED BY

Mns

Frionf

and

mat

(a)

4 Fint

wifif

1 kt

atit?

$\stackrel{\circ}{0}$

\begin{tabular}{|c|c|c|}
\hline & nWE: & $\begin{array}{l}\text { Wh } \\
\text { PHOBS: } \\
\text { Mr: }\end{array}$ \\
\hline $5 / 275$ & . , & \\
\hline i & $n *$ & $\begin{array}{l}\text { Mr: } \\
\text { FHOHF. }\end{array}$ \\
\hline$=7=$ & & \\
\hline
\end{tabular}
GFFER

MN
FHiONE.
Mn:

MTi
FriONE
Min
PATIF

ARRIVE DEFART

STATUS

TYPE-RFG-SOLD-R.ATE

$5 / 20 / 76$ TEN

$5 / 21 / 76$
$5 / 20 / 78$

2. $40,0,30.0503,2,0,4100$

$5 / 210776$ TEN

$5 / 2 \mathrm{~L}>76$

$5 / 20176$

$5,20,78$ TEN

$5 / 21 / 76$

$5 / 21776$

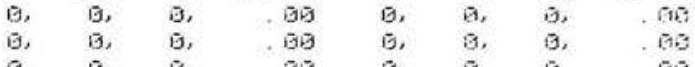

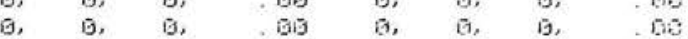

2. 10, 0. 30.60 3. $2,0.4101$

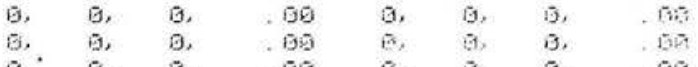

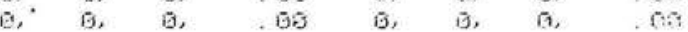

2. $10,0,30.60$ 3, 2, 6, 41 ब0

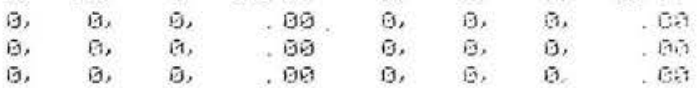

$5 / 20 / 75$ TEN

$5 / 21 / 76$

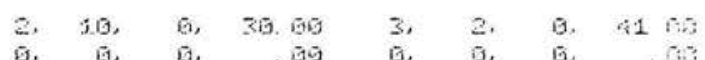

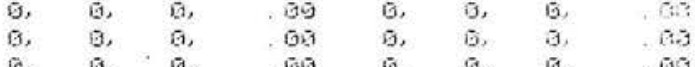

$5 / 20 / 76$ TEN $5 / 2,76$ 


$$
\text { 1, 7E-4. EXIT }
$$

This function allows the operator to return to the Convention Monitor (1, 7-1) for further job functions in the Convention programs.

Enter the number (4) on the Convention Report Monitor $(1,7 \mathrm{E}-1)$ and XMIT. 


\section{F. EXIT}

This function allows the operator to return to the Reservation Monitor (1-A).

Enter the number (6) on the Convention Monitor (1, 7-1) and XMIT. 
1, 8. REPORTS MONITOR

A. This program enables the reservationist to retrieve reservation reports generated by the system for all reservation activities. NOTE - This does not include convention reports. To gain access to Convention Reports enter the Convention Monitoorprogram.

B. The program is accessed-by typing the number (8) on the Reservation Monitor (1-A). The system will respond with a sub-program 1 ist, display $(1,8-1)$.

$$
(1,8-1)
$$

RESERVATIONS REPORTS MONITOR 5/13/1976 17:11

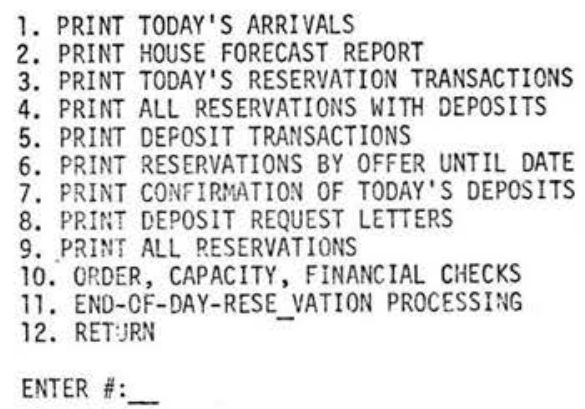

c. The reservationist need only select the job/function by number from the Reports Monitor $(1,8-1)$, XMIT and receive the appropriate instructions and/or frame fill to accomplish the task. 


\section{1, 8A. PRINT TODAY'S ARRIVALS}

A. This program will generate a 1 ist of all expected arrivals for the day of operation.

B. The program is accessed by typing the number (8) on the Reservation Monitor (1-A) and receiving the Reports Monitor $(1,8-1)$. Then type the number (1) on the Reports Monitor to generate the report.

c. The system responds by printing the report display $(1,8 A-1)$, and returning to the Reports Monitor $(1,8-1)$ for the generation of additional reports or exit to the Reservation Monitor. See Page 45. 


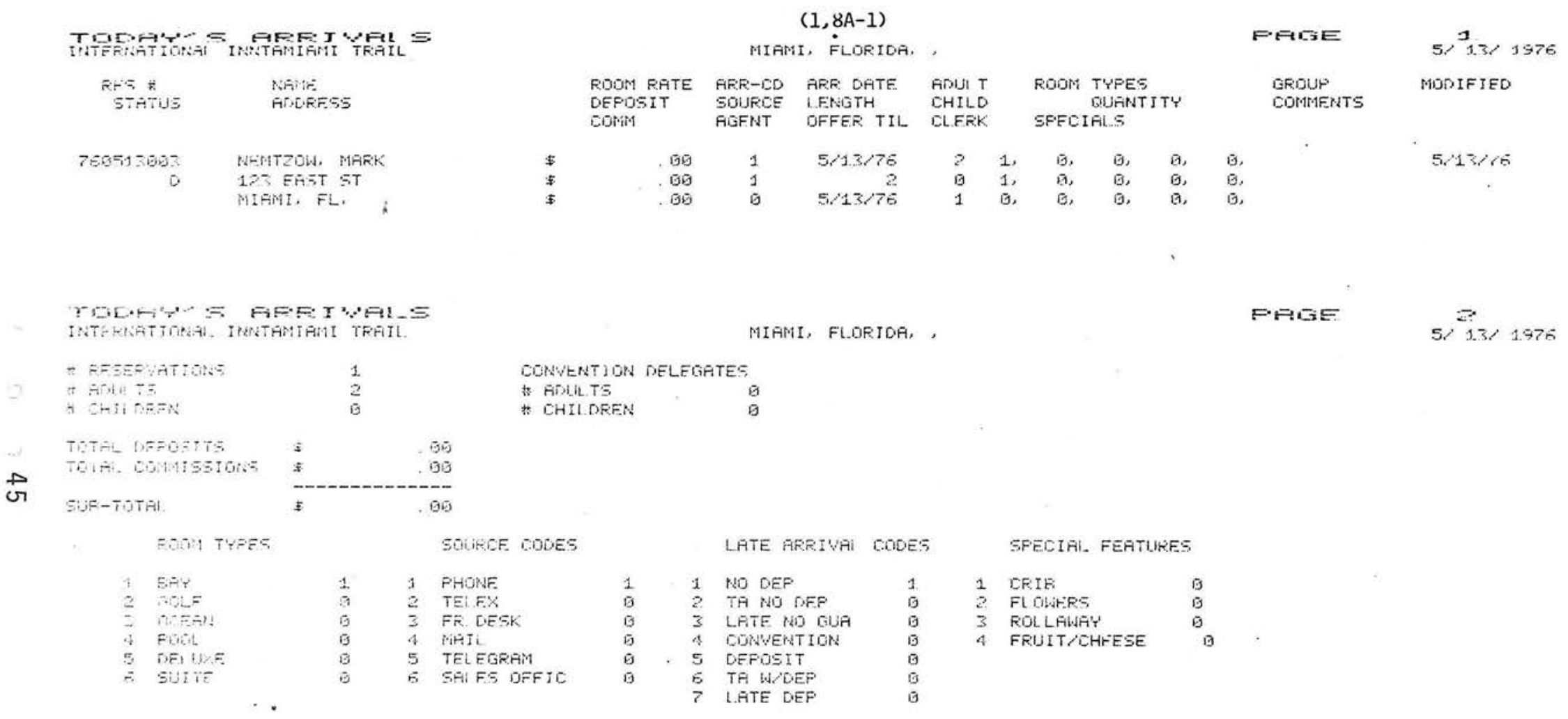




\section{1, 8B. PRINT HOUSE FORECAST REPORT}

A. This program will generate a forecast report for today's date or any future date in a two year period.

B. The program is accessed by typing the number (8) on the Reservation Monitor (1-A) and receiving the Reports Monitor (1, 8-1). Then type the number (2) on the Reports Monitor to receive display $(1,8 \mathrm{~B}-1)$.

$$
(1,88-1)
$$

HOUSE FORECAST REFORT

1) START WITH TODAY'S DATE

2) START WITH FUTURE DATE

C. Today's Date -

If a forecast report is needed for today's date, enter the number (1) and XMIT. The system will respond by asking for "HOW MANY DAYS" you want the report to include.

1. Enter the number of days needed and XMIT. The system will print the forecast report, display (1,8B-2). See Page 47. [Ex. 15 days]

2. After printing the report, the system responds with display $(1,8 B-3)$ to be answered by the operator with a Yes or No answer.

$$
(1,88-3)
$$

PRINT ANOTHER FORECAST REPORT?:

a. If yes, enter ( $Y$ ) and XMIT. The system will return to display $(1,8 B-1)$ for another selection. 


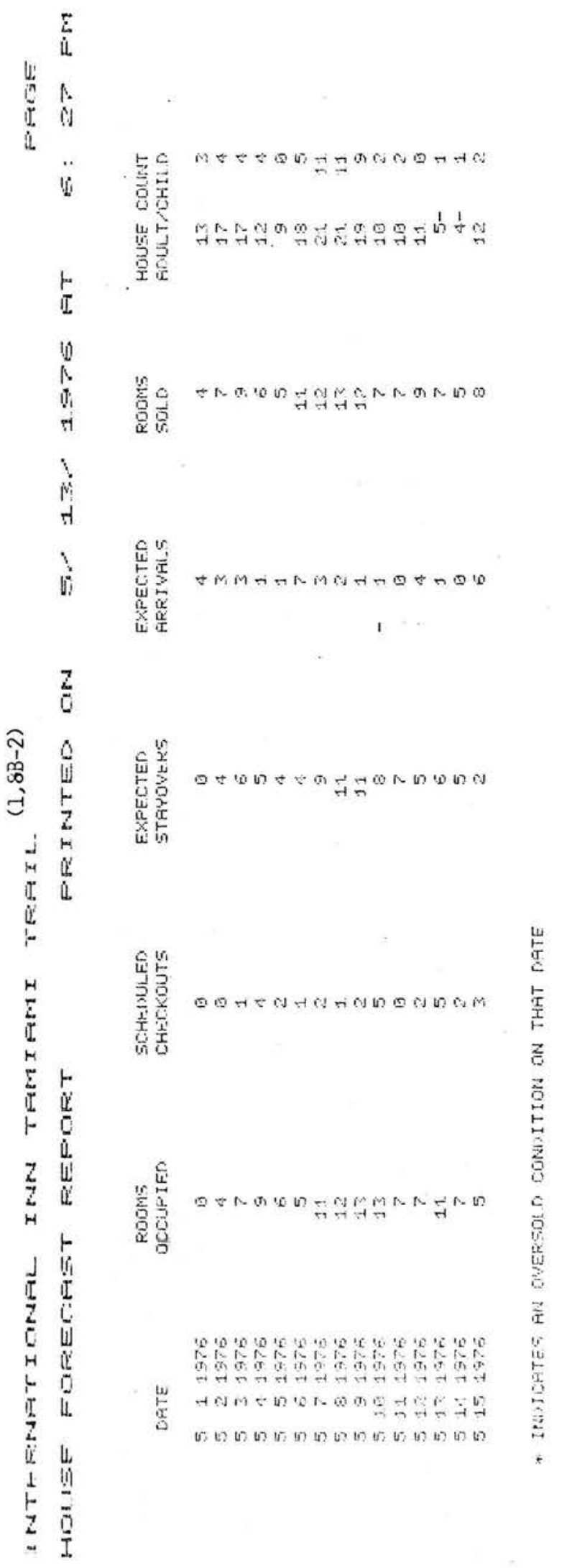


c. 2. b. If no, enter (N) and XMIT. The system will return to the Reports Monitor $(1,8-1)$ for another selection.

D. Future Date -

If a forecast report is needed for a future day, enter the number (2) and XMIT. The system will respond with the frame fill $(1,8 B-4)$.

$$
(1,8 B-4)
$$

ENTER. STARTING DATE (MM/DD/YYYY): ENTER \# OF DAYS TO BE PRINTED:

1. Enter the date as shown in the display, mm/dd/yyyy, and XMIT.

2. Enter the number of days needed and XMIT. The system will print the forecast report for the date/s requested, display (1, 8B-5). See Page 49. [Ex. 5/21, 15 days]

3. After printing the report, the system responds with display $(1,8 B-6)$ to be answered by the operator with a Yes or No answer.

$$
(1,8 B-6)
$$

PRINT ANOTHER FORECAST REPORT?:

a. If yes, enter (Y) and XMIT. The system will return to display $(1,8 B-1)$ for another selection.

b. If no, enter (N) and XMIT. The system will return to the Reports Monitor (1, 8-1) for another selection.

E. Return - This function allows the operator to return to the Reports Monitor $(1,8-1)$. 


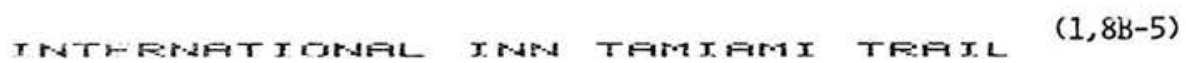

HUU:FE FDFER:ADT FEFEFT

FFEIMTE!' GR

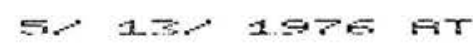

PFIF

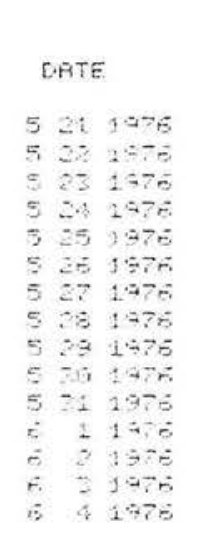

RoOMs
OCDIj'IEn
4
4
4
4
3
4
4
3
3
2
2
2
2
5
4
5

GCHHDULFD
CHECKIJUTS
1
1
1
0
0
0
1
9
1
0
0
0
1
4
1
1

EXPECTED
STHYOVERS
3
3
3
3
4
3
3
2
2
2
2
1
2
3
4

EXFECT
FRRIVA
1
1
1
0
1
0
10
19
19
19
10
0
5
2
2
3

ROOM
SOLD
4
4
3
4
4
3
3
2
2
2
2
6
4
5
7

$E: \quad 5=F \cdot r \cdot 1$ 
1, 8C. PRINT TODAY'S RESERVATION TRANSACTIONS

A. This program will generate a list of all the reservation transactions that were executed today.

B. The program is accessed by typing the number (8) on the Reservations Monitor (1-A) and receiving the Reports Monitor (1, 8-1). Then typing the number (3) on the Reports Monitor to print transaction list, display $(1,8 \mathrm{C}-1)$. See Page 51 .

C. After the system prints the report it returns to the Reservation Reports Monitor (1,8-1) for another selection. 


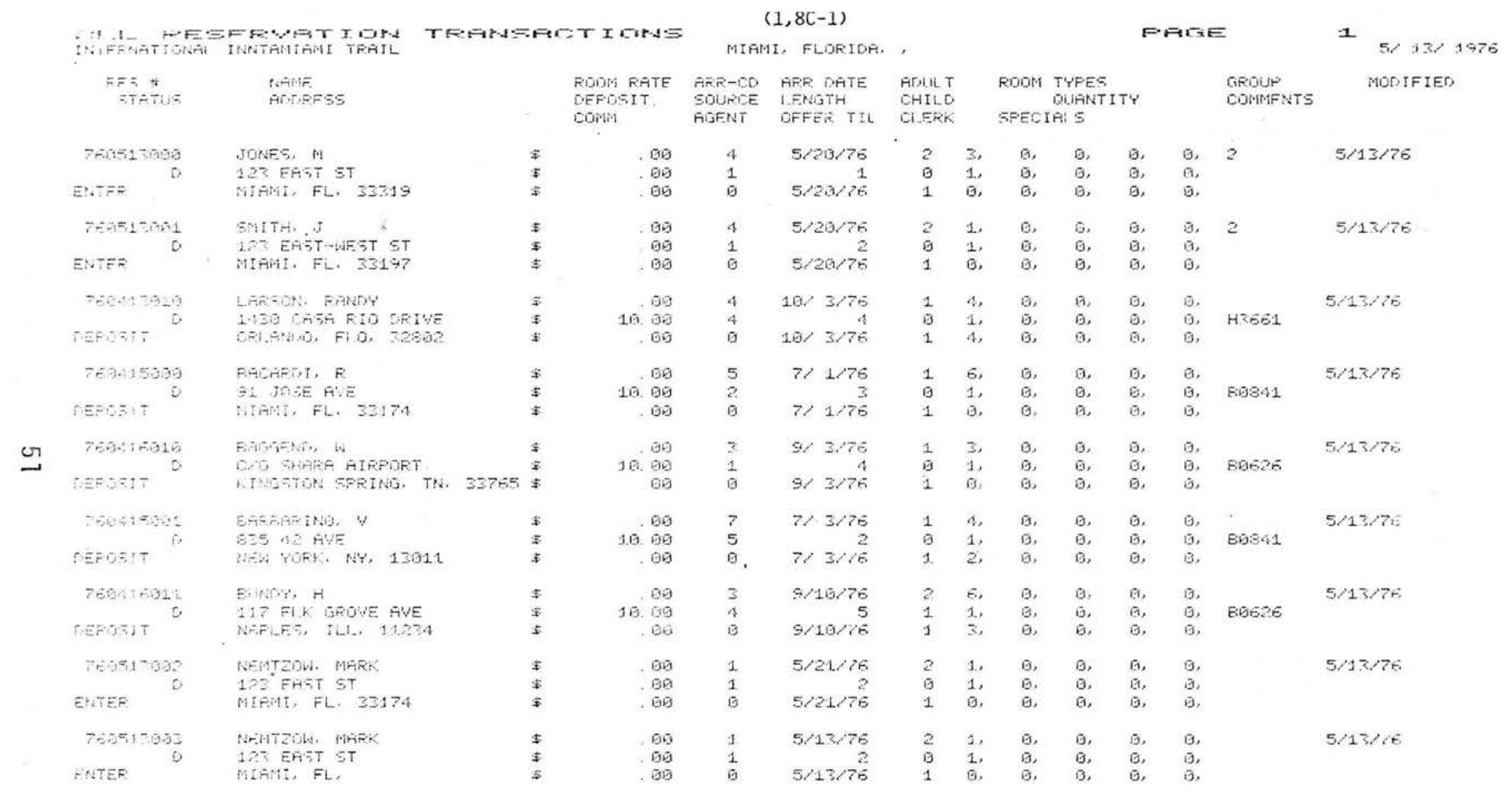




\section{1, 8D. PRINT ALL RESERVATIONS WITH DEPOSITS}

A. This program will generate a list of all the reservations in Master file that have deposits applied.

B. The program is accessed by typing the number (8) on the Reservations Monitor (1-A) and receiving the Reports Monitor (1, 8-1). Then type the number (4) on the Reports Monitor to receive display (1, 8D-1).

c. The operator may then choose the order in which to list reservations with deposits.

1. If number order, enter (1) and XMIT. The system will print a 1 ist in reservation number order, display $(1,8 \mathrm{D}-2)$. See Page 53.

2. If alpha order, enter (2) and XMIT. The system will print a list in alpha order, display (1, 8D-3). See Page 54.

3. If date order, enter (3) and XMIT. The system will print a list by arrival date, display (1, 8D-4). See Page 55.

D. In all cases the system returns to the Reports Monitor (1, 8-1) after printing. 
HLLL MEFP:

$\begin{array}{ll}\text { RES \#\# } & \text { NAME } \\ \text { STATISS } & \text { PDORESS }\end{array}$

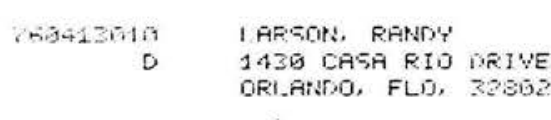

769415 RACARDI, $R$

P1 JUSE RWE
MIAMI, FL, 33174

7e.1415001

EARRARTIG,

E35 $\$ 2$ AVI

NFW YURK, NU, $1391 \%$

CR+100:

$\omega$

C/D SHAFA PIRFIOET

KI

\section{7egatint

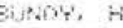 \\ 117 ELK GROUE AVE \\ PHFt FS, ILT, 11234}

100942160

DEEFNTWL, D

125 W 14 ST.

TI-L :EFH-T:

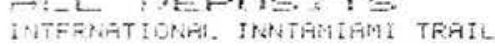

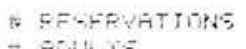

- THILPE:

6
7
1

MTAL DTFOSITE

TOTHi COMHISSIONE

ate-Tutit

E.5. 68

\begin{tabular}{lr}
5 & 55.69 \\
\hline & 595 \\
\hline & 55.65
\end{tabular}

FOOM T'TFES

SOURCF CROES

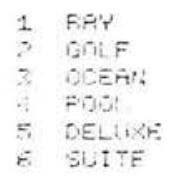

1 FHONE

2 TEI FY
3 FR DFEK

4 MAIL 5 TEI FISEAM

5 SAI.FS OFFIC

$(1,8 \mathrm{D}-2)$ FBCIE

1

ROOM RATE
DEFOSIT ARR -CO
SOIJRCE

ADIULT

ROOM T'TPES

QUANTIT'Y

GLFRK SPECIALES

T'Y

GROUP

$5 / 1 \% / 1776$

\begin{tabular}{|c|c|}
\hline 4. & $10 / 3 / 76$ \\
\hline 4 & $10,320^{\circ}$ \\
\hline & \\
\hline 5 & $\geqslant 1 / 7 \mathrm{a}$ \\
\hline$?$ & 3 \\
\hline 8 & $\geqslant 1 / 76$ \\
\hline 7 & $7 / 3 / 76$ \\
\hline 5 & $?$ \\
\hline 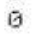 & $7 / 3.76$ \\
\hline 3 & S/ $3 / 76$ \\
\hline 1 & 4 \\
\hline 8 & $9 / 3 / 76$ \\
\hline 3 & $9 / 13 / 76$ \\
\hline 4 & 5 \\
\hline 10 & $9 / 19 / 76$ \\
\hline 3 & $5 / 12 / 76$ \\
\hline & $5 / 12 / 7)^{1}$ \\
\hline
\end{tabular}

$\begin{array}{ll}1 & 4 \\ 5 & 1 \\ 1 & 4 \\ 1 & 6 \\ 0 & 1 \\ 1 & 6 \\ 1 & 4 \\ 0 & 1 \\ 1 & 2 \\ 1 & 3 \\ 0 & 1 \\ 1 & 10 \\ 2 & 6 \\ 1 & 1 \\ 1 & 3 \\ 1 & 1 \\ 1 & 1 \\ 1 & 4\end{array}$

4,
1,
4,
5,
1,
5,
4,
1,
2,
3,
1.
1,
6,
1,
3,
1.
1.
4.
COMPENTS

MODIFIED

$4 / 13 / 70$

$4 / 15 / 75$

M/15/6E

4.1F/6

$4 / 16 / 75$

4/30/76

MIAMI, FLORIDA,

FERE

$z$

5/ $13 / 1970$

CONWENTION DELEGATES

告 CHILDRFN 


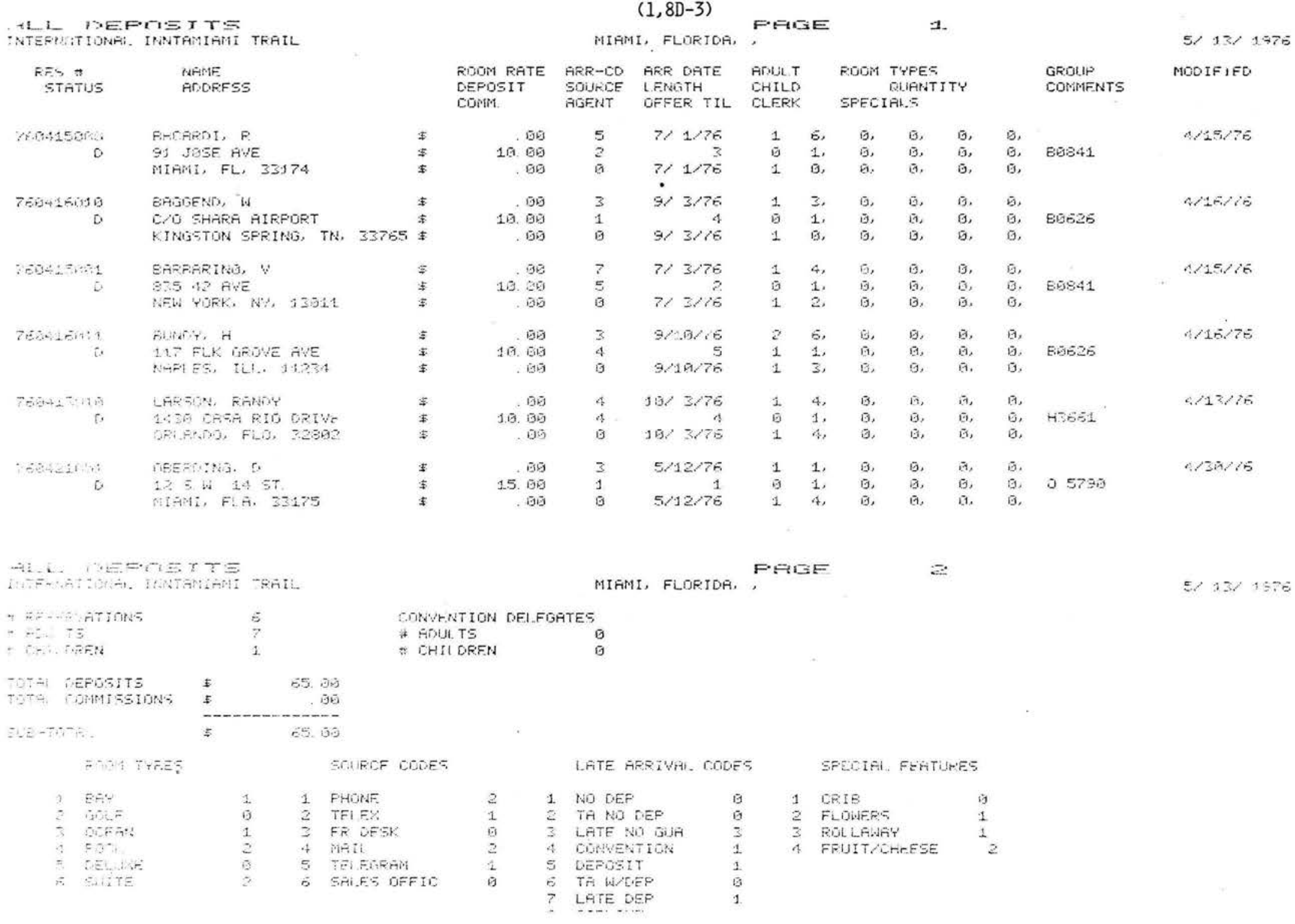




\section{1, 8E. PRINT DEPOSIT TRANSACTIONS}

A. This program will generate a list of all deposit transactions from the Master file.

B. The program is accessed byttyping the number (8) on the Reservation Monitor (1-A) and receiving the Reports Monitor $(1,8-1)$. Then typing the number (5) on Reports Monitor. The system responds by printing the list of transactions, display $(1,8 \mathrm{E}-1)$.

\begin{tabular}{|c|c|c|c|}
\hline \multicolumn{2}{|c|}{ 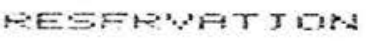 } & \multicolumn{2}{|c|}{ SEF IIST. $\mathrm{T}:$} \\
\hline & Nirti: & FF $=$ no & TIMF: \\
\hline 0 & D FiLIS & 7Е.ด1>10.1 & 224 \\
\hline 1. & IPNTE WFSTON & 761.131984 & 233 \\
\hline 2 & SLFHIS & 7F. 131 ดด & 237 \\
\hline 3 & 0 DAFFNIMG & 769421851. & 2149 \\
\hline 4 & D DEEROINIJ & 76.9421941. & 2246 \\
\hline 5 & KARE'T I ARSON & $76 \cdot 1413015$ & 1.718 \\
\hline $6+$ & $R$ EAICARDI & $76 B .15615$ & 1719 \\
\hline 7 & 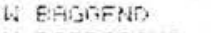 & 7ERั416510 & 1719 \\
\hline 8 & 'V EAR̈BAR ING & 769415961 & 1719 \\
\hline 9 & H Eijand ' & 76.541651 & 1720 \\
\hline & DFFOSIT CAND & TIONS): & 6 \\
\hline
\end{tabular}

$$
\begin{aligned}
& \text { 5. 1: } 19 \div 2 \\
& \text { AMOUNT. BFILANCF } \\
& \text { 45. बमे) ( 49. อ5) }
\end{aligned}
$$

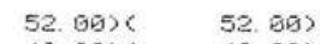

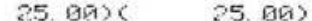

$$
\begin{aligned}
& 1203)(12 \text { 12 } 1 \\
& \begin{array}{rr}
12.03)(12.63) \\
2.97)(15.65)
\end{array} \\
& \text { 19. } 59)(19.59) \\
& 16.59)(19.05) \\
& \text { 10. Б19 })(10.05) \\
& \text { 10. } 95)(\text { 19. } 95 \text { ) } \\
& \text { 19. } 65)(\text { 19. } 55)
\end{aligned}
$$

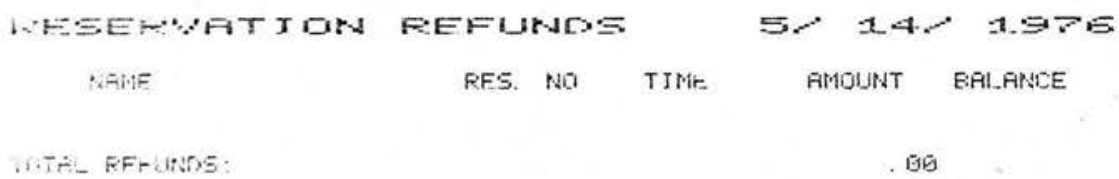

c. After printing the report, the system returns to the Report Monitor $(1,8-1)$ for another selection. 


\section{1, 8F. PRINT RESERVATION BY OFFER UNTIL DATE}

A. This program will generate a list of all reservation transactions from the Master file until the date requested.

B. The program is accessed by typing the number (8) on the Reservation Monitor (1-A) and receiving the Reports Monitor (1, 8-1). Then typing the number (6) on the Reports Monitor, the system responds with display $(1,8 \mathrm{~F}-1)$.

$$
(1,8 F-1)
$$

ENTER OFFER UNTIL DATE:

C. The operator enters the offer until date and XMIT. The system prints the 1 ist of transactions, display $(1,8 \mathrm{~F}-2)$. See Page 58 .

D. The program then returns to the "Do What?" statement. The operator must enter (RES) and XMIT to return to the Reservation Monitor (1-A). 


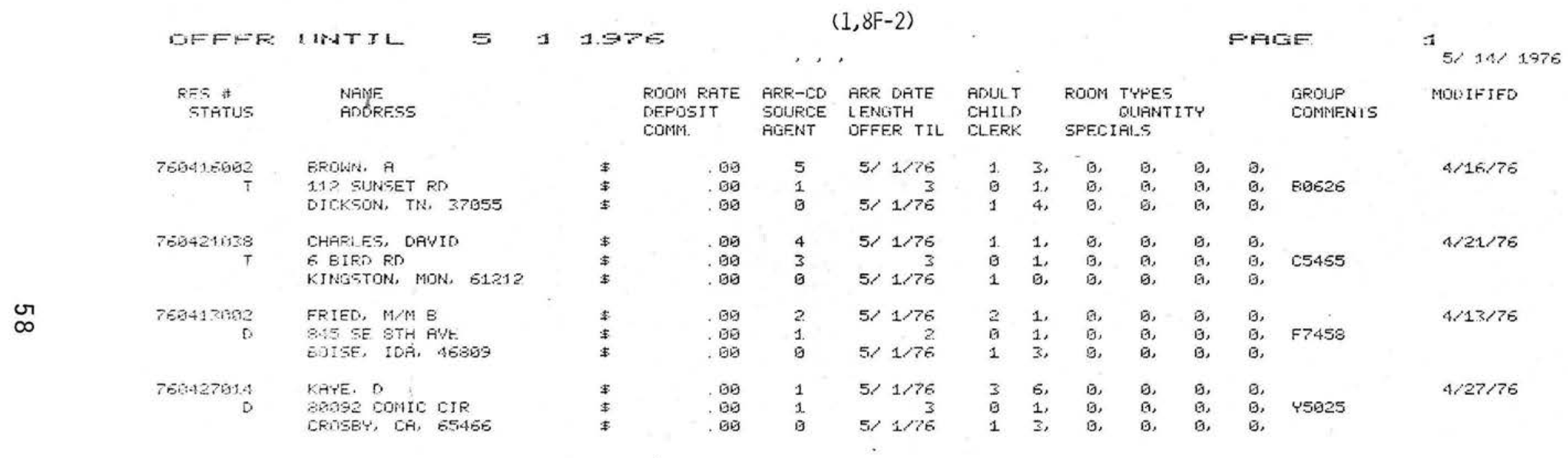


1, 8G. PRINT CONFIRMATION OF TODAY'S DEPOSITS

A. This program will generate a 1 ist of all reservation deposits for the day of operation.

B. The program is accessed by typing the number (8) on the Reservation Monitor (1-A) and receiving the Reports Monitor (1, 8-1). Then type the number (7) on the Reports Monitor. The system responds with display $(1,8 G-1)$.

$$
(1,8 \mathrm{G}-1)
$$

IGNORE FOR (\#DAYS?):

C. Type in the number of days you wish to ignore previous to the date of entrance to the program and XMIT. The system will print a confirmation letter to send to the guest.

NOTE - No confirmation letter is presented for display because the system at Florida International University generates no letters at this time. 


\section{1, 8H. PRINT DEPOSIT REQUEST LETTER}

A. This program will generate the deposit request letters needed for the day's transactions.

B. The program is accessed by typing the number (8) on the Reservation Monitor (1-A) and receiving the Reports Monitor, $(1,8-1)$. Type the number (8) on the Reports Monitor Monitor. The system responds with the deposit request letters needed.

NOTE - No letter is presented for display because the system at Florida International University generates no letters at this time. 


\section{1, 8I. PRINT ALL RESERVATIONS}

A. This program will generate a list of all reservations on the master file.

B. The program is accessed by typing the number (8) on the Reservation Monitor (1-A) and receiving the Reports Monitor, $(1,8-1)$. Then type the number (9) on the Reports Monitor. The system responds with display $(1,8 \mathrm{I}-1)$.

$$
(1,81-1)
$$

PRINT ALL RESERVATIONS

1. BY RESERVATION \#

2. BY NAME

3. BY ARRIVAL DATE

4. RETURN

ENTER \#:

C. The operator selects the type of 1 ist wanted by number.

1. By reservation \# - Enter (1) and XMIT. The system prints the reservation 1 ist by reservation number, display (1, 8I-2). See Page 62.

2. By name - Enter (2) and XMIT. The system prints the reservation 1 ist in alpha order, display (1, 8I-3). See Page 63.

3. By arrival date - Enter (3) and XMIT. The system prints the reservation list in arrival date order, display (1, 8I-4). See Page 64 .

4. Return - Enter (4) and XMIT. The systemwill abort the program and return to the Reports Monitor $(1,8-1)$.

D. After the system is finished printing each type of list it returns to the Reports Monitor. 
HAMT:FF: $I-T=T$

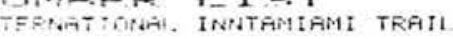

\begin{tabular}{|c|c|}
\hline $\begin{array}{l}\text { RES H } \\
\text { SRATUS }\end{array}$ & $\begin{array}{l}\text { NAME } \\
\text { ARORFSSS }\end{array}$ \\
\hline $760 \div-1$ 3ang 2 & $\begin{array}{l}\text { FRIED, MM E } \\
\text { B.S } \Xi E \text { STH AVE. } \\
\text { EOIEE, IOA, } 4 E 809\end{array}$ \\
\hline $\begin{array}{r}76041+0903 \\
0\end{array}$ & $\begin{array}{l}\text { FRONUE, MMC } \\
\text { GH9 NW GTH PLACE } \\
\text { LA. CA. } 41093\end{array}$ \\
\hline reb412n: & $\begin{array}{l}\text { FINK, } M / M M \\
18399 \text { W } 8 T H \text { PI RCE } \\
\text { Wh, WY, E31>9 }\end{array}$ \\
\hline $750+13005$ & $\begin{array}{l}\text { JANDWITZ. MARK } \\
\text { A4ZZ NE ZZ ST } \\
\text { MIAMI, FL. } 45219\end{array}$ \\
\hline 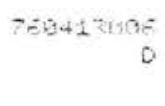 & $\begin{array}{l}\text { IAPZ. O } \\
2 B 2 A, S E \text { Q AVE } \\
\text { MIAMI, FL, 21,a53 }\end{array}$ \\
\hline $\begin{array}{r}700413049 \\
0\end{array}$ & $\begin{array}{l}\text { KERTZMAN, KAROL'YN } \\
333 \text { COUNTR' LFNE } \\
\text { PAIM EEACH, FI, } 5512 \text { ? }\end{array}$ \\
\hline $\begin{array}{r}7064120098 \\
0\end{array}$ & 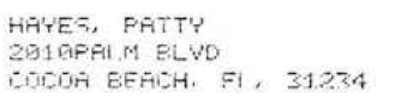 \\
\hline $\begin{array}{r}702+1 \operatorname{sac} 8 \\
0\end{array}$ & 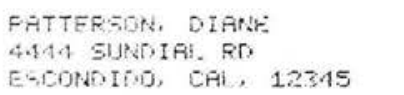 \\
\hline $\begin{array}{r}76041<910 \\
0\end{array}$ & 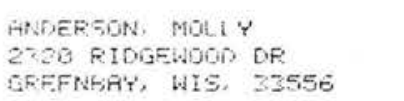 \\
\hline Fogent & 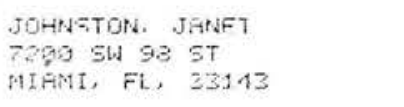 \\
\hline $70043 \mathrm{zan} 2$ & $\begin{array}{l}\text { SUjOS, LDUISE } \\
\text { MA1 FAI METTO DR } \\
\text { FT LALOEROAI E. FL, 21020? }\end{array}$ \\
\hline $\begin{array}{r}780+1 \times 13=3 \\
0\end{array}$ & 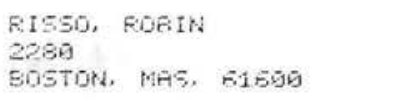 \\
\hline $2609+13914$ & $\begin{array}{l}\text { SHAGTEFN. HFRE: } \\
\text { E.5 OAK ST } \\
\text { SAI EN, OHI, } 44469\end{array}$ \\
\hline
\end{tabular}

$(1,81-2)$

MIAMI, FLORIDA.

FAR:

1

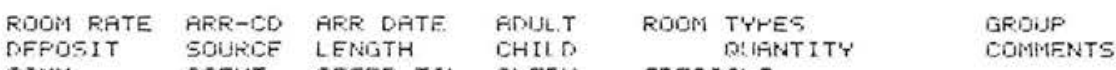

DFPOSIT

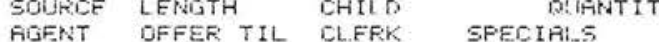

COMMENTS

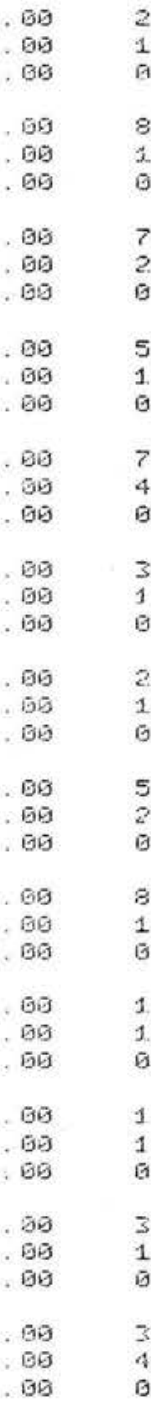

$$
\begin{aligned}
& 5 / 1 / 76 \quad 2 \quad 1, \text { B. } 5, \text { B, } 5,
\end{aligned}
$$

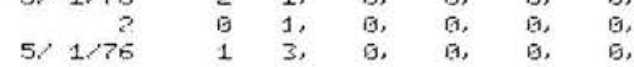

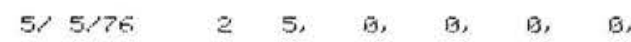

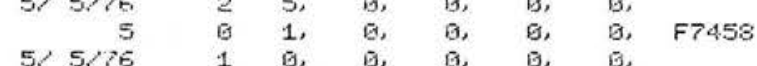

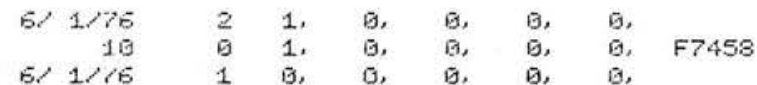

$$
\begin{aligned}
& \text { 5. } 6 / 76 \\
& \text { 5.) } 6 / 66^{4} \\
& 5 / 15 / 76 \\
& 5 / 15 / 76^{5} \\
& 6 / 2 / 76 \\
& \text { 6. } 2 \times 16 \\
& \text { 6. } 8 / 76 \\
& \text { 6. } 8 / 72 \\
& \text { 7/ } 2 / 16 \\
& \text { 7) } 2776 \\
& \text { 7) } 8 / 76 \\
& \text { 7. } 12 \\
& \text { 8. } 6 / 76 \\
& \text { 8. 6/i6 } \\
& \text { 8/19/76 } \\
& \text { 8/19/86 } \\
& \text { 9) } 5 / 76 \\
& \text { 9) } 5 / 76 \\
& 9 / 20 / 76 \\
& \text { 9/20/76 }
\end{aligned}
$$

$4 / 13 / 6$

$4 / 12 / 16$

$4 / 12 / / 6$

$4 / 23 / 6$

$8 / 13 / 26$

$4 / 12 / 76$

$4 / 13 / 76$

$4 / 12 / 16$

$4 / 13 / 6$

$4 / 12 / 76$

C/12//E

$4 / 12 / 6$

4is 13i7e

$1 / 13 / 16$ 


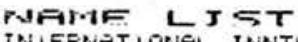

TAMI TRA

$\begin{array}{ll}\text { RFS \# } & \text { NFME } \\ \text { STHTIUS } & \text { FNDRFSS }\end{array}$

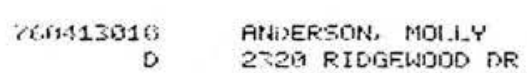
232G RIOGEWIDD DR

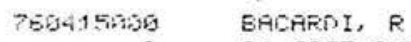

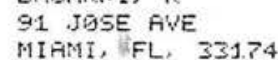

765416919

EAGGEND, W

COD SHARA AIRFORT KIMGSTON SPRING. TN, 33765

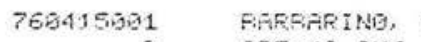
उद 42 तथ

NEW YORK, N'r, 13011

EARFER, $R$

24 MGIN ST

FOXFIUF', N Y, 12421

$\stackrel{\omega}{\omega}$

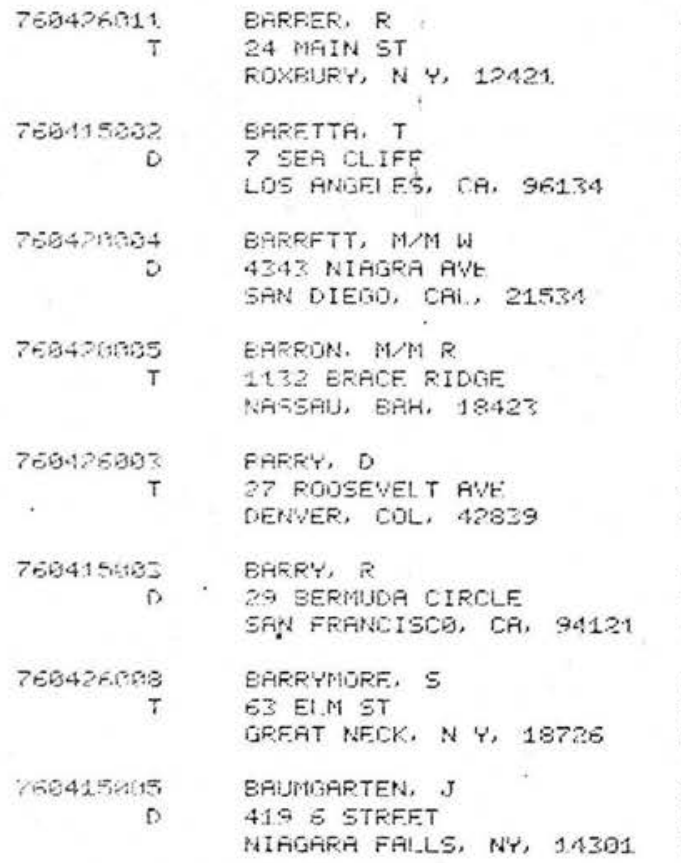

\section{$(1,8 \mathrm{I}-3)$}

MIAMI, FLIORIDA, ,

\section{ROOM RATE} DEFISIT CONTI.

FRR-CD ARR DATE SOUJKEE LFMGTH OFFER TIL

ADULT

\begin{tabular}{|c|}
\hline $\begin{array}{r}7 / 76 \\
12 \\
7,8,76\end{array}$ \\
\hline $\begin{array}{r}7 / 1 / 76 \\
3\end{array}$ \\
\hline $7 / 1 / 76$ \\
\hline $9 / 3 / 76$ \\
\hline $9 / 3 / 76$ \\
\hline $7 / 3 / 75$ \\
\hline $7 / 3 / 76$ \\
\hline $9 / 29 / 76$ \\
\hline $9 / 29 / 76^{4}$ \\
\hline $8 / 6,76$ \\
\hline $8 / 6,76$ \\
\hline $6 / 10 / 76$ \\
\hline $6 / 19 / 76$ \\
\hline \\
\hline $\begin{array}{r}5 / 76 \\
5\end{array}$ \\
\hline $6 / 5 / 76$ \\
\hline $5 / 24 / 76$ \\
\hline $\begin{array}{r}10 \\
5 / 24 / 16\end{array}$ \\
\hline $8 / 15 / 76$ \\
\hline $8 / 15 / 16$ \\
\hline $8 / 6 / 76$ \\
\hline 4 \\
\hline $8 / 6 / 76$ \\
\hline $9 / 17 / 76$ \\
\hline $9 / 17 / 76$ \\
\hline
\end{tabular}

FAGE

RIOOM THYTES

SEEOIANITY SPEEIALS

1

GROUNF COMMENTS

MODIFIFN

$\cdot$

J9785

69841

8 8อ26

E9841

81191

2. ब, ब, ब,

$12,0,0,0,0$,

Bgest

B9841

11,

(a) a, $\theta, 0$

11,4,

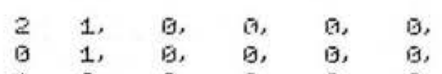

B394

ED394

2 G, a, a, $\theta, \quad 0$

$12,0,0,0,0$

Eiv394

$\begin{array}{lllllll}2 & 4 & 0, & 0, & 9, & 0 . & \\ 0 & 1, & 0 . & 0, & 0, & 0, & B 121\end{array}$

$4 / 26 / 76$

86841

/ $/ 15 / / 6$

$4 / 26 / 16$

$4 / 15 / 6$

$4 / 12 / 76$

$4 / 15 / 76$

$4 / 16 / 76$

$4 / 15 / 76$

$4 / 26 / 76$

$4 / 15 / 76$

$4 / 20 / 76$

$4 / 29 / 16$

2.

$\begin{array}{lllll}\text { 1. } & 0, & 0, & 5, & 0 . \\ \text { 2. } & 0, & 0 . & 0 . & 0 .\end{array}$

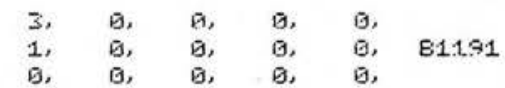

6. ด, ब, ब, क.

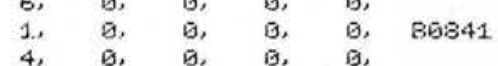

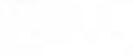




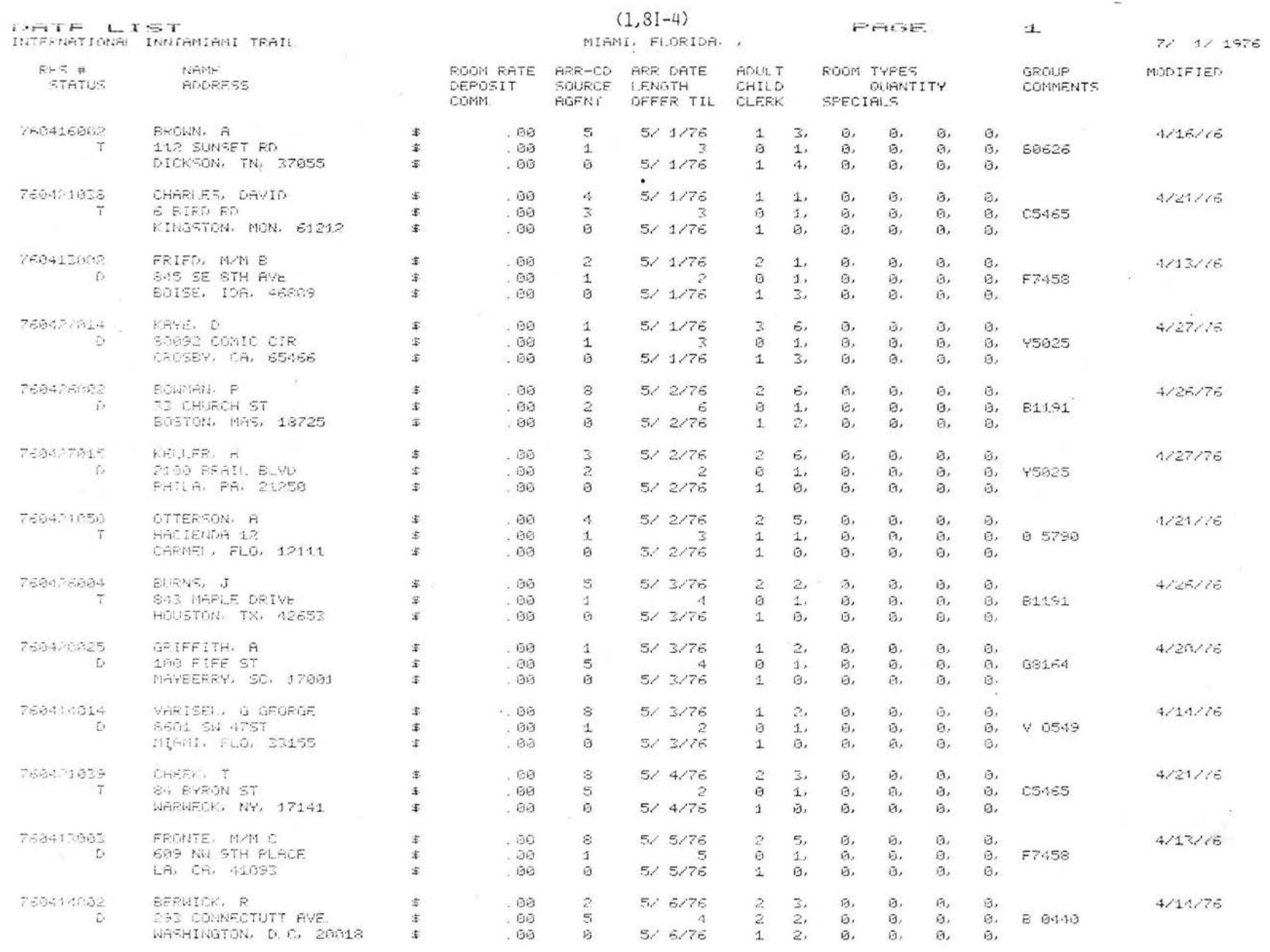




\section{1, 8J. ORDER, CAPACITY, FINANCIAL CHECKS}

NOTE - Restricted program. See supervisor for function and instructions on usage. 


\section{1, 8K. END-OF-DAY RESERVATION PROCESSING}

A. This program will generate a summary of the day's reservations.

B. The program is accessed-by typing the number (8) on the Reservation Monitor (1-A) and receiving the Reports Monitor, $(1,8-1)$. Then type the number (11) on the Reports Monitor. The system will print the end-of-day report, display $(1,8 \mathrm{~K}-1)$. See Page 67 .

C. After the report is printed the system returns to the Reports Monitor $(1,8-1)$. 
$(1,8 \mathrm{~K}-1)$

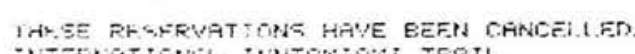

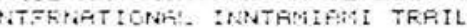

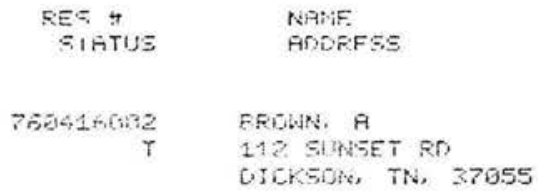

MUEE RFSERWATHONS ARE BWERDHE. INTEK:STIORAPI. IHETAMIAMI TRAIL.

$\begin{array}{cll}\text { RES }+ & \text { NAME } & \text { ROOM RATE } \\ \text { STHTUS } & \text { ADORESS } & \text { OEPOSIT } \\ & \text { COMM }\end{array}$

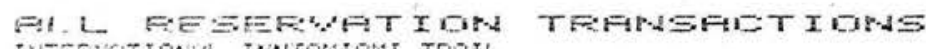
TWTEFISHTIONHI IMNIAMIAMI TRAIL.

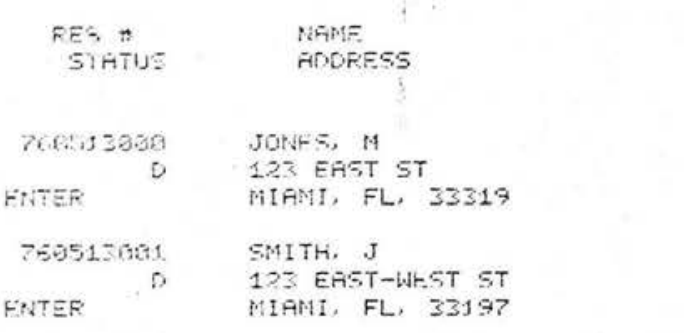

\section{ROOM RATE} OEFOSIT
COMAM.
RDON RATE COMMI.

MIAMI, FLORIOA,

ARR-CD RRR DATE ATUIT

SOURCE IFNGTH CHILD

AIENTT GFTER TIL CL.F.RK

ROON TYFES

REITINIT'

COMMENTS

5. $2 / 1976$

MUOIF IED

.09
.09
.00

$\begin{array}{rrr}5 / 1 / 76 & 1 & 3 \\ 3 & 8 & 1 . \\ 5 / 1 / 76 & 1 & 4\end{array}$

a.

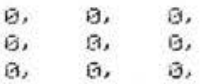

Eต626
ARR-CD ARR DATE ADULTT

OOURCF LENGTH CHIL RGENI OFFER TIL CLERK

\begin{tabular}{|c|c|c|}
\hline & $\begin{array}{l}\text { TYPES } \\
\text { QU.IFNTITYY }\end{array}$ & $\begin{array}{l}\text { GROIJP } \\
\text { COMMENTS }\end{array}$ \\
\hline
\end{tabular}

ARR-CD ARE DATE ADTIT SOURECE LFWGTH CHILD $\begin{array}{ll}\text { AIGENT } & \text { OFFER TIL CLERK }\end{array}$

GROUP COMMENTS
FFGE

FFEE

\section{ROOM TYPES} GUANIIT SFECIAILS

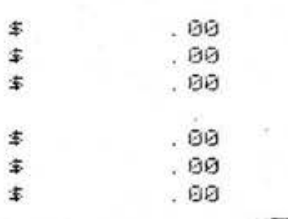

$\begin{array}{rrr}5 / 20 / 76 & 2 & 3, \\ 1 & 0 & 1, \\ 5 / 20 / 76 & 1 & 0, \\ 5 / 20 / 76 & 2 & 1, \\ 2 & 0 & 1, \\ 5 / 20 / 76 & 1 & 0,\end{array}$

$\begin{array}{ll}\text { a. } & 9 . \\ 0 . & 5 \\ 0 . & \\ \text { a. } & \end{array}$

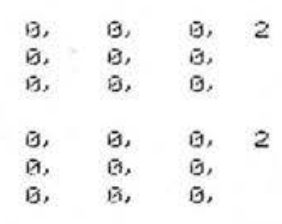

1 5) $\geqslant 1976$ MUDIFIED $5 / 13 / 16$

$5 / 13 / 76$

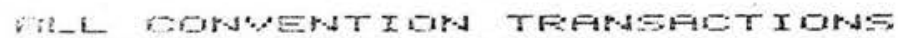

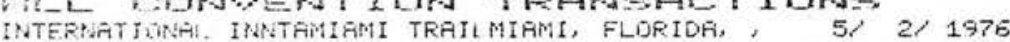

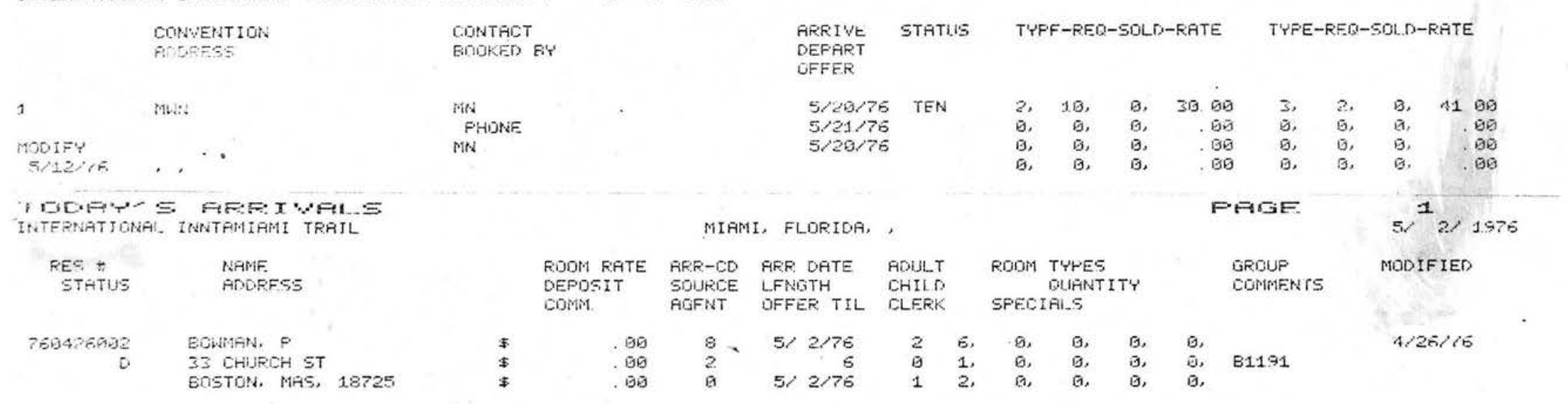


1,8 L. RETURN

A. This program is used to return to the Reservation Monitor.

B. The program is accessed by typing the number (12) on the Reports Monitor $(1,8-1)$. The system responds by returning to the Reservation Monitor (1-A). 


\section{1, 9. RETURN TO DO WHAT}

A. This program is used to return to the "Do What" Statement.

B. The program is accessed by typing the number (9) on the Reservation Monitor $(1-A)$. The system returns to the "Do What" Statement to enter a different monitor. 


\section{CHAPTER II}

REGISTRATION PROGRAMS :

A. The MOBYDATA HOSPITALITY SYSTEM enables any hotel employee to perform the job/function of a front desk clerk. All programs required to check in, post charges, update room status or general room accounting maintenance are contained in the FRONT DESK monitor.

B. The operator need only select the job/function by number from the Front Desk Monitor, display (2-A), XMIT and receive the appropriate instructions and/or frame fills to accomplish the task, and also print a variety of reports, forms and letters.

FRONT DESK MONITOR 5/14/1976 10:45
1. CHECK IN
3. POST CHARGES
2. UPDATE ROOM RECORDS
5. BILL LISTING, CHECKOUT
7. DEPARTED GUEST BILL
9. CHANGE ROOM STATUS
11. GUEST ROOM TRANSFER
4. REPORTS
6. PRINT GUEST MESSAGE
8. NAME SEARCH
10. AVAILABLE ROOMS
13. RETURN TO SYSTEM
12. PRINT/DISPLAY REGISTERED GUESTS
KEY NUMBER HERE: 


\section{2,1 . CHECK IN}

A. This function allows the operator to "check in" guests in the hotel and assign rooms for the guests.

B. There are three categories in the "check in" program:

1. Walk in - no reservations

2. With reservations

3. Special "check-ins" - joiners, masters, etc.

Each of these areas will be discussed in separate sections. 
2, 1A. CHECK IN; WALK IN

A. This function allows the operator to assign a room and folio to the "walk in" guest.

B. The program is accessed by typing the number (1) on the Front Desk Monitor (2-A), XMIT and receive frame fill $(2,1 A-1)$.

$$
(2,1 A-1)
$$

\section{LAST NAME:}

RESERVATION \#:

C. Type in the last name of the guest and CR. The cursor is then positioned to input the reservation number. Since a "Walk in" has no reservation, enter the number $(-1)$, XMIT. The system will respond by automatically selecting a type of room, preset in the program, for a walk in guest, display (2, 1A-2).

$$
(2,1 A-2)
$$

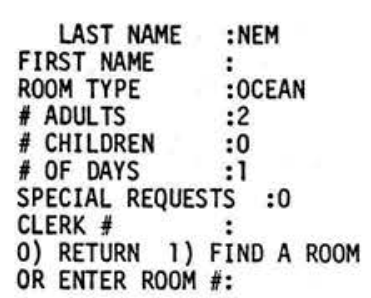

D. The information already displayed is preset by the program and must be changed by the operator. The cursor is automatically positioned on the last name for modification by the operator.

1. LAST NAME - Mandatory data. Data displayed is from display $(2,1 A-1)$. If it is correct $T A B$ to next line. If in error type the correct name and CR. 
2. FIRST NAME - Optional data. Enter the first name and CR. TAB if left blank.

3. ROOM TYPE - Mandatory data. The system automatically selected the room type for all "walk ins." If this is not the type wanted, type the new selection and CR. If the type is correct, TAB.

4. \# OF ADULTS - Mandatory data. The system automatically inputted the number (2). If this is not the number of adults, type the new number and CR. If the number is correct, TAB.

5. \# OF CHILDREN - Optional data (however, needed for correct house count). The system automatically inputted the number $(0)$. If this is not correct, type the new number and CR. If the number is correct, TAB.

6. \# OF DAYS - Mandatory data. The system automatically inputted the number (1). If this is not correct, reenter the number of days the stay is for and CR. If the number is correct, $T A B$.

7. SPECial REQUESTS - Optional data. Enter the "key" number of the special request and CR. If no request is wanted, $T A B$. 
8. CLERK \#- Mandatory data. Enter the clerk number and CR.

E. At the end of frame fill (2, 1A-2) there are two possible choices for selection:

1. RETURN - This function cancels the check in and returns to the Front Desk Monitor (2-A).

2. FIND A ROOM

OR ENTER RM \# - This selection allows the operator to have the system assign a room or enter an available room of the type desired.

a. If the operator wants the system to select a room, enter (1) and XMIT.

b. If the operator wants to assign a room manually, enter the room number and XMIT.

c. In either case the system will respond with frame fil1 (2, 1A-3).

$$
(2,1 A-3)
$$

$\begin{array}{ll}\text { ROOM NUMBER } & \text { 313 FOR MARK NEMTZOW } \\ \text { IS AVAILABLE AT } & : 38.00 \\ \text { TOTAL RATE } & : 38.00 \\ \text { AND PREPAYMENT } & \$: \\ \text { TYPE OF PAYMENT } & \vdots \\ \text { CREDIT CARD\# } & \vdots \\ \text { SELECTION 0.K.? } & \vdots\end{array}$

F. The cursor is automatically positioned on "Total Rate" line for modification.

1. TOTAL RATE - If the rate is correct, depress TAB to position the cursor on the next line. If the rate is not correct, type the new rate and $C R$. 
2. AND PREPAYMENT - If there is a prepayment, enter the amount and CR. If no prepayment, depress TAB to position the cursor on the next line.

3. TYPE OF PAYMENT - Enter how the account will be settled and CR.

4. CREDIT CARD \# - If the "Type of Payment" is a credit card, enter the card \# and CR. If no credit card is being used, $T A B$ to position the cursor on the next line.

5. SELECTION 0.K.? - This function must be answered with a yes or no statement.

a. If yes - Enter ( $Y$ ) and XMIT. The system will respond with display $(2,1 A-5)$.

b. If no - Enter (N) and XMIT. The system will respond with display $(2,1 A-4)$.

$(2,1 \mathrm{~A}-4)$

\section{ENTER ROOM NUMBER}

G. The operator enters the room number and XMIT. The system will redisplay display $(2,1 A-3)$ for the operator to reenter data.

NOTE: If the operator entered an occupied room or a room out-of-order, the system will 1 notify the operator and ask for another selection. 
H. At the bottom of the display the operator has 3 selections in which to choose from:

$$
(2,1 A-5)
$$

MARK NEMTZOW IS CHECKED INTO ROOM 313 WITH FOLIO \# 7600139

1 DONE 2 WELCOME 3ANOTHER CHECK IN \#-

1. DONE - If there are no more check-ins, enter (1) and XMIT. The system will return to the Front Desk Monitor (2-A).

2. WELCOME - Not functioning key.

NOTE: Normally this would print a welcome letter for the new guest.

3. ANOTHER CHECK-IN - If the operator has another checkin, enter (3) and XMIT. The system will return to display $(2,1 A-1)$ to enter the new name. 


\section{2, 1B. CHECK-IN; WITH RESERVATION}

A. This function allows the operator to assign a room and folio to a guest with a previous reservation.

B. The program is accessed by typing the number (1) on the Front Desk Monitor (2-A), XMIT and receive frame fill $(2,1 B-1)$.

$$
(2,18-1)
$$

\section{LAST NAME:}

RESERVATION \#:

C. Type in the last name of the guest and CR. The cursor is positioned to input the reservation number. There are two ways this line may be filled out:

1. If the reservation number is unknown - XMIT. The system will respond with display (2, 1B-2).

2. If the reservation number is known - enter the number and XMIT. The system will respond with display $(2,1 B-3)$.

$(2,18-2)$

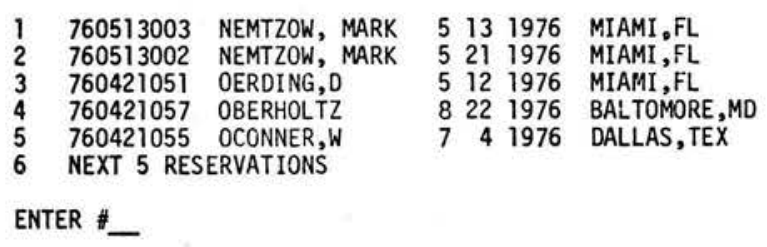

D. There are two choices for the operator from this display:

1. If the reservation being searched for is not found in the alpha list, XMIT and the system will return to the Front Desk Monitor (2-a) or enter the number (6), XMIT and the system will redisplay display (2, 1B-2) but with the next 5 alpha-like reservations. 
D. 2. If the reservation is in the list, enter the key number, XMIT and the system will respond with frame fill, display (2, 1B-3).

$(2,1 \mathrm{~B}-3)$

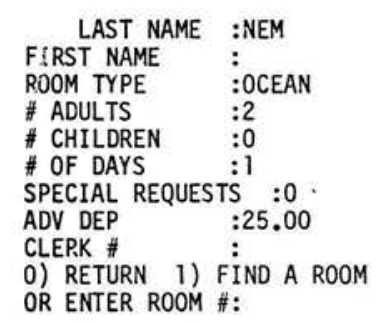

E. The information already displayed is extracted from the reservation data received before and may be changed by the operator if any errors. The cursor is automatically positioned on the last name for any modifications needed.

1. LAST NAME - Mandatory data. The information is generated from the reservation. If it is correct $T A B$ to next line. If in error type the correct name and CR.

2. FIRST NAME - Optional data. Enter the first name and $C R$ if not already given. If no correction or first name is not needed, TAB.

3. ROOM TYPE - Mandatory data. The information is generated from the reservation. If it is correct, $T A B$ to position cursor on next line. If the operator wants to change the type, enter the new room type and $C R$. 
4. \# OF ADULTS - Mandatory data. The information is generated from the reservation. If it is correct, $T A B$ to position cursor on the next line. If it is wrong, enter the new number and $C R$.

5. \# OF CHILDREN - Optional data (however, needed for current house count). The information is generated from the reservation. If it is correct, $T A B$ to position cursor on the next line. If it is wrong, enter the new number and $C R$.

6. \# OF DAYS - Mandatory data. The information is generated from the reservation. If it is correct, $T A B$ to position cursor on the next line. If it is wrong, enter the new number and $C R$.

7. SPECIAL REQUESTS - Optional data. The information is generated from the reservation. If it is correct, $T A B$ to position cursor on the next line. If it is wrong or something is requested enter the code number for the request and $C R$.

8. ADV DEP - This line only appears if an advanced deposit is to be credited to the account. The data cannot be modified or written over. To change the information enter (4) on the Reservation Monitor. 
9. CLERK \# - Mandatory data. Enter the clerk number and CR.

F. At the end of the frame fill (2, 1B-3) there are two possible choices for selection:

1. RETURN - This function cancels the check-in and returns to the Front Desk Monitor (2-A).

2. FIND A ROOM

OR ENTER RM.\# - This selection allows the operator to have the system assign a room or enter an available room.

a. If the operator wants the system to select a room, enter (1) and XMIT.

b. If the operator wants to assign a room manually, enter the room number and XMIT.

c. In either case the system will respond with frame fill (2, 1B-4).

$(2,1 \mathrm{~B}-4)$

$\begin{array}{ll}\text { ROOM NUMBER } & 313 \\ \text { FOR MARK NEMT7 } \\ \text { IS ANAILABLE AT } & : 38.00 \\ \text { TOTAL RATE } & \vdots 38.00 \\ \text { AND PREPAYMENT } & \$ \vdots \\ \text { TYPE OF PAYMENT } & \vdots \\ \text { CREDT CARD \# } & \vdots \\ \text { SELECTICN O.K.? } & \vdots\end{array}$

F. The cursor is automatically positioned on "Total Rate" line for modification.

1. TOTAL RATE - If the rate is correct, depress TAB to position the cursor on the next line. If the rate is not correct, type the new rate and $C R$. 
F. 2. AND PREPAYMENT - If there is a prepayment, enter the amount and CR. (This doesn't include advanced deposits. They are automatically transfered to the guest account.) If no prepayment, depress TAB to position the cursor on the next line.

3. TYPE OF PREPAYMENT - Enter how the account will be settled and CR.

4. CREDIT CARD \# - If the "type of payment" is a credit card, enter the card \# and CR. If no credit card is being used, $T A B$ to position the cursor on the next line.

5. SELECTION O.K.? - This information must be answered with a yes or no statement.

a. If yes, enter (Y) and XMIT. The system will respond with display $(2,1 B-6)$.

b. If no, enter (N) and XMIT. The system will respond with display (2, 1B-5).

$(2,18-5)$

ENTER ROOM NUMBER

G. The operator enters the room number and XMIT. The system will redisplay $(2,1 B-4)$ for the operator to reenter data. NOTE - If the operator entered an occupied room or a room out-of-order, the system notifies the operator and asks for another selection. 
H. At the bottom of the display the operator has 3 selections in which to choose from:

$$
(2,18-6)
$$

MARK NEMTZOW IS CHECKED INTO ROOM 313 WITH FOLIO \# 7600139

1 DONE 2 WELCOME 3 ANOTHER CHECK IN \#-

1. DONE - If there are no more check-ins, enter (1) and XMIT. The system will return to the Front Desk Monitor (2-A).

2. WELCOME - Not functioning key. NOTE: Normally this would print a

"Welcome" letter for the new guest.

3. ANOTHER CHECK-IN - If the operator has another checkin, enter (3) and XMIT. The system will return to display $(2,1 A-1)$ to enter the new name. 


$$
\text { 2, IC. SPECIAL CHECK-INS - "JOINER" }
$$

A. This function contains provisions allowing the generation of more than one guest account for the same room.

B. The program is accessed in the same manner as a check-in with a reservation, see section 2, 1B. However, the instructions vary starting in section 2, 1B step F. For easy reference refer to the next display.

$$
(2,1 \mathrm{C}-1)
$$

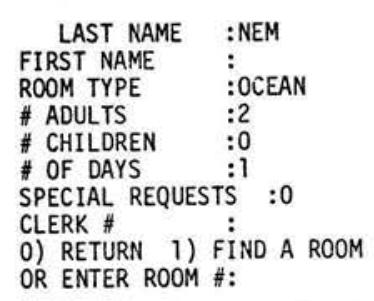

c. The first 9 lines of this frame fill ( 8 lines - if no advance deposit) are inputed the same as described in section 2, 1B - step E.

D. At the end of the frame fill (2, 1C-1) there are two possible choices for selection:

1. RETURN - This function cancels the check-in and returns to the Front Desk Monitor (2-A).

2. FIND A ROOM

OR ENTER RM \#:- This selection allows the operator to have the system assign a room or enter an available room.

- To enter a "joiner" manually enter the room number wanted and XMIT. The system will respond with display $(2,1 \mathrm{C}-2)$. 
ROOM 102 IS OCCUPIED BY R.D. MURPHY

DO YOU WANT TO SPLIT THE BILL?:-

E. The operator must answer with a yes or no response.

1. If yes - enter ( $Y$ ) and XMIT. The system will respond with display $(2,1 \mathrm{C}-4)$. (Refer to step H)

2. If no - enter (N) and XMIT. The system will respond with display $(2,1 C-3)$.

$$
(2,1 \mathrm{C}-3)
$$

ROOM 102 IS NOT AVAILABLE. TRY AGAIN?:

F. The operator must answer with a yes or no response.

1. If yes - enter $(Y)$ and XMIT. The system will respond with display (2, 1C-2). (Refer to step I)

2. If no - enter (N) and XMIT. The system will respond with display $(2,1 \mathrm{C}-5)$.

$$
(2,1 C-5)
$$

DO YOU WISH THE SYSTEM TO SELECT A ROON?:

G. The operator must answer with a yes or no response.

1. If yes - enter (Y) and XMIT. The system will find an available room for the guest. For further instructions refer to section 2 , $1 B$ step $F$. and continue the check in using the instructions in that section.

\begin{tabular}{|c|c|}
\hline $\begin{array}{l}\text { ROOM NUMBER } 313 \\
\text { IS AVAILABLE AT } \\
\text { TOTAL RATE } \\
\text { AND PREPAYMENT } \\
\text { TYPE OF PAYMENT } \\
\text { CREDIT CARD \# } \\
\text { SELECTION 0.K.? }\end{array}$ & $\begin{array}{l}\text { FOR MARK NEMT } \\
: 38.00 \\
: 38.00 \\
\$: \\
: \\
\vdots\end{array}$ \\
\hline
\end{tabular}

$$
(2,1 \mathrm{C}-4)
$$


H. The cursor is automatically positioned on the "Total Rate" line for modification.

1. Change room rate to proper amount:

a. 1/2 of double rate, if 2 persons

b. $1 / 3$ of triple, if 3 persons

c. 0 if complete rate is to be on one bill.

2. Complete the frame fill and the rest of the check in procedures in the normal manner. For complete instructions refer to section 2, 1B step $F$. NOTE: After completing the check in the operator must enter the Night Audit Monitor to manually change the room rate for the guests already registered in the room.

I. Enter the new room number and XMIT.

a. If the new selection is an occupied room the system will respond with display (2, 1C-2). Refer to section 2, IC step E. for instructions.

b. If the new selection is an available room the system will respond with display (2, 1B-4). Refer to section 2, 1B step $F$. for instructions. 


\section{2, 1D. SPECIAL CHECK-INS - MASTER ACCOUNT}

A. This function contains provisions allowing the registration of more than one room to a Master Account.

B. There are two methods that may be used:

1. Method A

a. Check in First Room to guest per normal procedure.

b. Change room rate on "Master" Room Account to sum of all rooms.

c. Check in additional rooms, type guests' last name.

d. Under guest "first name", type C-\#\#. (The \#\#\# is the room number of master room account.)

e. Change room rates to " 0 ".

2. Method B

a. Check in First Room to guest per normal procedure.

b. Check in additional rooms, referencing each room to Master Room Account (See Method A (d) above). Continue with normal check-in procedure.

c. Upon check out use Selection \#5, "Transfer to Guest Account", and transfer all accounts to Master Account. 


\section{2, 2. UPDATE ROOM RECORDS}

A. Since the system is designed to allow the desk clerk to register the guest with a minimum amount of data entry, it becomes necessary to return to the guest's permanent record and add various items. This function allows the operator to do so.

B. The program is accessed by typing the number (2) on the Front Desk Monitor (2-A), XMIT and receive frame fill $(2,2-1)$.

$$
(2,2-1)
$$

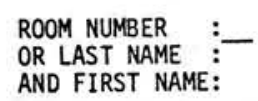

c. There are two methods the operator may use to continue the program:

1. If the room number is known, enter the number and XMIT. The system will respond with display (2, 2-3). 2. If the room number is not known, $T A B$ to position the cursor on the next line and enter the last name, CR, and the first name of the guest, XMIT. The system will respond with a list of alpha-like names and room numbers, display (2, 2-2).

$$
(2,2-2)
$$

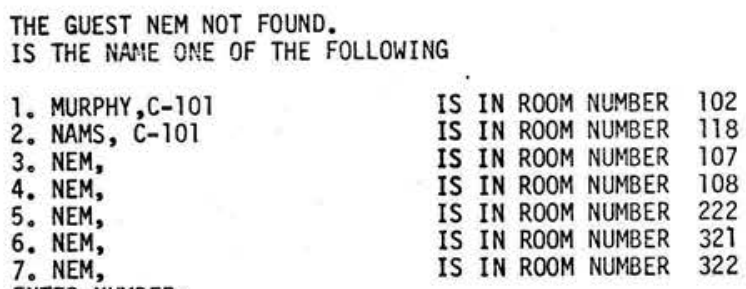

IS IN ROOM NUMBER 102

IS IN ROOM NUMBER 118

IS IN ROOM NUMBER 107

IS IN ROOM NUMBER 108

IS IN ROOM NUMBER 222

IS IN ROOM NUMBER 321

IS IN ROOM NUMBER 322 
D. Enter the key number of the guest being searched for and XMIT. The system will respond with display $(2,2-3)$ for the update.

$(2,2-3)$

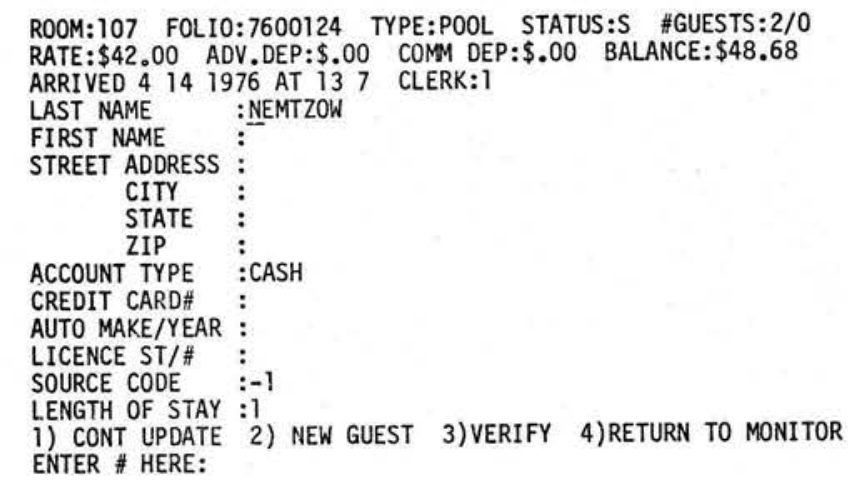

E. The first three lines of the display may not be modified.

The cursor is automatically positioned on the "last name"

line for modification.

1. LAST NAME - To modify, enter the new data and CR. If no modifications are needed, TAB.

2. FIRST NAME - To modify, enter the new data and CR. If no modifications are needed, TAB.

3. STREET ADDRESS - To modify, enter the new data and CR. If no modifications are needed, TAB.

4. CITY - To modify, enter the new data and CR. If no modifications are needed, TAB.

5. STATE - To modify, enter the new data and CR. If no modifications are needed, TAB.

6. ZIP - To modify, enter the new data and CR. If no modifications are needed, TAB.

7. ACCOUNT TYPE - To modify, enter the new data and CR. If no modifications are needed, TAB. 
8. CREDIT CARD \# - To modify, enter the new data and CR. If no modifications are needed, TAB.

9. AUTO MAKE/MODEL - To modify, enter the new data and CR. If no modifications are needed, TAB.

10. LICENSE ST/\# - To modify, enter the new data and CR. If no modifications are needed, TAB.

11. SOURCE CODE - To modify, enter the new data and CR. If no modifications are needed, TAB.

12. LENGTH OF STAY - To modify, enter the new data and CR. If no modifications are needed, TAB.

F. At the bottom of the frame fill (2, 2-3) the operator has four selections to choose from:

1. CONT UPDATE - This function will continue with the second half of the update record. Enter (1) and XMIT. The system will respond with frame fill (2, 2-4).

2. NEW GUEST - This function enters the modification on the master file and redisplays frame fill (2, 2-1) for updating another guest. Enter (2) and XMIT.

3. VERIFY - This function redisplays display $(2,2-2)$ with the updated information. Enter (3) and XMIT.

4. RETURN TO MONITOR - This function returns to the Front Desk Monitor (2-A). Enter (4) and XMIT. 
$(2,2-4)$

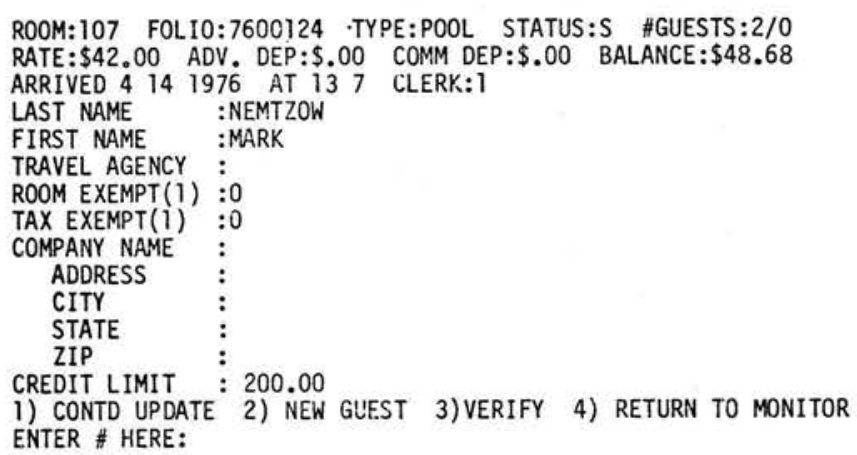

G. The first 5 lines of the display may not be modified.

The cursor is automatically positioned on the "Travel Agency" line for modification.

1. TRAVEL AGENCY \# - NOT functioning.

2. ROOM EXEMPT (1) - This function allows the operator to automatically set the room rate to $\emptyset$. Enter (1) and CR. NOTE: Use this function with special check-ins.

3. TAX EXEMPT (1) - This function allows the operator to have a tax exempt account. Enter (1) and $C R$.

4. COMPANY NAME - To modify, enter new data nad CR. If no modifications are needed, TAB.

5. ADDRESS - To modify, enter new data and CR. If no modifications are needed, TAB.

6. CITY - To modify, enter new data and CR. If no modifications are needed, TAB.

7. STATE - To modify, enter new data and CR. If no modifications are needed, TAB. 
8. ZIP - To modify, enter new data and CR. If no modifications are needed, TAB.

9. CREDIT LIMIT - To modify, enter new data and CR. If no modifications are needed, $T A B$.

H. At the bottom of frame fill (2, 2-4) the operator has four selections to choose from:

1. CONT UPDATE - This function will redisplay the first half of the update record. Enter (1) and XMIT. The system will respond with frame fil1 (2, 2-3).

2. NEW GUEST - This function enters the modifications on master file and redisplays frame fill (2, 2-1) for updating another guest. Enter (2) and XMIT.

3. VERIFY - This function redisplays display (2, 2-3) with the updated information. Enter (3) and XMIT .

4. RETURN TO MONITOR - This function returns to the Front Desk Monitor (2-A). Enter (4) and XMIT. 
c. 4. c. If there is only one folio assigned to the room the system will respond with display (2, 3-4).

$$
(2,3-2)
$$

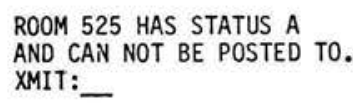

D. The operator may not post charges to a vacant room. XMIT as stated on the display. The system will return to display $(2,3-1)$ to report the charges.

$$
(2,3-3)
$$

WHICH OCCUPANT IN ROOM 107

1. C-101 KELLY

2. MARK NEMTZOW

NUMBER:

E. Select the guest wanted by "key" number and XMIT. The system will respond with display $(2,3-4)$.

$$
(2,3-4)
$$

THE GUEST MARK NEMTZOW IS IN ROOM 107

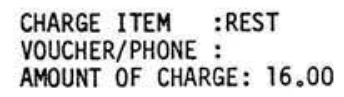

IS THIS CORRECT?:

F. The cursor is positioned to answer the question with a yes or no statement.

1. If no, enter (N) and XMIT. The system will erase the charge and return to display (2, 3-1).

2. If yes, enter ( $Y$ ) and XMIT. The system will respond in one of four manners:

a. If the amount of the charge is not above the charge limit ( $\$ 15)$, the sales code entered is correct, and the charge will not place the guest 
over his credit limit, the system will post the charge and redisplay frame fill (2, 3-1) for another posting or exit to the monitor.

b. If the sales code is not correct as entered in display $(2,3-1)$ the system will respond with display $(2,3-5)$.

c. If the amount of the charge is above the charge limit (\$15) and the sales code entered is correct the system will respond with display (2,3-6).

d. If the amount of the charge is not above the charge limit $(\$ 15)$ and the sales code entered is correct but the amount places the guest above his credit limit, the system will respond with display $(2,3-7)$.

\begin{tabular}{|c|c|c|c|}
\hline & & $(2,3-5)$ & \\
\hline $\begin{array}{l}\text { ROOM } \\
\text { FOOD ROOM SER } \\
\text { MAP } \\
\text { FLORIST } \\
\text { BEVERAGE BQT } \\
\text { MISC. } \\
\text { PAID OUT } \\
\text { CABANA+GOLF } \\
\text { F/COST OD SAL } \\
\text { TELEGRAM } \\
\text { S+P ENTERTAIN } \\
\text { BALANCE } \\
\text { RGENCY COMM. } \\
\text { ASLES TAX } \\
\text { ALUNCH CAFE } \\
\text { ACLUB HOUSE } \\
\text { APOOL BAR } \\
\text { ALONG DIS } \\
\text { AOTHER MISC. } \\
\text { ARENTAL } \\
\text { ATIPS PAY } \\
\text { AO/SHORT CASH } \\
\text { AMGR'S } \\
\text { AA/C REC CLR. } \\
\text { ABOVE ITEMS } \\
\text { ENTER HERE: }\end{array}$ & $\begin{array}{l}\text { ROOM } \\
\text { BREAKFAST CAFE } \\
\text { LAUNDRY/VAL } \\
\text { COCKTAIL PARTY } \\
\text { R/SER BEV } \\
\text { BOAT RENTAL } \\
\text { REFUND } \\
\text { CYCLE RENTAL } \\
\text { B/COST OF SAL } \\
\text { C/C COMM } \\
\text { HOUSE BANKS } \\
\text { +TRANS. } \\
\text { G. CONRADE } \\
\text { AGROUP ROOMS } \\
\text { ALAUNDRY/VAL } \\
\text { ABQT FOOD } \\
\text { ABAR GOLF } \\
\text { ADRUG STORE } \\
\text { AGIFT SHOP } \\
\text { AVENDING } \\
\text { AGOLF FEES } \\
\text { CASH SALES } \\
\text { AA+G ENTERTAIN } \\
\text { AUNCOLLECTABLE } \\
\text { VAILABLE ONLY }\end{array}$ & $\begin{array}{l}\text { SALES TAX } \\
\text { LUNCH CAFE } \\
\text { CLUB HOUSE } \\
\text { POOL BAR BEV. } \\
\text { LONG DISTANCE } \\
\text { OTHER MISC. } \\
\text { RENTAL INCOME } \\
\text { TIPS PAYABLE } \\
\text { O/SHORT CASH } \\
\text { MGR'S } \\
\text { A/C REC CLEAR } \\
\text {-TRANS. } \\
\text { DEPOSIT } \\
\text { AFFOD RM. SER. } \\
\text { AMAP } \\
\text { AFLORUST } \\
\text { ABEVERAGE BQT } \\
\text { AMISC. } \\
\text { PAYMENT } \\
\text { ACABANA } \\
\text { AF/COST OF SAL } \\
\text { ALATE CHARGE } \\
\text { AS+P ENTERTAIN } \\
\text { ARICH+MARK }\end{array}$ & $\begin{array}{l}\text { GROUP ROOMS } \\
\text { RESTAURANT } \\
\text { BQT FOOD } \\
\text { BAR/CLUB HOUSE } \\
\text { ORUG STORE } \\
\text { GIFT SHOP } \\
\text { VENDING } \\
\text { GOLF FEES } \\
\text { COMMUNICATIONS } \\
\text { A+G ENTERTAIN } \\
\text { UNCOLLECTABLE } \\
\text { ADINING ROOM } \\
\text { AROOM } \\
\text { ABREAKFAST } \\
\text { ASNACK } \\
\text { AWINE/DINE } \\
\text { AR/SERVICE } \\
\text { ABOAT RENTAL } \\
\text { AREFUND } \\
\text { ACYCLE RENT } \\
\text { AB/COST OF SAL } \\
\text { AC/C COMM } \\
\text { AHOUSE BANKS }\end{array}$ \\
\hline
\end{tabular}


G. Enter the correct code and XMIT. The system will respond in one of three ways:

1. If the amount of the charge is not above the charge limit (\$15) and the charge will not place the guest over his credit limit, the system will post the charge and redisplay frame fill (2, 3-1) for another posting or exit to the monitor.

2. If the amount of the charge is above the charge limit $(\$ 15)$, the system will respond with display (2, 3-6).

3. If the charge is not above the charge limit (\$15) but the amount places the guest above his credit limit, the system will respond with display (2, 3-7).

$$
(2,3-6)
$$

CHARGE AMOUNT HIGH. IS 16.00 CORRECT?:

H. Answer with a yes or no statement:

1. If no, enter (N). The system will respond with "Enter correct charge amount." Enter the amount of the charge and XMIT. The system will change the charge and will respond in one of three ways:

a. If the charge is less than the charge $1 \mathrm{imit}$ and does not make the guest exceed his credit limit, it is posted and the system will return to display $(2,3-1)$.

b. If the charge is over the charge limit, the system will return to $(2,3-6)$. 
H. 1. c. If the charge is under the charge limit but exceeds the credit limit, the system will respond with display $(2,3-7)$.

2. If yes, enter (Y) and XMIT. The system will respond in one of two ways:

a. If the charge will not place the guest above his credit limit, the system will respond by posting the charge and returning to display (2, 3-1).

b. If the charge will place the guest above his credit limit, the system will respond with display $(2,3-7)$.

$$
(2,3-7)
$$

GUEST MARK NEMTZOW WILL EXCEED HIS CREDIT LIMIT
OF $\$ 200.00 \mathrm{BY} \$ \$ 866.36$

DO YOU WANT TO POST THIS CHARGE? :

I. Answer with a yes or no statement.

1. If yes, enter (Y) and XMIT. The system will post the charge and return to display (2, 3-1).

2. If no, enter (N) and XMIT. The system will respond by canceling the charge and return to display $(2,3-1)$. 


\section{2,4 . REPORTS}

A. This program enables the operator to retrieve front office reports generated by the system for all front desk activities.

B. The program is accessed by typing the number (4) on the Front Desk Monitor (2-A). The system will respond with a sub-program 1ist, display (2, 4-1).

$$
(2,4-1)
$$

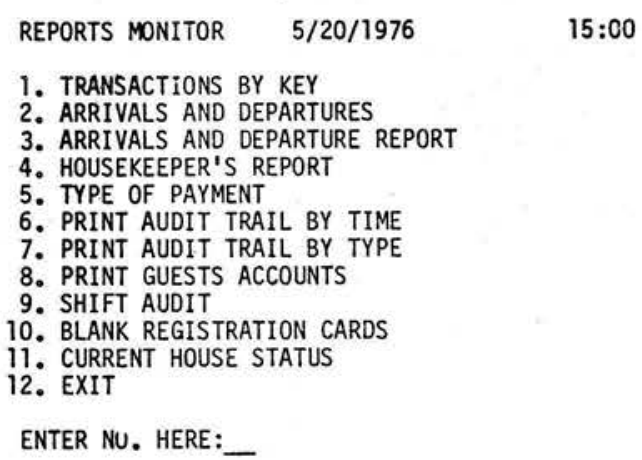

c. The operator need only to select the job/function by number from the Reports Monitor (2, 4-1), XMIT and receive the appropriate instructions and/or frame fill to accomplish the task.

NOTE: An example section of the reports are only given. The reason being that most of the reports are too long to reproduce. 


\section{2, 4A. TRANSACTIONS BY KEY}

A. This program will generate a list of all posting transactions by one key type.

B. The program is accessed by typing the number (4) on the Front Desk Monitor (2-A) and receiving the Reports Monitor (2, 4-1). Then type the number (1) on the Reports Monitor and receive frame fill (2, 4A-1).

$(2,4 A-1)$

PRINT TRANSACTIONS FOR WHICH KEY?:

C. Enter the key code name wanted and XMIT. The system will print a 1 ist of transactions, display (2, 4A-2), after which it will return to display (2, 4A-1).

$$
(2,4 A-2)
$$

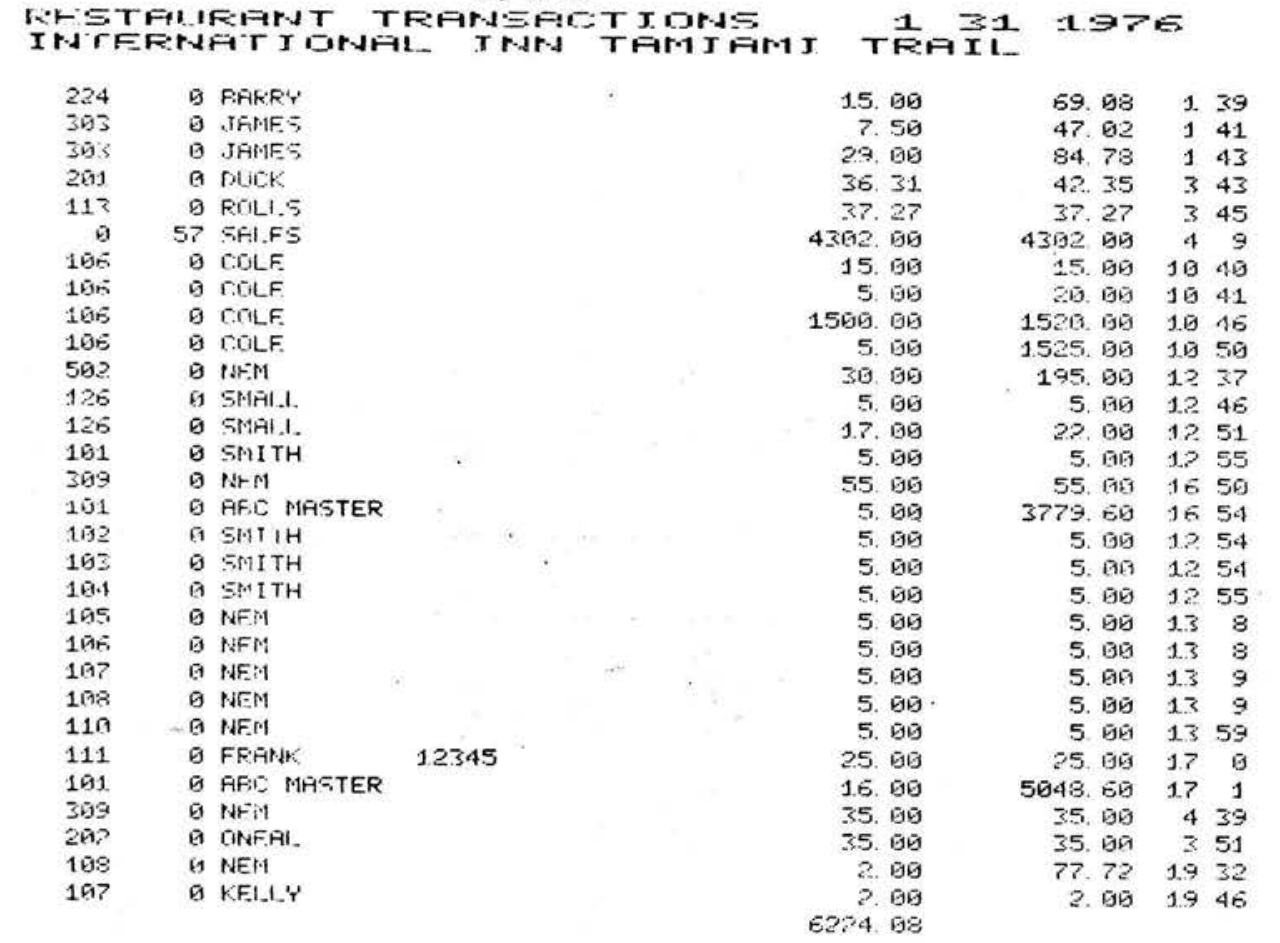




\section{2, 4B. ARRIVALS AND DEPARTURES}

A. This program will generate a list of all arrivals or departures for the date of operation.

B. The program is accessed by typing the number (4) on the Front Desk Monitor (2-A) and receive the Reports Monitor (2, 4-1). Then type the number (2) on the Reports Monitor and receive display (2, 4B-1).

$(2,4 B-1)$

\section{1) TODAY'S ARRIVALS OR}

2) TODAY'S DEPARTURES:

C. Enter the key number wanted and XMIT.

1. If today's arrivals, enter (1) and XMIT. The system responds with display $(2,4 B-2)$.

2. If today's departures, enter (2) and XMIT. The system responds with display (2, 4B-2).

$$
(2,48-2)
$$

\section{DISPLAY \\ 2. PRINT:}

D. Enter the way the form is to be generated.

1. If display, enter (1) and XMIT. The system will display the arrival or departure list. (The display for the CRT display is the same as the print-out.

2. If print, enter (2) and XMIT. The system will print either an arrival list or a departure list.

a. Arrival list $(2,4 B-3)$.

b. Departure 1 ist $(2,4 B-4)$.

3. After generating the report the system will return to the Reports Monitor $(2,4-1)$. 
$(2,4 B-3)$

\begin{tabular}{|c|c|c|c|c|c|}
\hline ROOM & GUEST NAIAF. & ARRIVE & DE.PART & BAI. ANCE & FOL.Io \\
\hline 111 & SAIILOF, $N$ & 521 & 526 & .90 & 7600149 \\
\hline 234 & HAMIZOW. MARK & 521 & 523 & .60 & 7600146 \\
\hline 236 & HEMTZOW. MAFK & 521 & 523 & .90 & 7698148 \\
\hline 323 & SM!TH, & 521 & 522 & .09 & 76551.47 \\
\hline
\end{tabular}

\section{$(2,4 B-4)$}

IPTERIUIIONAI, MUITAMIAMI TRAIL OEFARTURF LIST $5 / 21 / 1976$
MIAMI, FIORIOA. ROOM GIJEST RIAME

191. FEO MASTEF.

- 192 MJFFr' $\mathrm{E}-101$

$19 \overline{\mathrm{N}} \mathrm{CON}, \mathrm{C}-1 \mathrm{CS}$

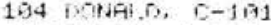

195 CUEF', C-191

197 + F. I \& $C-191$

197 PHETZOW. PARE:

198 RH-WT, C-101

193 thT.

199 FFIRC $5-101$

110 GITTHE. C-JWI

113 FitL $L=C-1,1]$

$114 \mathrm{Fi} I \mathrm{I}, \mathrm{c}-\mathrm{jal}$

115 BUTHR F. E-101

116 FFArik: $5, c-101$

117 HILL. C-161

118 1:7.155, $\quad-101$

119 bifit. C-Jin

120 THOHAE, $C-101$

121 bisijl. $C-151$

12? MITCHFAl, r-101

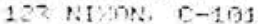

DA Foner. c-int

12S FILT, C-19:

1.6 औाA $\mathrm{C}-1 \mathrm{n} 1$

127 I ITTLF, O-10.1

128 Hifil, $5-191$

12 A BHATRT, -101

178 CA I T $\mathrm{C}-101$

231 An CHATF

2all night.

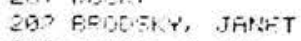

21\% IONF $=$ C-1a1

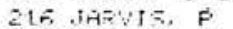

$2 \geq \mathrm{N}=\mathrm{M}$.

226 SNITH. J

2.28 NEUTZOW, MAFK

200 NEMIZOW. $M$

20 MFIITUS. MHFK

24 CFACF. G

$39<1$ ULL, TEFF'Y

205 STORE, J

2107 THOHA GONA. F

311 .THF $=M$

31 ₹ PFHTZIWW. MAFK

31.5 MAETFE:

317 NFMIOWW. MAFK

319 GilTHF. LOWIS

$321 \mathrm{NHW}$.

$32 ? \mathrm{NFM}$.

BAI.ANCE FOL.IO

7543. 697609073 05 7600983

. 957596975

(99) 7699675

ดด 7609077

2. ดต 7695979

1959. $36 \quad 7695124$ อด 7 हดตด्ล

77. $72 \quad 76901.25$ 195 7699681 607696982

37. $27 \quad 7696985$ [19 7600086

. 597600087

. 1957696083

. 657695989

. 997699990

. 997660991

.

195 7600033

. $9576 ต ด ต 94$

อด 7696995

6ค 7699096

. 0 7 7 6.99597

37. 907605998

.097695993

.657609190

. ब15 769ด101.

.967699192

135. 31 7659196

204.597605110

54. 687605144 อ9 7659384

212. 16 76019107

95. 687690126

31207605137

6. 207690149

6. 297600141

31. 297608142

265. 9376019112

35. 367609133

197. $60 \quad 7699114$

197. $69 \quad 7609115$

39. $52 \quad 7690133$

39. 527698139

251. 8776915109

39. 527600143

273. 647690108

39. 5276410145

95. 83 7696127 


\section{2, 4C. ARRIVAL AND DEPARTURE REPORT}

A. This program will generate a formal arrival and departure report for the day of operation.

B. The program is accessed by typing the number (4) on the Front Desk Monitor (2-A) to receive the Report Monitor $(2,4-1)$. Then type the number (2) on the Reports Monitor and receive a CRT display of the report.

c. At the bottom of the display theoperator has 2 selections to choose from.

1. Print - This function will print a copy of the report, display $(2,4 C-1)$. Enter (1) and XMIT.

2. Return - This function will abort the program and return to the Reports Monitor (2, 4-1).

MOE'Y'OATA HOSFITAI_IT'Y' S'YSTEMS

CUREENT HOUSE COMPLEMFNT HT $9: 23$ ON $5 / 21 / 1976$

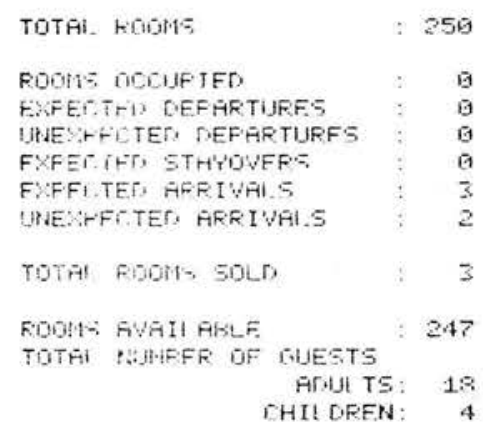

D. After the system prints the report it will return to the Reports Monitor (2, 4-1). 


\section{2, 4D. HOUSEKEEPER'S REPORT}

A. This program will generate a room status, housekeeping report for the day of operation.

B. The program is accessed by typing the number (4) on the Front Desk Monitor (2-A) to receive the Reports Monitor (2, 4-1). Then type the number (4) on the Reports Monitor and the system will print the Housekeeper's Report, display (2, 4D-1). See Page 103.

c. After the report is printed the system returns to the Reports Monitor (2, 4-1). 


\section{$(2,4 \mathrm{D}-1)$}

DAXL' HCULEREFFIMTA RERERT

INTERNATIONAI. INN TAMIAMI TRAIL

\begin{tabular}{|c|c|c|c|c|c|c|c|c|c|c|c|c|}
\hline ATF & 5. $2 \mathrm{~L}$ & 1976 & & TIMF: & 9: & 49 & . & & & & & \\
\hline 151 & $x \ldots \ldots$ & 152 & $x$ & $\ldots$ & $19 \overline{3}$ & $x \ldots$ & 104 & $x \ldots$. & $1.95:$ & $x \ldots$ & 106 & A $\ldots$. \\
\hline $10 ?$ & $x \ldots$ & 168 & $x$ & $\ldots$ & 169 & $x \ldots \ldots$ & 110 & $x \ldots \ldots$ & 111 & s.... & 112 & A. .... \\
\hline 113 & $x \ldots$ & 114 & $x$ & $\ldots$ & 115 & $x \ldots$ & 1.16 & $x \ldots \ldots$ & $117:$ & $x \ldots \ldots$ & 118 & $x \ldots$ \\
\hline 114 & $\ddot{x} \ldots$. & 120 & $x$ & $\ldots$ & 121. & $x \ldots$ & 122 & $x \ldots$ & $123:$ & $x \ldots$ & 124 & $x \ldots$ \\
\hline 125 & $x \ldots \ldots$ & 126 & $x$ & $\ldots$ & 127 & $x \ldots$. & 128 & $x \ldots$ & $129:$ & $x \ldots$. & 130 & $x \ldots$. \\
\hline 201 & $\therefore \ldots$ & 202 & $x$ & $\ldots$ & 203 & A $\ldots$. & 204 & A $\ldots$. & 205 & A $\ldots$. & 206 & A. .... \\
\hline 207 & 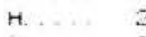 & 208 & A & $\therefore$. & 209 & $A \ldots$. & 210 & A $\ldots$. & 211 & A $\ldots$. & 212 & $x \ldots$ \\
\hline 212 & H.... & 214 & A. & $\ldots$ & 215 & A.... & 216 & $x \ldots$ & 217 & A. .... & 218 & A. .... \\
\hline 21.9 & A $\ldots$ & 280 & A & $\ldots$ & 221 & A $\ldots$ & 222 & $x \ldots$ & 223 & 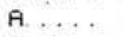 & 224 & c.... \\
\hline 225 & $A \ldots$. & 226 & $x$ & $\ldots$ & 227 & A $\ldots$. & 228 & $x \ldots$ & 229 & A. .... & 280 & $x \ldots$ \\
\hline 251 & $H \ldots$ & $2 \div 2$ & $x$ & $\ldots$ & 233 & A $\ldots$. & 234 & $5 \ldots$ & 235 & A. .... & 236 & s..... \\
\hline 237 & A ........ & $2=8$ & A & $\ldots$ & 239 & A $\ldots$. & 240 & $x \ldots$ & 241 & A. $\ldots$ & 42 & A. $\ldots$ \\
\hline 243 & A .... & 244 & $\bar{H}$ & $\ldots$ & 245 & A. .... & 246 & A. .... & 247 & A. .... & 48 & A $\ldots$ \\
\hline $2+3$ & A. .... & 250 & $\hat{A}$ & $\ldots$ & 251 & A $\ldots$. & 252 & A $\ldots$ & 253 & A. $\because$. & 54 & A. .... \\
\hline 255 & A .... & 361 & A & $\ldots$ & 302 & A $\ldots$. & $30 \overline{3}$ & $x \ldots$ & 304 & A $\ldots$. & 155 & $x \ldots$ \\
\hline $3 \overline{5}$ & A... & 307 & $\times$ & $\ldots$ & 358 & A $\ldots$. & 369 & c.... & 310 & A $\ldots$. & 11 & $x \ldots$ \\
\hline 212 & H.... & 313 & $x$ & $\ldots$ & 314 & A $\ldots$. & 15 & $x \ldots$ & 316 & A. .... & 17 & $x \ldots$ \\
\hline 318 & $H \quad \ldots$ & 319 & 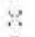 & $\ldots$ & 320 & A $\ldots$. & 321 & $x \ldots$. & 322 & $x \ldots$ & 323 & $5 \ldots$ \\
\hline 224 & A .... & $\geq 25$ & A & $\ldots$ & 326 & A $\ldots$. & 327 & s.... & 328 & A $\ldots$. & 29 & A. .... \\
\hline $3 \geq 5$ & $\vec{A} \ldots$. & 321 & $\mathrm{~A}$ & $\ldots$ & 332 & A $\ldots$. & 333 & A. .... & 334 & A. .... & 335 & A. $\ldots$ \\
\hline 326 & $A \ldots$. & 337 & $A$ & $\ldots$ & 338 & A $\ldots$ & 339 & A. ... & 340 & c..... & 341 & A. ... \\
\hline $3 \cdot 12$ & A. $\ldots$. & 343 & $A$ & $\ldots$ & 344 & A. .... & 345 & A. .... & 346 & A. .... & 347 & A $\ldots$ \\
\hline 348 & A $\ldots .$. & 349 & A & $\ldots$ & 350 & A $\ldots$ & 351 & A... & 352 & A $\ldots$. & 353 & A. .... \\
\hline 354 & A $\ldots .$. & 355 & A & $\ldots$ & 401 & A $\ldots$ & 402 & A. ... & $403:$ & $x \ldots$ & 484 & A. $\cdots$ \\
\hline 465 & H. ... & 4156 & $x$. & $\ldots$ & 407 & A $\ldots$. & 408 & A. .... & 409 & A. .... & 410 & A. .... \\
\hline 411 & F. .... & $41 ?$ & A. & $\ldots$ & 413 & A $\ldots$. & 414 & A $\ldots$. & 415 & A. .... & 416 & A. .... \\
\hline 41.7 & A $\ldots$. & 418 & $\vec{A}$ & $\ldots$ & 419 & A. $\ldots$. & 420 & A $\ldots$. & 421 & A $\ldots$. & $42 ?$ & $x \ldots$ \\
\hline 423 & A..... & 424 & A & $\ldots$ & 425 & $A \ldots$. & 426 & A $\ldots$. & 427 & A..... & 428 & A. $\ldots$ \\
\hline 429 & A. ... & 130 & A. & $\ldots$ & 431 & A. .... & 432 & A. ... & $4 \overline{3}$ & A. $\ldots$ & 434 & A. .... \\
\hline 435 & A $\ldots$. & 436 & A & $\ldots$ & 437 & A $\ldots$. & 438 & A $\ldots$. & 439 & A. .... & 440 & $x \ldots$ \\
\hline 441 & A... & 442 & A & $\ldots$ & 443 & A $\ldots$. & 444 & A. .... & 445 & A .... & 446 & A.... \\
\hline 447 & a..... & 448 & A & $\ldots$ & 449 & $A \ldots$ & 455 & A $\ldots$ & 451 & A. . . . & 452 & A. .... \\
\hline 453 & $H \ldots$ & 454 & A & $\ldots \ldots$ & 455 & A $\ldots$. & 501 & $x \ldots$ & 502 & A. ...: & 503 & F $\ldots$ \\
\hline 594 & A $\ldots$ & 505 & A & $\ldots \ldots$ & 566 & A $\ldots$. & 597 & A .... & 598 & A. .... & 509 & A. .... \\
\hline S15 & H.... & 511. & A. & $\ldots \ldots$ & $51 ?$ & A $\ldots$. & 513 & A. ... & 514 & A. $\ldots$ & 515 & A $\ldots$ \\
\hline 516 & A. . . . & 517 & A. & $\ldots \ldots$ & 518 & A $\ldots$ & 519 & A $\ldots$. & 520 & A. .... & 521 & A. .... \\
\hline 22 & $\ddot{A} \ldots$ & 523 & A & $\ldots$ & 524 & A $\ldots$. & 525 & A. .... & 526 & A. .... & 527 & $A \ldots$. \\
\hline 528 & A $\ldots$ & 529 & A & $\ldots$ & 530 & A. ... & 531 & A $\ldots$. & 5,22 & A. ... & 533 & A........ \\
\hline 534 & $A \ldots$ & 53.5 & A & $\ldots$ & 536 & A..... & 537 & A. .... & 538 & A. .... & 539 & A. .... \\
\hline 540 & $x \ldots$ & 541 & A & $\ldots$ & 542 & A $\ldots .$. & 543 & A. .... & 544 & A. .... & 545 & A..... \\
\hline 546 & A $\ldots$ & 547 & A & $\ldots$ & 548 & A .... & 549 & A $\ldots$. & 550 & A..... & 551. & A. .... \\
\hline 552 & $A \ldots$ & 553 & A & $\ldots$ & 554 & A $\ldots$. & 555 & A $\ldots$. & & & & \\
\hline & FRONA & DESK & & COOES & & & & HOUS & FPER & $R^{\prime} s \mathrm{COOE}$ & & \\
\hline & ON C.HANAFF & & & c & & & & ACANT $/ A$ & AILAF & BLE $\quad V$ & & \\
\hline & OCUF IFD & & & 5 & & & & SCUPIED & STA'Y'O & DVER 5 & • & \\
\hline & SHC:AT:S & & & A & & & & AGLEAGE & LFEFO & DUT $B$ & & \\
\hline & CHrokusur & TOR.A & & $x$ & & & & SERVII & & NS & & \\
\hline & nitr DF OR & & & 0 & & & & JT OF OF & DER & 000 & & \\
\hline
\end{tabular}




\section{2, 4E. TYPE OF PAYMENT}

A. This program will generate a list of types of payments, Travel Agent payments, and a 1 ist of the guests who have exceeded their credit 11 imit.

B. The program is accessed by typing the number (4) on the Front Desk Monitor (2-A) and receive the Reports Monitor (2, 4-1). Then type the number (5) on the Reports Monitor. The system will print the report as requested, display $(2,4 E-1)$.

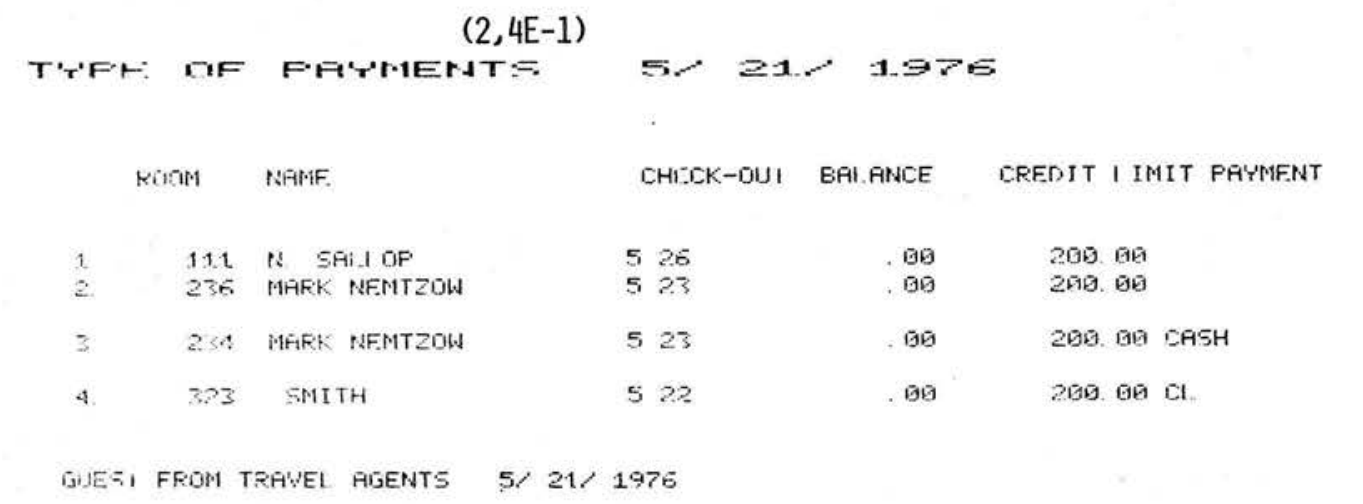

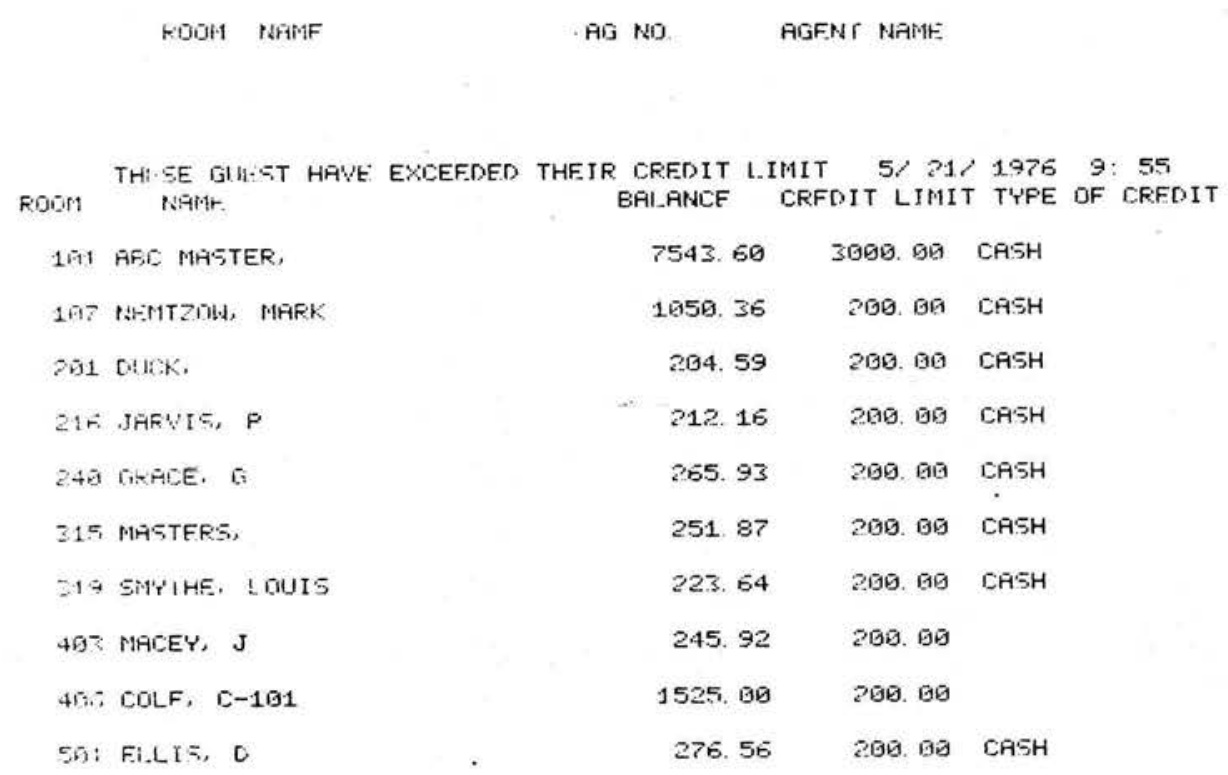




\section{2, 4F. PRINT AUDIT TRAIL BY TIME}

A. This program will generate audit trail by the time of day the transaction took place.

B. The program is accessed by typing the number (4) on the Front Desk Monitor (2-A) and receiving the Reports Monitor $(2,4-1)$. Then type the number (6) on the Reports Monitor. The system will print the report as requested, display $(2,4 \mathrm{~F}-1)$. See Page 106.

NOTE: The complete report is not shown because of its Tength. 
$(2,4 \mathrm{~F}-1)$

AISIT TRAIL. B'Y TIMF FOR INTERIIATIONAI. INN TAMIAMI TRAIL. 1311976 MIAMI, FIORIDA.

\begin{tabular}{|c|c|c|c|c|c|c|c|c|c|}
\hline MAMF & TIMF & ROOM & ACC.T & CHARIIF & BAI_ANCE & Accolsu & & P\# & 1 \\
\hline PATIENNI & $1 E$ & 191 & B- & $200.80-$ & 200.199 & ABC MAS & STER & & \\
\hline FA'TH:FIS & 116 & 0 & $51-$ & 4227 & .05 & AMX & & & \\
\hline FATHEUI & 120 & B & $57-$ & 195. 195 & .85 & SAI FS & & & \\
\hline Roist & 127 & 201 & 0 & 52 ดื & 52.56 & ARC.HFR & & ${ }^{*}$ & * \\
\hline SALFS TAK & 128 & 291 & D & 2. 68 & 54.68 & ARCHF.R & & & \\
\hline Rönt & 123 & 261 & 0 & 5200 & 196,08 & ARCHFE & & & \\
\hline SFLFS TFX & 129 & 201 & 13 & 2. 58 & 158. 16 & ARCHFR & & & \\
\hline Foñ & 129 & 201 & 6 & 526 ด & 169.16 & ARCHFR & & & \\
\hline SFLE- TAK & 135 & 291 & 0 & 268 & 162. 24 & ARCHER & & & \\
\hline kribit & 139 & 201 & $B$ & 52.90 & 214.24 & ARCHFR & & & \\
\hline S.ALES TA: & 131 & 201 & .0 & 2. 198 & 216.32 & AFCHFR & & & \\
\hline LONG DS STARSE & $1 \leq 1$ & 291 & 0 & 4. 35 & 220,67 & ARECHFE & & & \\
\hline KDूut & 133 & 522 & G & 46. 99 & 46. 15 & HUNT , & . & & \\
\hline SFI_FS TAK & 133 & 522 & B & 1. 84 & 47. 84 & HUNT & & & \\
\hline Fonot & 134 & 522 & 0 & 46.01 & 93.84 & HUNT & & & \\
\hline G.ALES THK & 135 & 522 & B & 1. 84 & 95.68 & HUINT & & & \\
\hline Rond & 135 & 274 & 8 & 26. 515 & 26.95 & BARR'Y & & & \\
\hline SPLES TAX & 136 & 224 & 0 & 1. 54 & 27.84 & BARR'Y & & & \\
\hline Fonit & 136 & 522 & B & 46.96 & 141. 68 & HLIRST & & & \\
\hline SHLE $=$ TAX & 137 & 522 & B & 184 & 143.52 & HUINT & $\cdot$ & & \\
\hline IDH DISTANEE & 137 & 522 & Q & 4. 68 & 147. 69 & HUNT & & & \\
\hline Foutit & 1. 38 & 224 & $B$ & 2.6. 99 & 53.194 & BARE'T' & & & \\
\hline SFILES TAX & 139 & 224 & $\theta$ & 1. 94 & 54. 198 & EARR'Y & & & \\
\hline RF.STALITERT & 139 & 224 & B & 15.90 & 69. 08 & RAREY & & & \\
\hline I.OHIE RTSTANHE. & 146 & $2 ? 4$ & B & 4. 2.3 & 73.31 & BARRY & & & \\
\hline
\end{tabular}

IITAI 5

\begin{tabular}{|c|c|c|}
\hline 5 & Rours & 15. 28 \\
\hline 1 & FoOM & 10854.00 \\
\hline 2 & SAI_FS TAX & 43.5. 84 \\
\hline 3 & GFOHIP ROOMS & .09 \\
\hline 4 & FODO RODMM SER & 97.98 \\
\hline 5 & BEFAKFAST CAF & ติ \\
\hline 6 & LINWH CAFE. & .59 \\
\hline 7 & RF:STAUERANT & 6224.98 \\
\hline 8 & MFP & .69 \\
\hline 9 & LAURWOR'T' 'VAI_FT & 3.90 \\
\hline 10 & CLIIE: HOUSEE & ตอิ \\
\hline 11 & ENT FOOD & .010 \\
\hline 12 & FL UFIST & .515 \\
\hline 13 & COCKTAIL PART & .09 \\
\hline 14 & FUIIL EARR EEV. & .55 \\
\hline 15 & EAR:CIUE HIJUS & 1017.79 \\
\hline 1.7. & FEVERAIIF EOT & 75. 50 \\
\hline 17 & $\mathrm{R} / \mathrm{SEF} \%$ ICF EEV & \\
\hline
\end{tabular}




\section{2, 4G. PRINT AUDIT TRAIL BY TYPE}

A. This program will generate an audit trail by the type of transactions for the day the transactions took place.

B. The program is accessed by typing the number (4) on the Front Desk Monitor (2-A) and receiving the Reports Monitor (2, 4-1). Then type the number (7) on the Reports Monitor. The system will print the report as requested, display $(2,4 G-1)$.

NOTE: The complete report is not shown becuase of its' length.

$(2,4 G-1)$

RUIIT TRAII FY TYPE FOR INTERNATIONAI- INN TAMIAMI TRAIL 1.291976 MIFIII, FL GRIDA.

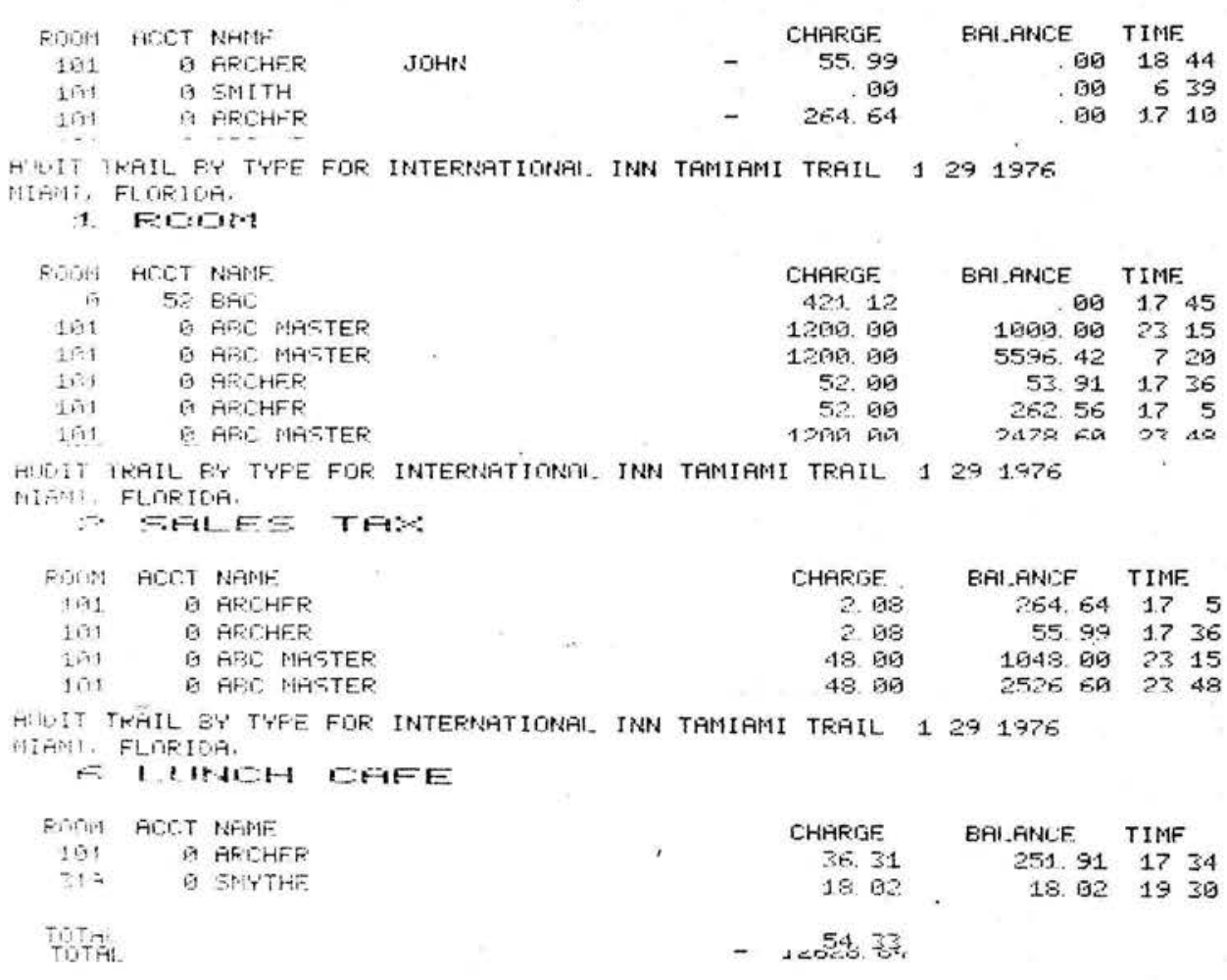




\section{$2,4 H$. PRINT GUEST ACCOUNTS}

A. This program will reproduce a copy of all the guest folios.

B. The program is accessed by typing the number (4) on the Front Desk Monitor (2-A), receiving the Reports Monitor $(2,4-1)$, and-then typing the number (8) on the

Reports Monitor. The system will respond with display (2, 4H-1).

$$
(2,4 \mathrm{H}-1)
$$

WHICH ACCOUNT DO YOU WANT PRINTED;

1. ALL ACCOUNTS 2. DEPARTED GUESTS ONLY:

START AT ROOM \#:

c. Select what guest folios you want printed.

1. If all, enter (1), XMIT. The system will respond with the second half of the display. Enter the room \# you wish to start with and XMIT. The system will generate the copies of the folios requested, display $(2,4 H-2)$.

2. If departed guests, enter (2), XMIT. The system will respond with the second half of the display. Enter the room \# you wish to start with and XMIT. The system will generate the copies of the folios requested, display $(2,4 \mathrm{H}-2)$. See Page 109. 


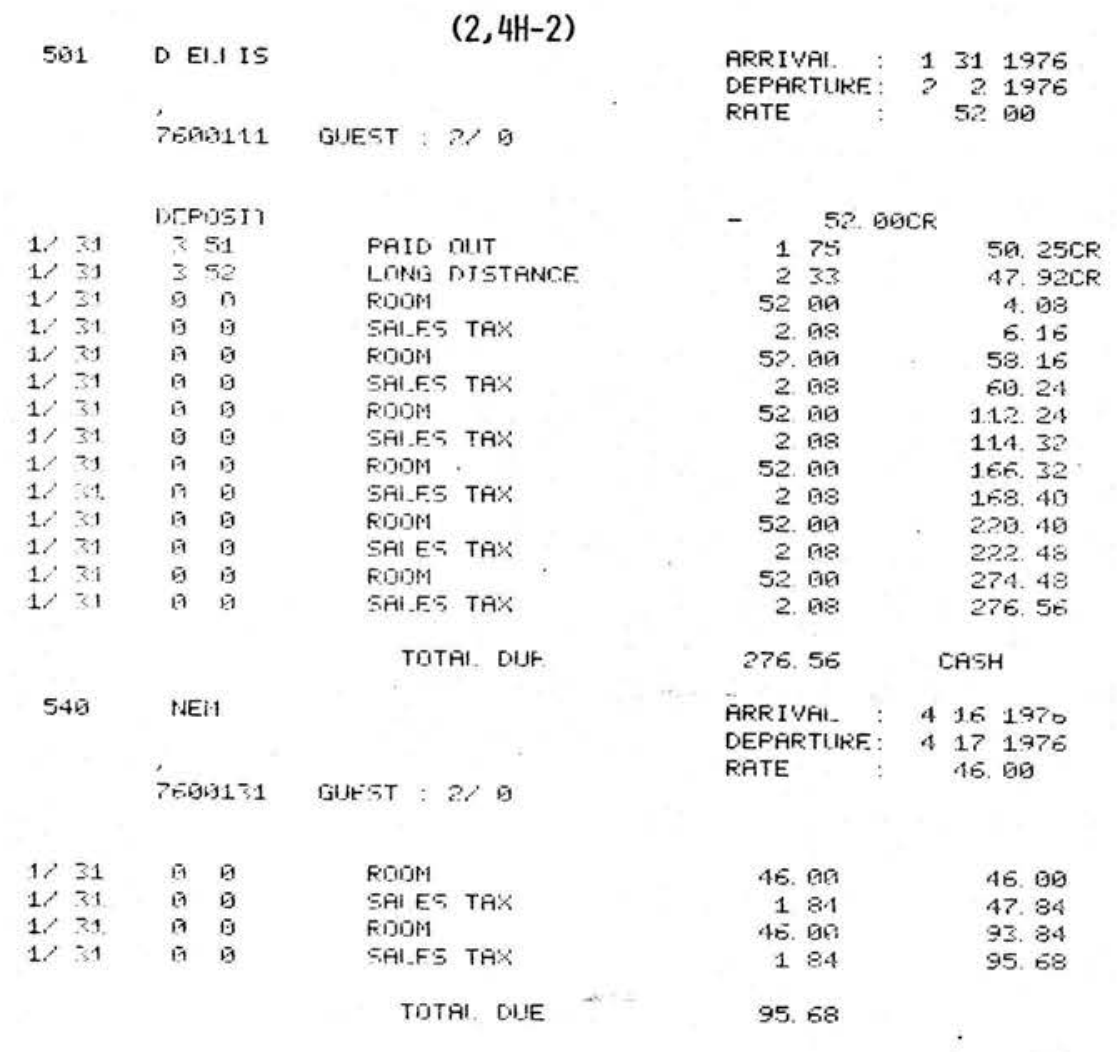




\section{2,4 I. SHIFT AUDIT}

A. This program will generate the shift audit report for the end of the shift.

B. The program is accessed by typing the number (4) on the Front Desk Monitor (2-A) and receiving the Reports Monitor (2, 4-1), and then typing the number (9) on the Reports Monitor to receive frame fill (2, 4I-1).

$$
(2,4 \mathrm{I}-1)
$$

THE AMOUNT IN THE CASH DRAW:

c. Enter the amount and XMIT. The system will generate the audit as requested, display (2, 4I-2). See Page 111. 


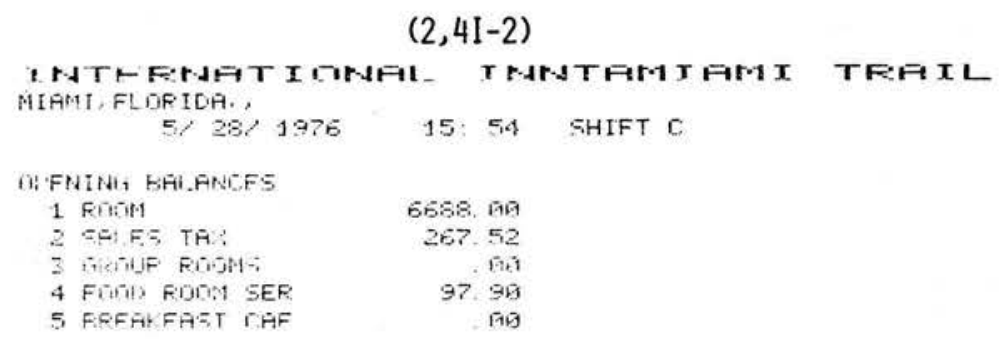

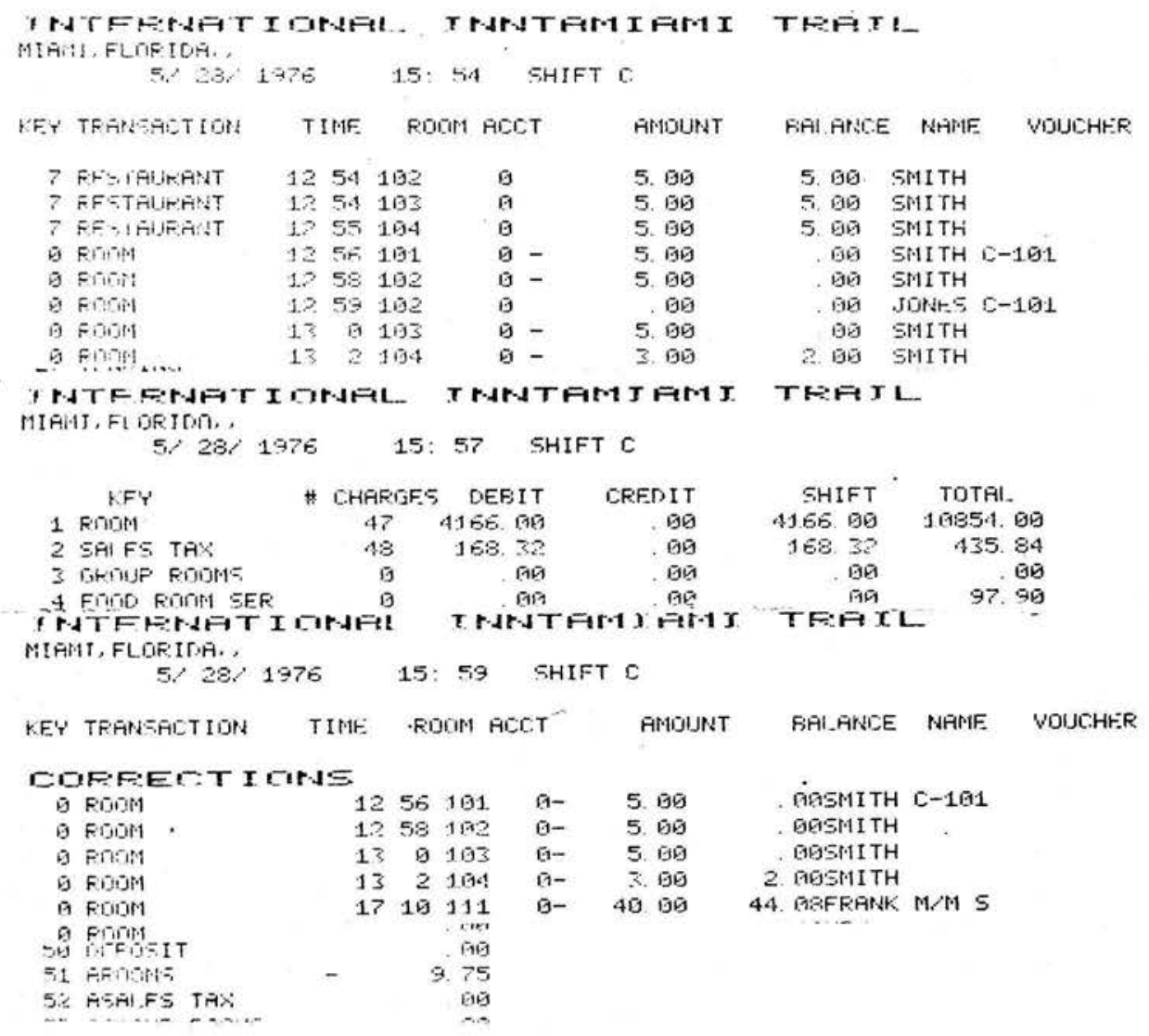


A. This program will print blank forms for registration to be used at the front desk.

B. The program is accessed by typing the number (4) on the Front Desk Monitor (2-A) and receiving the Reports Monitor (2, 4-1). Then type the number (10) on the Reports Monitor. The system will respond with frame fi11 (2, 4J-1).

$(2,4 j-1)$

HOW MANY COPIES?:

C. Enter the number of copies requested and XMIT. The system will respond by printing the blank forms, display $(2,4 J-2)$.

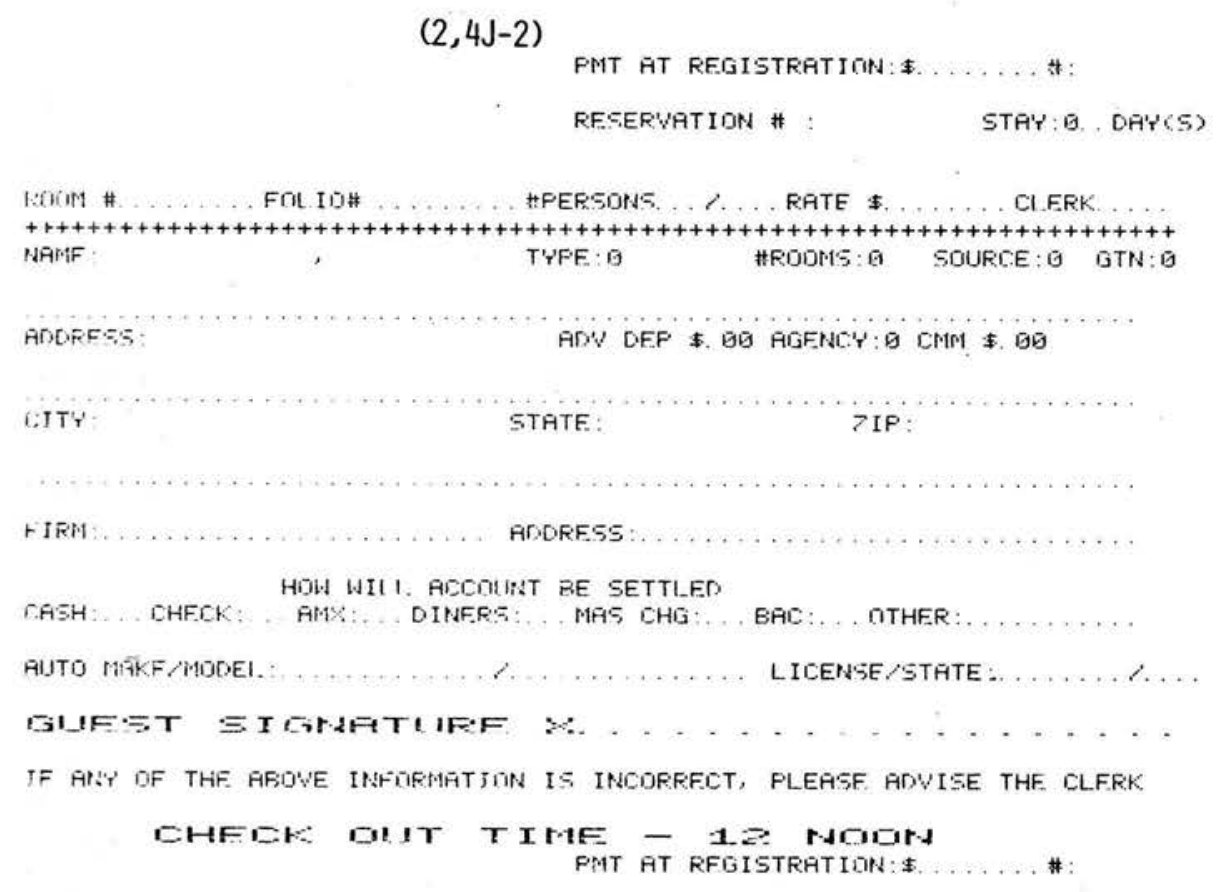




\section{$2,4 K$. CURRENT HOUSE STATUS}

A. This program will generate a status report, room by room, for the date of the report.

B. The program is accessed by typing the number (4) on the Front Desk Monitor (2-A) and receiving the Reports Monitor.(2, 4-1). Then type the number (11) on the Reports Monitor. The system will respond with display $(2,4 K-1)$.

$$
(2,4 \mathrm{~K}-1)
$$

$$
\begin{aligned}
& \text { 1. DISPLAY } \\
& \text { 2. PRINT } \\
& \text { 3. RETURN } \\
& \text { ENTER: }
\end{aligned}
$$

c. Enter the type of response to be generated.

1. If display, enter (1) and XMIT. The system will respond with a display of the house status. NOTE: Display on CRT is the same as print-out. Refer to display $(2,4 K-2)$.

2. If print, enter (2) and XMIT. The system will respond by printing the current house status, display (2, 4K-2). See Page 115.

3. If no report is wanted, enter (3) and XMIT. The system will return to the Reports Monitor. 


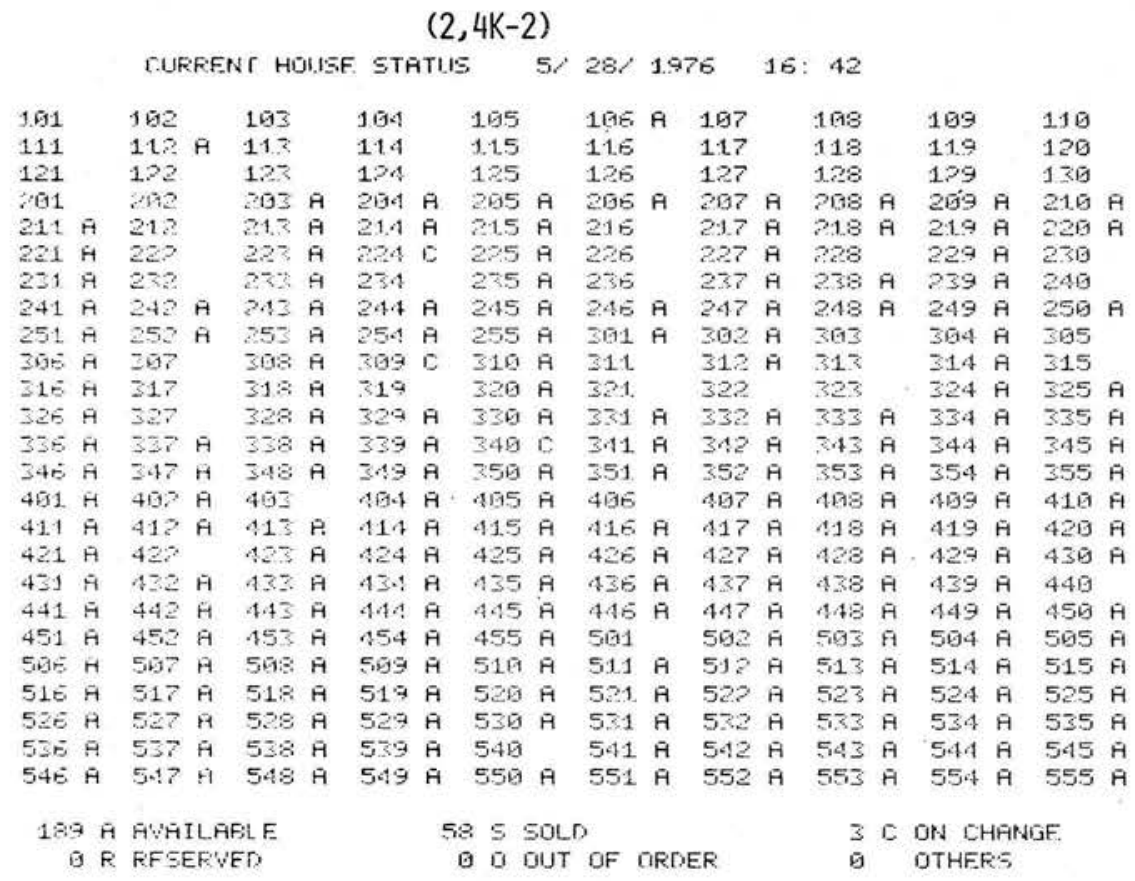




\section{$2,4 L$. EXIT}

A. This program is used to return to the Front Desk Monitor from the Reports Monitor.

B. The program is accessed by typing the number (12) on the Reports Monitor (2, 4-1). The system will return to the Front Desk Monitor (2-A). 


\section{2, 5. BILL LISTING, CHECK OUT}

A. This program enables the operator to examine any guest folio, while registered in the hotel, and check a guest out of the hotel.

B. The program is accessed by typing the number (5) on the Front Desk Monitor (2-A) and receiving frame fill $(2,5-1)$.

c. There are two methods the operator may use to continue the program:

1. If the room number is known, enter the number and XMIT. The system will respond with display (2, 5-4).

2. If the room number is not known, $T A B$ to position the cursor on the next line and enter the last name, $C R$, and the first name of the guest, XMIT. The system will respond with a list of alpha-like names and room numbers, display (2, 5-2).

$(2,5-2)$

THE GUEST NEM NOT FOUND.

IS THE NAME ONE OF THE FOLLOWING

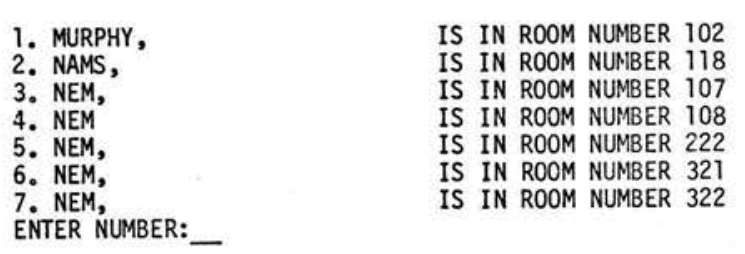

D. Enter the key number of the guest being searched for and XMIT. The system will respond with display (2, 5-4). 
E. If there is more than one guest registered for the room wanted, the system will respond with display (2, 5-3).

$$
(2,5-3)
$$

WHICH OCCUPANT IN ROOM 107

1. C-101 KELLY

2. MARK NEMTZOW

NUMBER:

Enter the key number of the guest wanted and XMIT. The system will respond with display (2, 5-4).

$$
(2,5-4)
$$

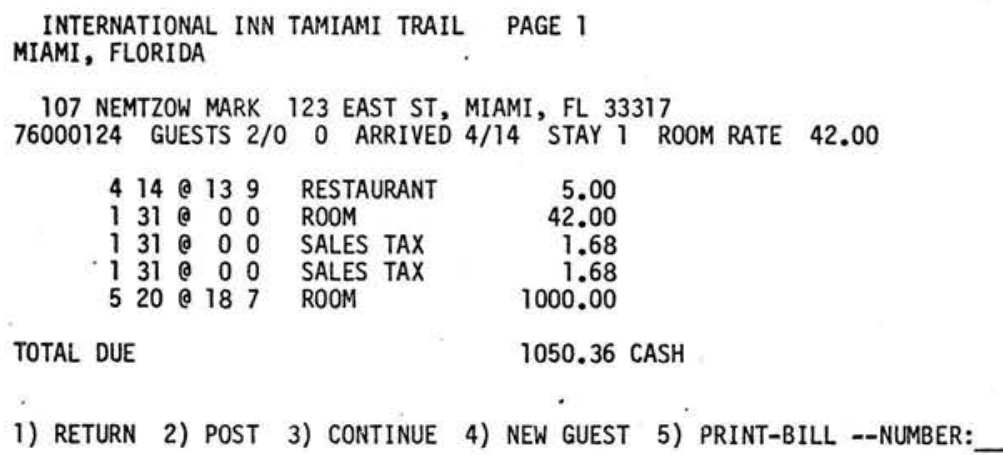

F. The cursor is automatically positioned at the bottom of of the display for the operator to choose from the list of possible types of action.

1. RETURN - This function will abort the program and return to the Front Desk Monitor (2-A). Enter the number (1) and XMIT.

2. POST - This function allows the operator to post to any account. Enter the number (2) and XMIT. The system will go to display $(2,3-1)$ for posting charges. Refer to section 3 of this chapter for instructions. 
F. 3. CONTINUE - This function allows the operator to continue with the check out function. Enter the number (3) and XMIT. The system will respond with question for settlement of the bill, display $(2,5-6)$.

4. NEW GUEST - This function allows the operator to examine the folio for another guest. Enter the number (4) and XMIT. The system will return to display (2, 5-1) for entering the guest's name.

5. PRINT BILL - This function allows the operator to generate a hard copy of the guest bill being examined. Enter the number (5) and XMIT. The system will print the folio on the on-line printer, display $(2,5-5)$.

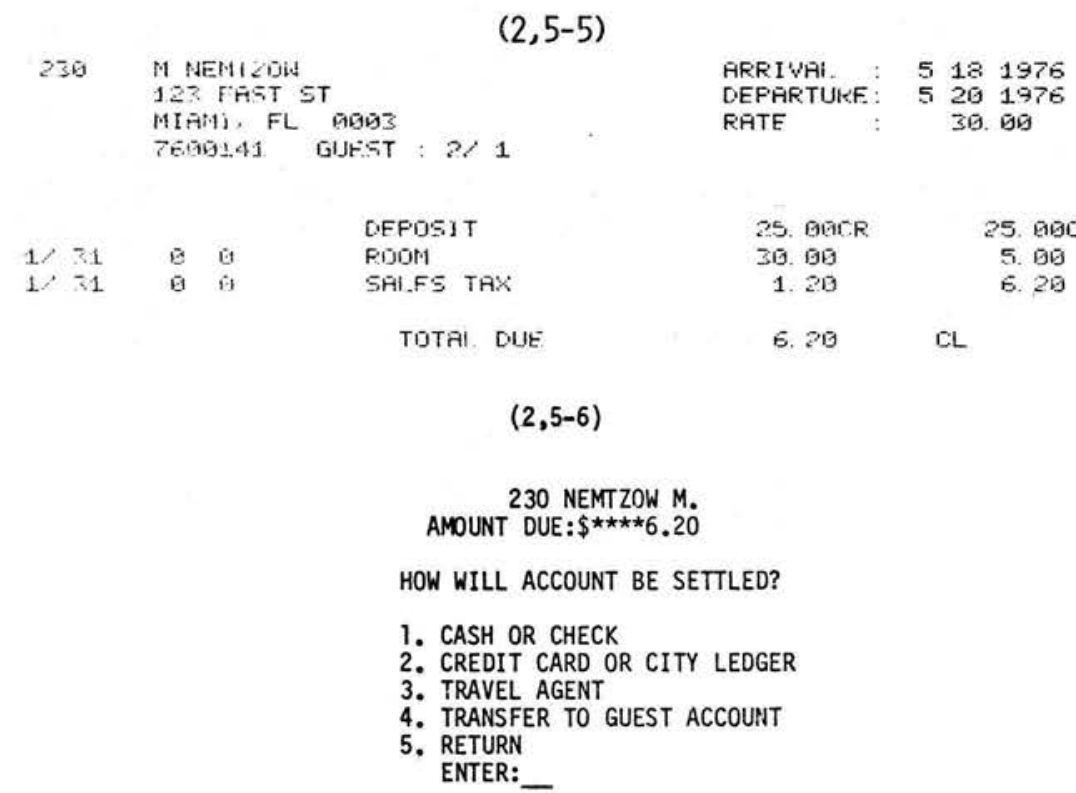


G. The operator need only to enter the key number corresponding to the settlement type and XMIT.

1. CASH or CHECK - If the guest will pay by cash or check, enter the number (1) and XMIT. The system will respond with display $(2,5-7)$.

2. CREDIT CARD or

CITY LEDGER - If the guest will pay by credit card or have it billed to the city ledger, enter the number (2) and XMIT. The system will respond with frame fill $(2,5-9)$.

3. TRAVEL AGENT - At this time not a functioning mode. 4. TRANSFER TO GUEST ACCOUNT - If the settlement will be by another guest, enter the number (4) and XMIT. The system will respond with display (2, 5-10).

$(2,5-7)$

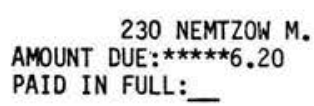

H. The cursor is automatically placed at the end of the display to answer the question with a yes or no statement.

1. If yes, enter (Y) and XMIT. The system will check out the guest and respond with display (2, 5-12).

2. If no, enter (N) and XMIT. The system will respond with display $(2,5-8)$. 
$(2,5-8)$

230 NEMTZOW M. AMOUNT DUE: $* \star \star \star \star \star 6.20$

PAID IN FULL:N

AMOUNT TO BE PAID?:

I. Enter the amount to be paid and XMIT. The system will deduct the amount from the balance and redisplay (2, 5-6) for settlement of the remainder of the bill.

$$
(2,5-9)
$$

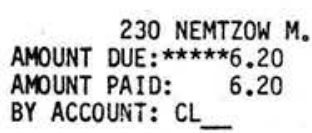

J. There are two ways for the operator to continue with the program:

1. If the account to be transfered to is correct, XMIT. The system will transfer the balance to the account selected and will respond with display (2, 5-12).

2. If the account to be transfered to is not correct, use the cursor direction arrows to place the cursor on the first letter of the wrong account, retype the correct account name, CR, and XMIT. The system will transfer the balance to the correct account and respond with display $(2,5-12)$.

$$
(2,5-10)
$$

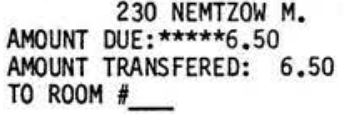

K. Enter the room number to be transfered to and XMIT. The system wil1 respond with display (2, 5-11). 


\section{$(2,5-11)$}

IS SMYTHE, ROOM 207 CORRECT?:

L. The cursor is automatically placed at the end of the display to answer the question with a yes or no answer.

1. If yes, enter (Y) and XMIT. The system will respond with display $(2,5-12)$.

2. If no, enter $(N)$ and XMIT. The system will redisplay $(2,5-10)$ to enter the room \#.

$(2,5-12)$

1- PRINT BILL. 2- ANOTHER CHECKOUT 3- RETURN ENTER-->:

M. After the guest is checked out of the hotel the system allows the operator to make a selection from a list of three choices.

1. PRINT BILL - Enter (1) and XMIT. The system wi11 print the bill on the on-line printer, display $(2,5-13)$ and returns to the Front Desk Monitor, (2-A).

2. ANOTHER CHECK OUT - Enter (2) and XMIT. The system will return to display $(2,5-1)$ for entering another room.

3. RETURN - Enter (3) and XMIT. The system will return to the Front Desk Monitor (2-A). $(2,5-13)$

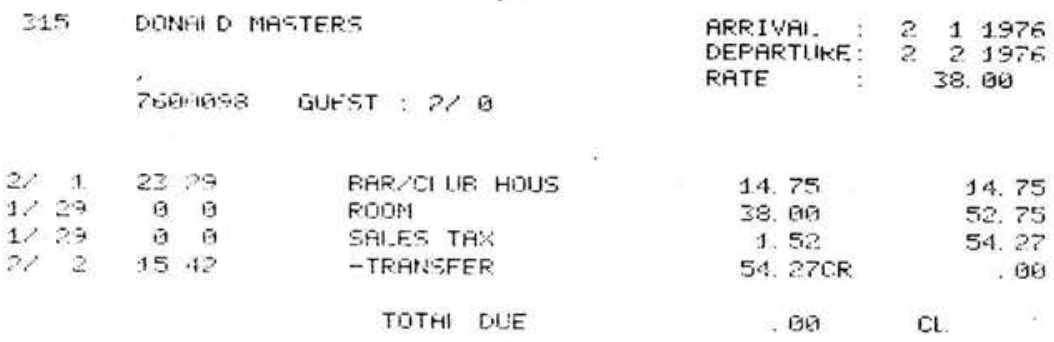




\section{2, 6. PRINT GUEST MESSAGE}

A. This program enables the operator to print a 2-1ine message for any registered guest of the hotel.

B. The program is accessed by typing the number (6) on the Front Desk Monitor $(2-A)$. The system will respond with frame fil1 $(2,6-1)$.

$$
(2,6-1)
$$

c. There are two methods the operator may use to continue the program:

1. If the room number is known, enter the number and XMIT. The system will respond with display (2, 6-3) .

2. If the room number is not known, $T A B$ to position the cursor on the next line and enter the last name, CR, and the first name of the guest, XMIT. The system will respond with a list of alpha-like names and room numbers, display $(2,6-2)$.

$(2,6-2)$

THE GUEST NEM NOT FOUND
IS THE NAME ONE OF THE FOLLOWING
$\begin{array}{ll}\text { 1. MURPHY, } & \\ \text { 2. NAMS, } & \text { IS IN ROOM NUMBER } 102 \\ \text { 3. NEM, } & \text { IS IN ROOM NUMBER } 118 \\ \text { 4. NEM, } & \text { IS IN ROOM NUMBER } 107 \\ \text { 5. NEM, } & \text { IS IN ROOM NUMBER } 108 \\ \text { 6. NEM, } & \text { IS IN ROOM NUMBER } 222 \\ \text { 7. NEM, } & \text { IS IN ROOM NUMBER } 321 \\ \text { ENTER NUMBER: } & \text { IS IN ROOM NUMBER } 322\end{array}$

D. Enter the key number of the guest registered for the room wanted; the system will respond with display $(2,6-3)$. 
$(2,6-3)$

ROOM 107 SMITH AT 5/30/1976 AT 15:34

ENTER 2 LINE MESSAGE THEN TRANSMIT:

E. Type the message to be printed and XMIT. The system will

print the message on the on-line-printer, display (2, 6-4) and return to the Front Desk Monitor (2-A).

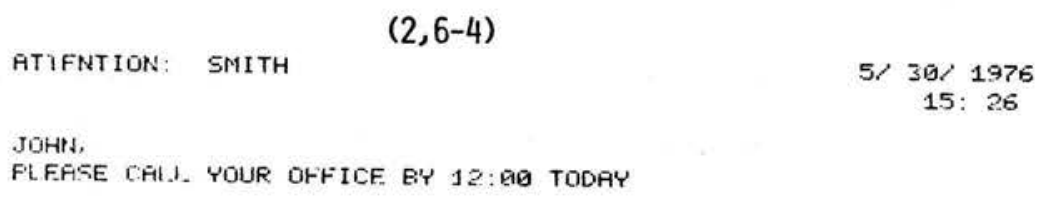




\section{2, 7. DEPARTED GUEST BILL}

A. This program enables the operator to retrieve a folio of a guest that has checked out at an earlier date to copy the bill, post charges, or transfer the charges on the bi11.

B. The program is accessed by typing the number (7) on the Front Desk Monitor (2-A). The system will respond with display $(2,7-1)$.

$$
(2,7-1)
$$

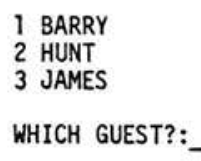

C. Enter the key number of the guest wanted and XMIT. The system will respond by displaying the guest folio requested, display $(2,7-2)$.

$$
(2,7-2)
$$

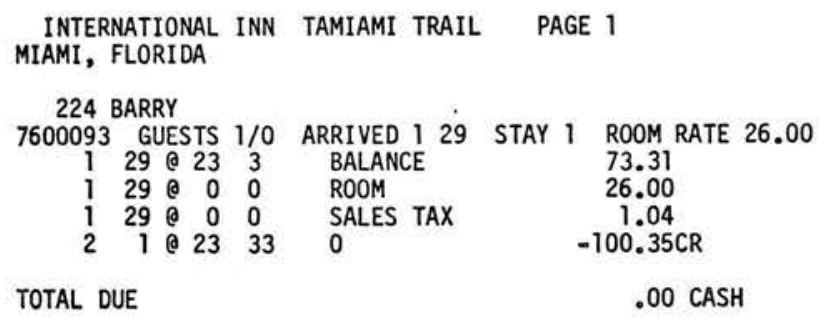

1) RETURN 2) POST 3) TRANSFER 4) ANOTHER BILL 5) PRINT --:

D. The cursor is automatically positioned at the end of the display for the operator to select a mode of action from the choices 1 isted:

1. RETURN - This function allows the operator to return to the Front Desk Monitorewithout changing the folio. Enter the number (1) and XMIT. 
The system will return to the Front Desk Monitor (2-A).

2. POST - This function allows the operator to post additional or late charges to the guest folio. Enter the number (2) and XMIT. The system will respond with a modified posting frame fill, display $(2,7-4)$.

3. TRANSFER - This function allows the operator to transfer the remaining balance to another account. Enter the number (3) and XMIT. The system will respond with display $(2,7-5)$.

4. ANOTHER BILL - This function enables the operator to examine another folio of a departed guest. Enter the number (4) and XMIT. The system will return to display (2, 7-1) for another selection.

5. PRINT - This function enables the operator to print a copy of the folio. Enter the number (5) and XMIT. The system will print the bill on the on-1ine printer, display (2, 7-3).

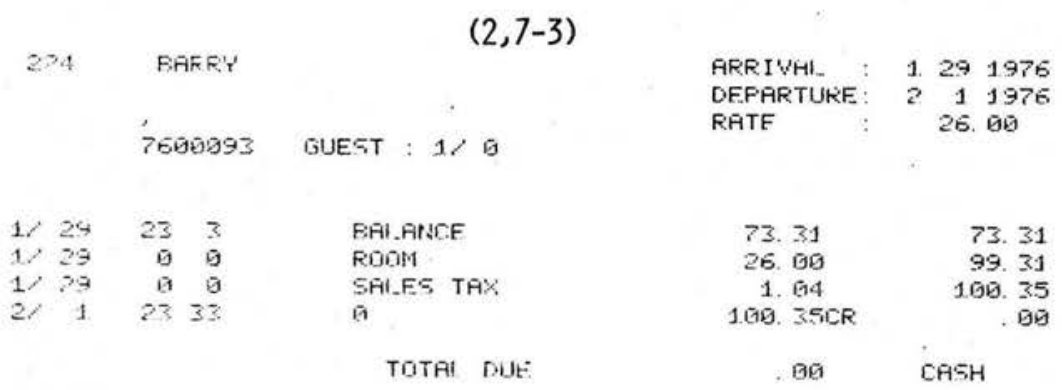


$(2,7-4)$

7600093 BARRY
CHARGED ITEE:
VOUCHER/PHONEF:
AMOUNT CHARGED:

E. To complete the charge to the folio enter the following information:

1. Enter the charged item sales code and CR.

2. Enter the voucher number and CR.

3. Enter the amount of charge and XMIT.

The system will redisplay display (2, 7-2) with the new charge added.

$(2,7-5)$

230 NEMTZOW M.

AMOUNT DUE: $\$ \star \star \star \star 6.20$

HOW WILL ACCOUNT BE SETTLED?

1. CASH OR CHECK

2. CREDIT CARD OR CITY LEDGER

3. TRAVEL AGENT

4. TRANSFER TO GUEST ACCOUNT

5. RETURN

F. The operator need only to enter the key number corresponding to the settlement type and XMIT.

1. CASH or CHECK - If the guest will settle the bill by cash, the operator must return to display (2, 7-2) and enter number (2) to post charges and enter the payment as described in section 2, 5-E.

2. CREDIT CARD or

CITY LEDGER - If the guest will pay by credit card or have the bill charged to his account, enter (2) and XMIT. The system will transfer the balance due to the 


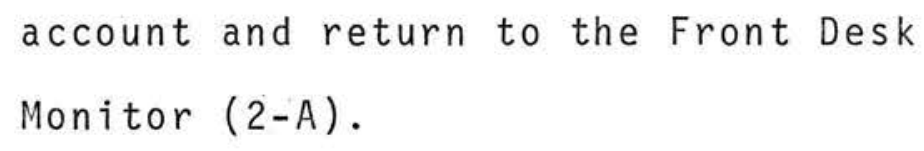

3. TRAVEL AGENT - At this time not a functioning mode. 4. TRANSFER TO A GUEST ACCOUNT - The system will not let the transfer to a guest account take place for a departed guest bi11. The system returns to the Front Desk Monitor $(2-A)$. 


\section{2, 8. NAME SEARCH}

A. This program enables the operator to search for a name in any of the master files.

B. The program is accessed by typing the number (8) on the Front Desk Monitor (2-A). The system will respond with display $(2,8-1)$.

$$
(2,8-1)
$$

ENTER LAST NAME TO BE LOOKED FOR:

C. Enter the last name of the party being searched for and XMIT. The system will respond with display (2, 8-2).

$$
(2,8-2)
$$

LOOKING FOR NEM

THESE GUESTS ARE SIMILIAR;

$\begin{array}{ll}\text { ROOM } 108 \text { NEWT } & 7600069 \\ \text { ROOM } 118 \text { NAMS } & 7600074\end{array}$

ROOM 123 NIXON 7600081

1) KEEP LOOKING 2) RÉ-ENTER NAME 3) RETURN TO MONITOR:

D. The cursor is automatically positioned at the end of the display for the operator to select a mode of action from the choices listed:

1. KEEP LOOKING - This function allows the operator to search the other master files for the name of the party. Enter the number (1) and XMIT. The system will search the other files and respond with display $(2,8-3)$. 
D. 2. RE-ENTER NAME - This function enables the operator to search for another name. Enter the number (2) and XMIT. The system will return to display $(2,8-1)$ for reentering the name.

3. RETURN - This function enables the operator to leave the program and return to Front Desk Monitor. Enter the number (3) and XMIT.

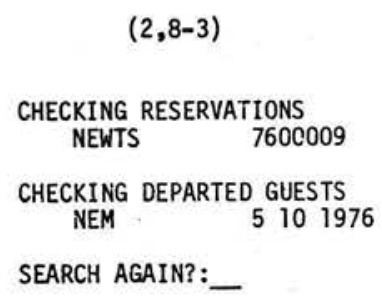

E. The cursor is automatically positioned to answer the question with a yes or no answer.

1. If yes, enter (Y) and XMIT. The system will redisplay display $(2,8-1)$ for a new name.

2. If no, enter (N) and XMIT. The system will return to the Front Desk Monitor (2-A). 


\section{2, 9. CHANGE ROOM STATUS}

A. This program enables the operator to change a room with an out-of-order, change, or reserved status to another room status type.

B. The program is accessed by typing the number (9) on the Front Desk Monitor $(2-A)$. The system will respond with display $(2,9-1)$.

$$
(2,9-1)
$$

ENTER ROOM NUMBER(0=EXIT):

c. The operator has a choice of mode of action:

1. If no entry is to be made or the operator is finished with the program, enter the number (0) and XMIT. The system will return to the Front Desk Monitor, (2-A).

2. If a room number is to be entered, enter the room \# and XMIT. The system will respond with display (2, 9-2).

$$
(2,9-2)
$$

ENTER ROOM NUMBER( $0=$ EXIT): 224

ROOM 224 HAS STATUS C. CHANGE TO :

D. The operator may change the status to any of four status conditions:

1. If the room is out-of-order, enter (0) and XMIT. The system will return to display (2, 9-1).

2. If the room is on change, enter (C) and XMIT. The system will return to display (2, 9-1).

3. If the room is on reserve, enter (R) and XMIT. The system will return to display (2, 9-1). 
D. 4. If the room is available, enter (A) and XMIT.

The system will return to display (2, 9-1).

NOTE: When a guest is checked into the hotel the system automatically changes the status to sold. To change a sold status the operator must check out the guest. 


\section{2, 10. AVAILABLE ROOMS}

A. This program enables the operator to display or print a list of available rooms by type or combined.

B. The program is accessed by typing the number (10) on the Front Desk Monitor (2-A). The system will respond with display $(2,10-1)$.

$$
(2,10-1)
$$

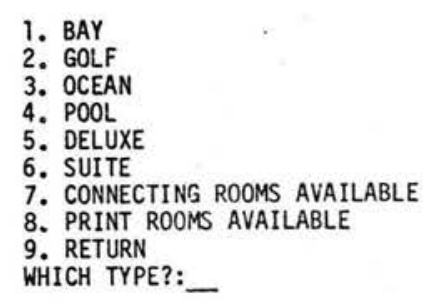

c. The operator need only enter the key number of the selection for review.

1. If Bay type rooms, enter (1) and XMIT. The system will respond with a list of available Bay rooms, display $(2,10-2)$.

2. If Golf type rooms, enter (2) and XMIT. The system will respond with a display like (2, 10-2) except with the Golf rooms available.

3. If Ocean type rooms, enter (3) and XMIT. The system will respond with a display 1 ike $(2,10-2)$ except with the 0cean rooms available.

4. If Pool type rooms, enter (4) and XMIT. The system will respond with a display like $(2,10-2)$ except with the Pool rooms available. 
5. If Deluxe type rooms, enter (5) and XMIT. The system will respond with a display 1 ike $(2,10-2)$ except with the Deluxe rooms available.

6. If Suite type rooms, enter (6) and XMIT. The system will respond with a display like (2, 10-2) except with the Suite rooms available.

7. If Connecting type rooms, enter (7) and XMIT. The system will respond with a display like $(2,10-2)$ except with the Connecting rooms available.

8. If the operator wants the available rooms printed on the on-line printer, enter (7) and XMIT. The system will print a list of all available rooms, display $(2-10-3)$.

9. If no further action is wanted for this program, enter (9) and XMIT. The system will return to the Front Desk Monitor (2-A).

$$
(2,10-2)
$$

$\begin{array}{lccc}5 / 30 / 1976 & \begin{array}{c}15: 30 \\ \text { ROLL-A-WAY BED }\end{array} & \begin{array}{c}\text { BAY ROOMS AVAILABLE } \\ \$ 5.00\end{array} \\ \text { ROOM \# } & \text { RATE 1 PERSON } & \text { RATE 2 PERSONS } & \text { X PERSON } \\ 226 & \$ 26.00 & \$ 30.00 & \$ 5.00 \\ 228 & \$ 26.00 & \$ 30.00 & \$ 5.00 \\ 230 & \$ 26.00 & \$ 30.00 & \$ 5.00 \\ 232 & \$ 26.00 & \$ 30.00 & \$ 5.00 \\ 234 \star \star & \$ 26.00 & \$ 30.00 & \$ 5.00\end{array}$

** DENOTES $1 / 2$ OF A CONNECTING ROOM AVAILABLE

(1) RET'URN (2) ANOTHER TYPE (3) CONTINUE (4) CHECK-IN:

3. The cursor is automatically positioned at the end of the display for the operator to choose the mode of action to take:

1. RETURN - This function allows the operator to return to the Front Desk Monitor (2-A). Enter the number (1) and XMIT. 
2. ANOTHER TYPE - This function allows the operator to examine the availability for another type room. Enter (2) and XMIT. The system will return to display (2, 10-1).

3. CONTINUE - This function allows the operator to examine the rest of the rooms of the type being examined. Enter (3) and XMIT. The system witl display a list like (2, 10-2) with the additional rooms.

4. CHECK IN - This function allows the operator to check in a guest after examining the availability. Enter (4) and XMIT. The system will enter the check in program and display (2, 1-1). See Page 136 for display (2, 10-3). 


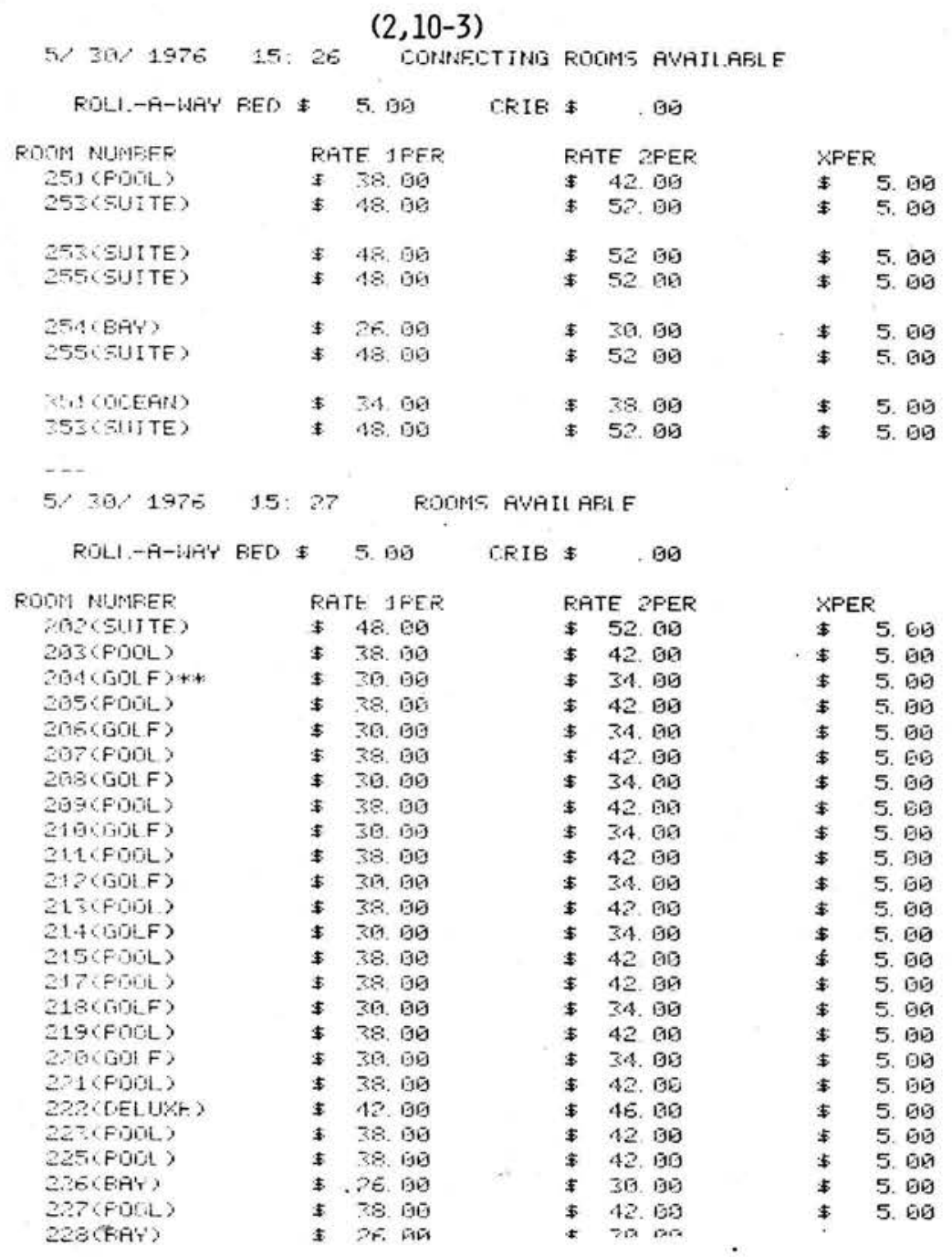




\section{2, 11. GUEST ROOM TRANSFER}

A. This program enables the operator to transfer a guest from one room to another.

B. The program is accessed by typing the number (11) on the Front Desk Monitor (2-A). The system will respond with frame fil1 $(2,11-1)$.

$$
(2,11-1)
$$

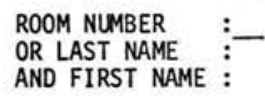

c. There are two methods the operator may use to continue the program:

1. If the room number is known, enter the number and XMIT. The system will respond with display (2, 11-3).

2. If the room number is not known, $T A B$ to position the cursor on the next line and enter the last name, CR, and the first name of guest, XMIT. The system will respond with a list of aplha-like names and room numbers, display $(2,11-2)$.

$$
(2,11-2)
$$

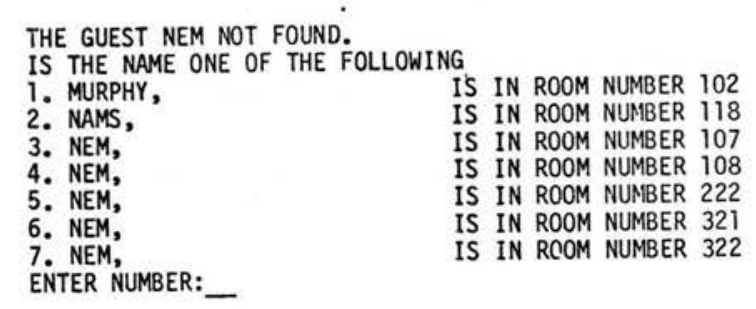

D. Enter the key number of the guest registered for the room wanted, the system will respond with display (2, 11-3). 
$(2,11-3)$

C-101 KELLY IN ROOM NUMBER 107

SHOULD BE TRANSFERED TO ROOM:

E. Enter the room number to be transfered to and XMIT. The system will respond in one of two ways.

1. If the room is already occupied or is out of order, the system will respond with display (2, 11-4).

2. If the room is available, the system will transfer the guest and respond with display (2, 11-5).

$$
(2,11-4)
$$

ROOM 108 IS NOT AVAILABLE TRY AGAIN?:

F. The cursor is positioned at the bottom of the display to answer the question with a yes or no statement.

1. If yes, enter (Y) and XMIT. The system will return to display (2, 11-3) for a new room.

2. If no, enter (N) and XMIT. The system will return to the Front Desk Monitor (2-A).

$$
(2,11-5)
$$

DO YOU WISH TO TRANSFER ANY OTHER GUESTS?:

G. The cursor is positioned at the end of the display to answer the question with a yes or no statement.

1. If yes, enter (Y) and XMIT. The system will return to display $(2,11-1)$ to enter the new name.

2. If no, enter (N) and XMIT. The system will return to the Front Desk Monitor (2-A). 


\section{2, 12. PRINT/DISPLAY REGISTERED GUESTS}

A. This program enables the operator to display or print a list of all the registered guests.

B. The program is accessed by typing the number (12) on the Front Desk Monitor (2-A). The system will respond with display $(2,12-1)$.

$$
\text { (2,12-1) }
$$

1) DISPLAY 2) PRINT:-

c. The operator need only select the type of display by entering the key number.

1. If the list is to be displayed on the CRT, enter the number (1) and XMIT. The system will respond with display $(2,12-2)$.

2. If the list is to be printed on the on-line-printer, enter the number (2) and XMIT. The system will respond with display $(2,12-2)$.

$$
\text { (2,12-2) }
$$

1) DISPLAY 2) PRINT: 2

1) WITH BALANCE 2) WITHOUT BALANCE:

D. The operator need only select the key number to produce the list with or without the balance due for each guest. 1. If with a balance, enter the number (1) and XMIT. The system will respond with display (2, 12-3).

2. If without a balance, enter the number (2) and XMIT. The system willirespond with display (2, 12-3). 
$(2,12-3)$

1) DISPLAY 2) PRINT: 2 -

1) WITH BALANCE 2) WITHOUT BALANCE:

1) BY ROOM NUMBER 2) BY NAME:

E. To select the order of the list, the operator need only to select the corresponding key number.

1. If by room number, enter the number (1) and XMIT.

The system will respond with either a display or

print-out of the list depending on which selection was made in display $(2,12-1)$.

2. If by name, enter the number (2) and XMIT. The system will respond with either a display or printout of the list depending on which selection was made in display $(2,12-1)$.

F. The following is an example of a list produced by the system, display $(2,12-4)$.

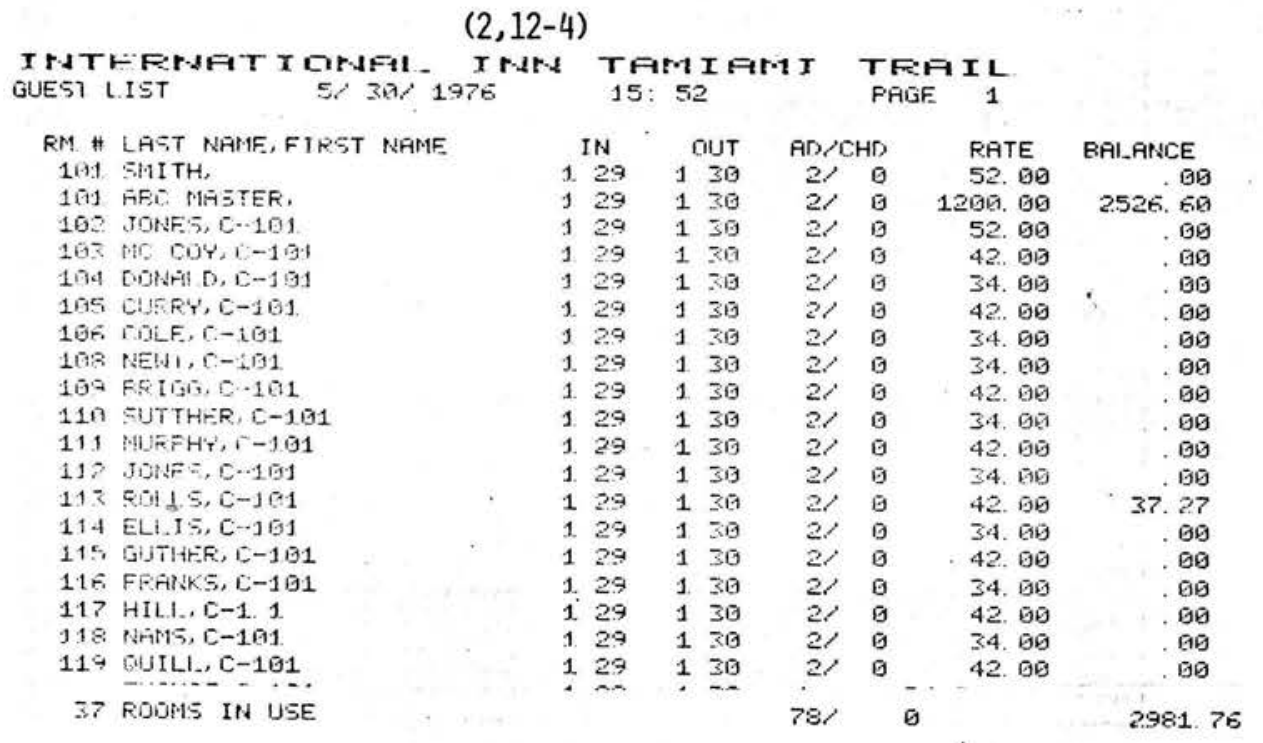


G. After the system produces the 1ist, by CRT display or print-out, it responds with display (2, 12-5).

$$
(2,12-5)
$$

1) REPEAT LISTING 2) RETURN 3) ANOTHER LIST NUMBER:-

H. The cursor is positioned at the end of the display for the operator to select the next mode of action. 1. REPEAT LISTING - This function will repeat the list for further examination. Enter the number (1) and XMIT.

2. RETURN - This function allows the operator to exit from the program. Enter the number (2) and XMIT. The system will return to the Front Desk Monitor (2-A).

3. ANOTHER LIST - This function allows the operator to print/display another list. Enter the number (3) and XMIT. The system will respond with display (2, 12-1). 
2, 13. RETURN TO SYSTEM

A. This program enables the operator to exit the Front Desk Monitor and enter another monitor.

B. The program is accessed by typing the number (13) on the Front Desk Monitor (2-A). The system will return to the "Do What Statement". 


\section{KEYBOARD ENTRY AND FUNCTION}

Communication:

Communications with the MOBY DATA HOSPITALITY SYSTEM through the CRT and keyboard are generally less complicated and more straight forward than other input devices.

Essentially, the keyboard was designed to be compatible with, and imitate a standard TELEX, or TELETYPE (TTY) system.

Keys :

For reference as to where on the keyboard the keys are positioned, Figure I. See Page 146.

A. TAB - This key is used when no data is to be entered on the line the cursor is positioned at, to move the cursor to the next 1 ine for input.

B. CTRL - This key when depressed simultaneously with one of the character keys activates one of the control modes built into the program.

c. SHIFT - This key is used to type the characters on the upper half of the character keys. Depress the SHIFT simultaneously with the other key. The action is similar to the action of shift on a typewriter.

D. SPACE BAR - This key is used to leave a space between characters while inputing data.

E. REPEAT - As the name implies, by depressing the repeat key and the object key, the object character will rapidly repeat itself. 
F. NUMERIC KEYS - These keys may be used when the input is of a numeric nature. Numeric characters may also be entered from the alpha keyboard.

G. CURSOR DIRECTION ARROWS -

These are for direction arrows surrounding the HOME key. They are used to move the cursor in any direction to place a change input in the frame fill.

H. HOME - This key places the cursor at the upper left corner of the display screen.

I. CLEAR - This key will clear the screen of all displays or input. However, it will not function unless the SHIFT key is depressed simultaneously.

J/ I/L - This key will insert a line of data. Used in the program mode on $1 y$.

K. D/L - This key will delete a line of data. Used in the program mode on $1 y$.

L. XMIT - This key will deliver, transmit, the information on the display screen to the central processing unit.

M. BREAK AND RESET -

1. BREAK - This button is used to cause the computer on "Tine to break off transmission.

2. RESET - This button causes the equipment to reset to normal start up configuration.

N. PRINT - This indicator is lit when the on-line printer is activated. 
0 LOCAL - This indicator is on when the system is ready for the keyboard to function.

P. XMIT - This indicator is on when thereitis transmission between the CRT and CPU.

Q. ON/OFF - This acts as a power button and a indicator when the CRT is functioning.

R. D/C - This key deletes a character. When used in conjunction with the SHIFT key it sets the system in a control mode.

S. ALPHA KEYBOARD - These keys are used to input alpha characters.

T. CR - This key functions as a carriage return. It is used to move the cursor to the next line after data has been inputed. 


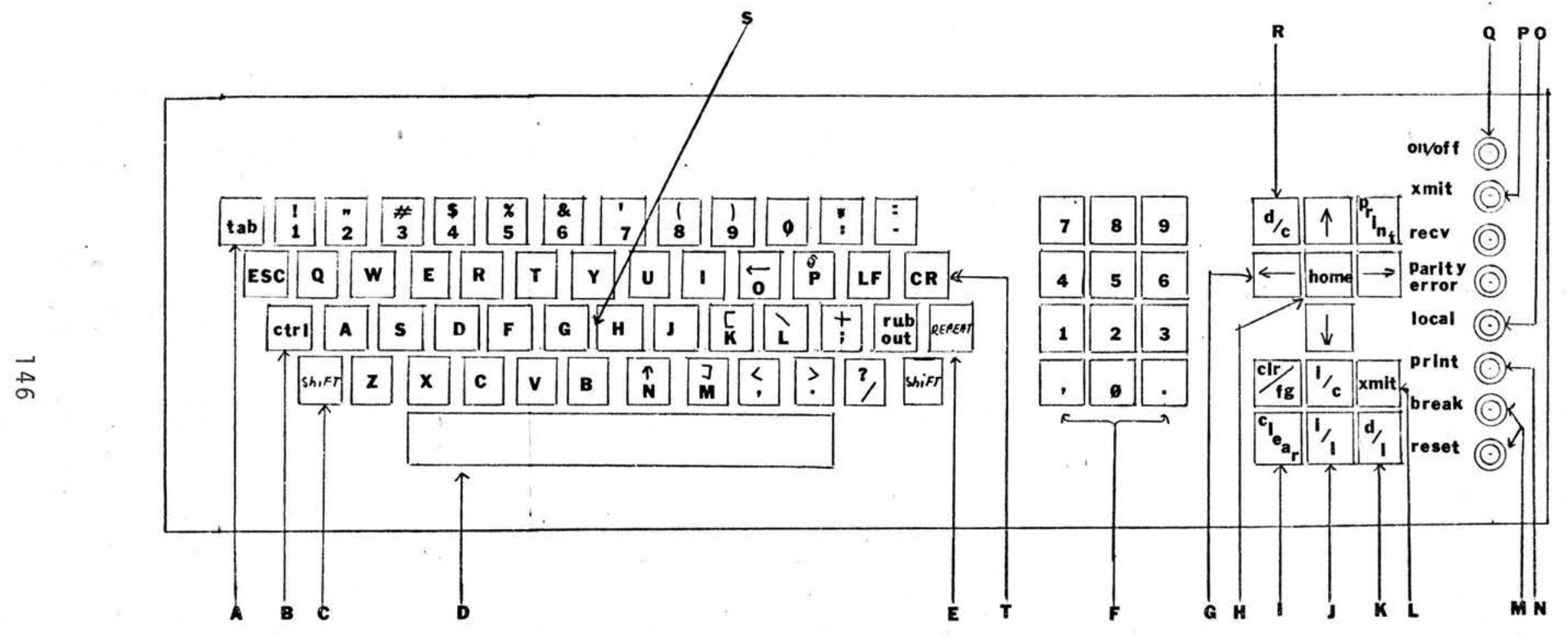

KEYBOARD

Figure I 


\section{INTRODUCT I ON}

\section{Guide to Understanding the \\ Logic-Tree Flow Chart \\ for the \\ Moby Data Hospitality System}

A. Standard block instruction:

1. The number in the top center of the box is the operation step number.

2. The statement in the block is the operating direction or display.

For example, (A) in Figure I would be step 1 A which is the "Do What Statement".

B. Direction Lines:

Letter (B) in Figure I demonstrates the direction in which the flowchart is proceeding.

c. "Go to" statements:

1. The command "go to" informs the reader to skip a a certain section of the flowchart and continue reading at a specified point.

2. The second line states where to continue with the reading. This statement is numeric in nature, A/B.

a. $A=$ the operation step number

b. $B=$ the page number

Thus, in the example (C) in Figure I, it states go to step \#6 found on page 2. 
D. Connecting statement:

1. The connecting statement is found at the end of the direction line. It may be in a connecting circle or freestanding.

2. It consists of three parts:

a. The prefix is a alpha symbol. This states the row in which the next instruction will be found. b. The next character is numeric. This states the column the next instruction is found in.

c. The last character is numeric. This states the page number the next instruction will be.

Thus, in example (D) in Figure I, it states that the next instruction is number 65 , found on row $A$ in column 4. 
Figure I

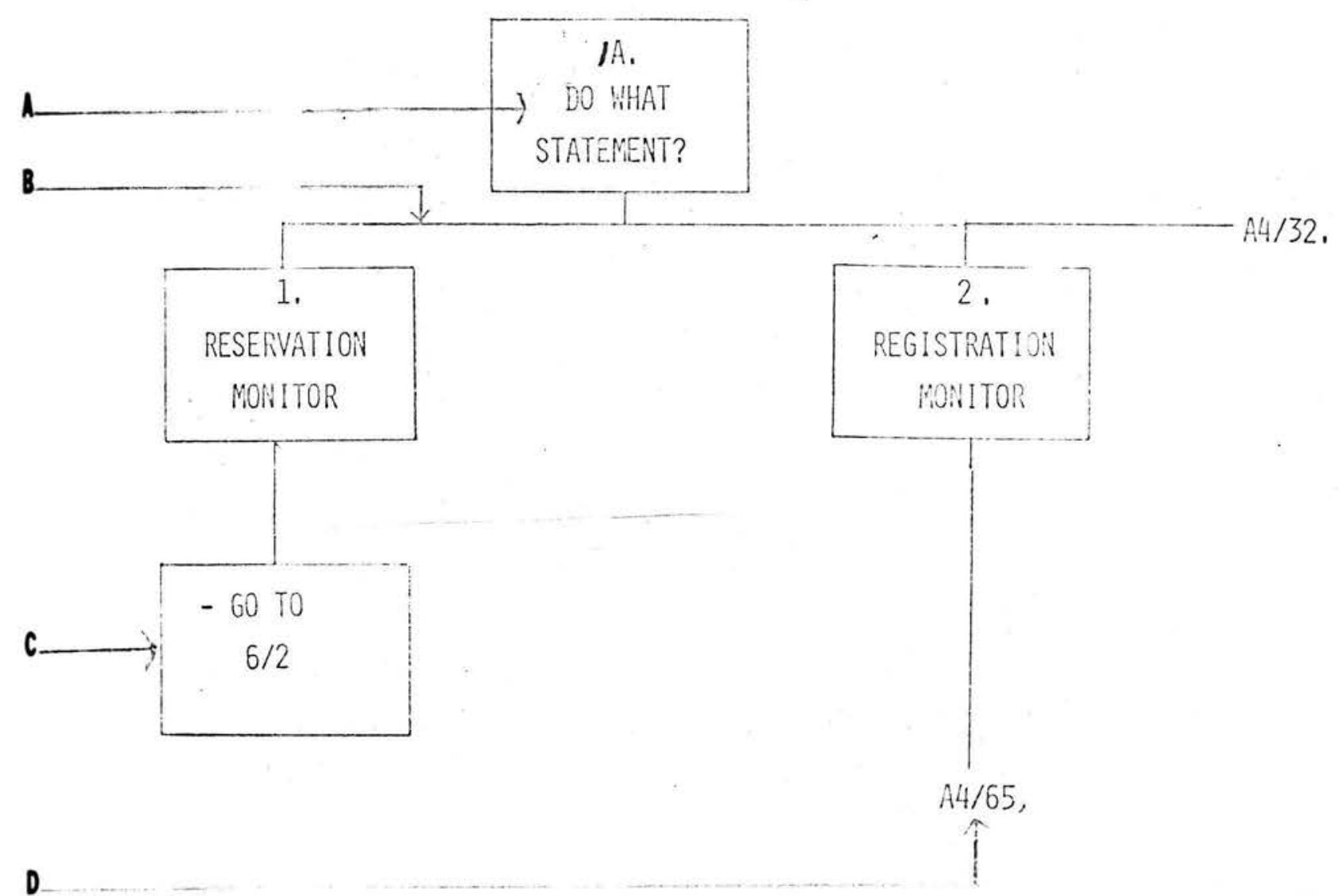




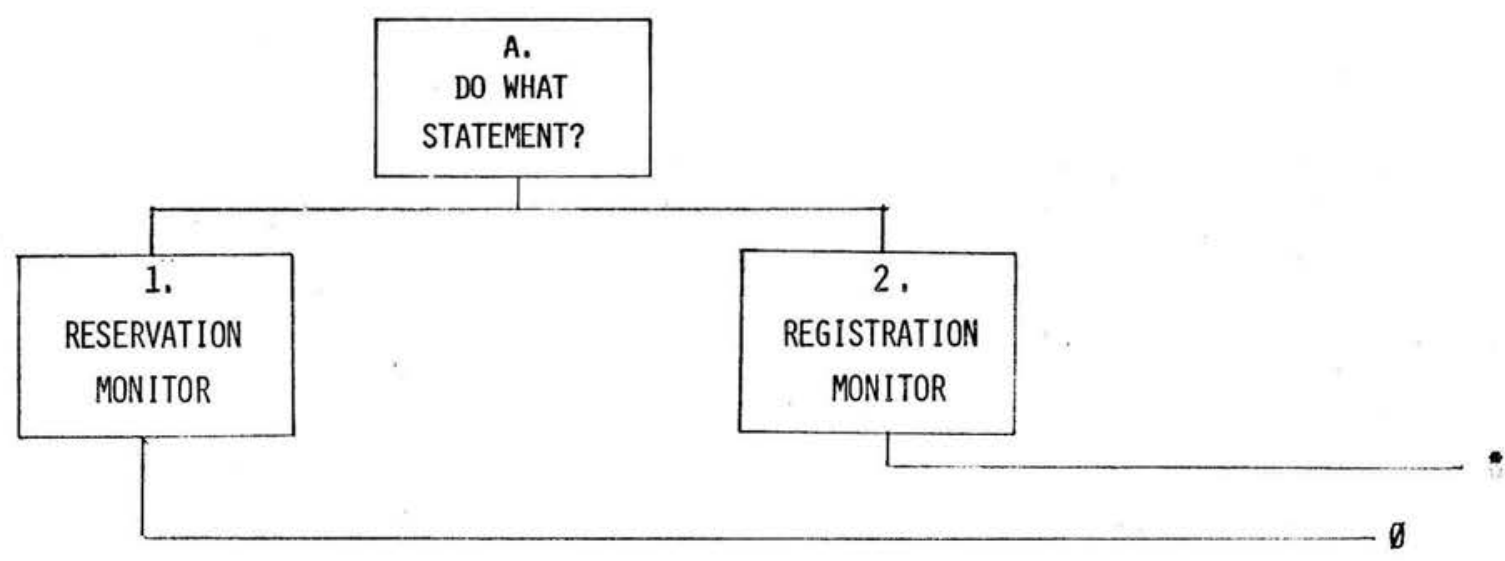

D - A4/2, A4/4, A4/10, A4/13, A4/17, A4/20, A4/27, A4/32.

* A4/33, Ak/39, A4/41, A4/46, A4/55, A4/61, A4/63, A4/65, $A 4 / 67, A 4 / 69, A 4 / 73, A 4 / 76, A 4 / 79$. 


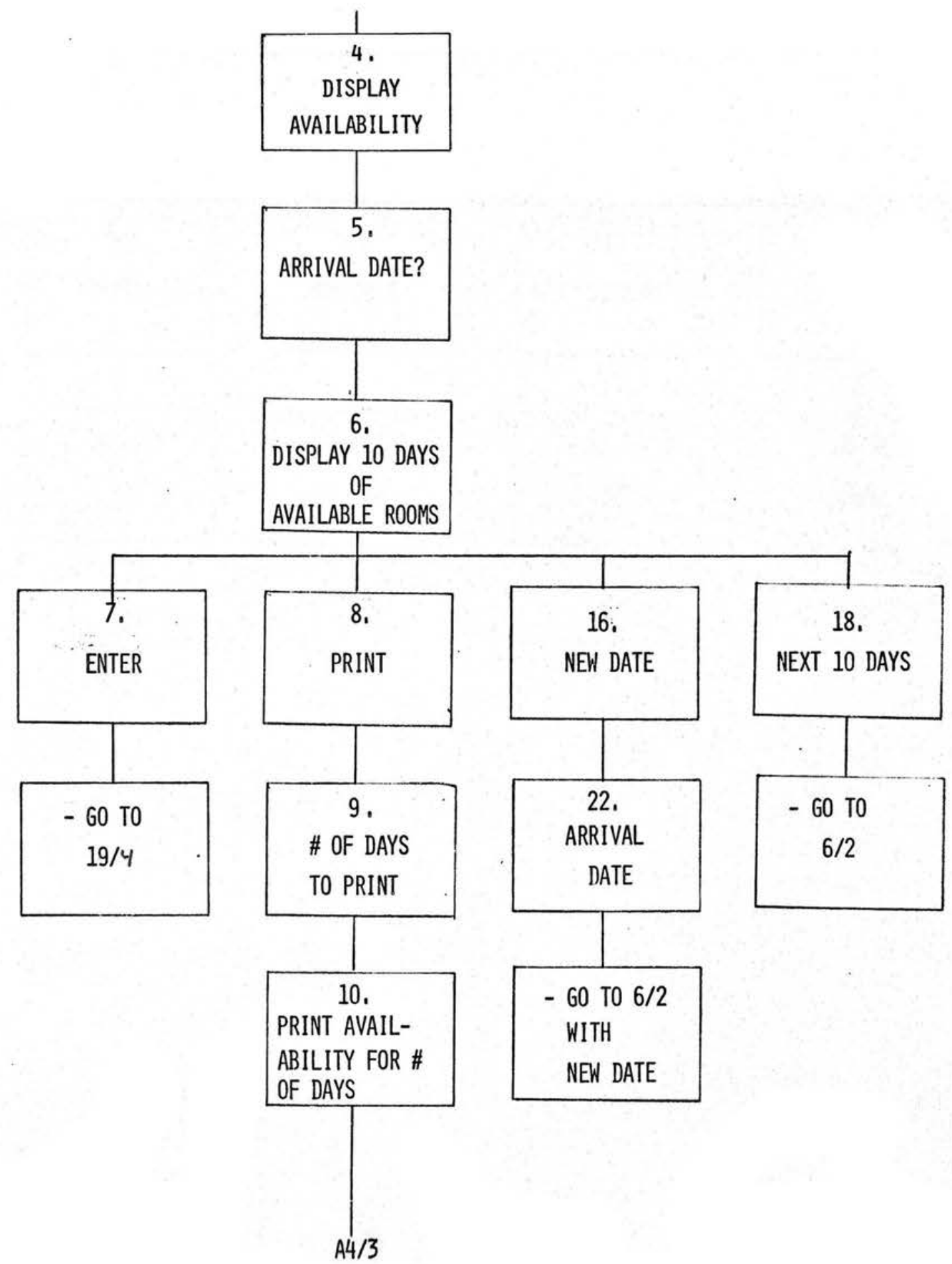




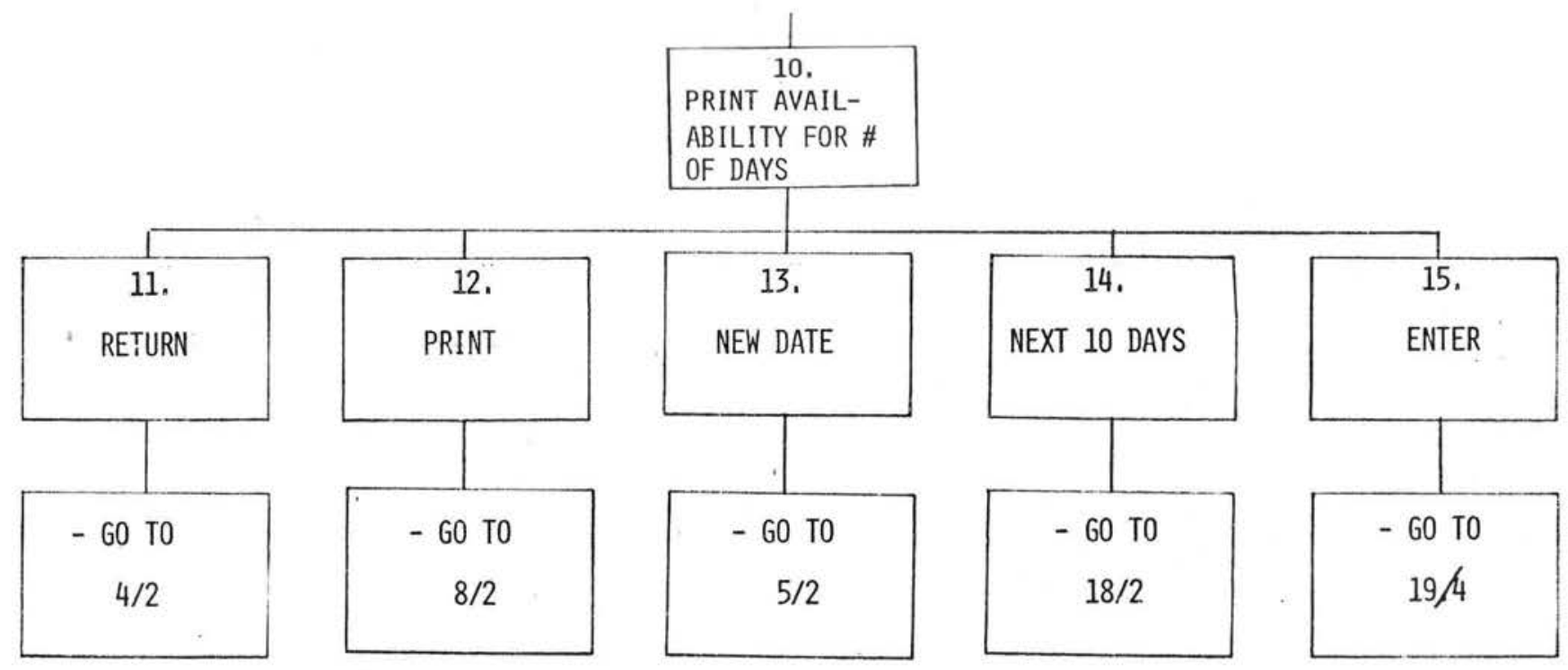




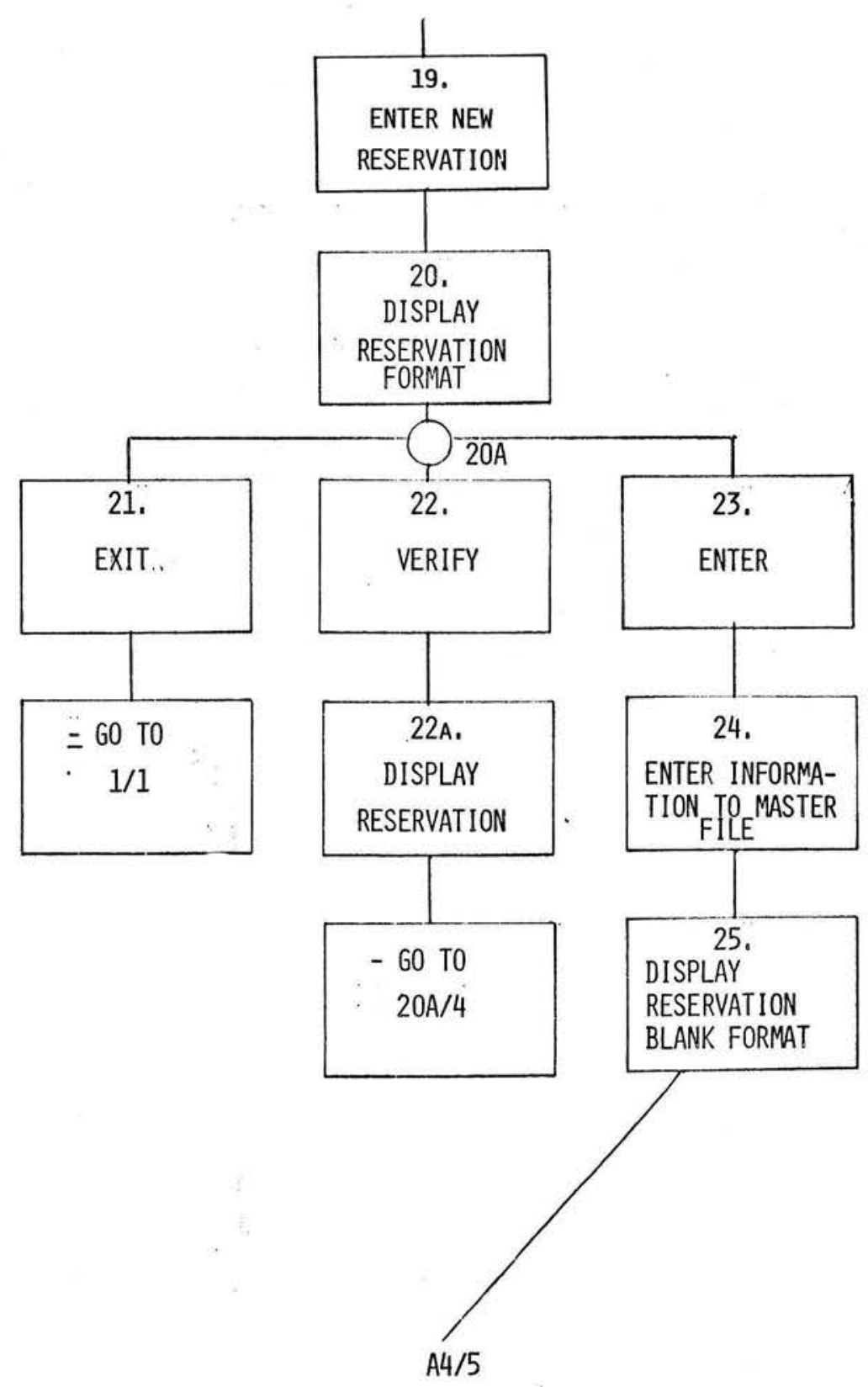




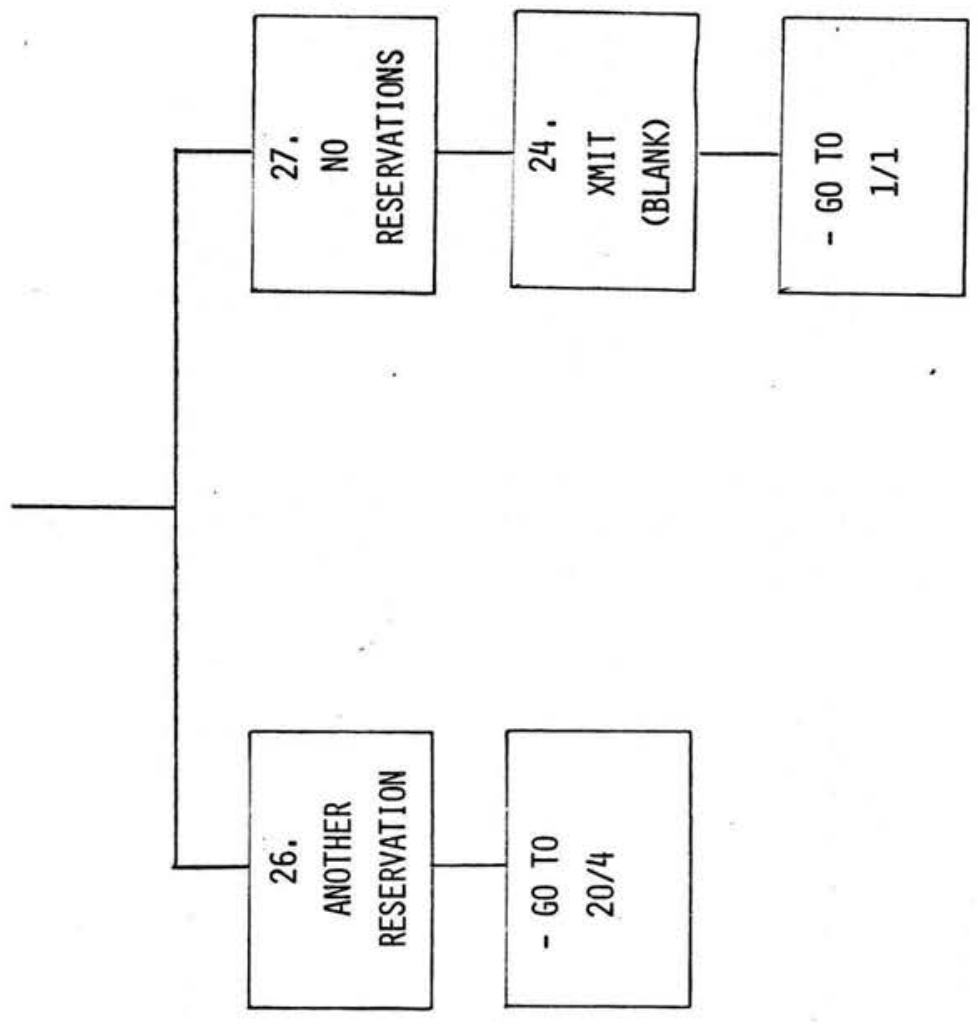




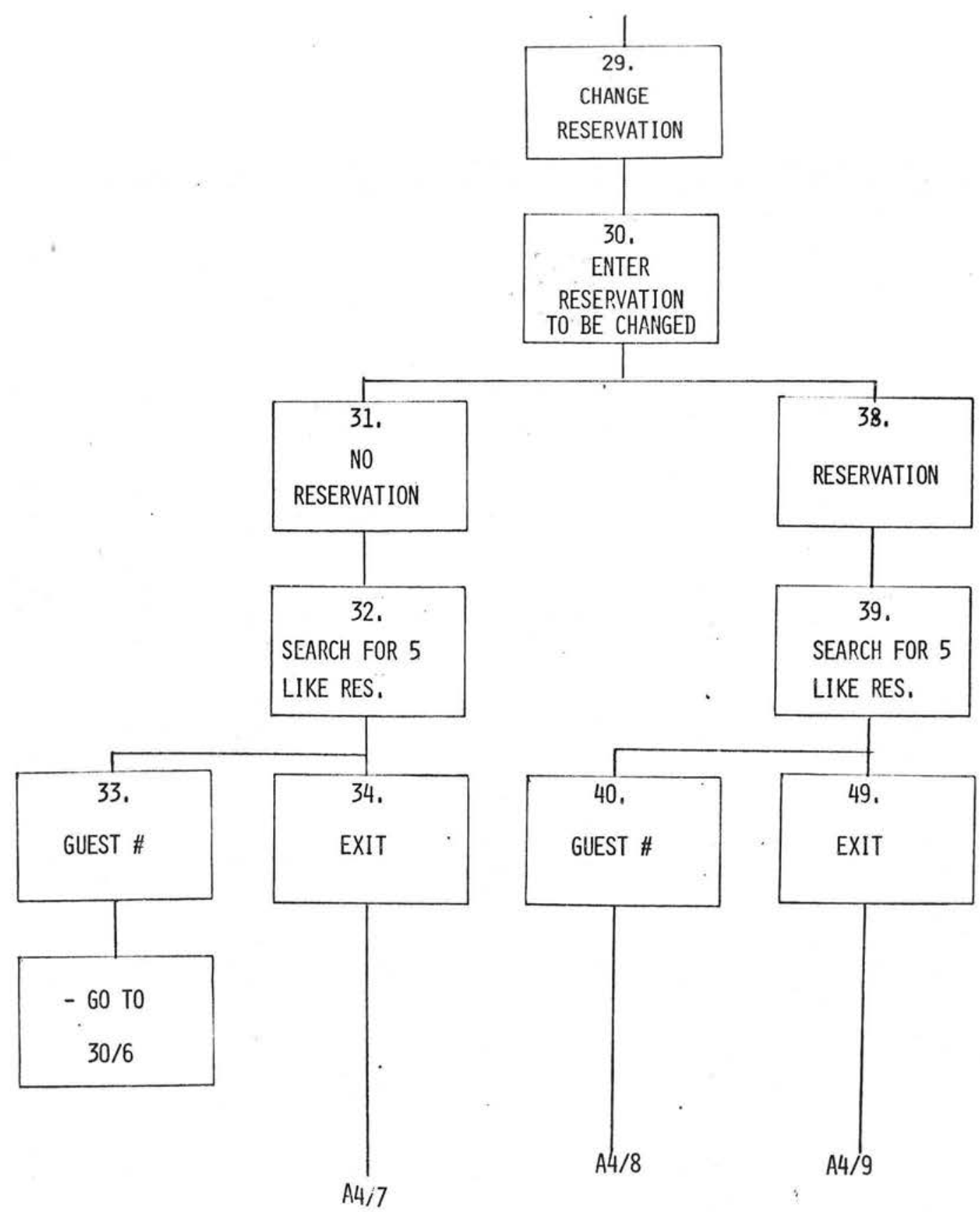




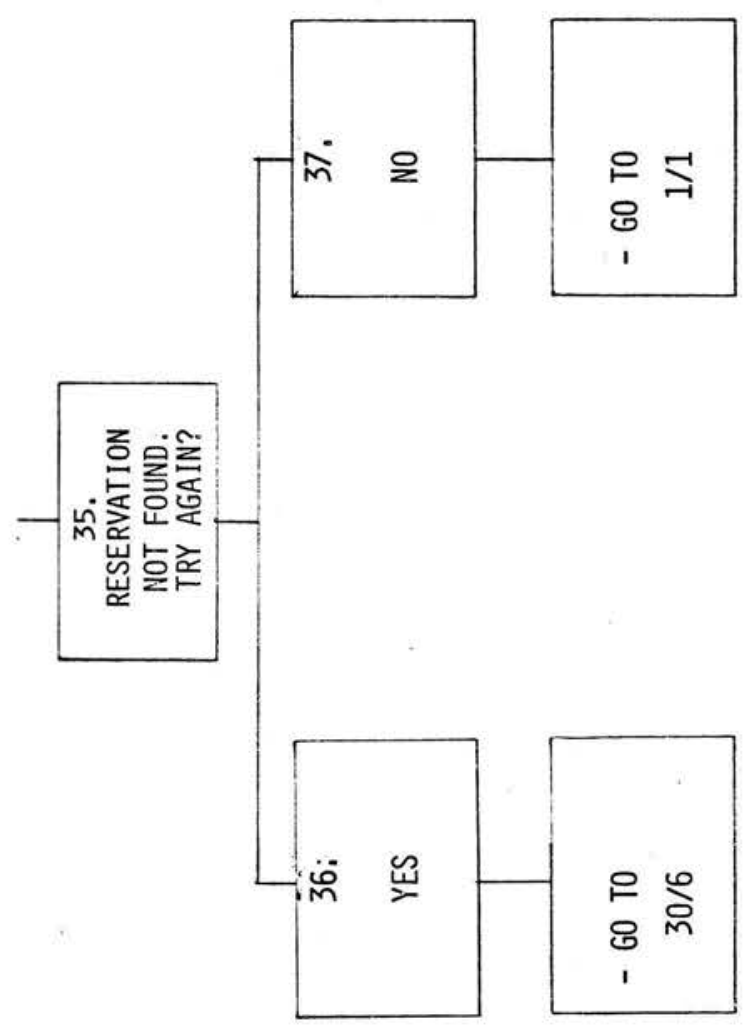




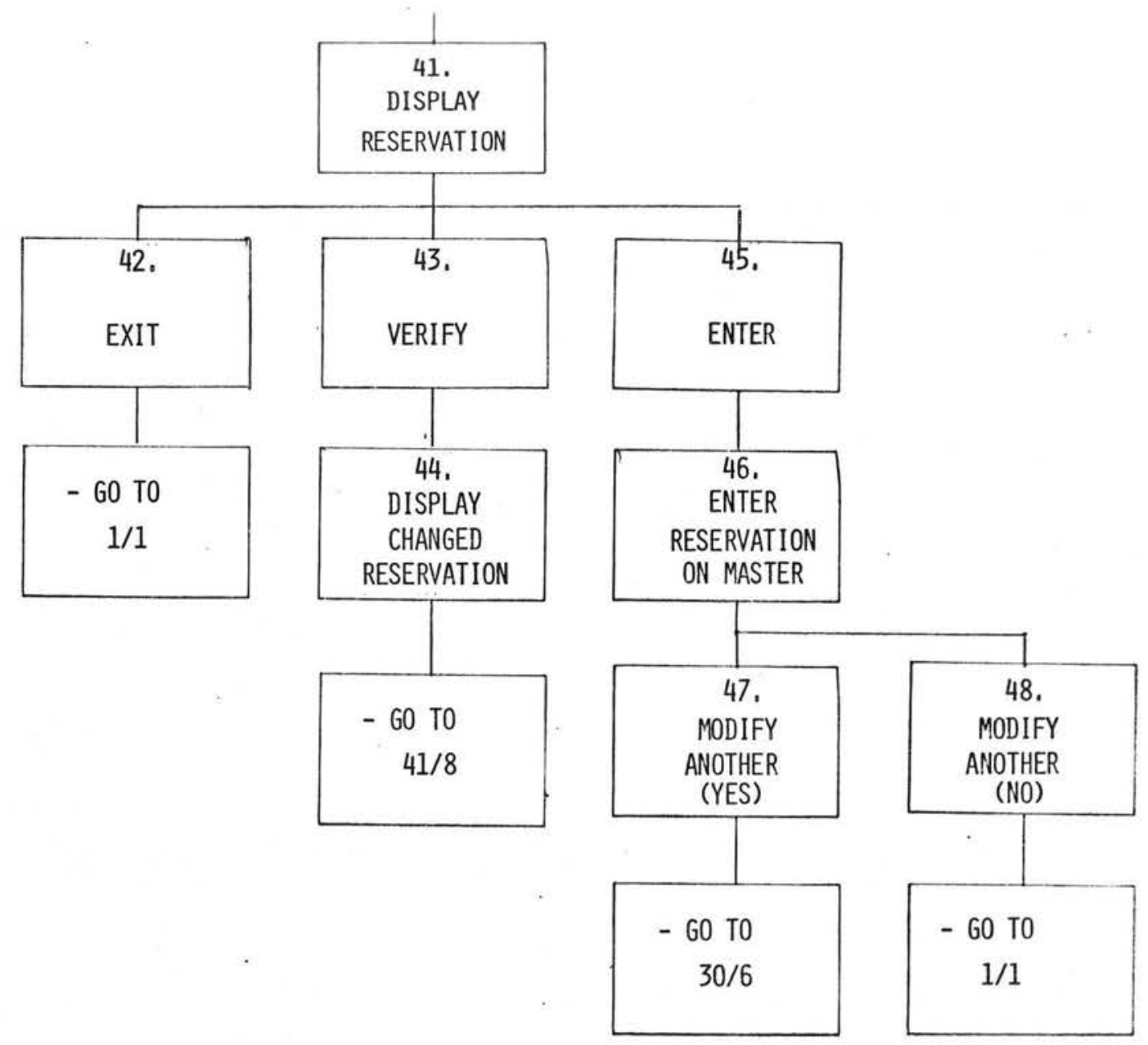




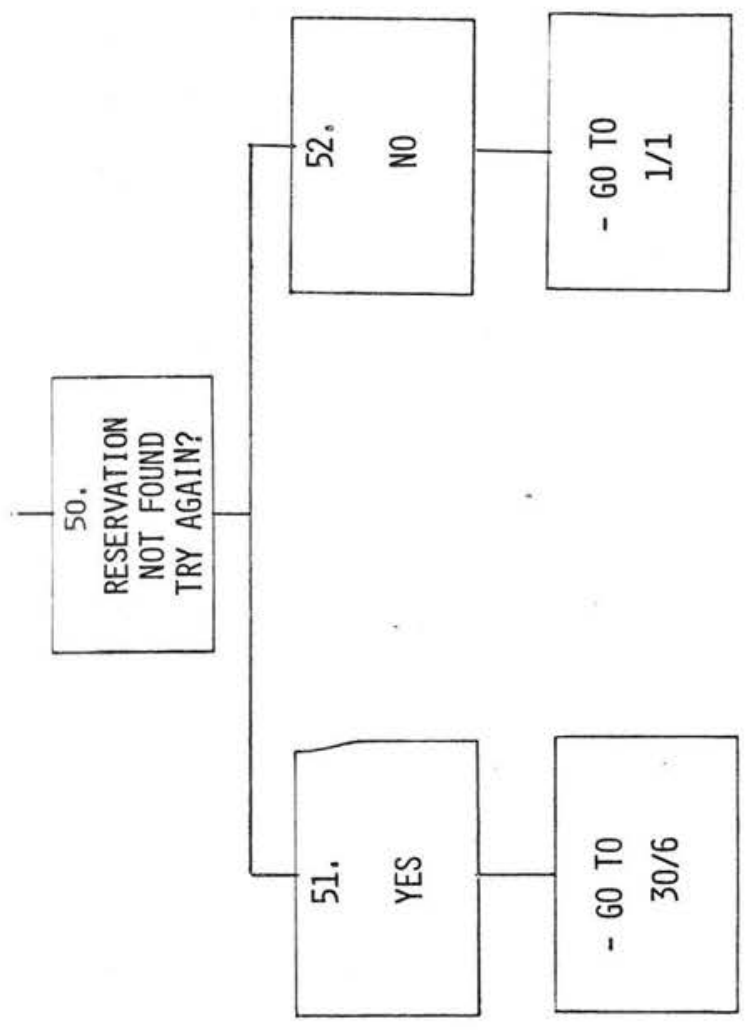




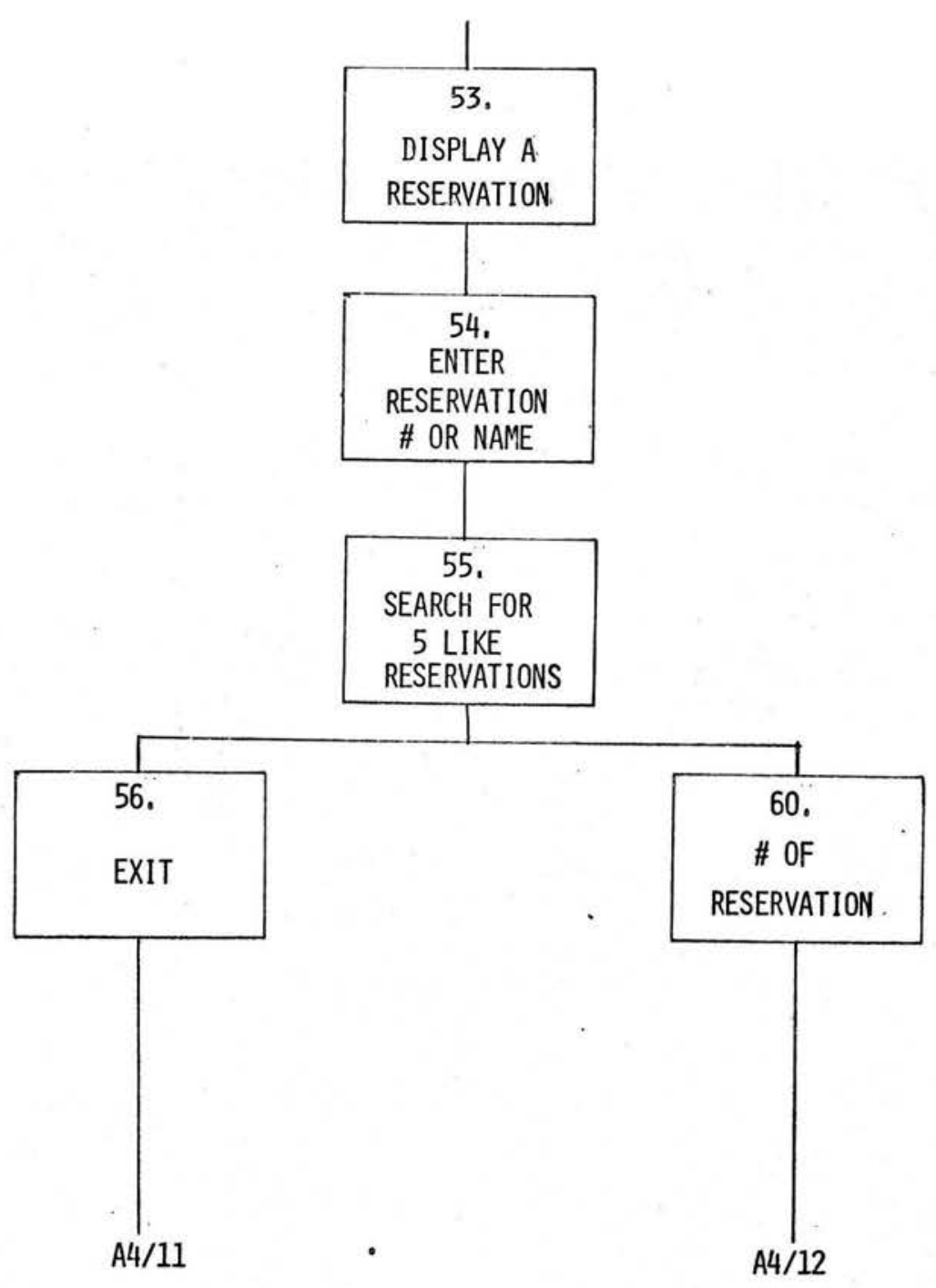




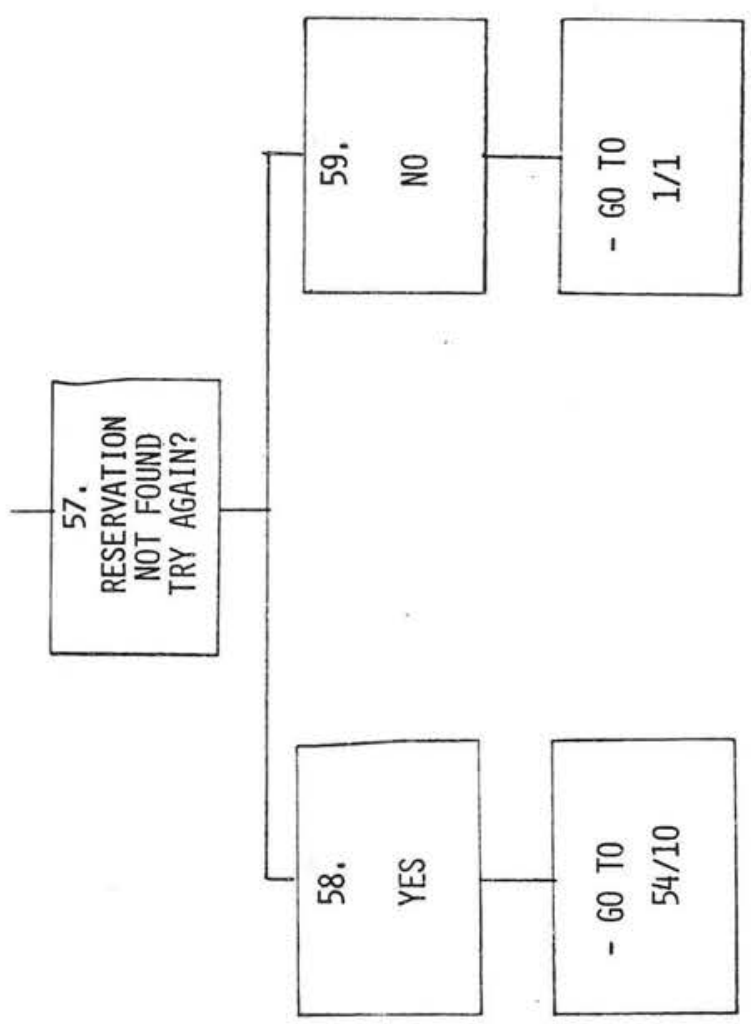




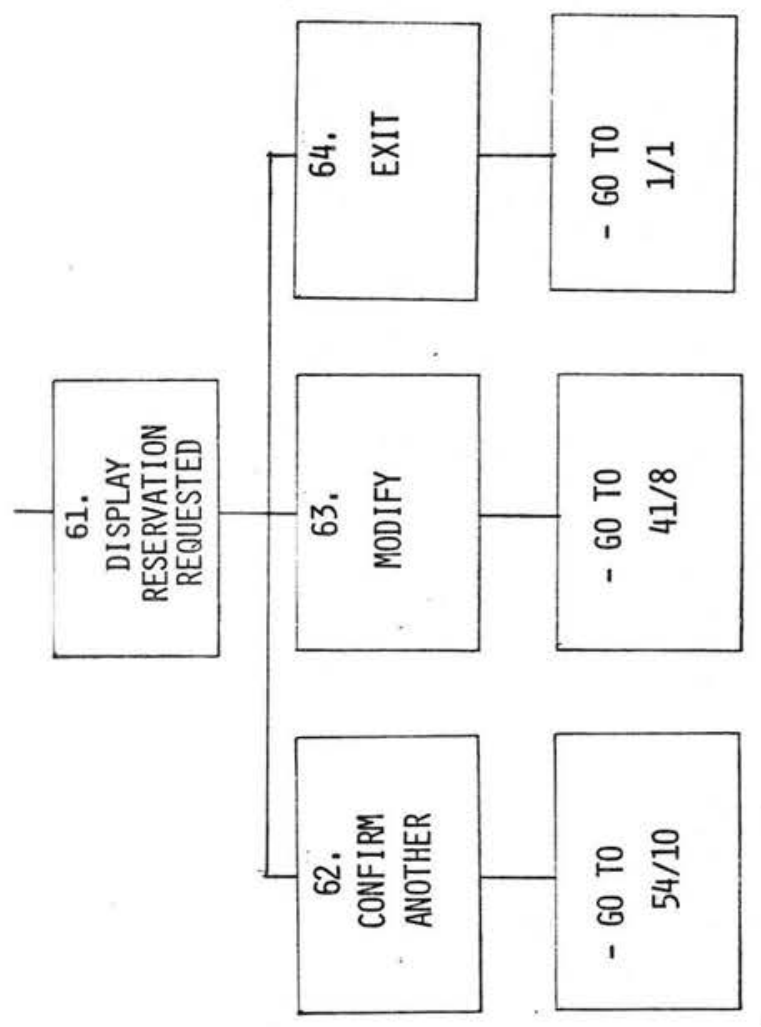




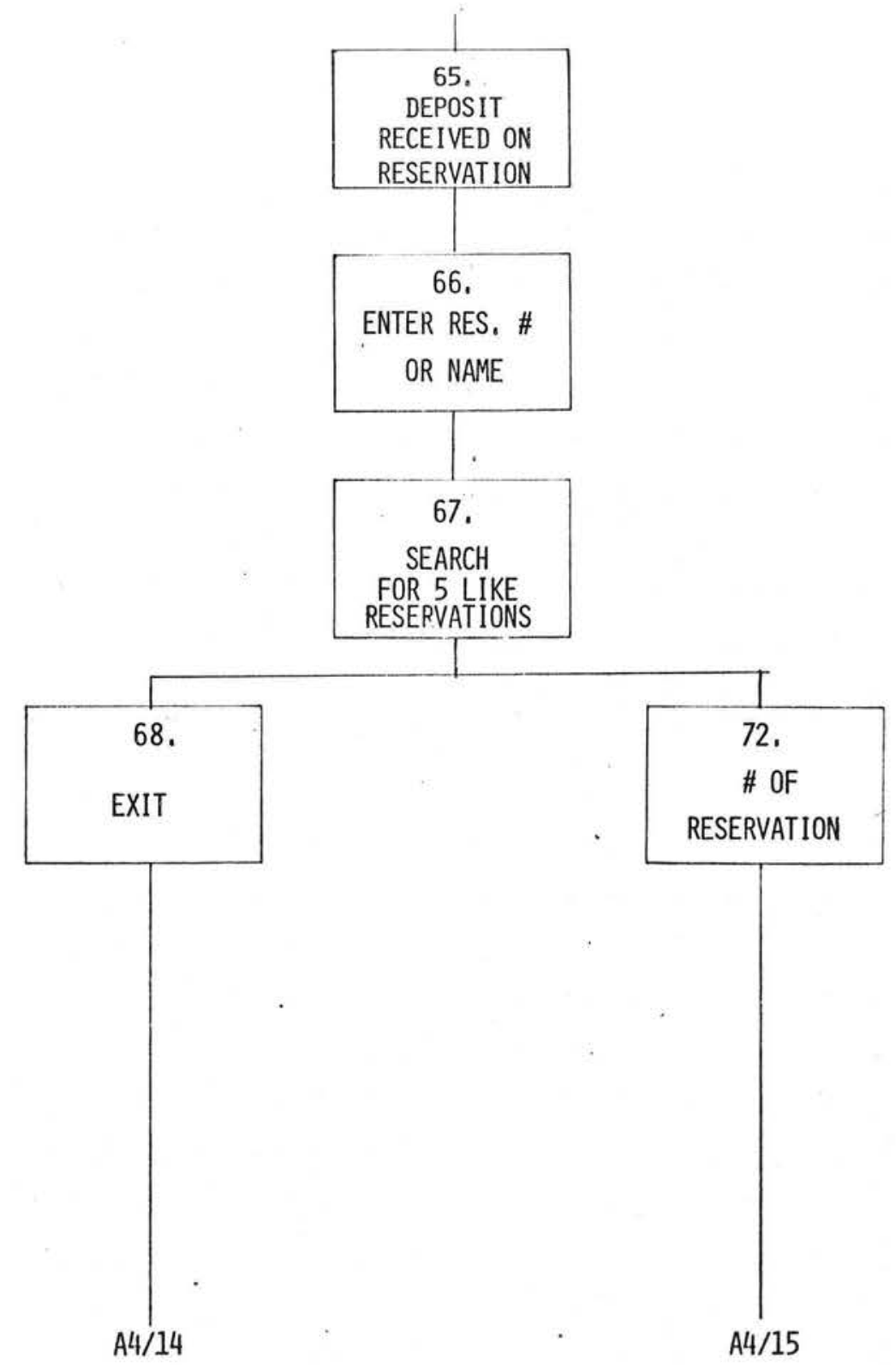




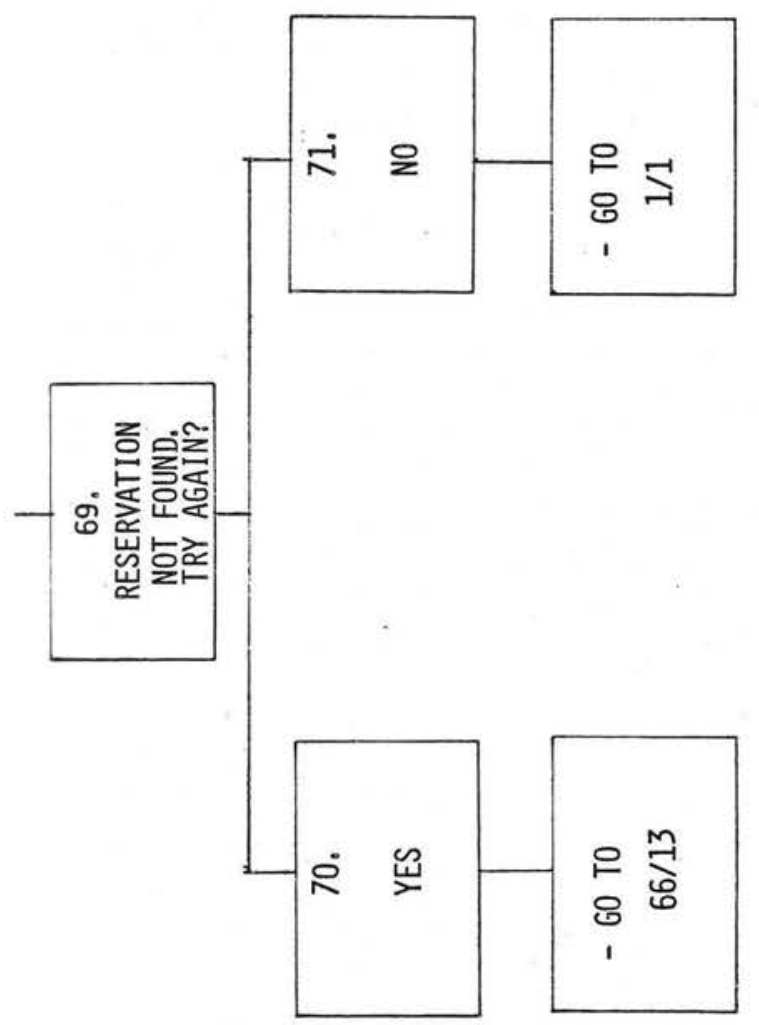




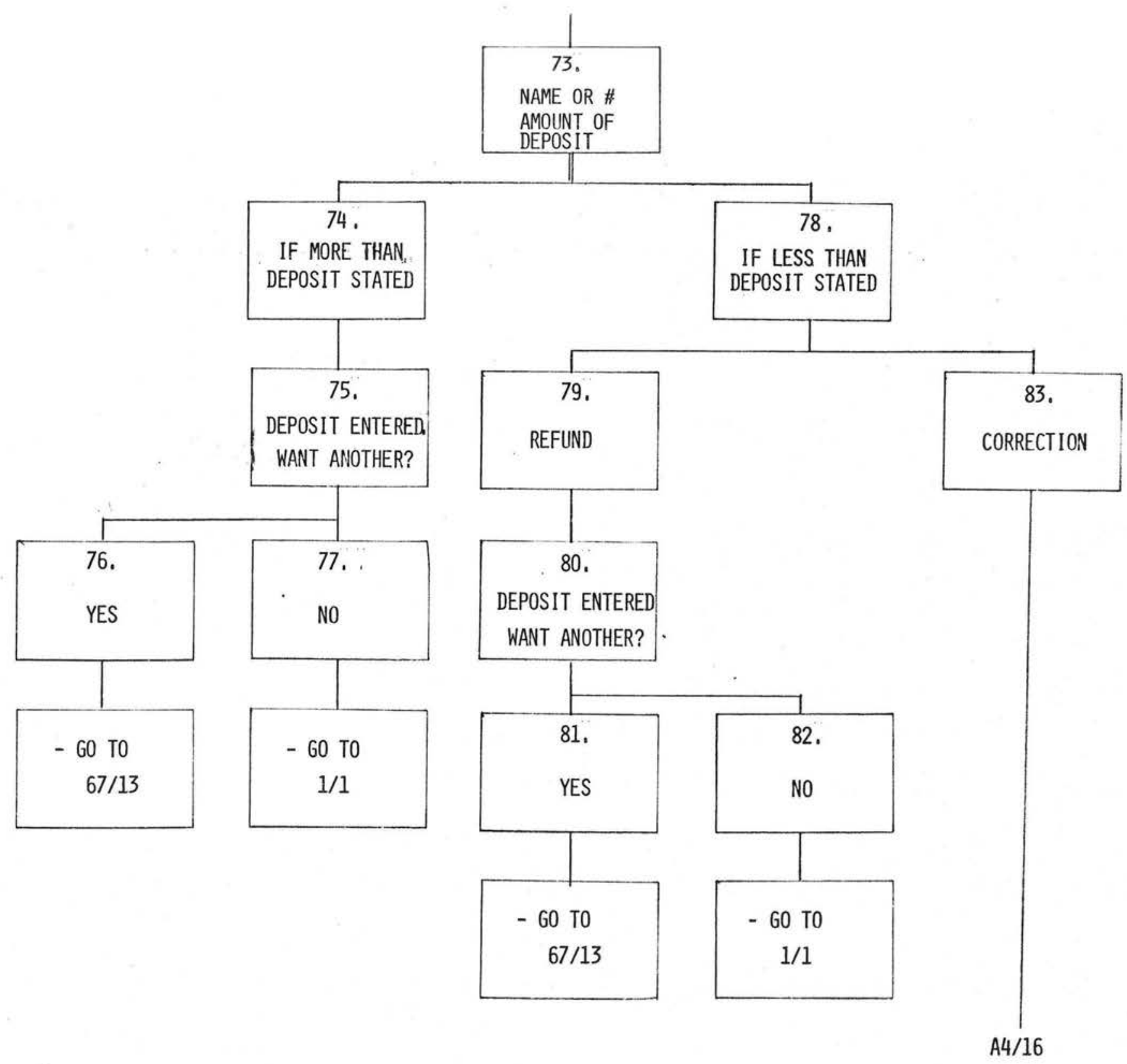




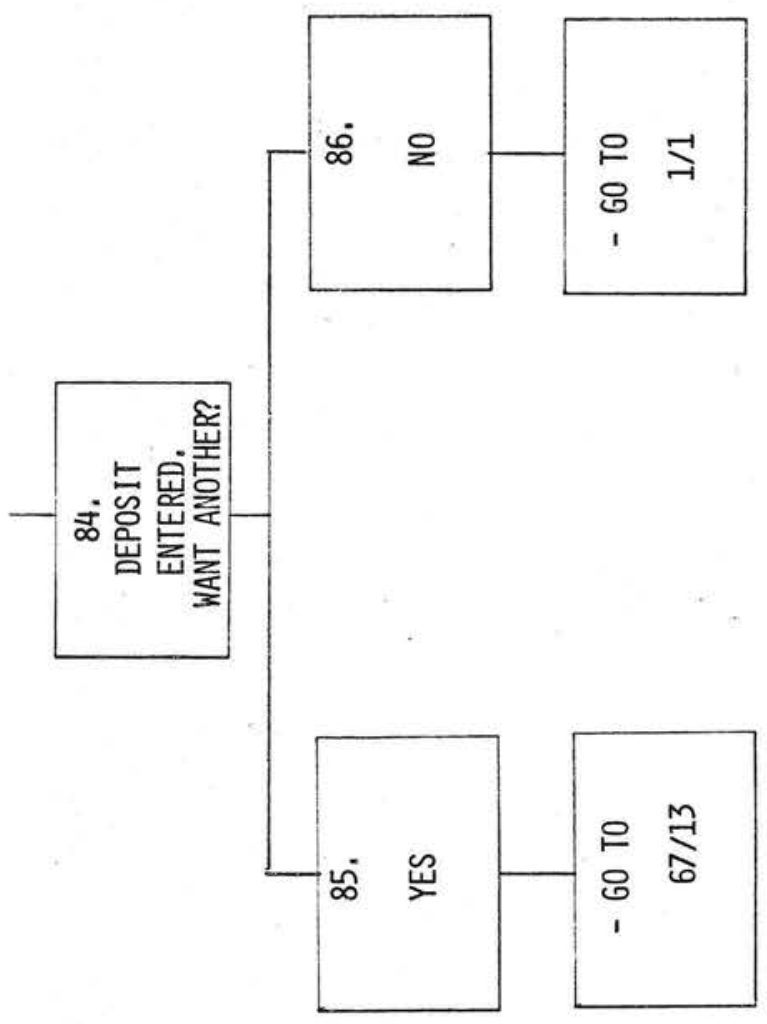




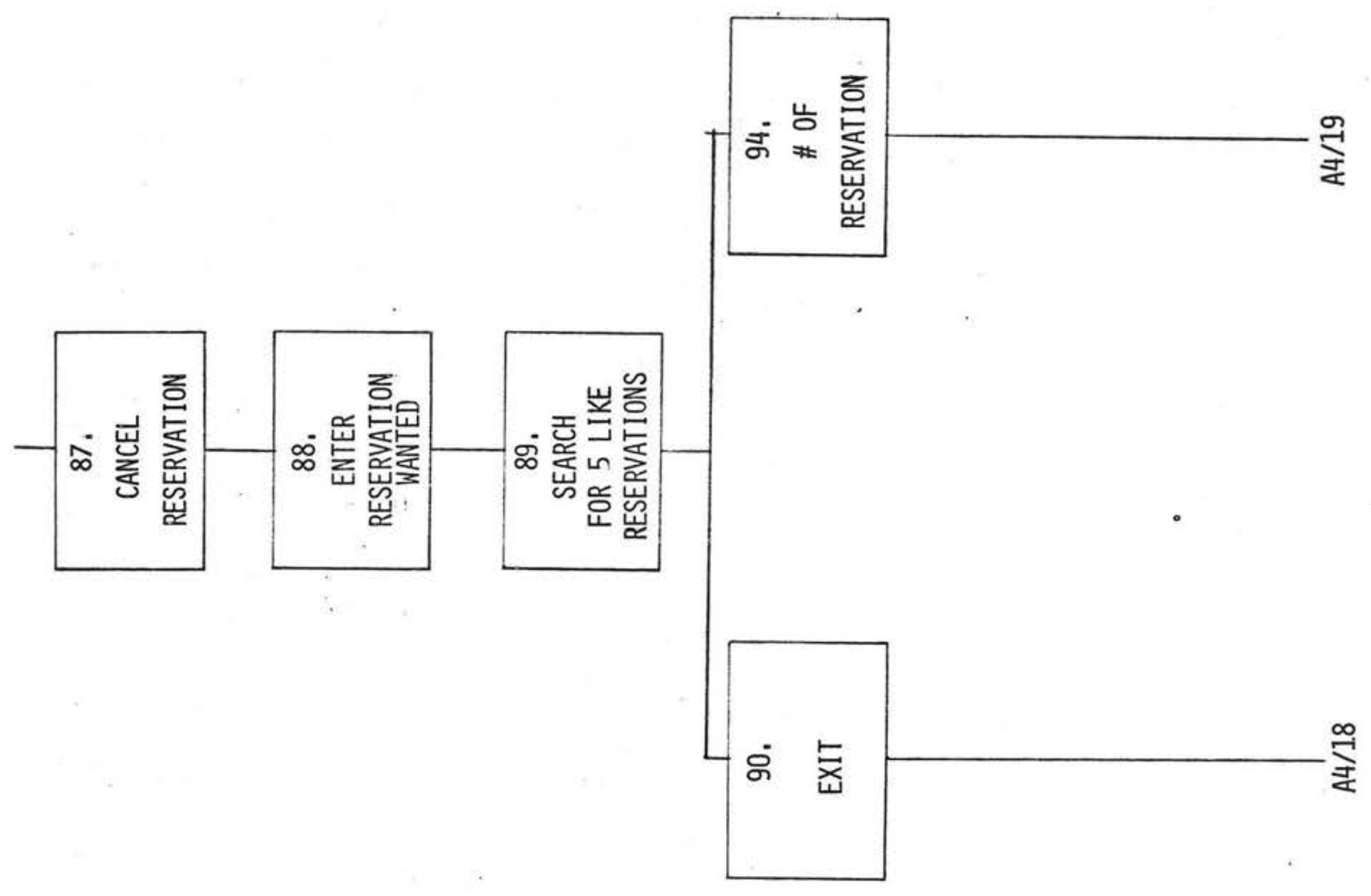




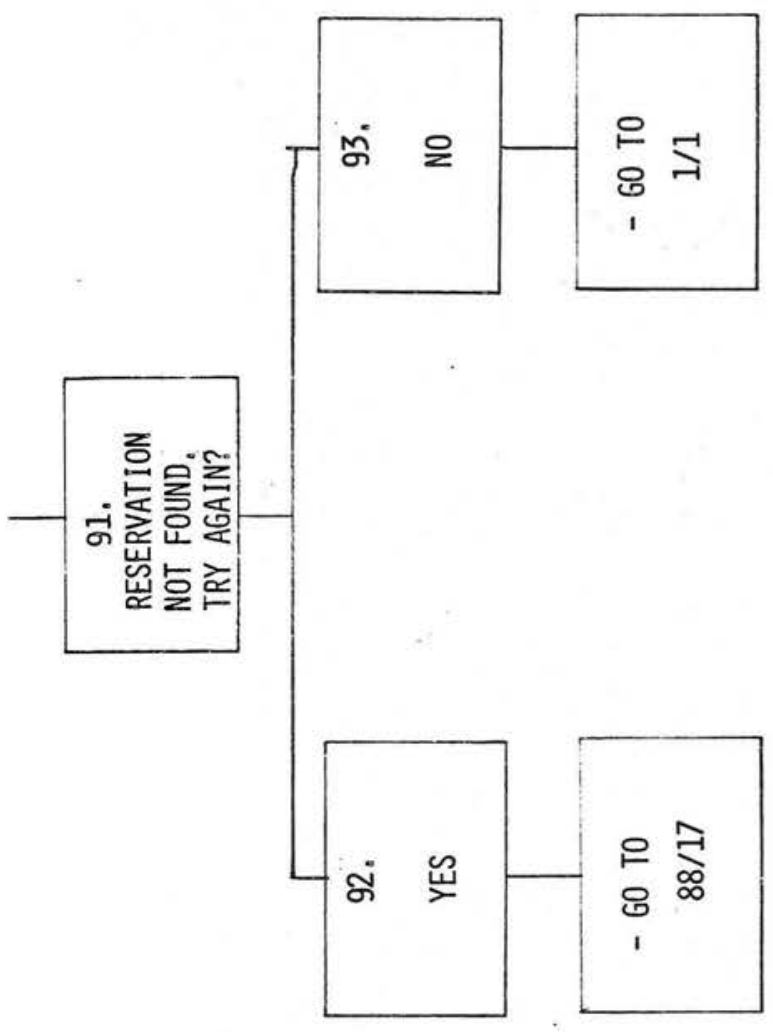




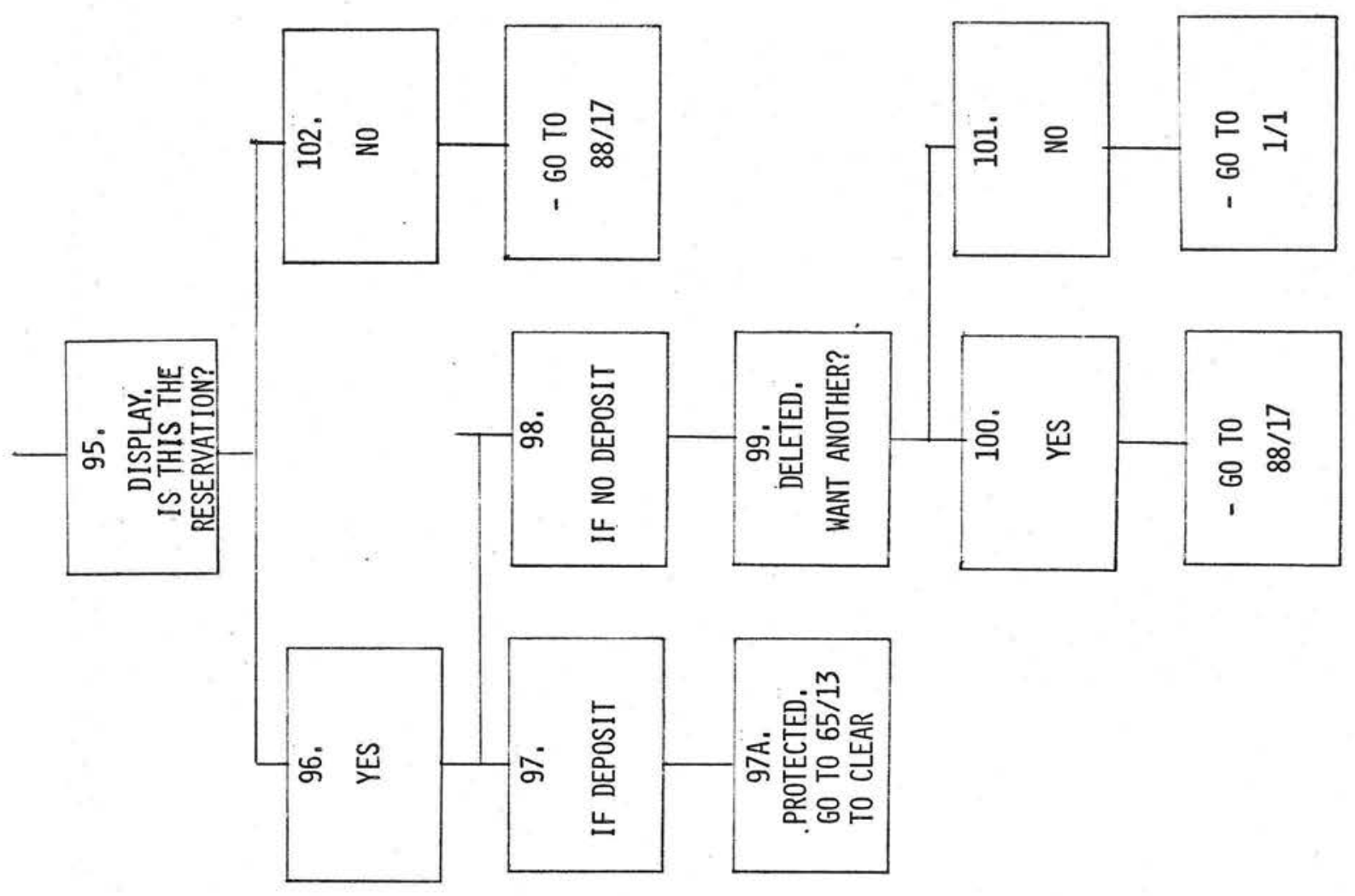




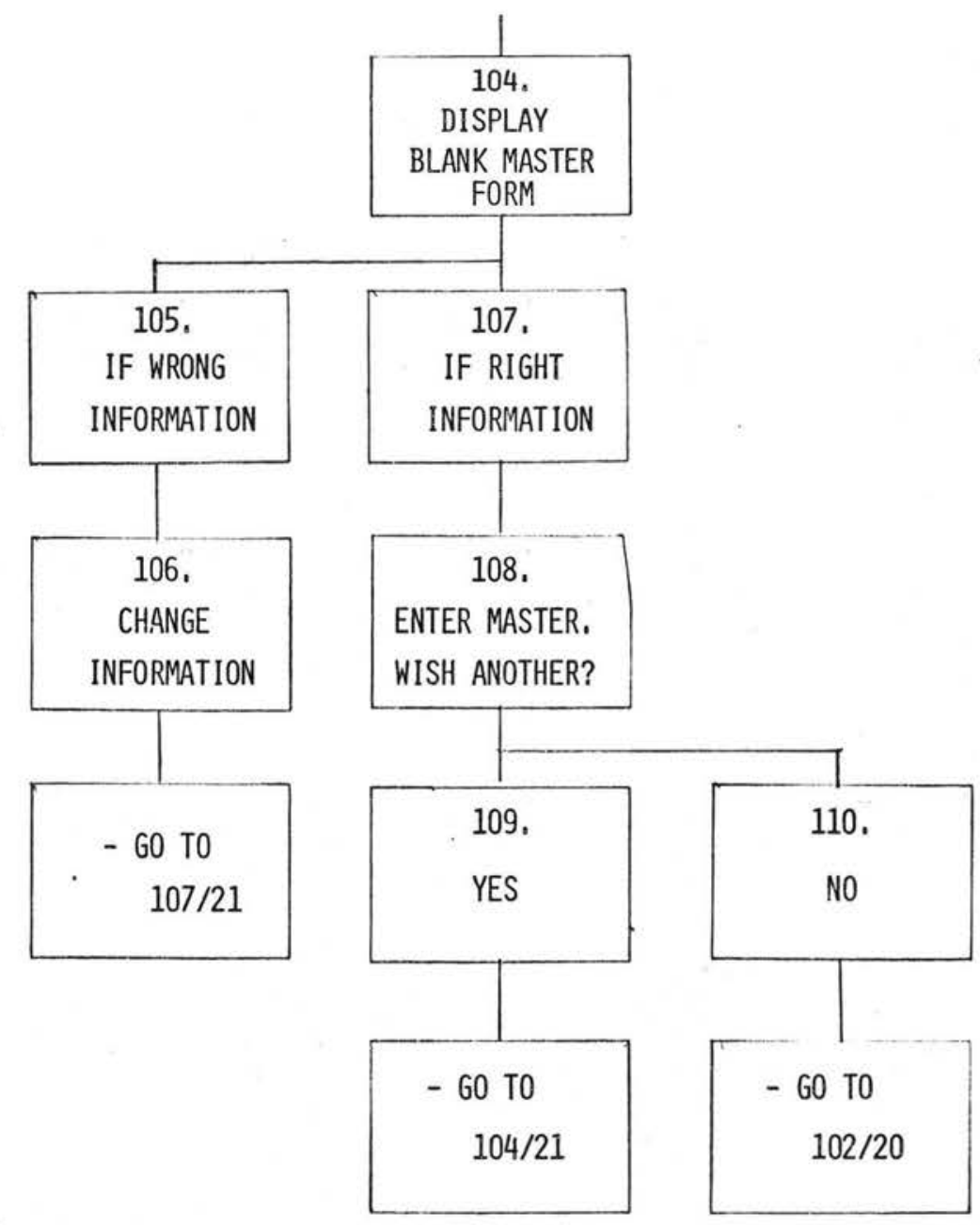




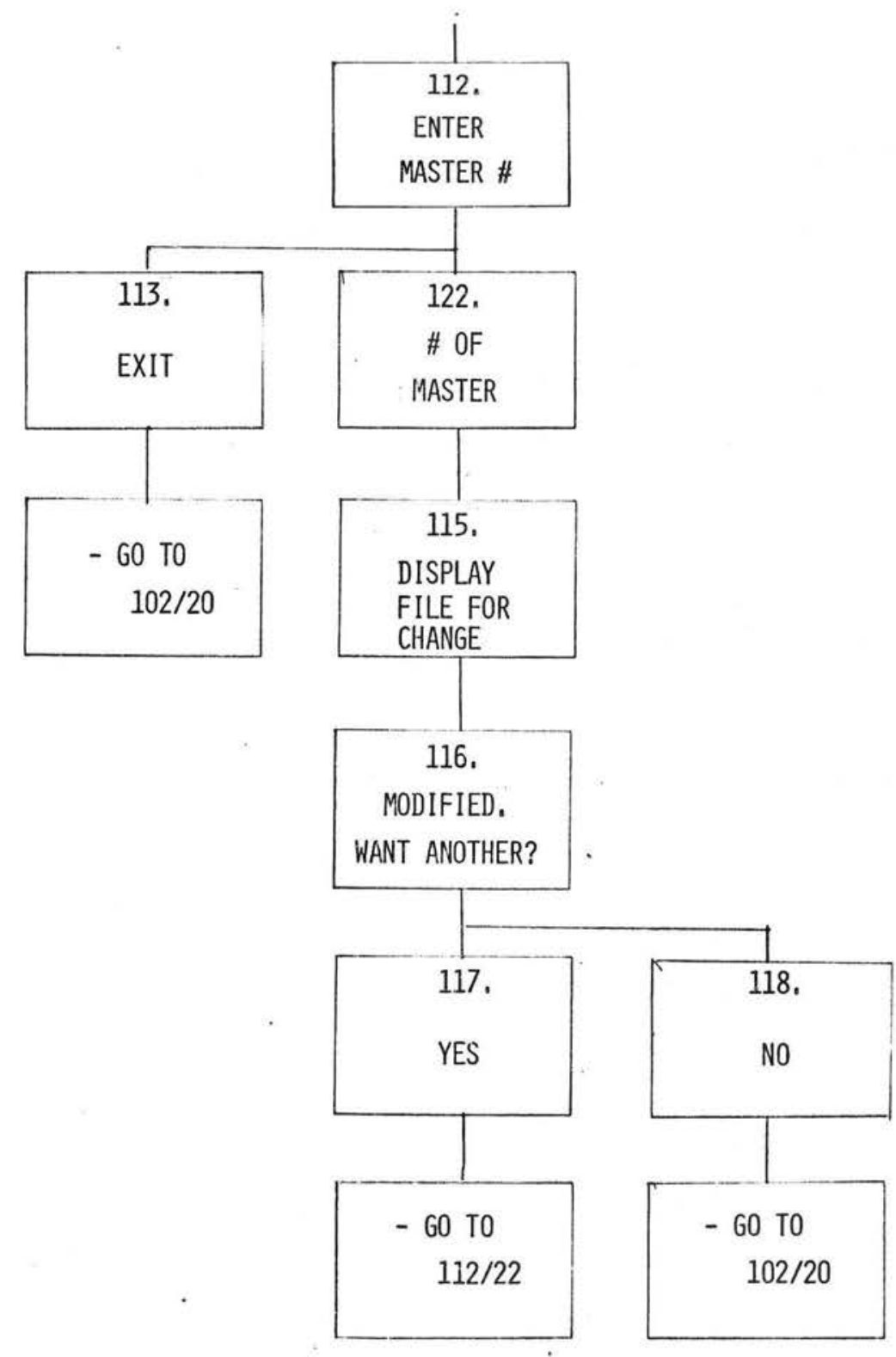




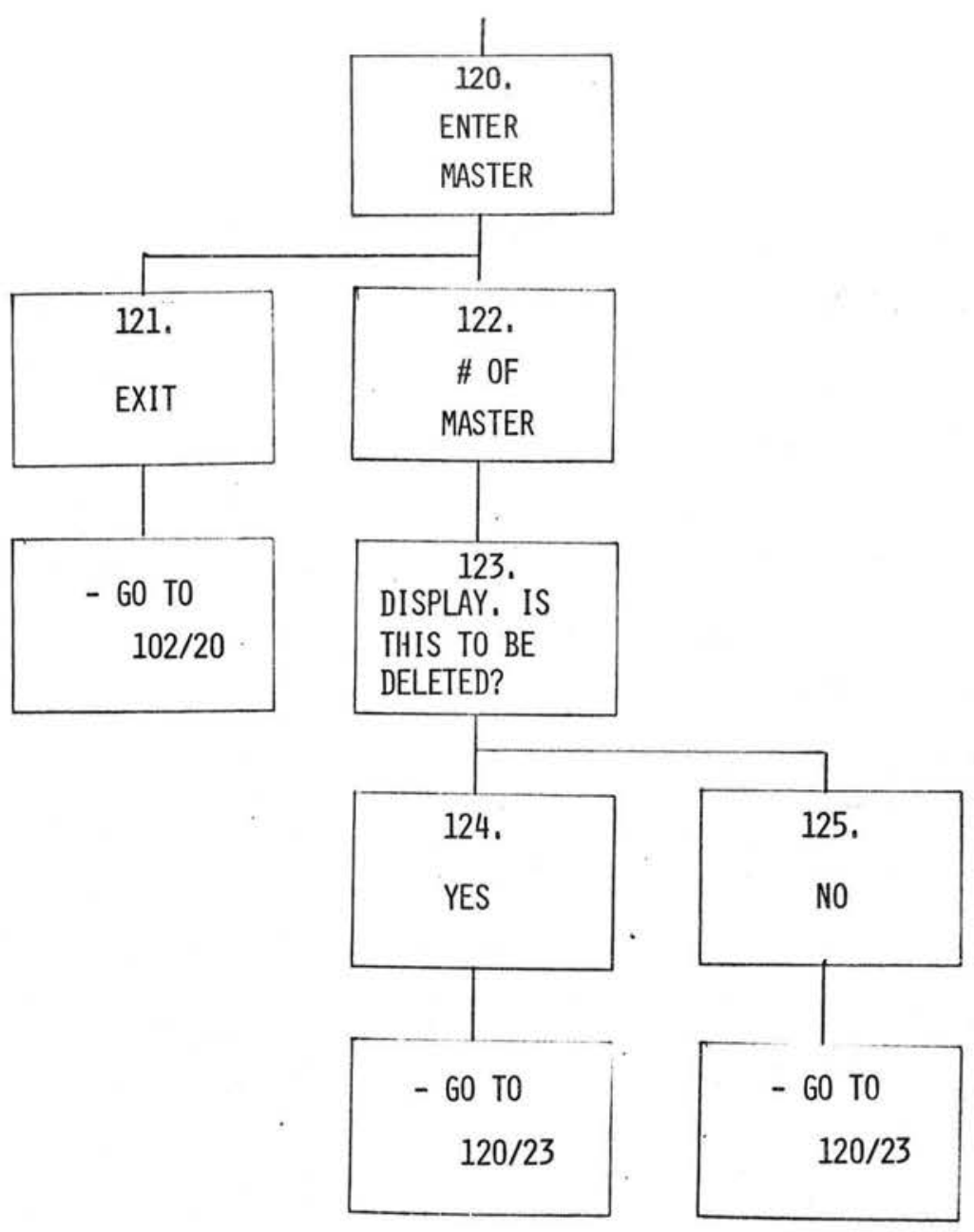




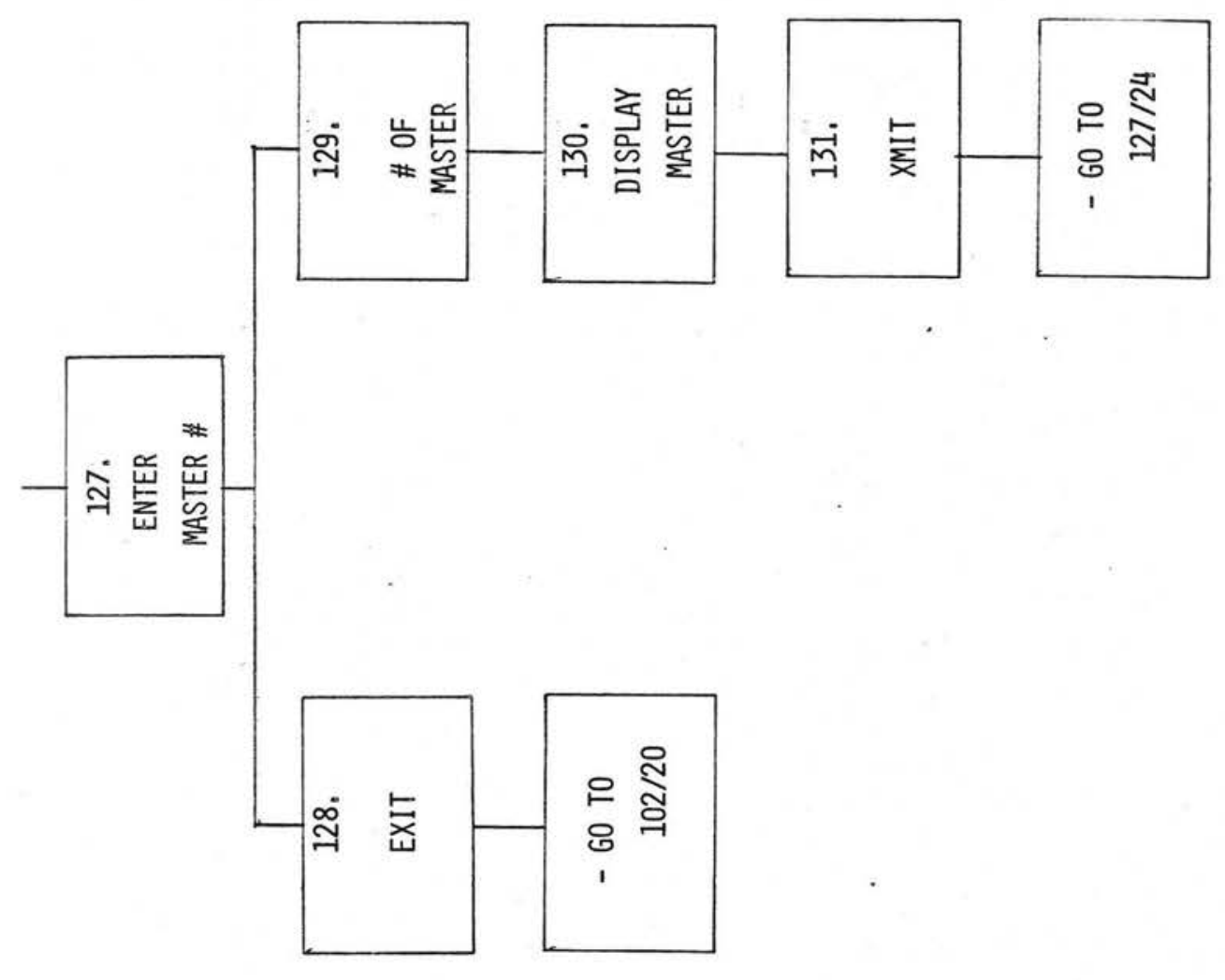




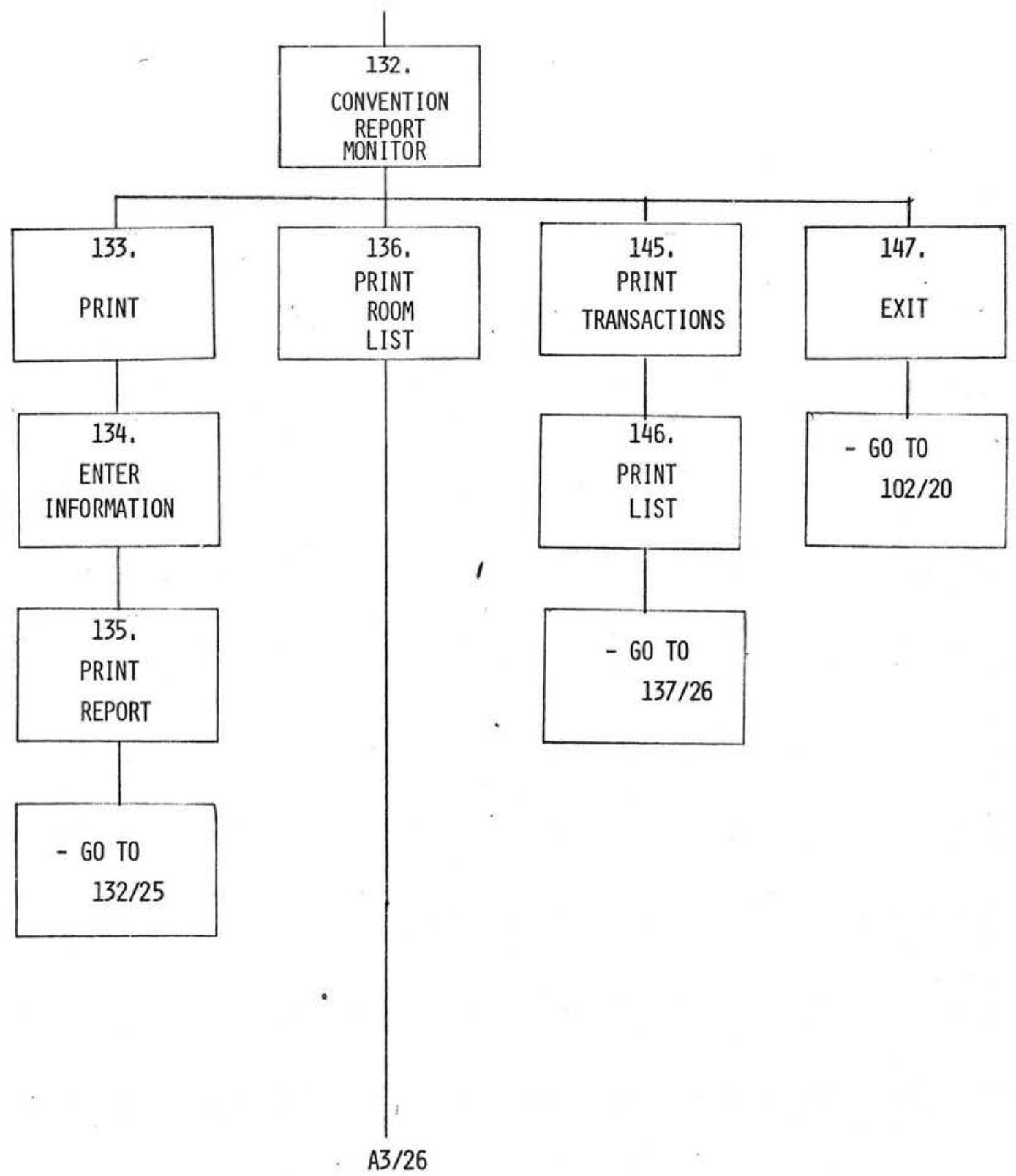




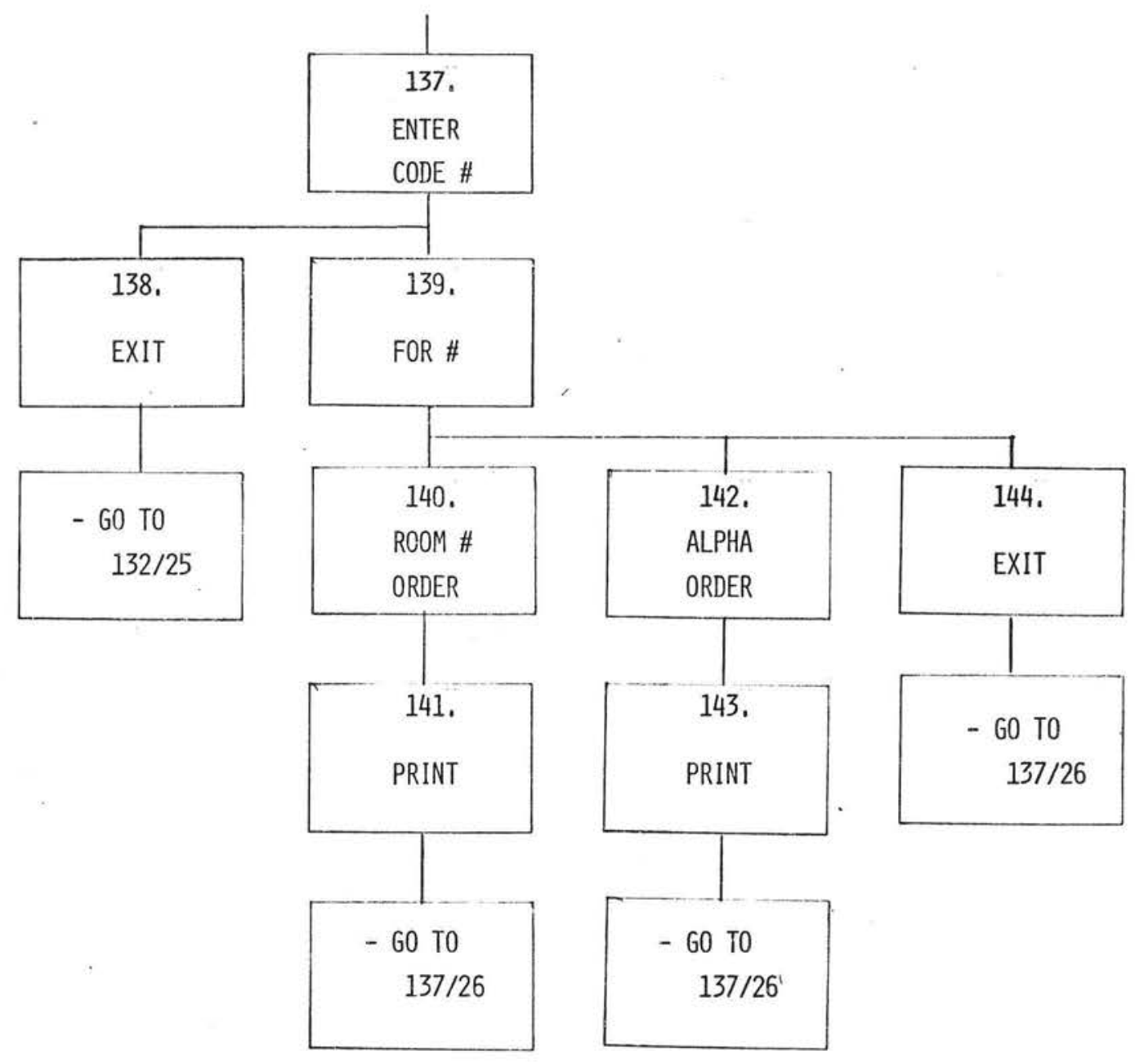




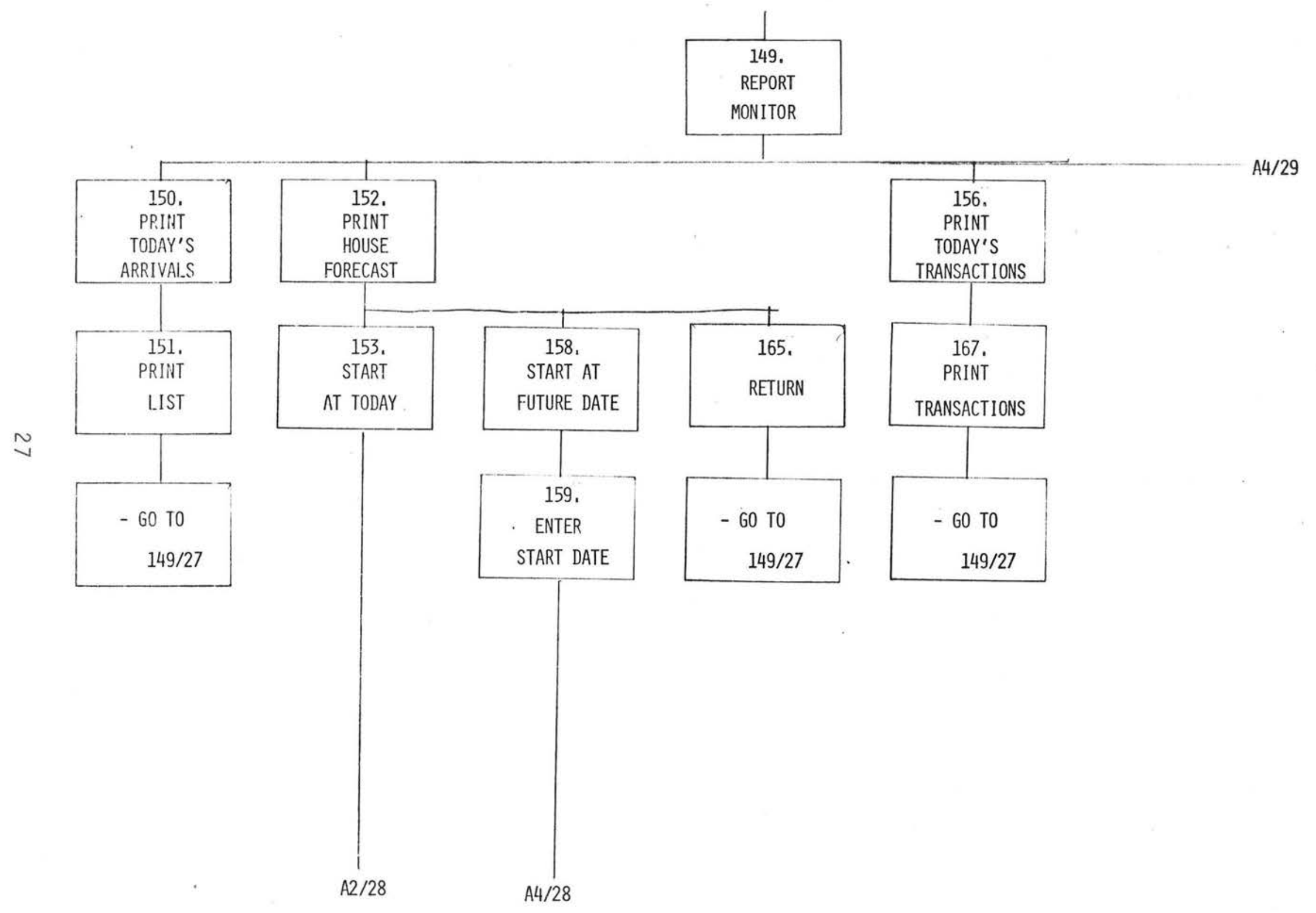



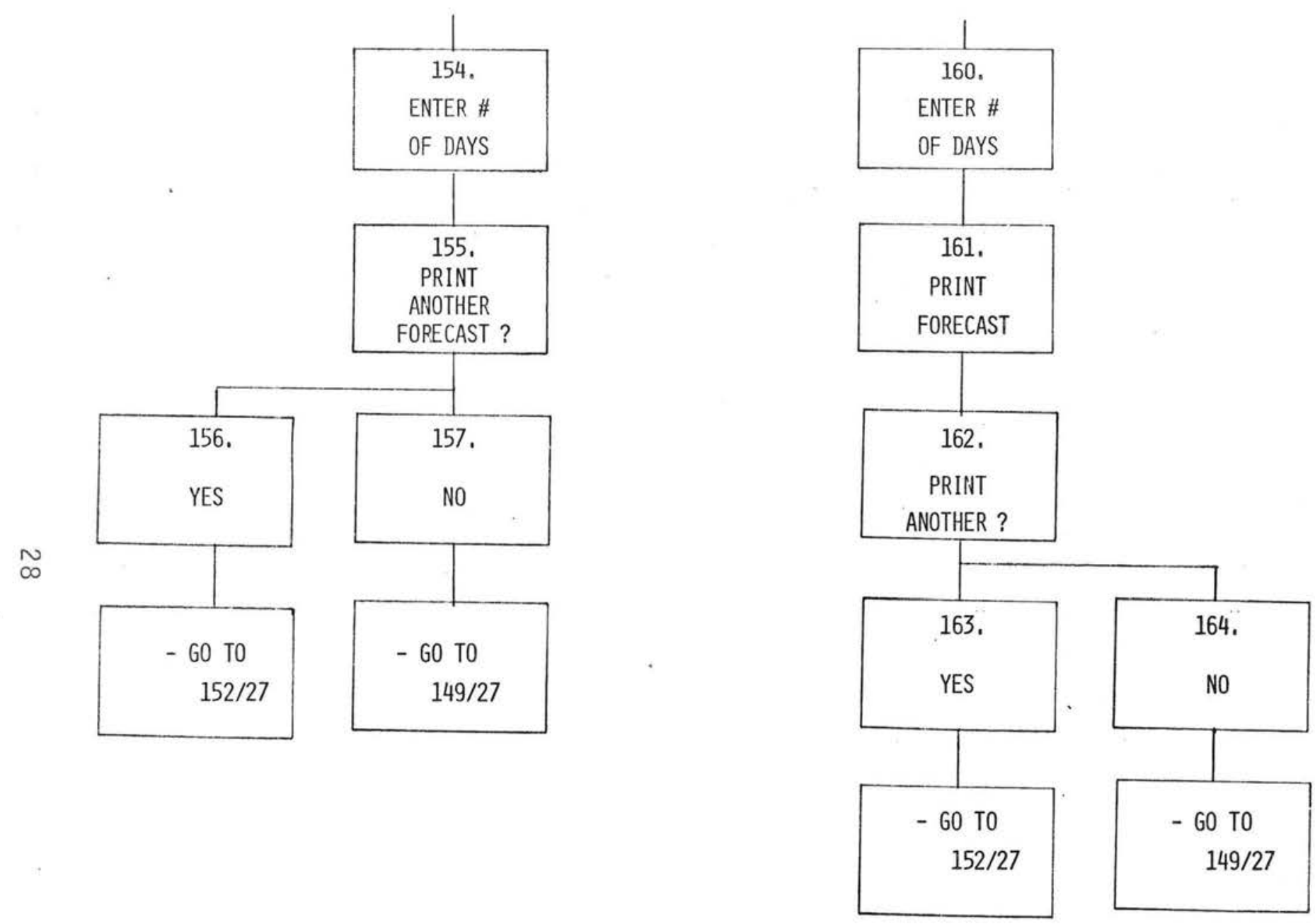


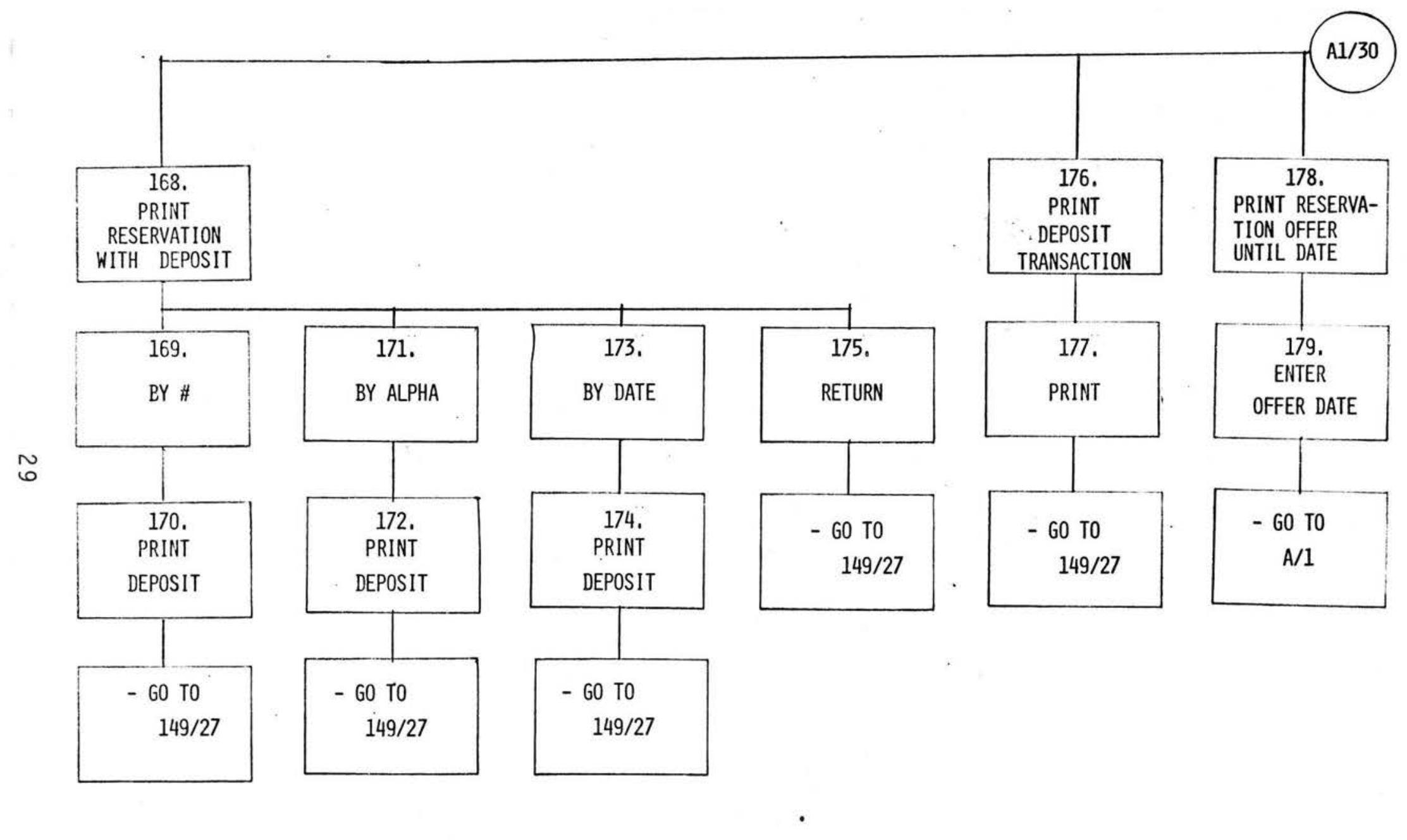




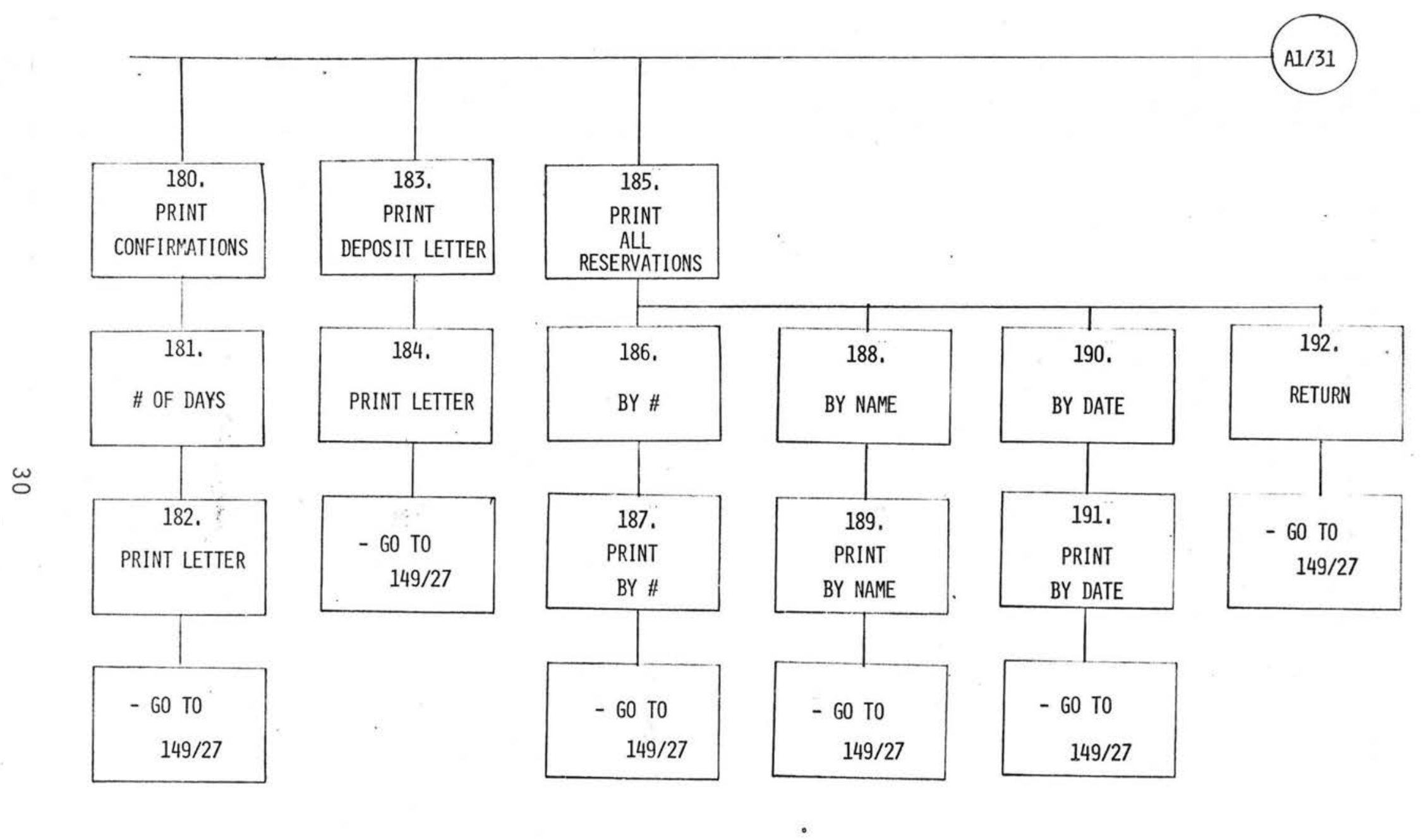




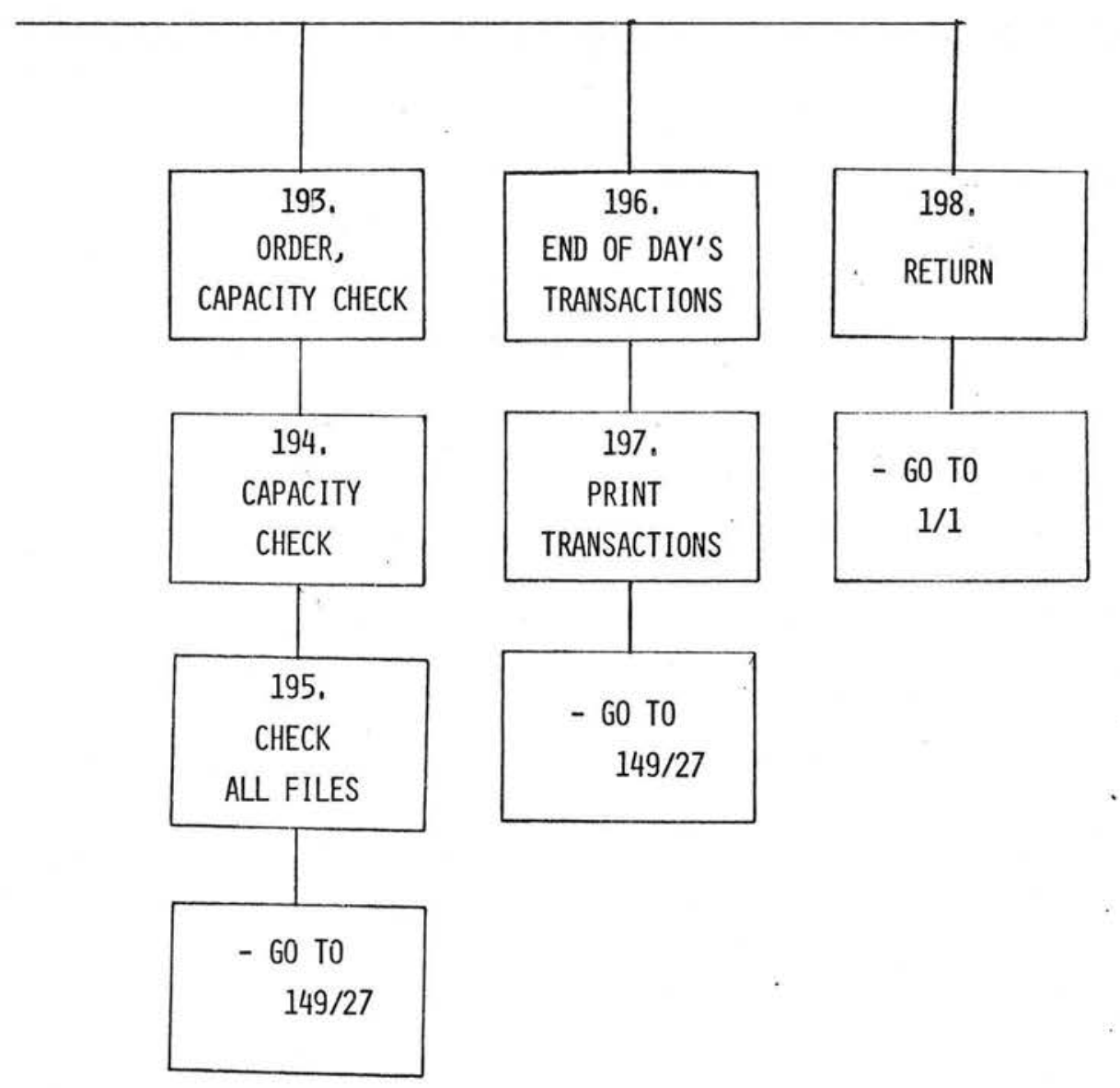




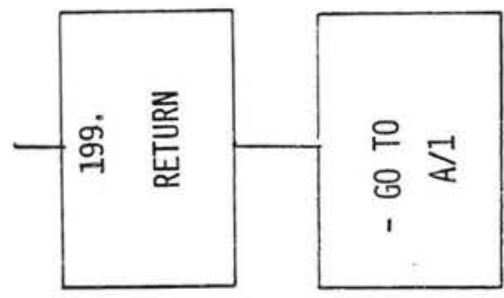




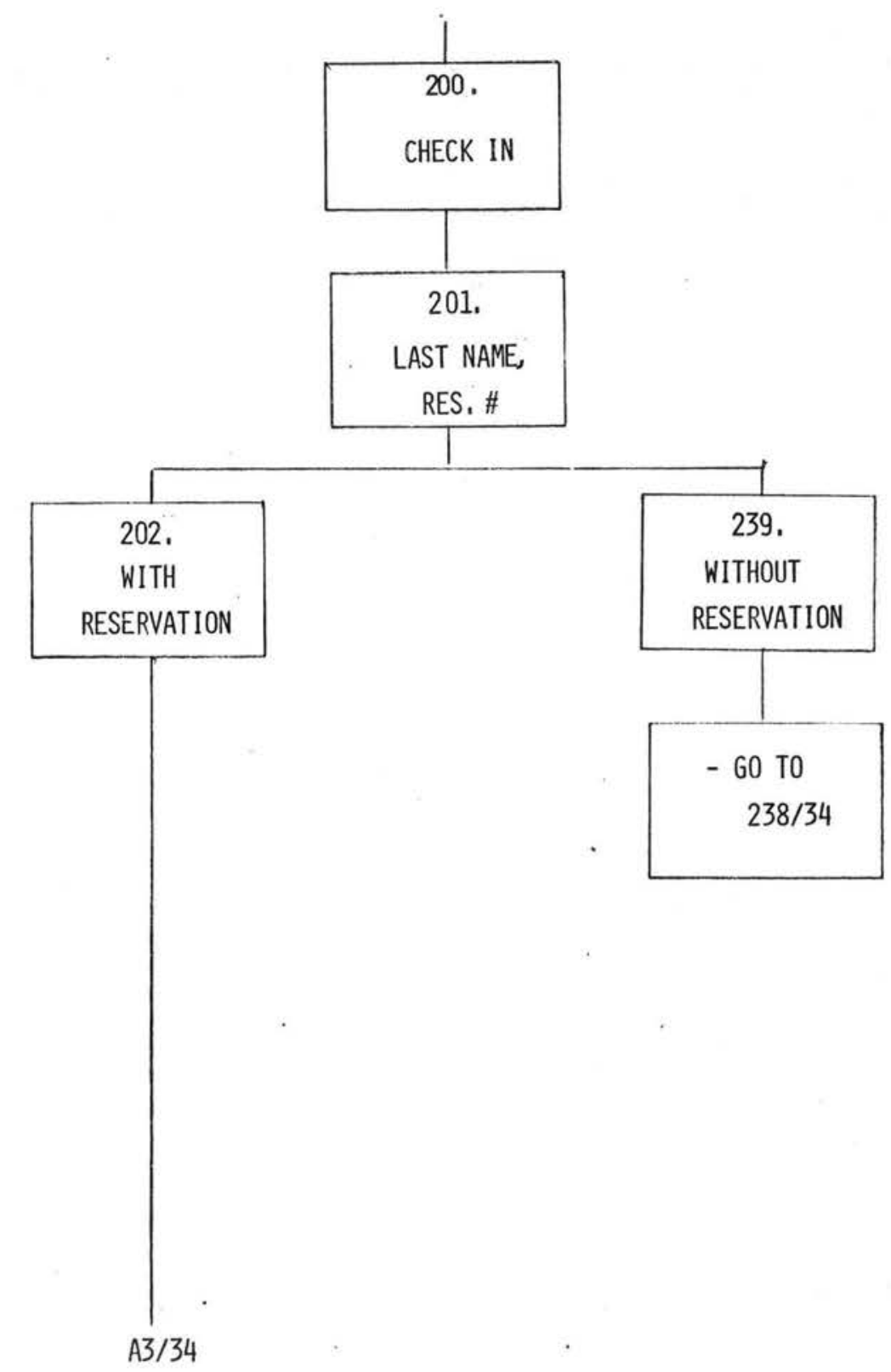




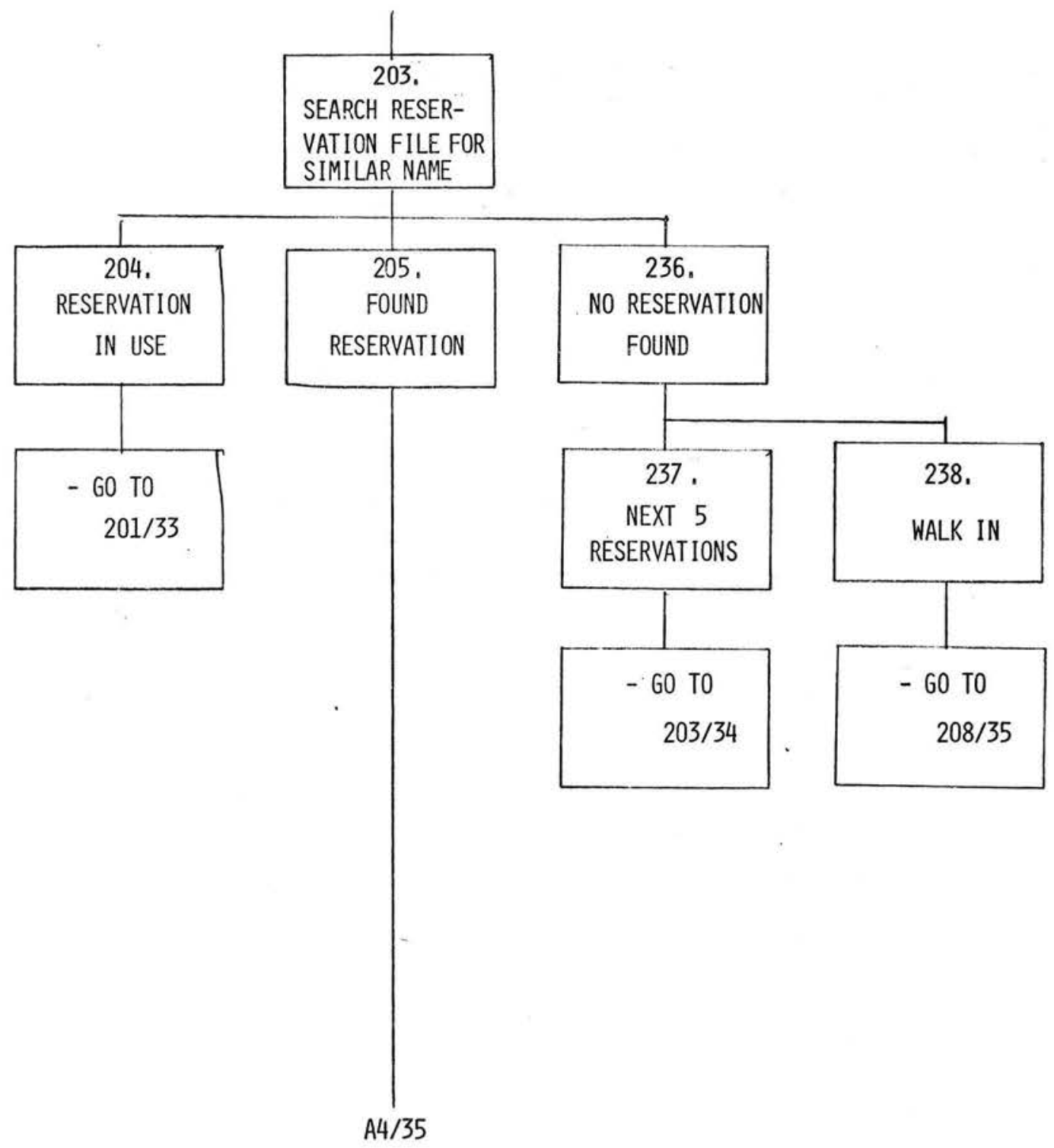




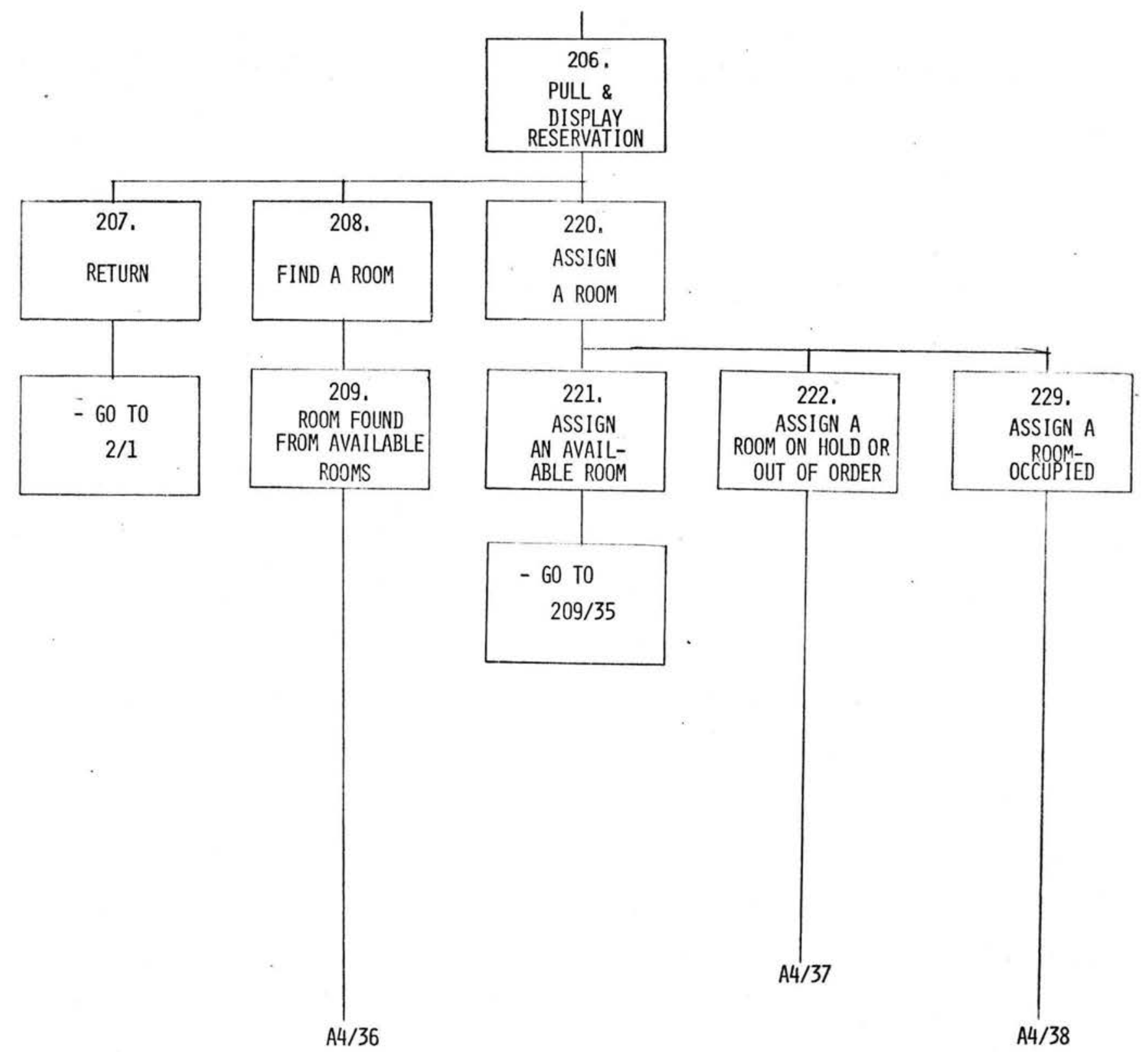




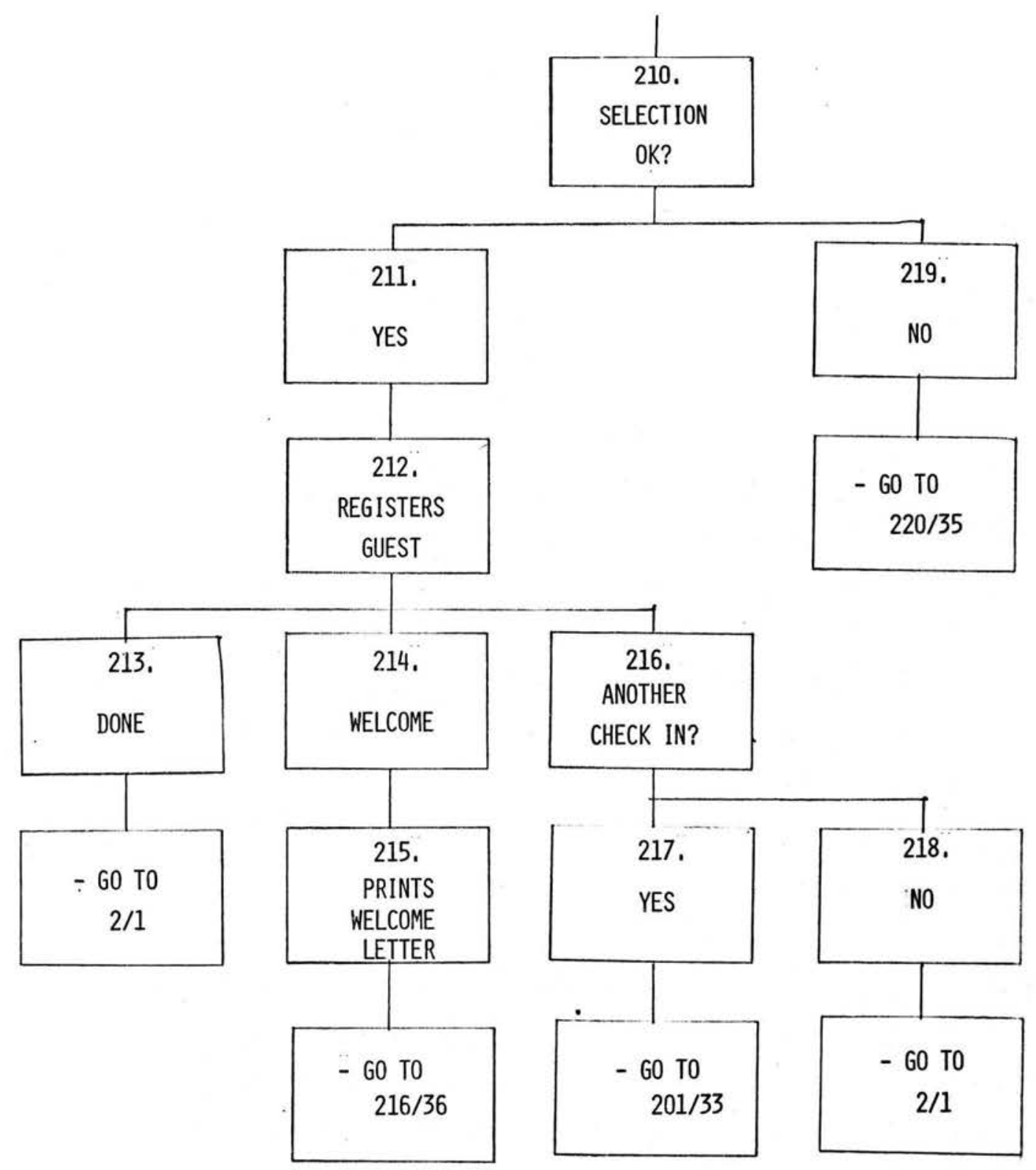




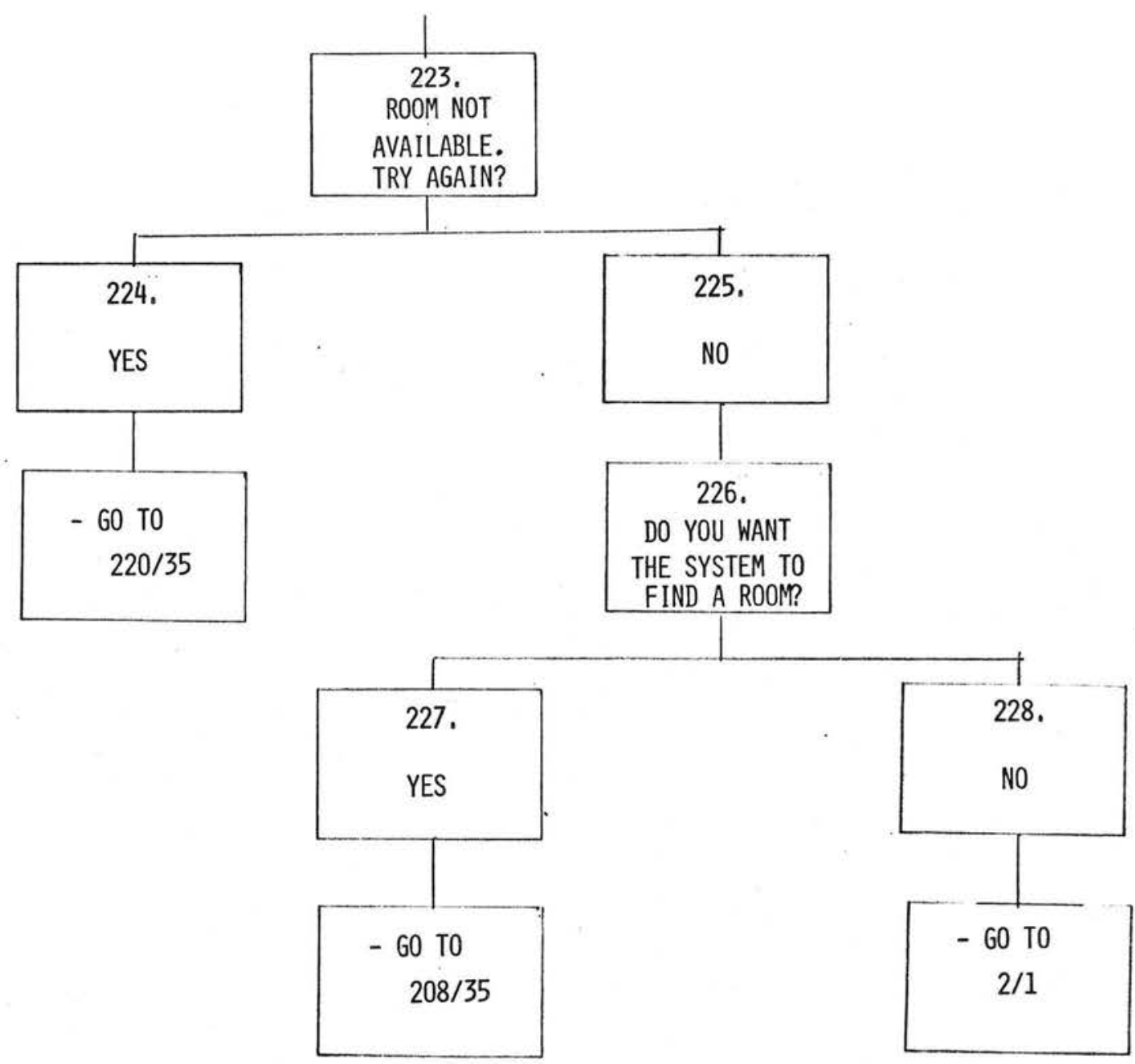




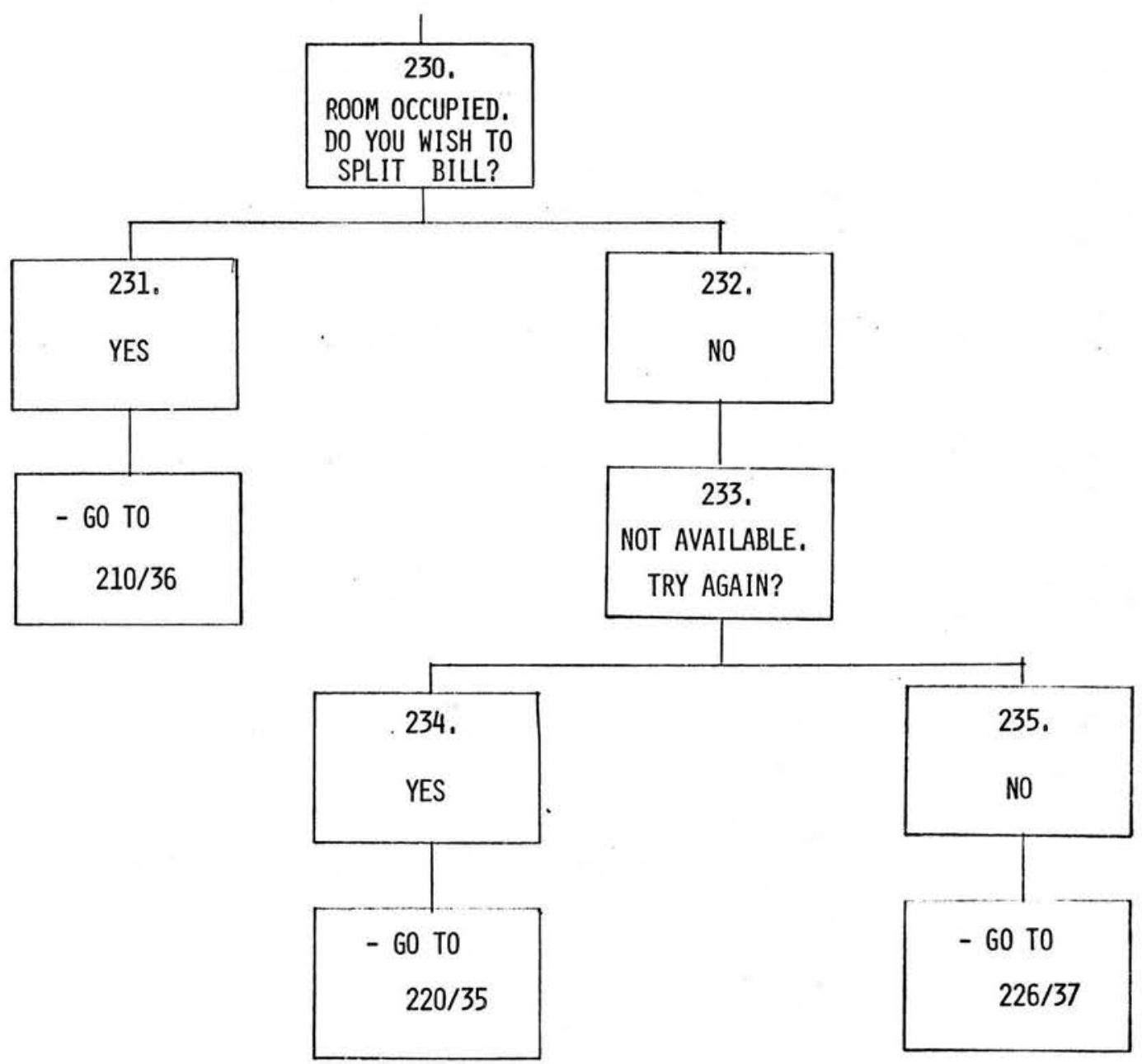




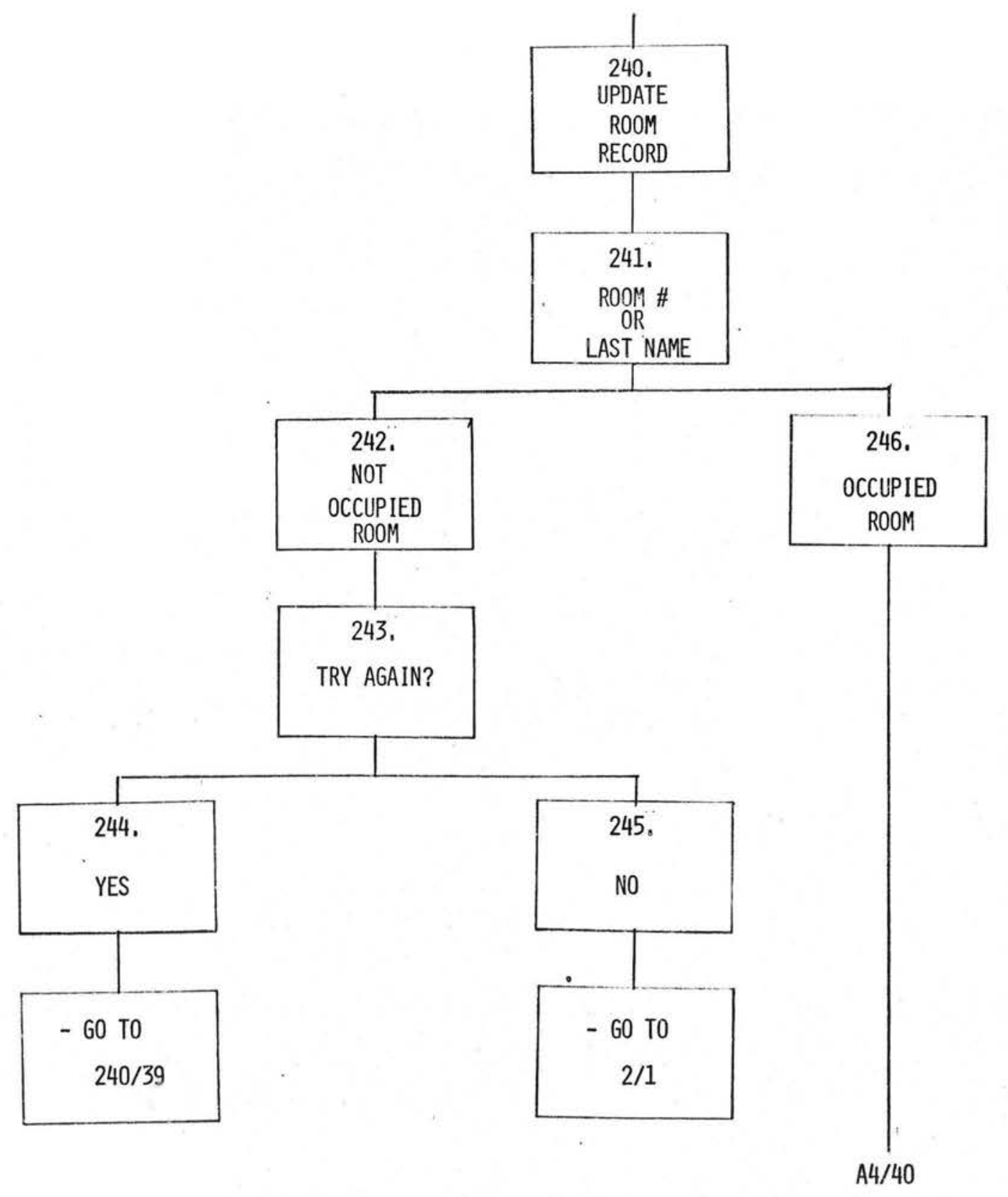




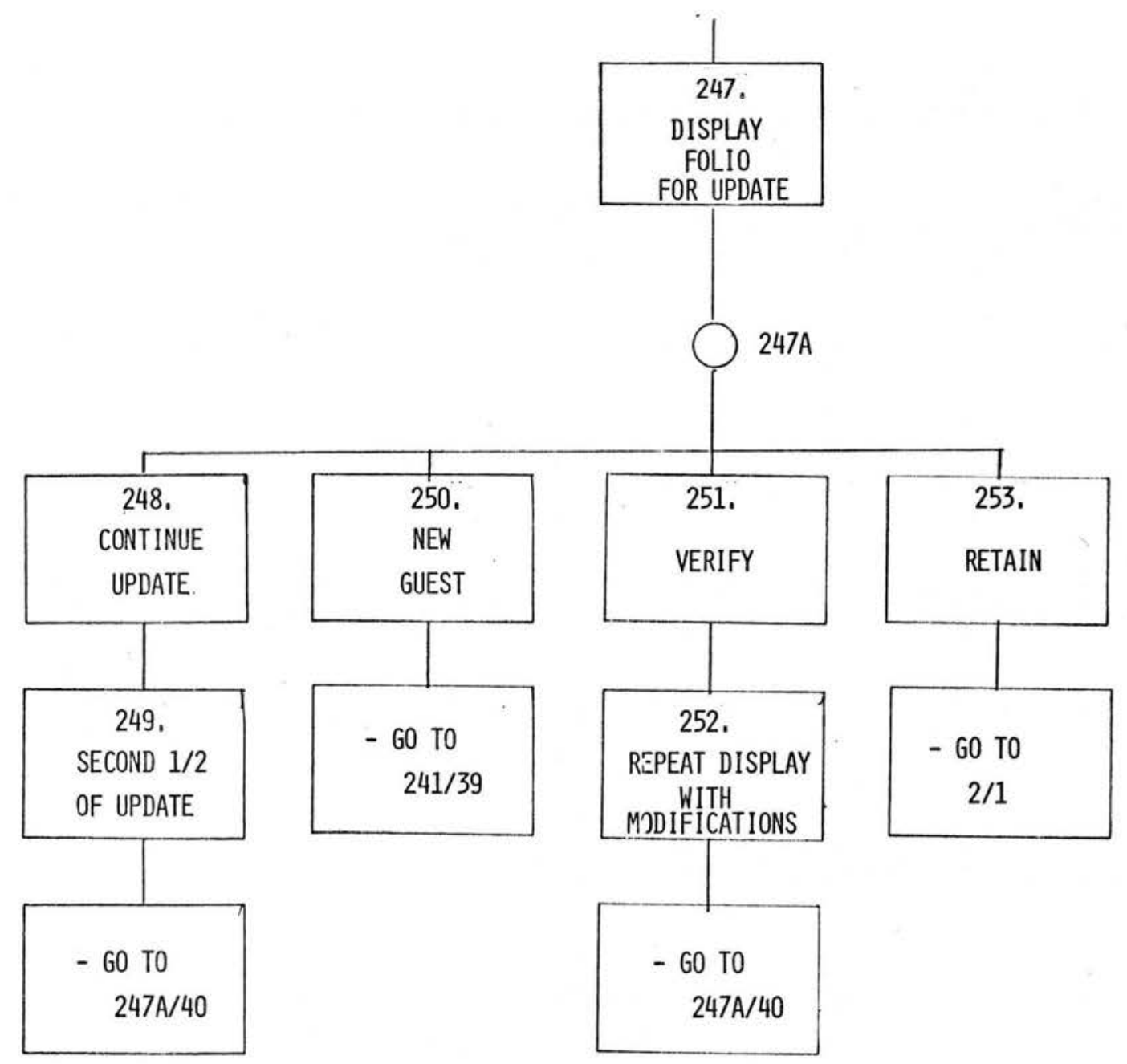




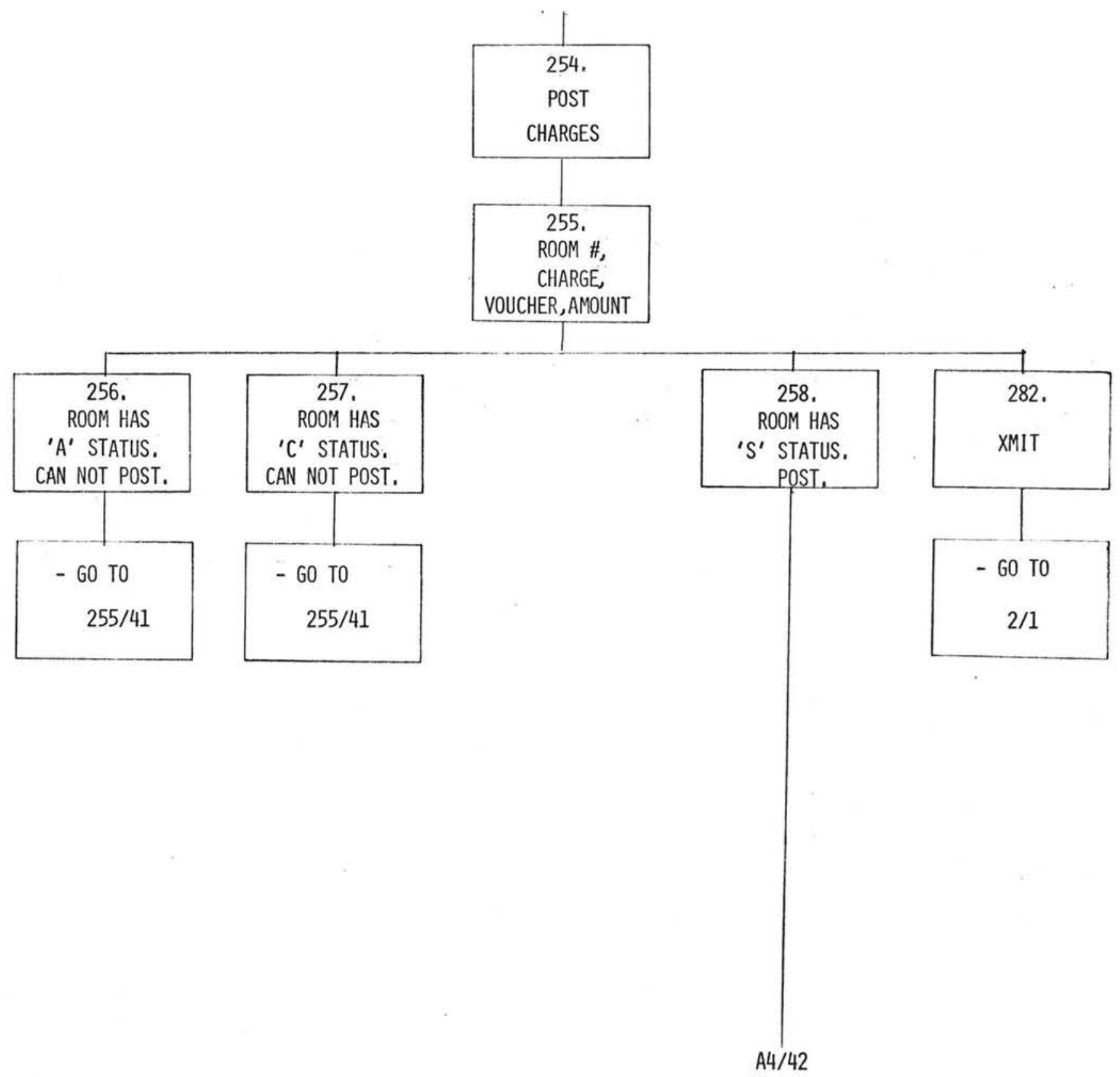




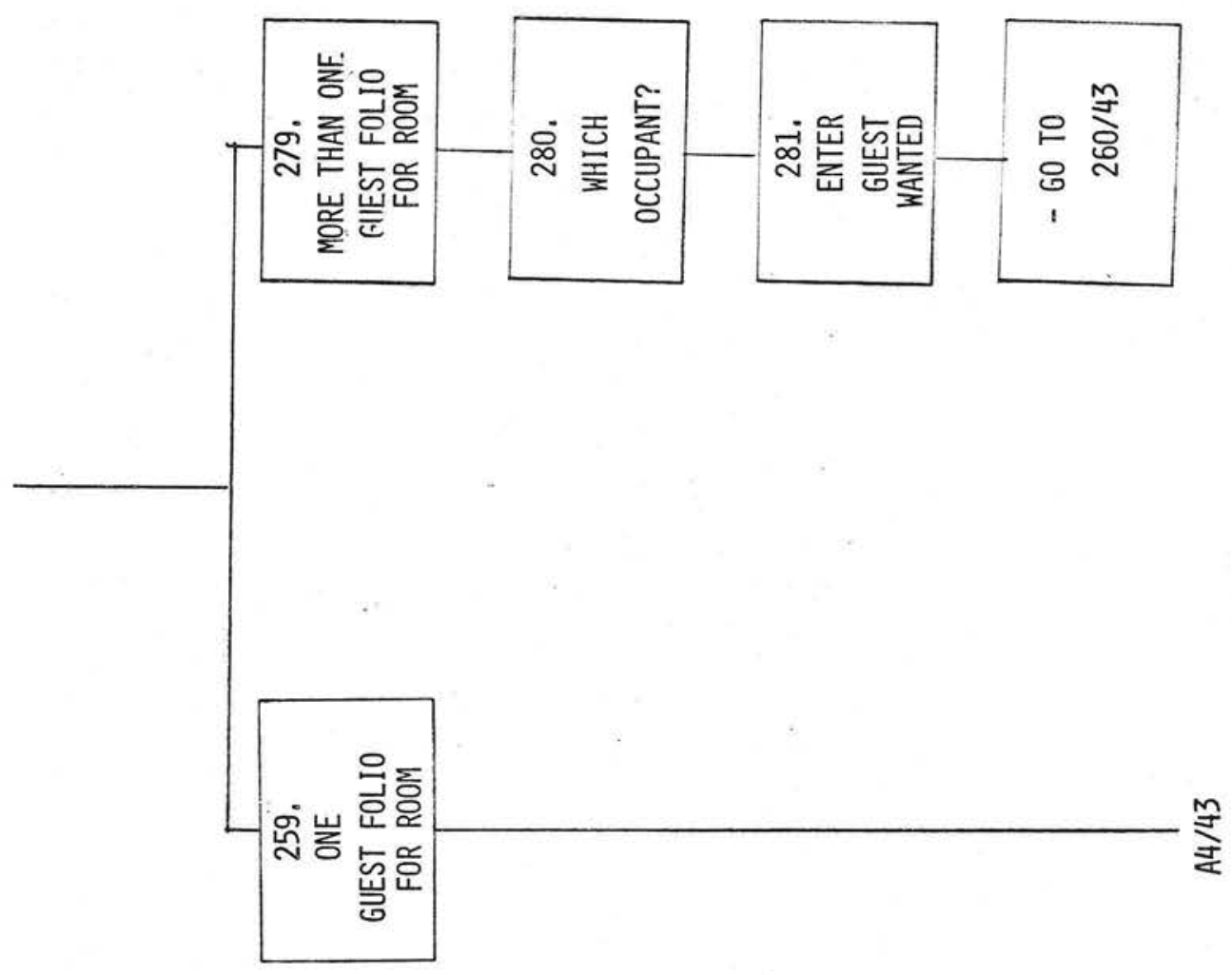




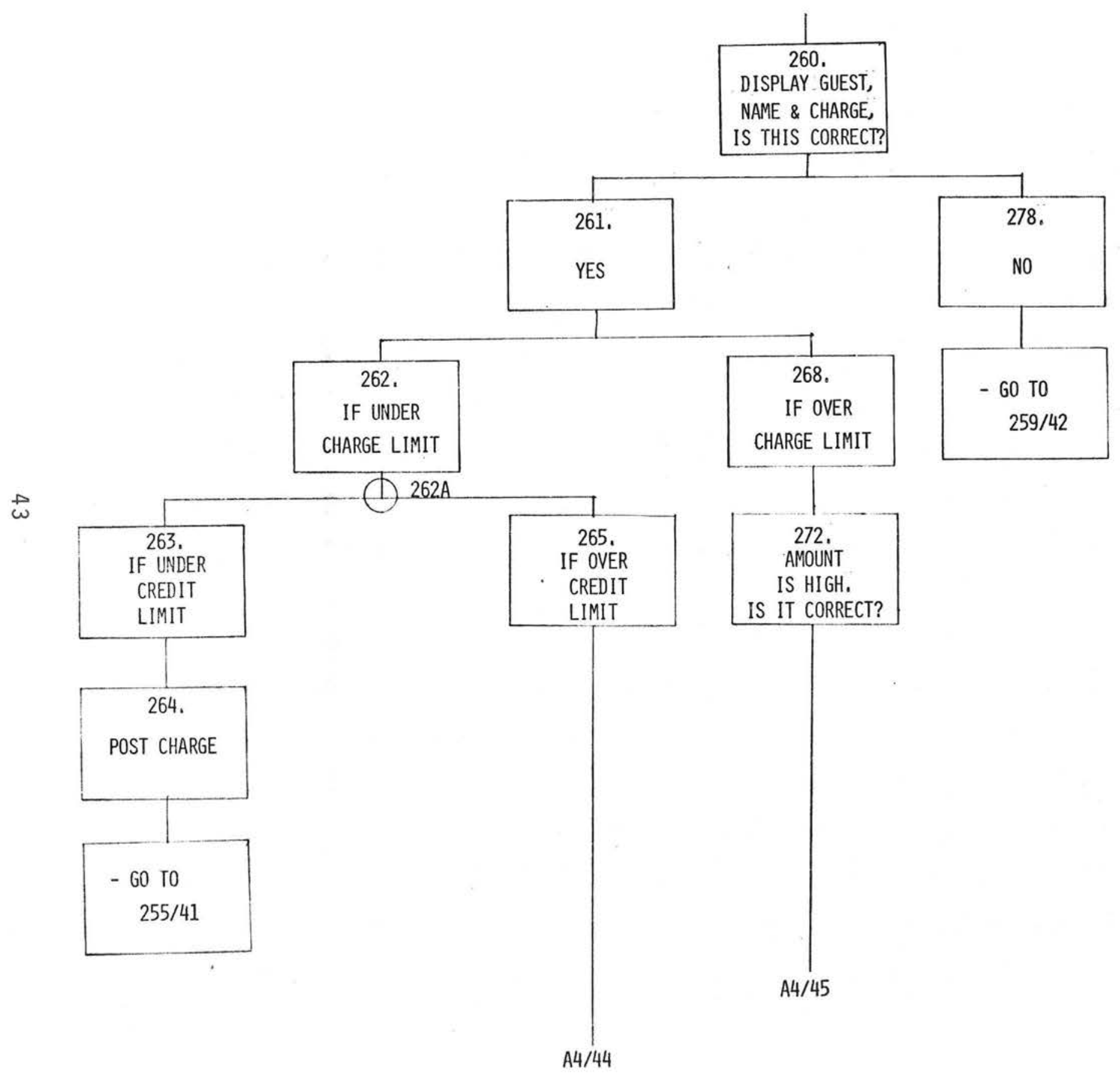




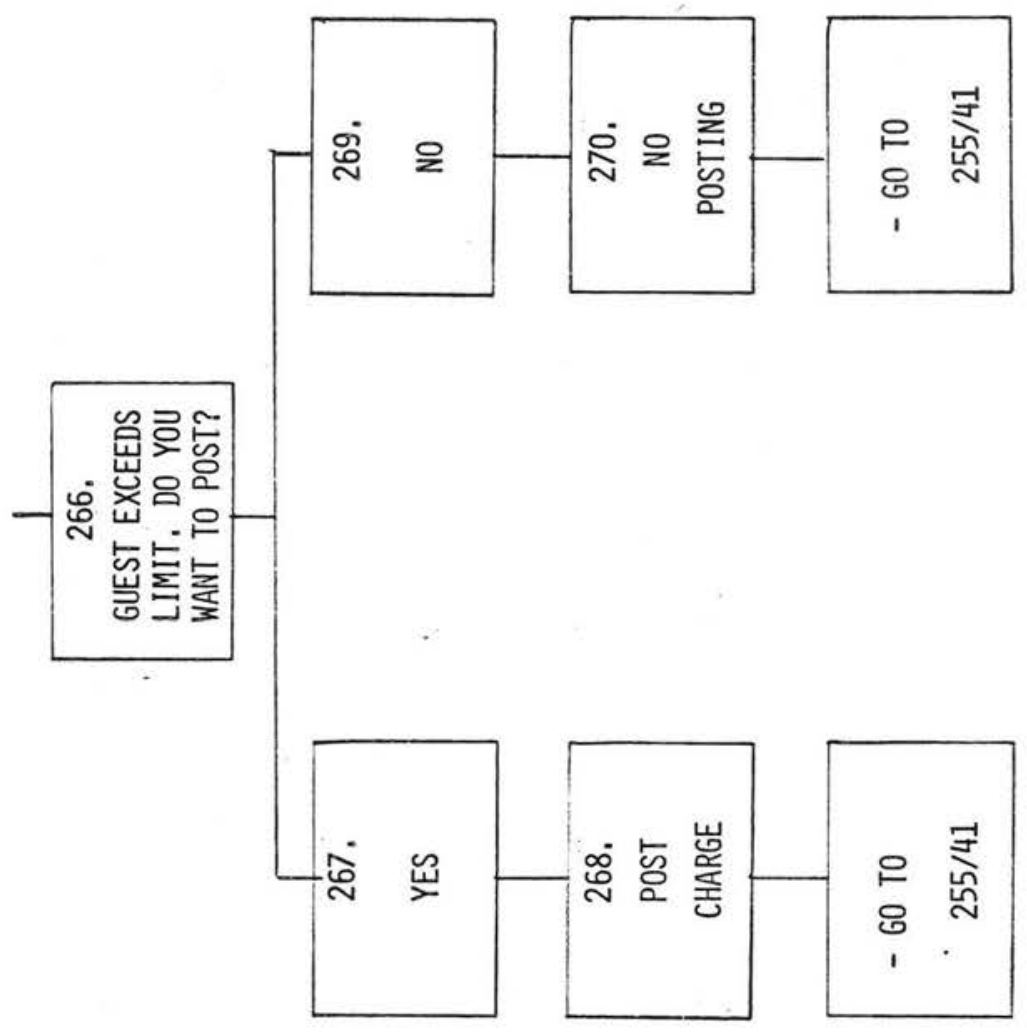




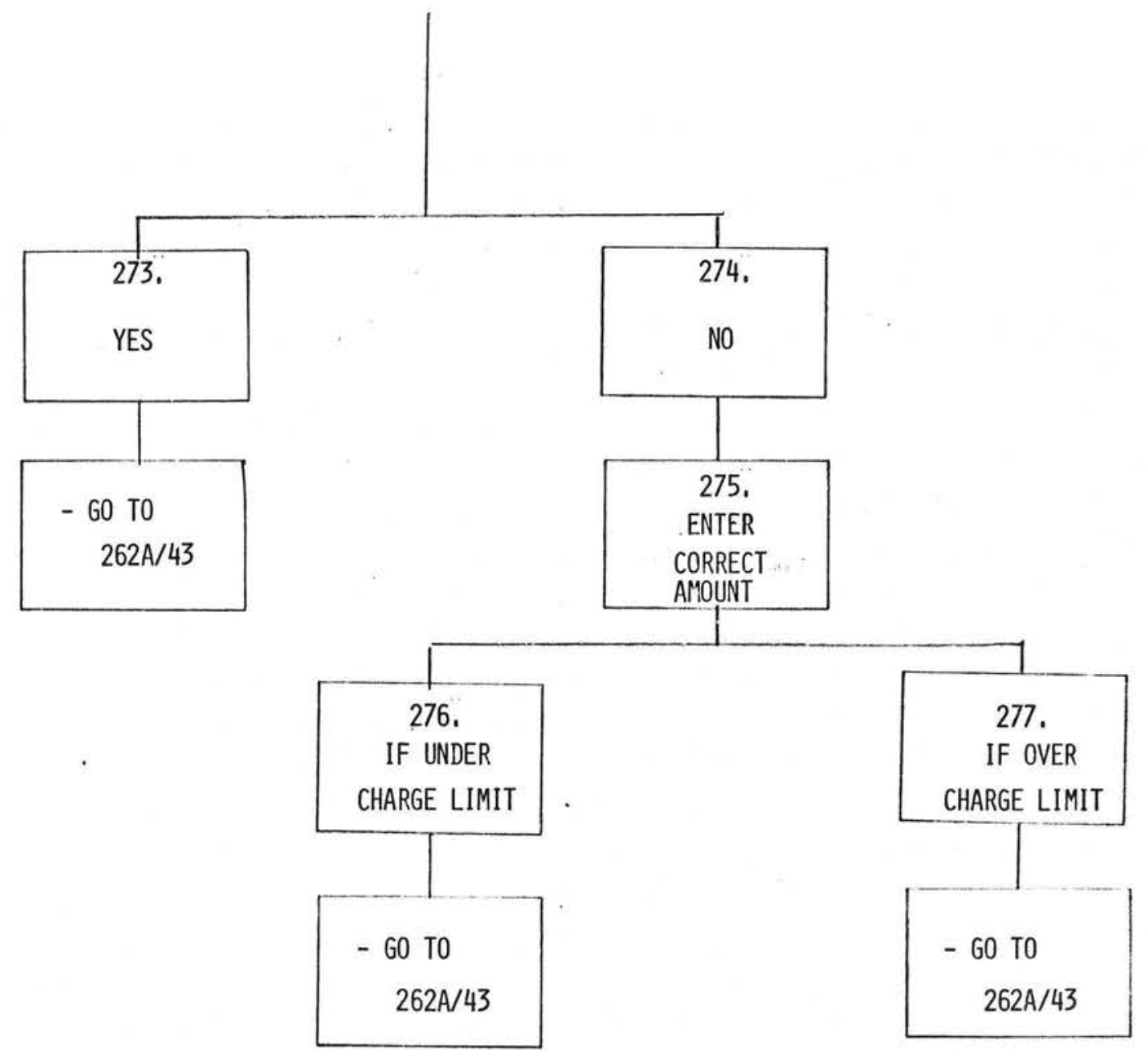




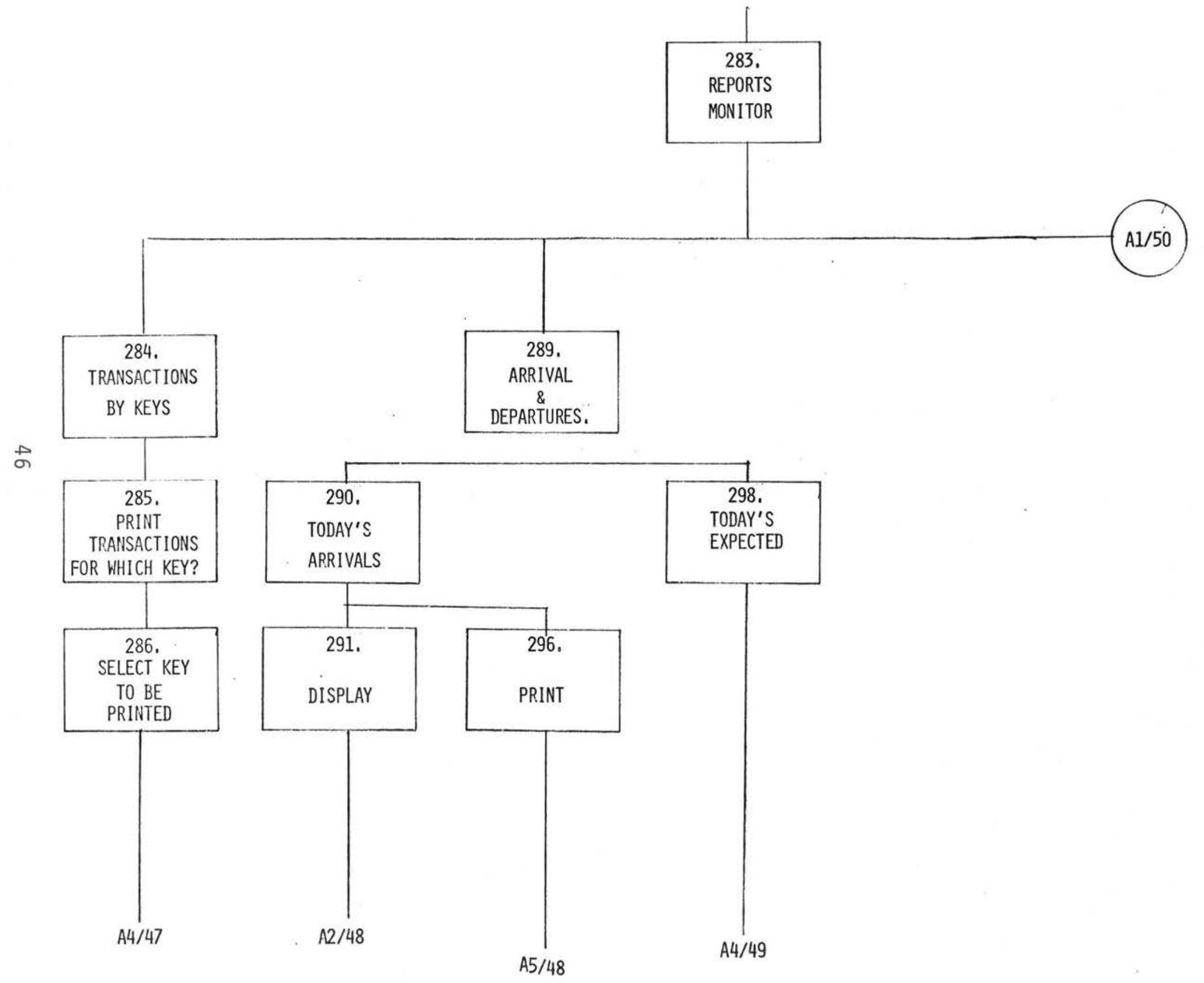




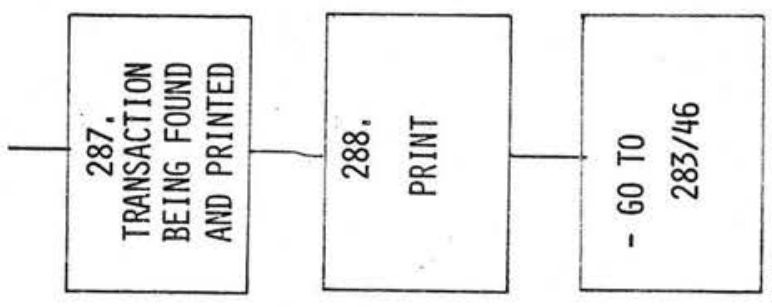



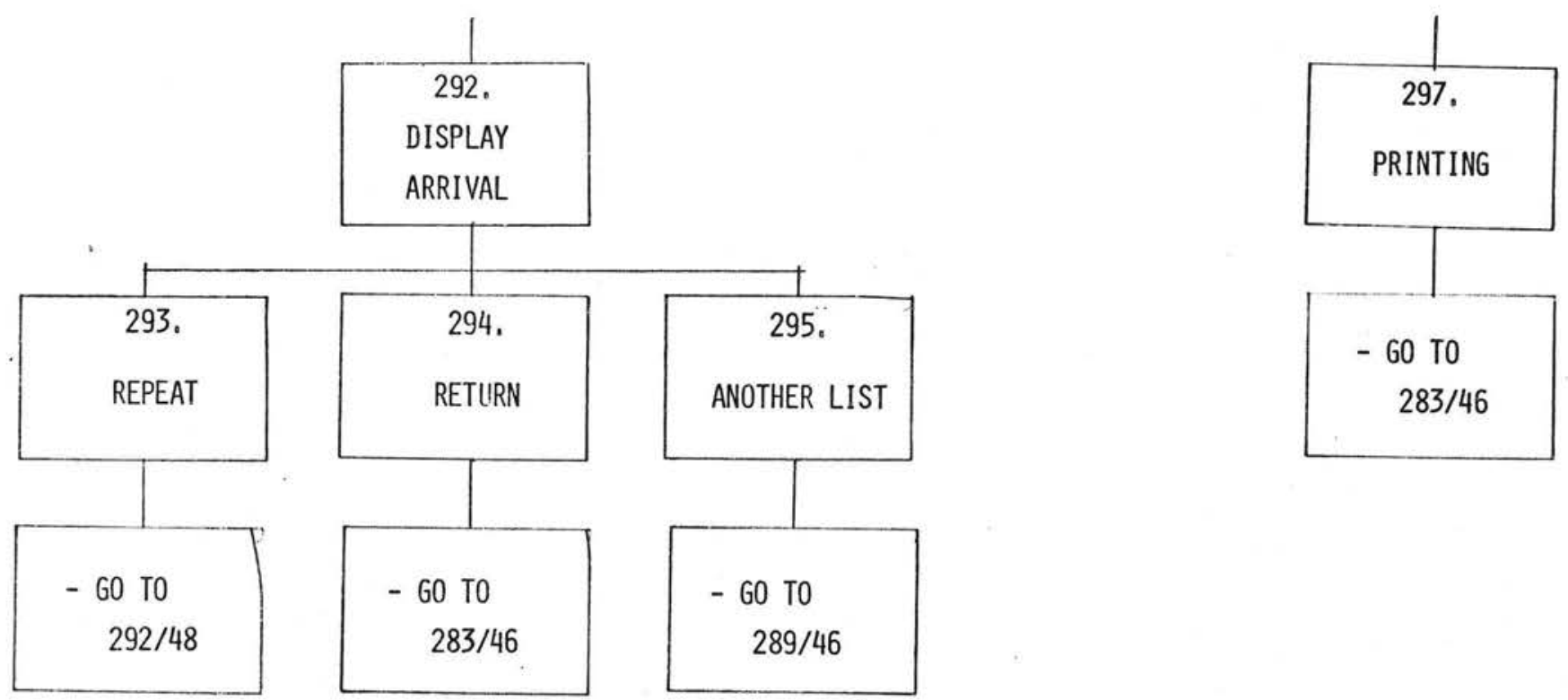

$\stackrel{\infty}{\infty}$ 


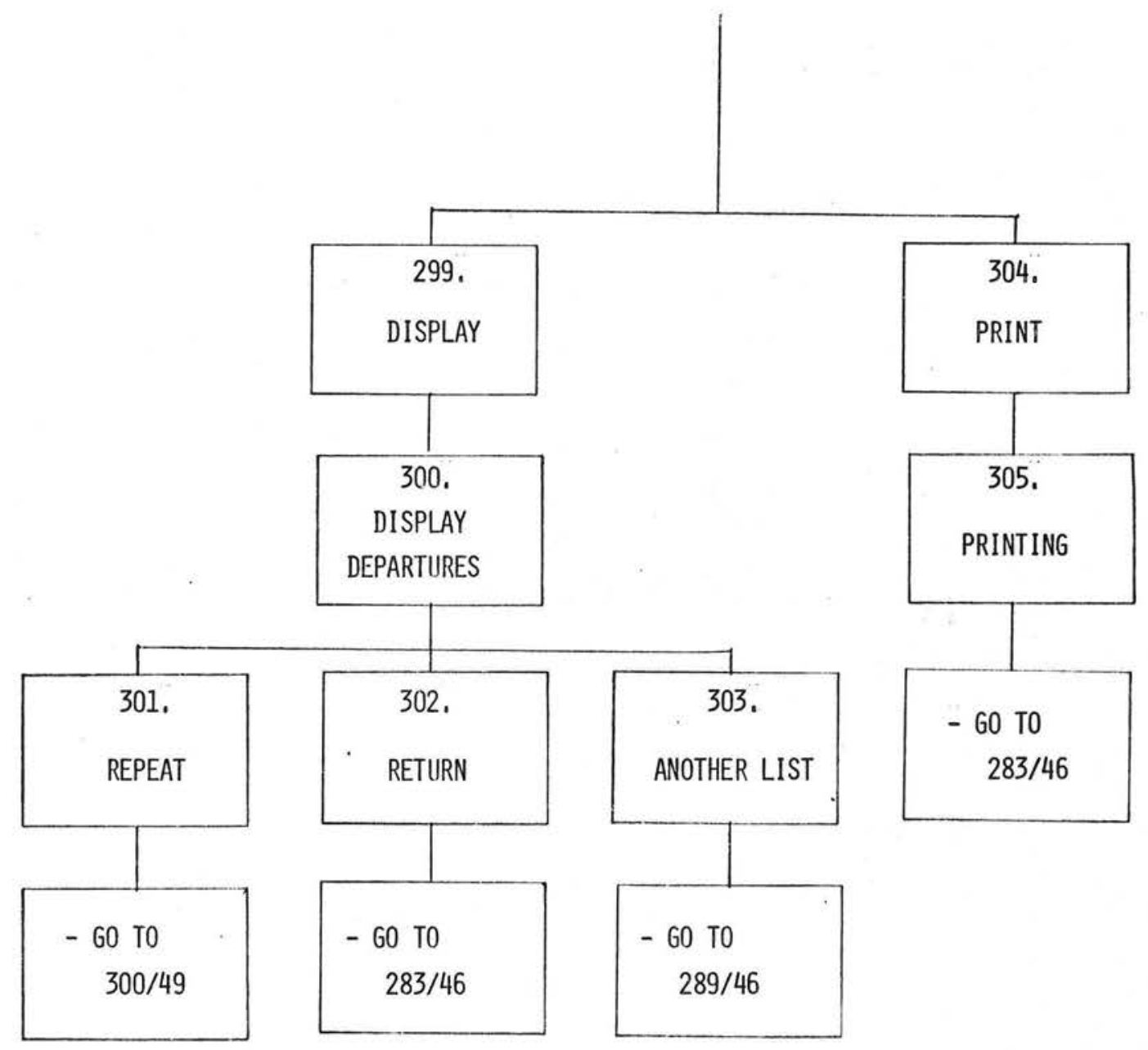




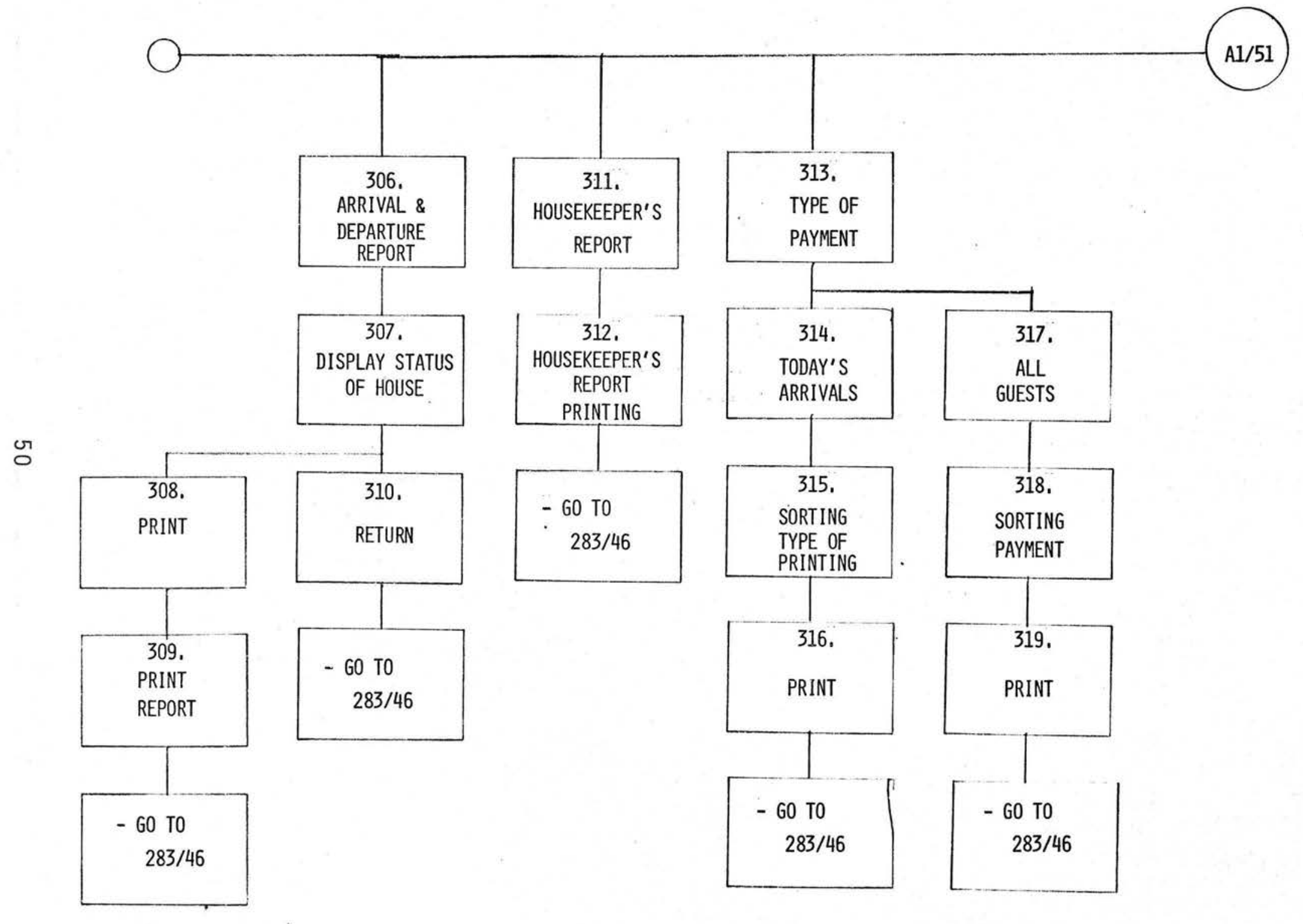




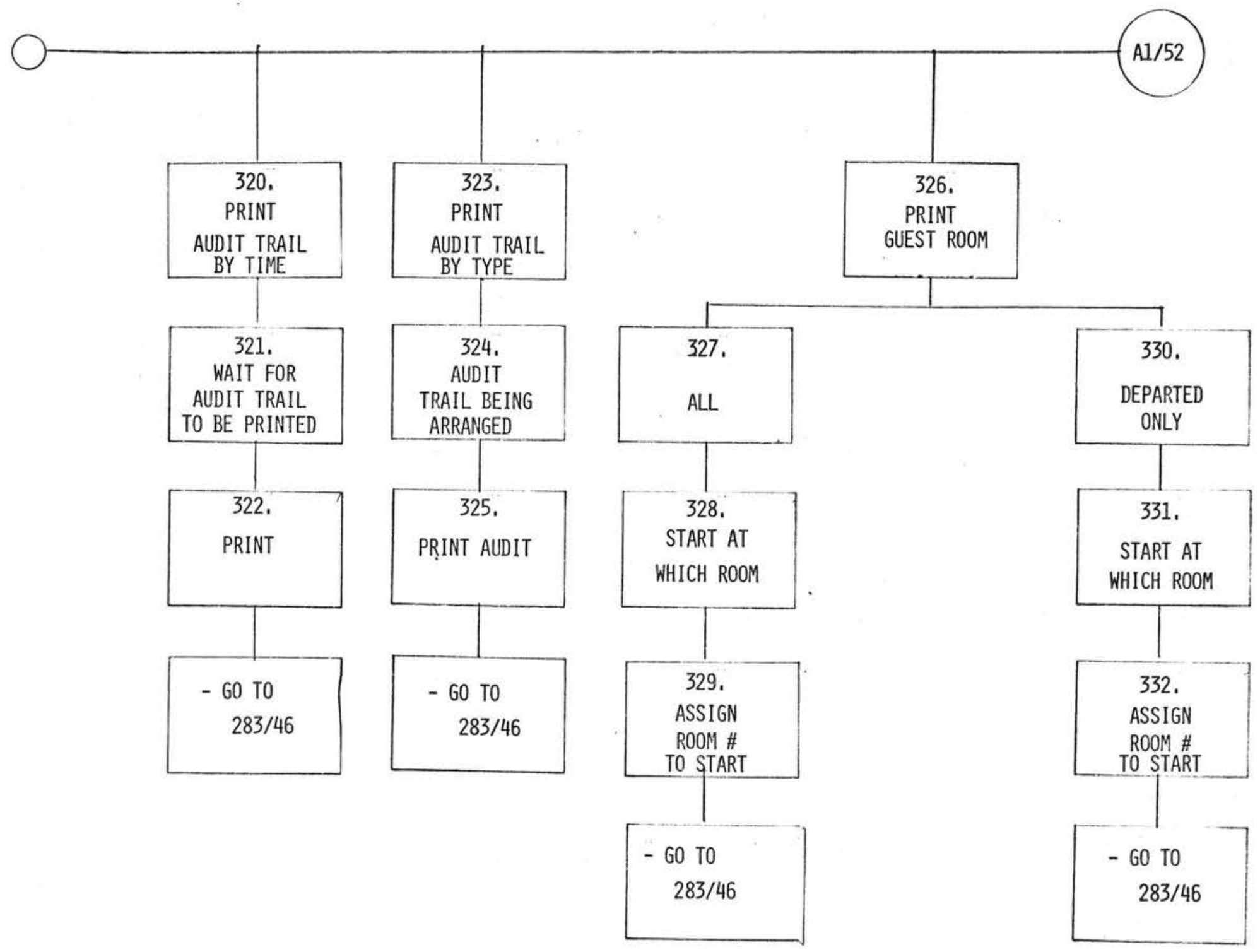




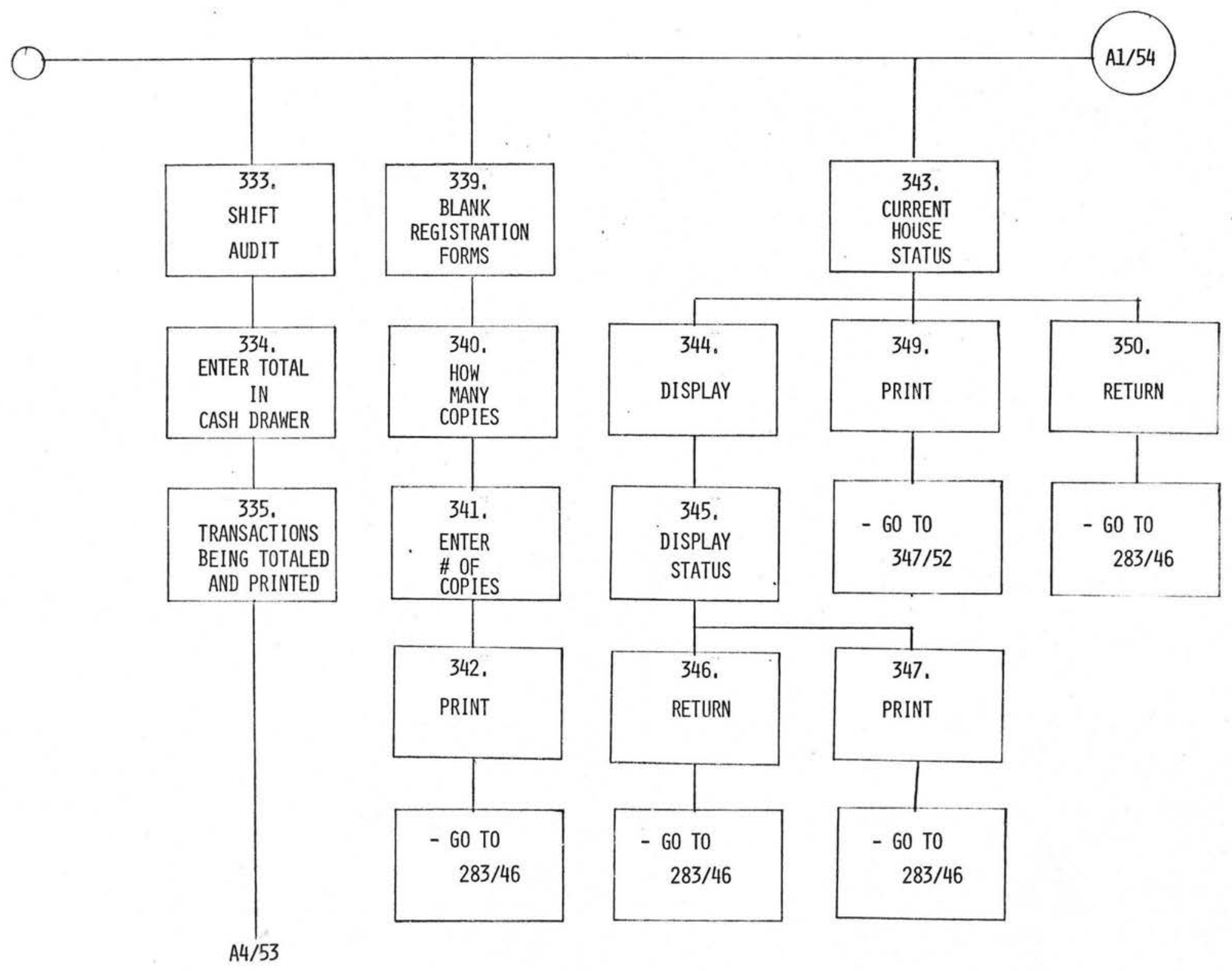




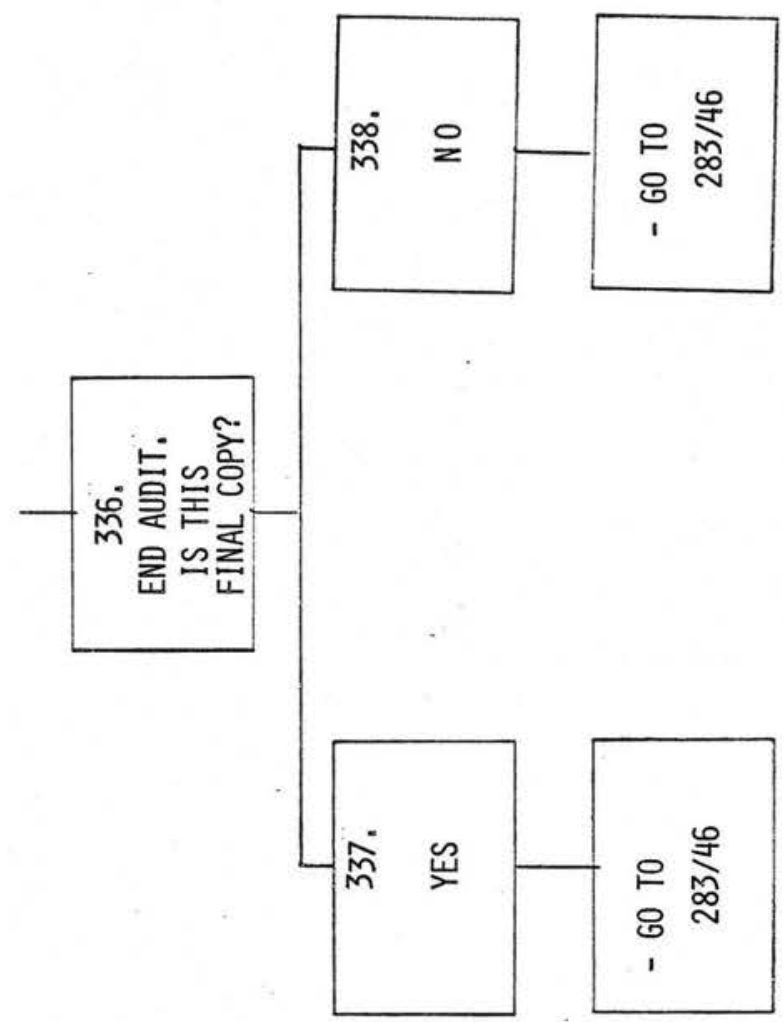




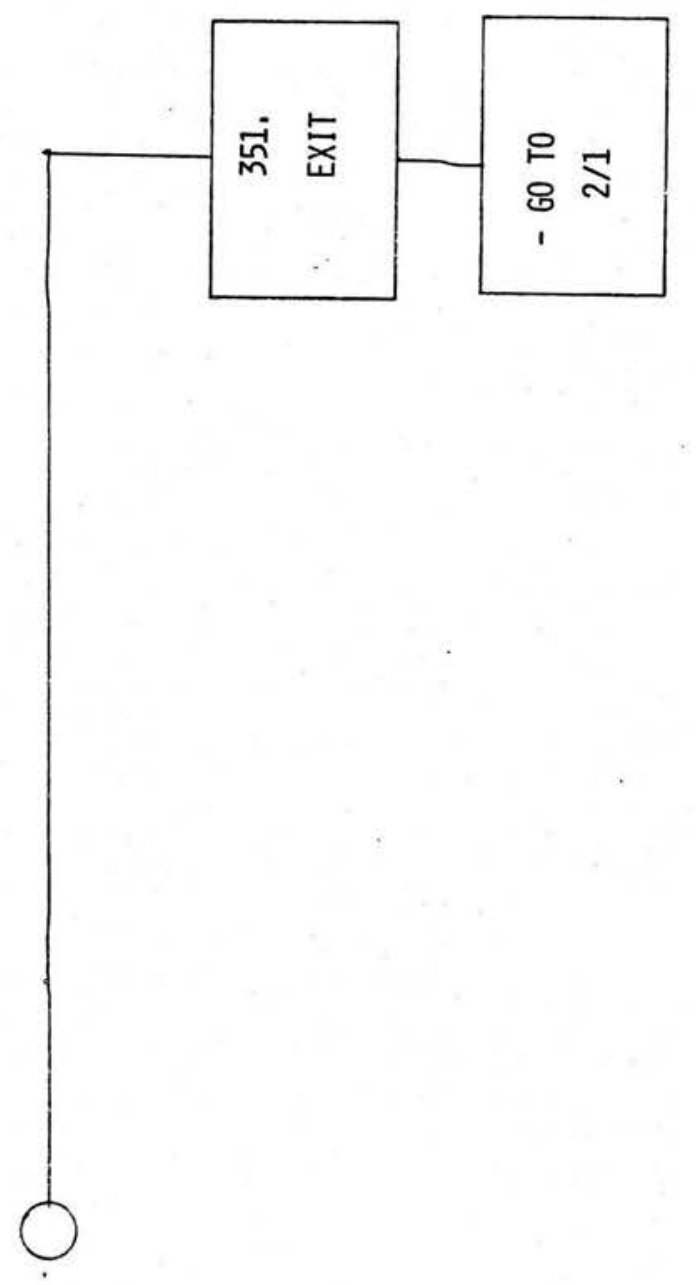




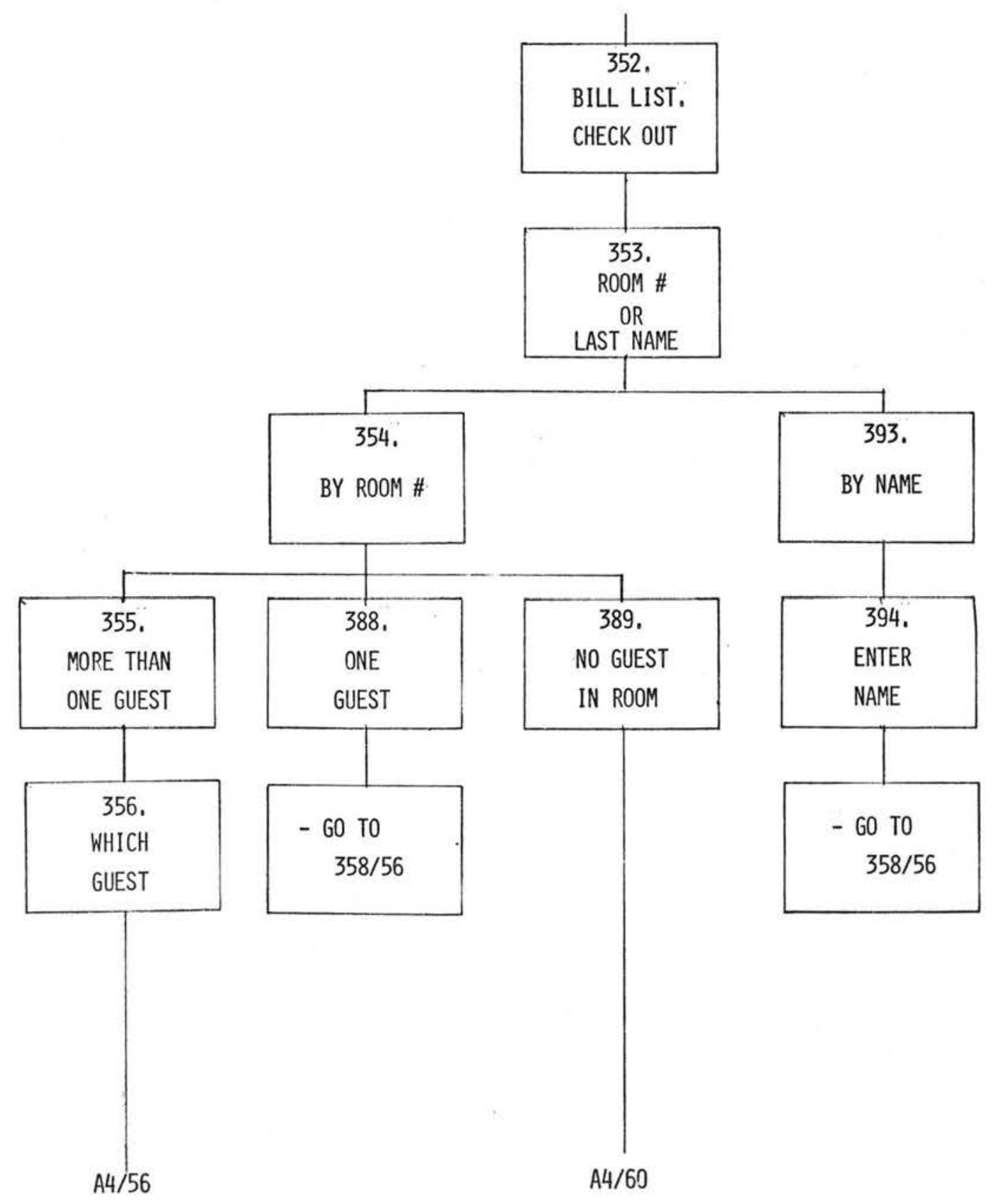




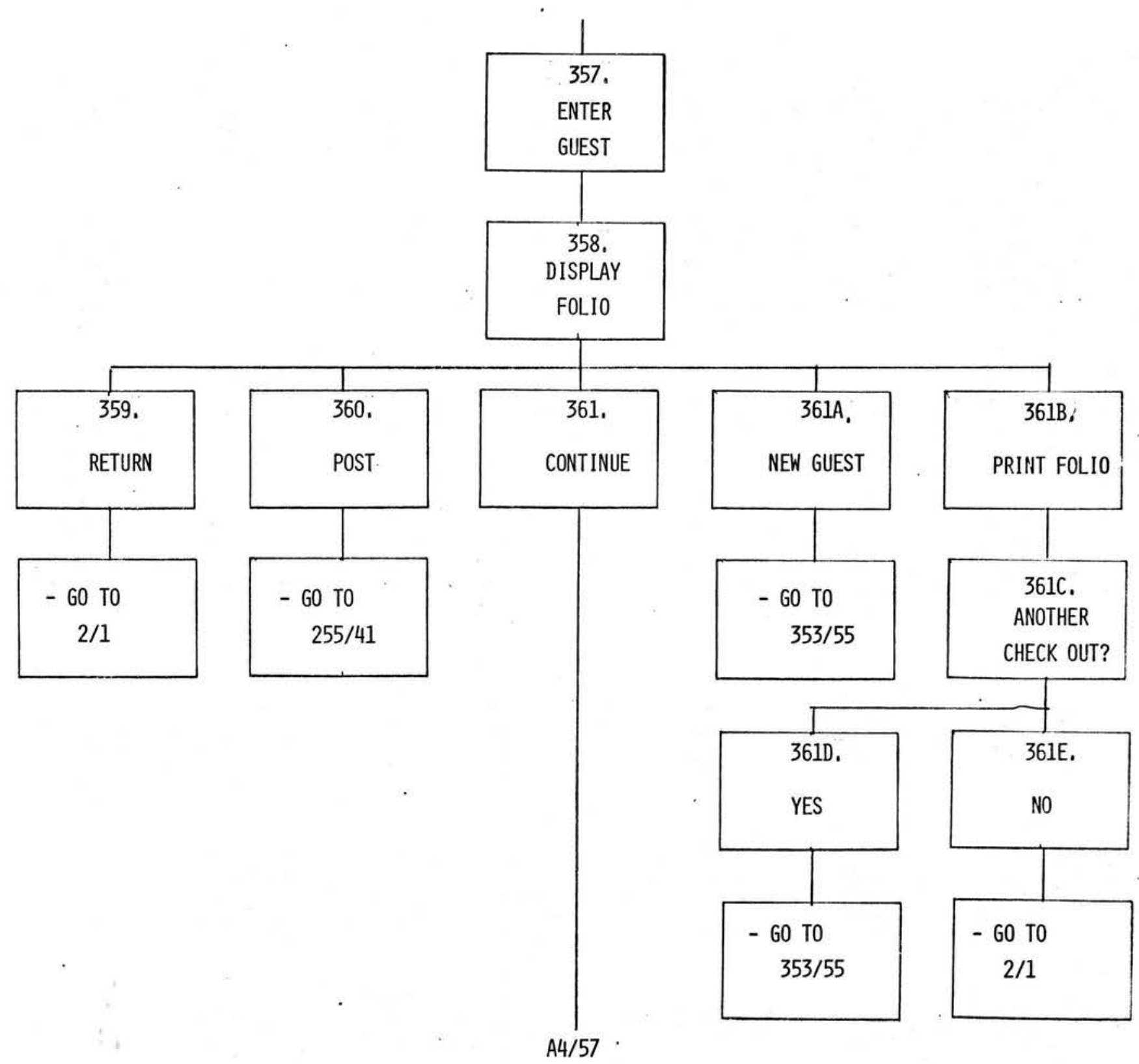




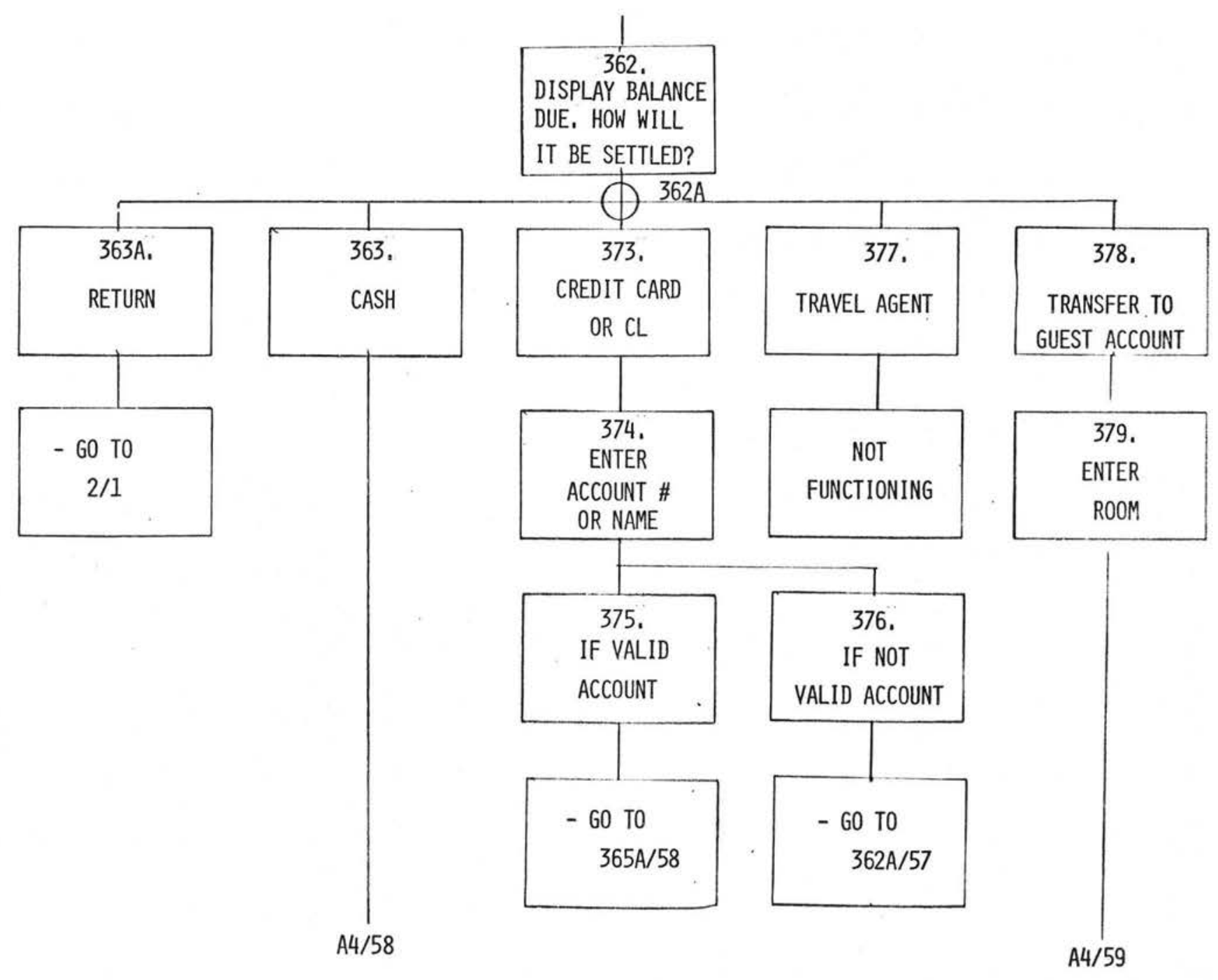




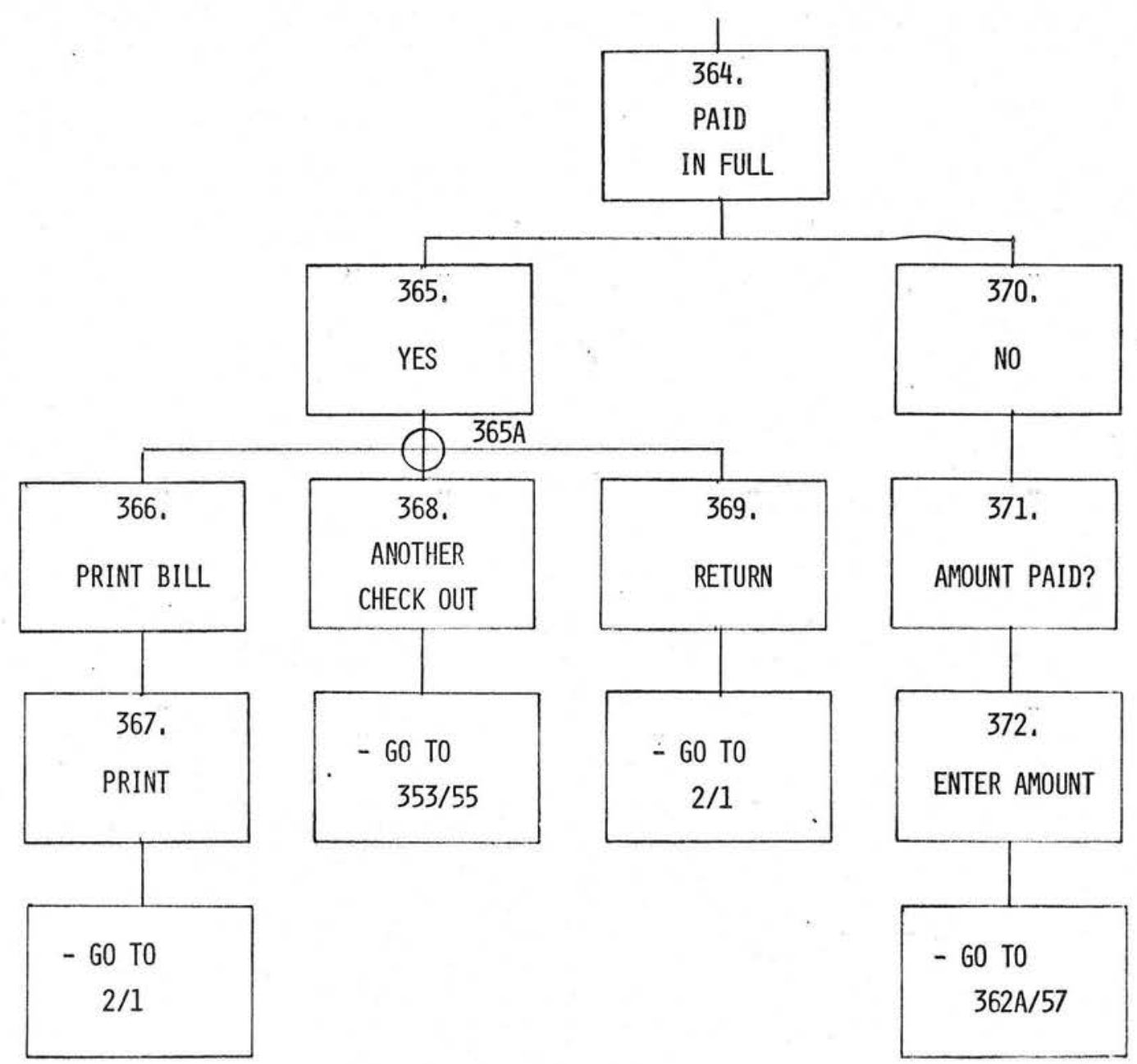




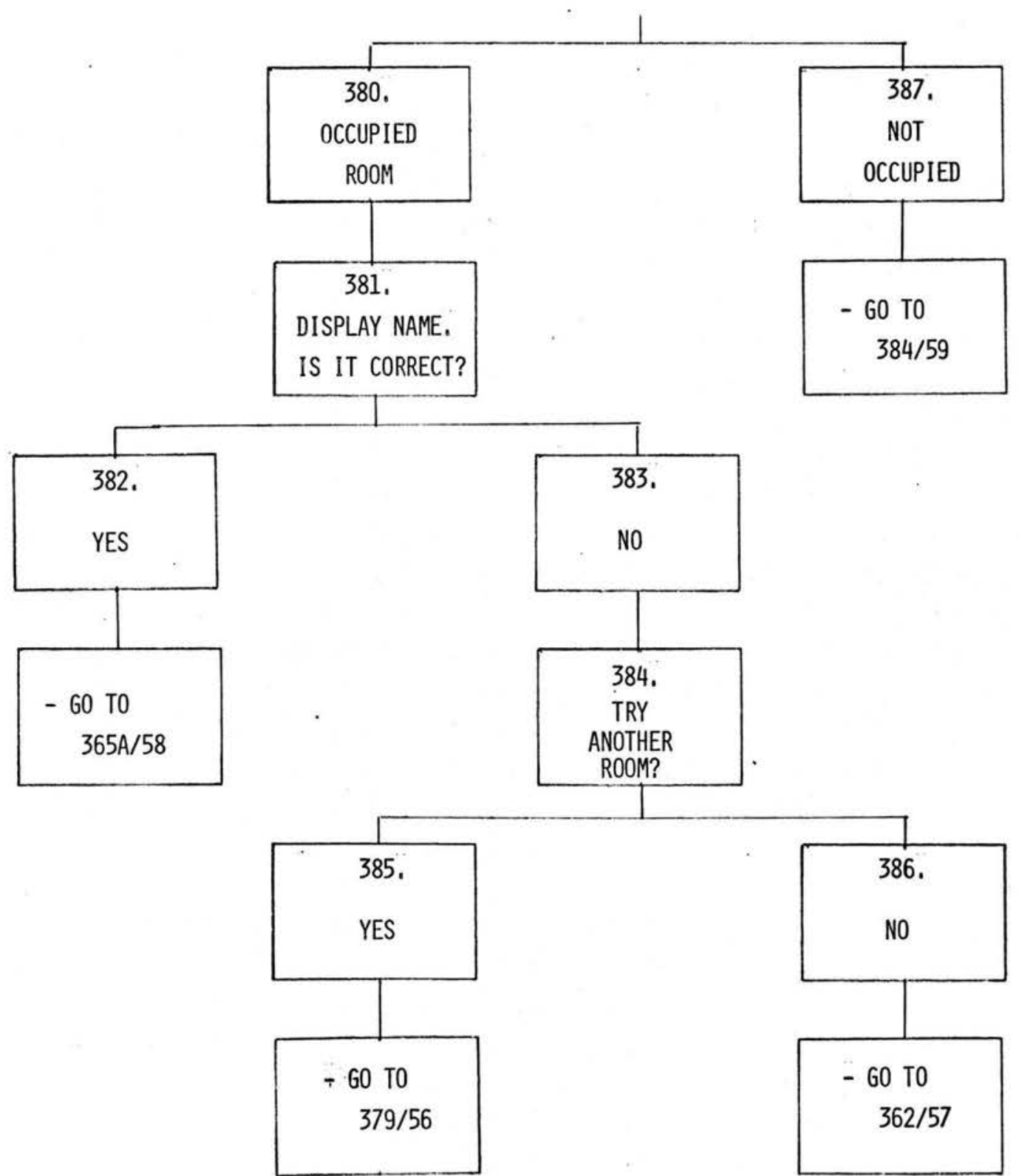




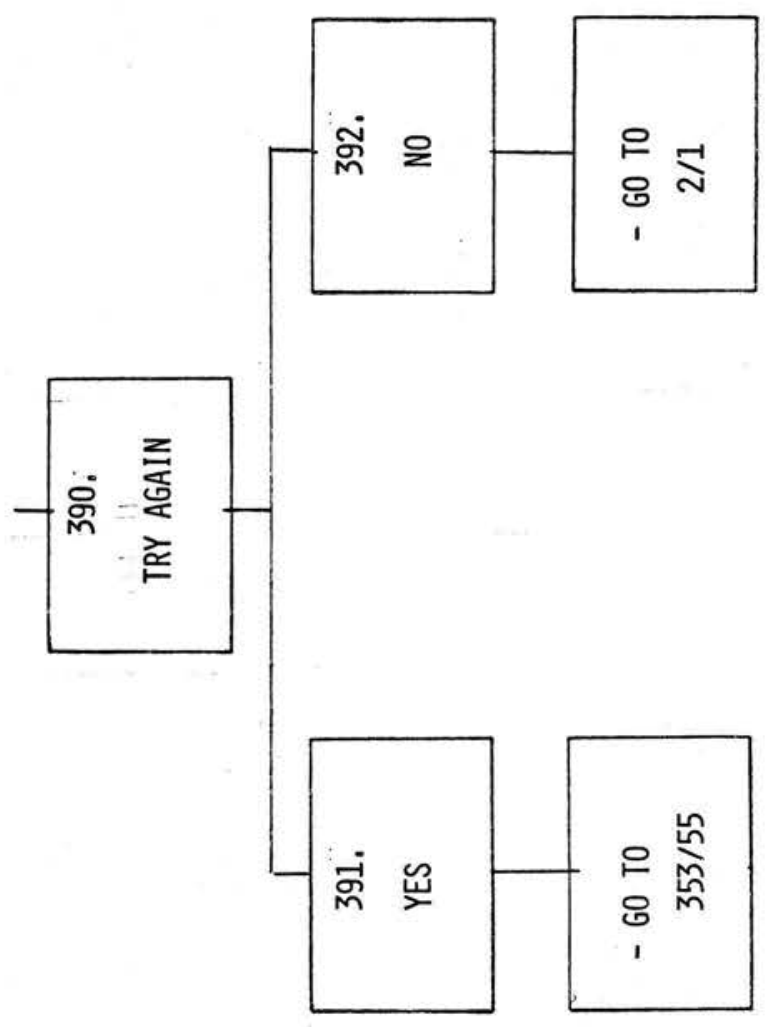




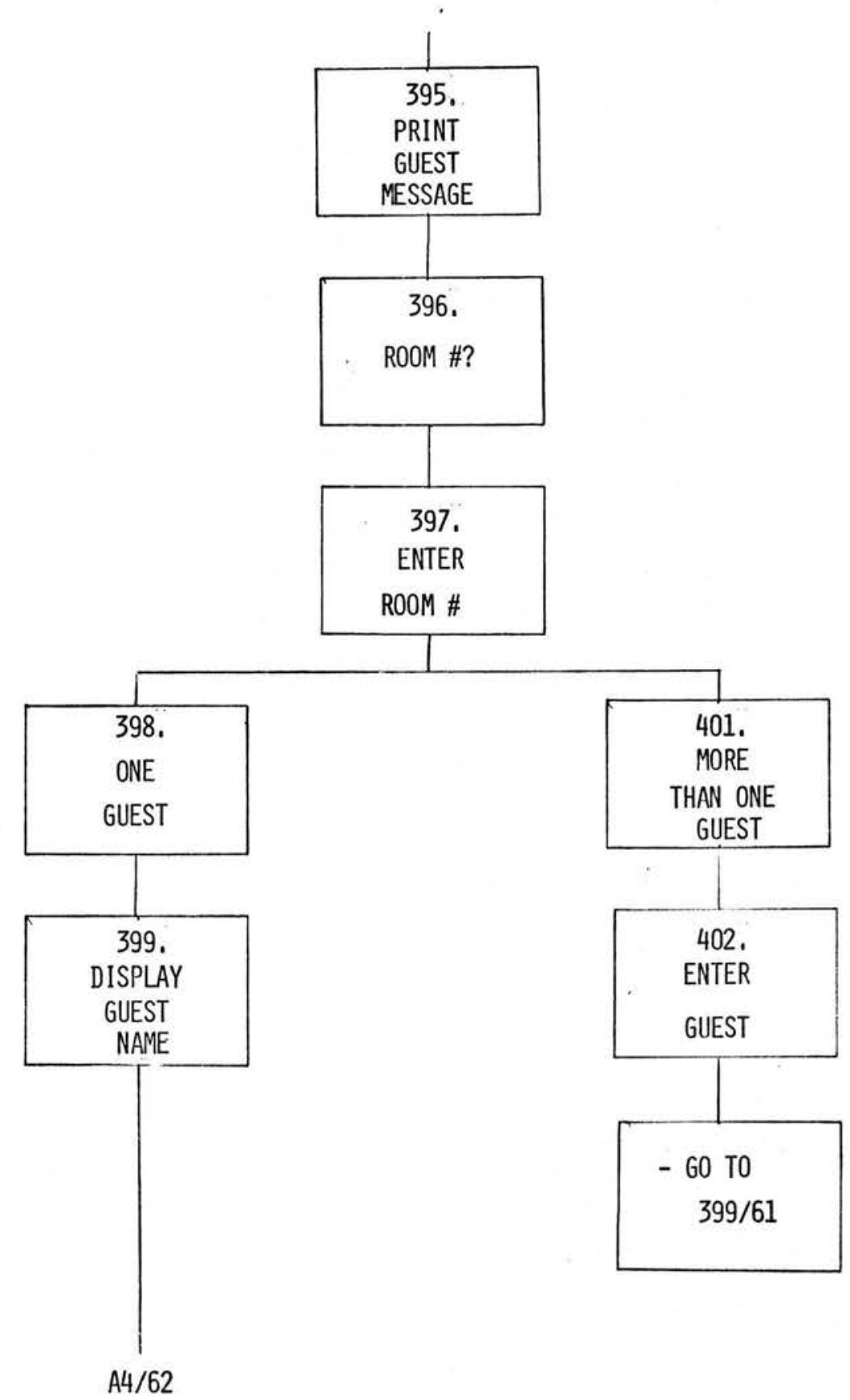




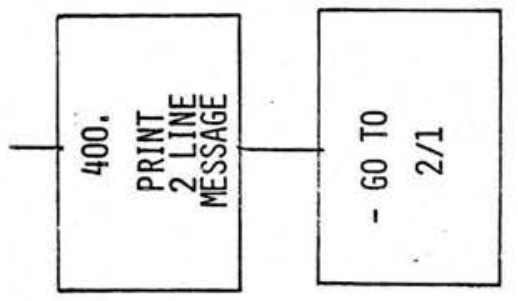




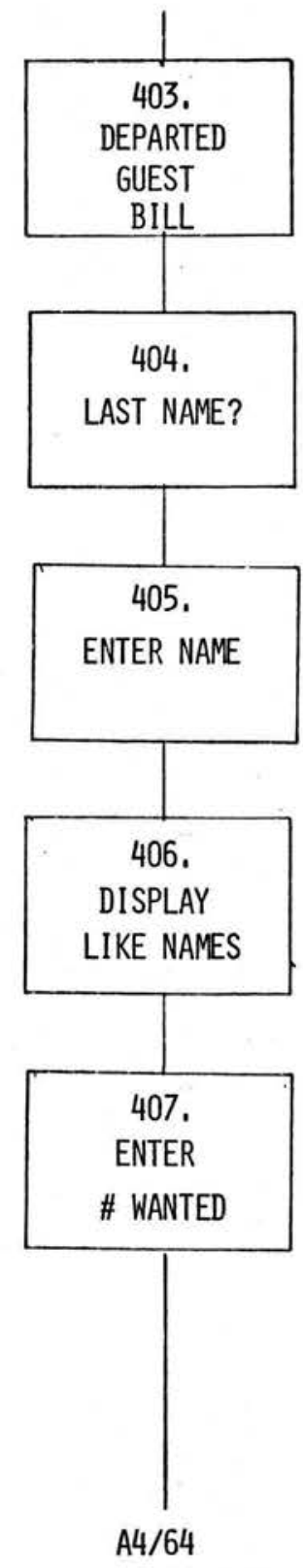




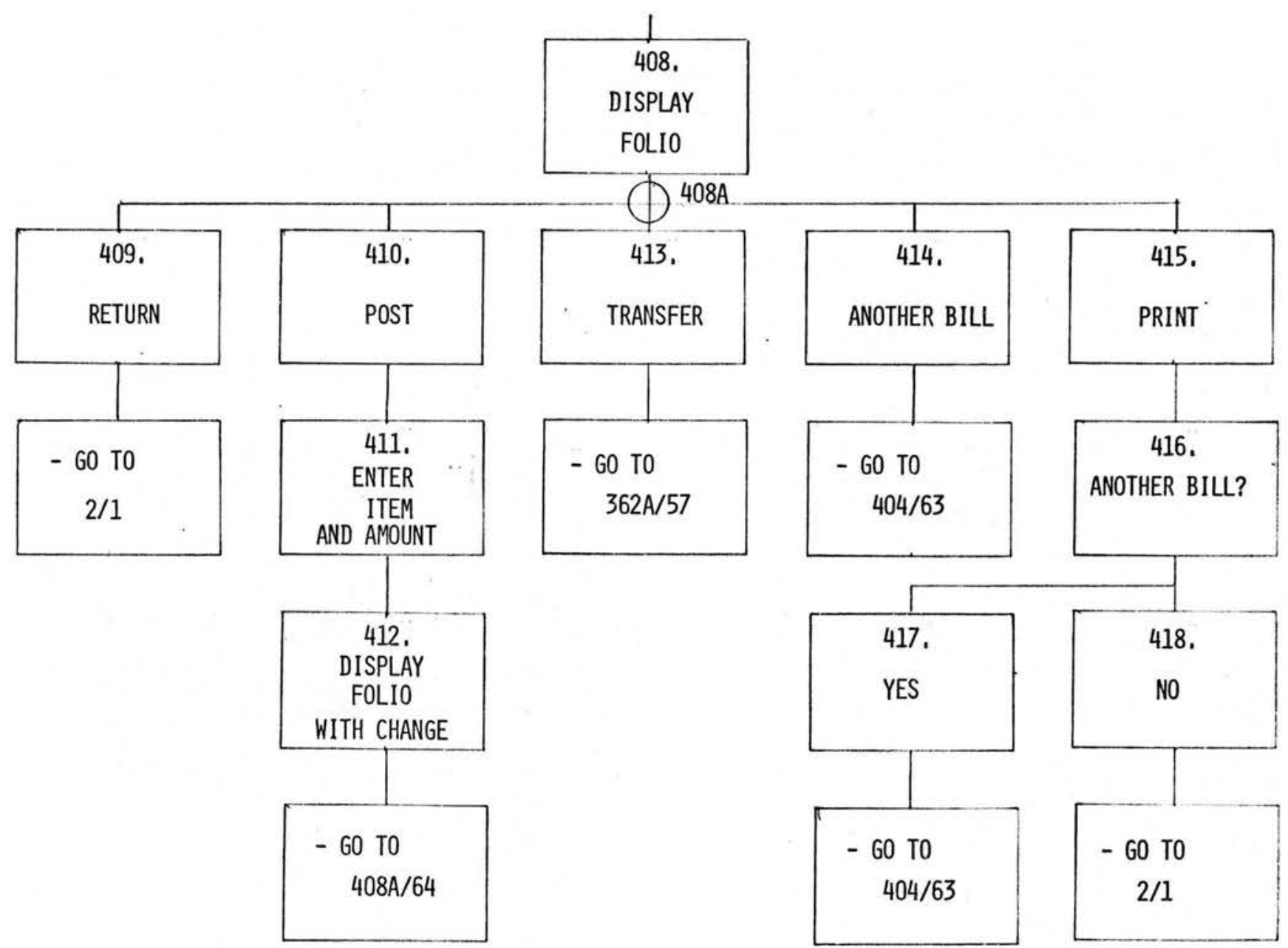




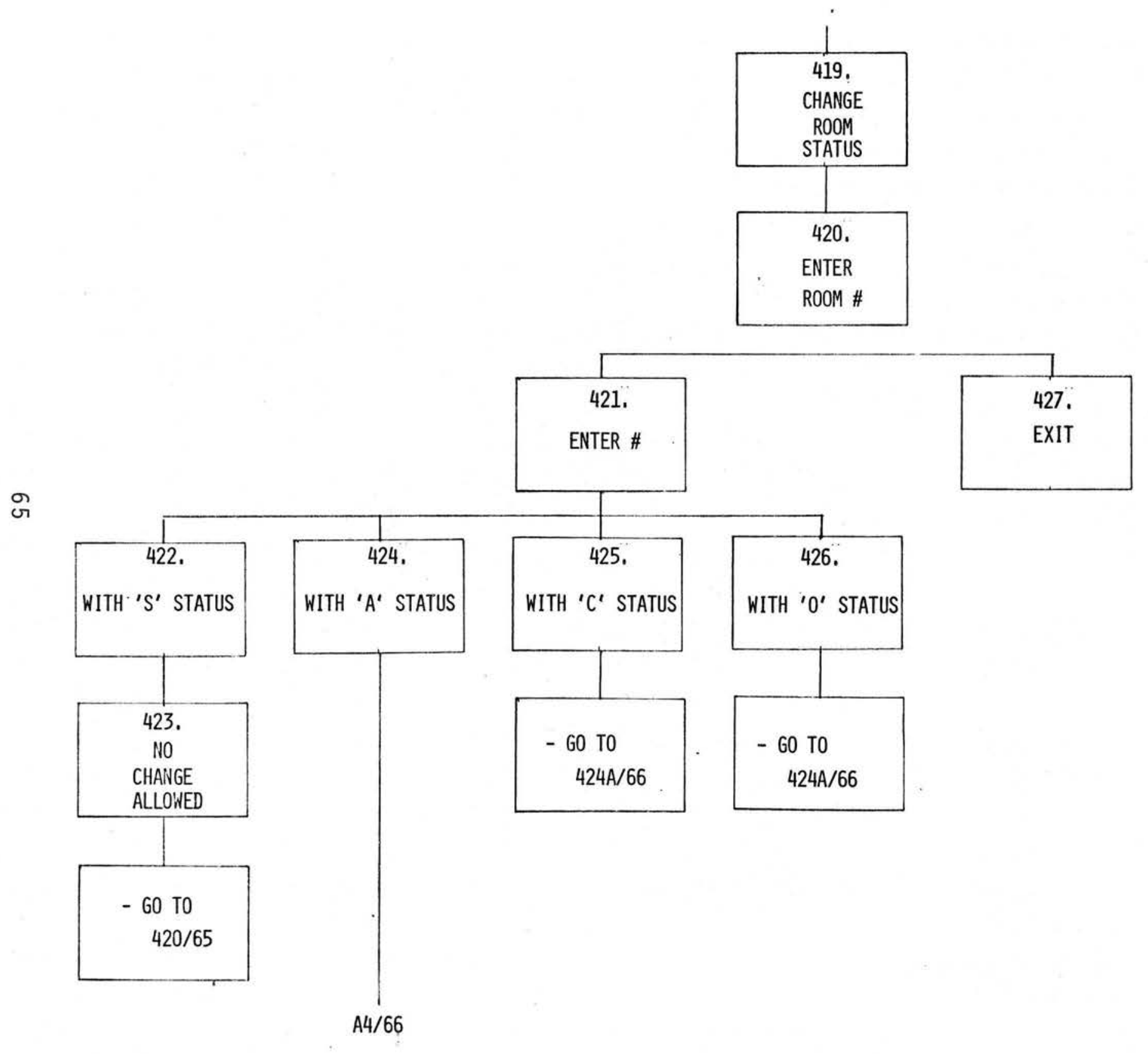




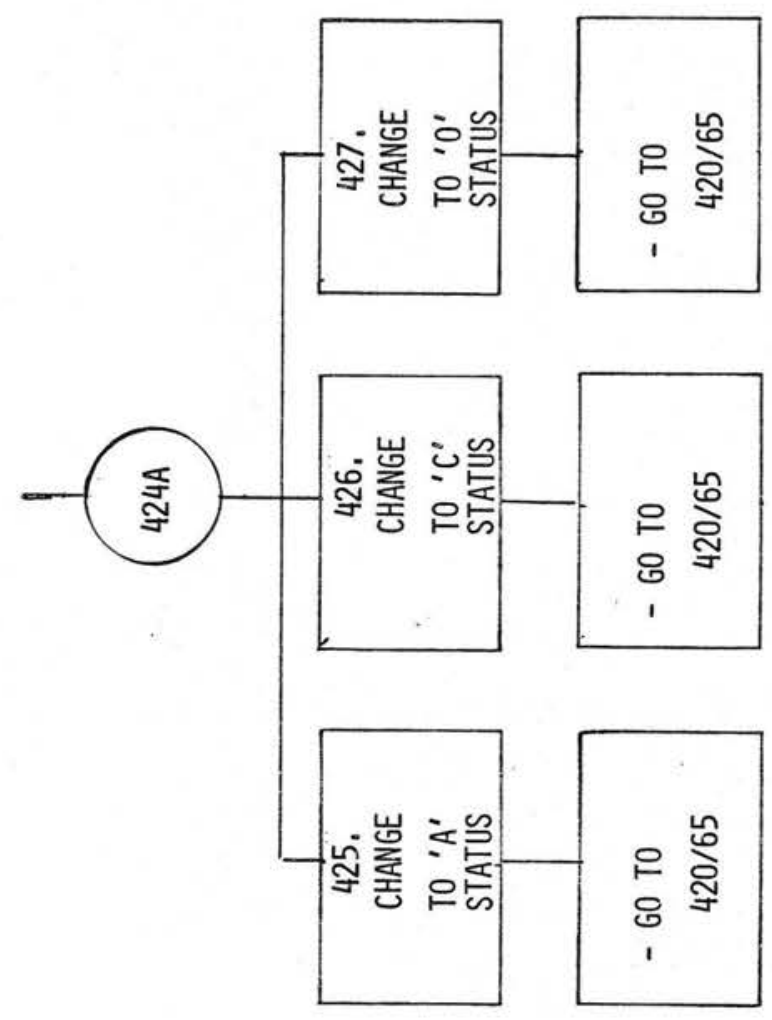




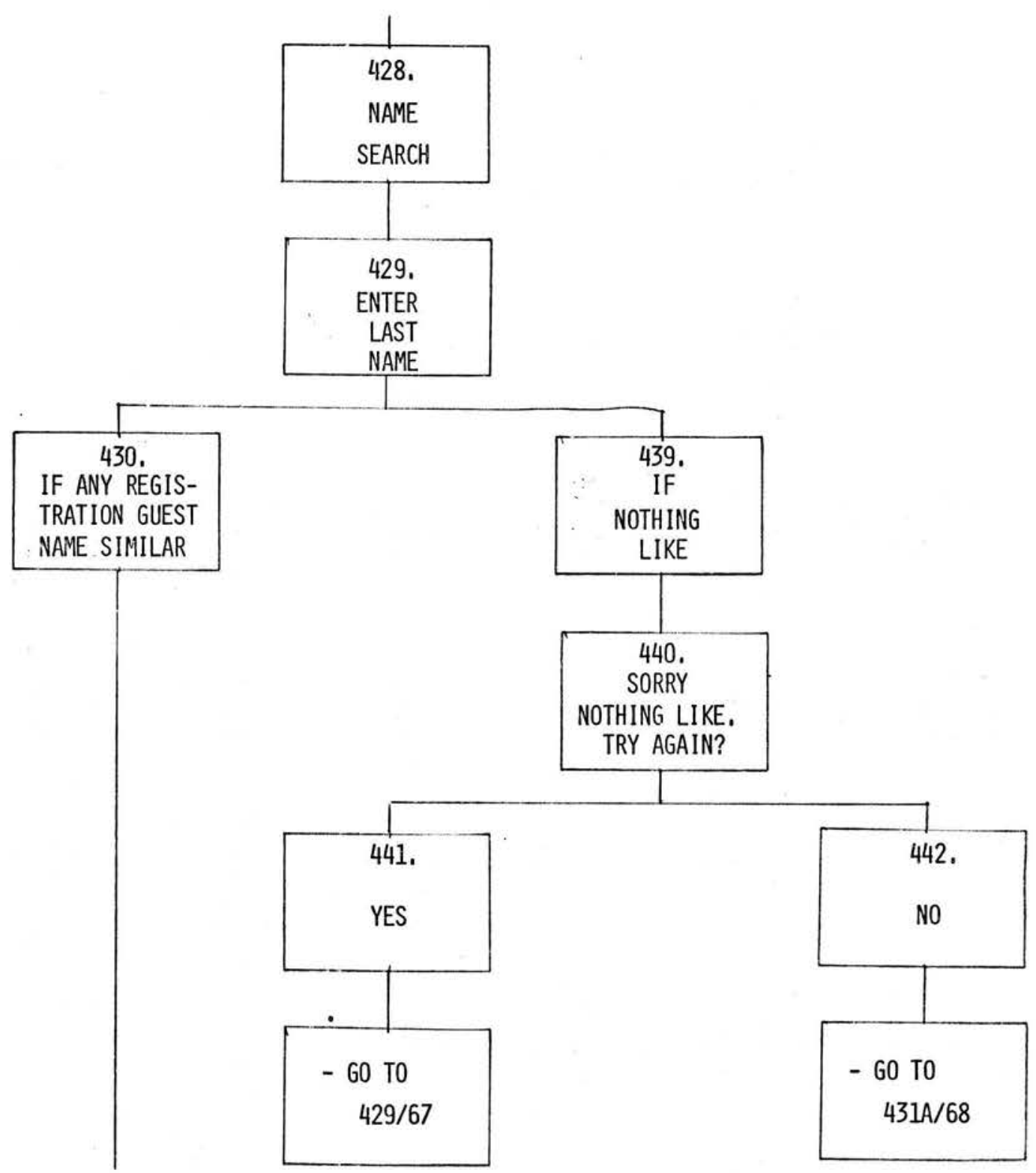



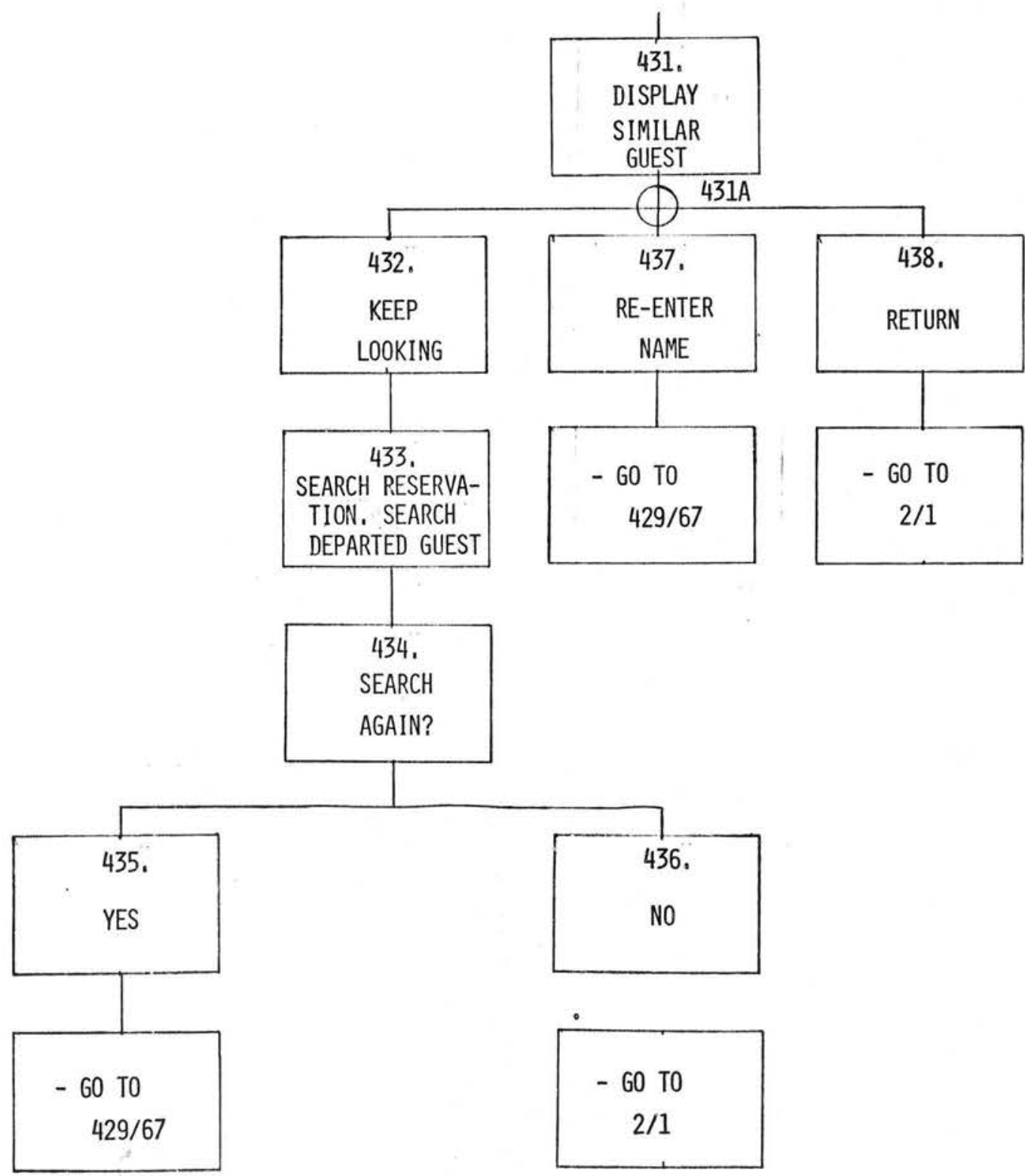


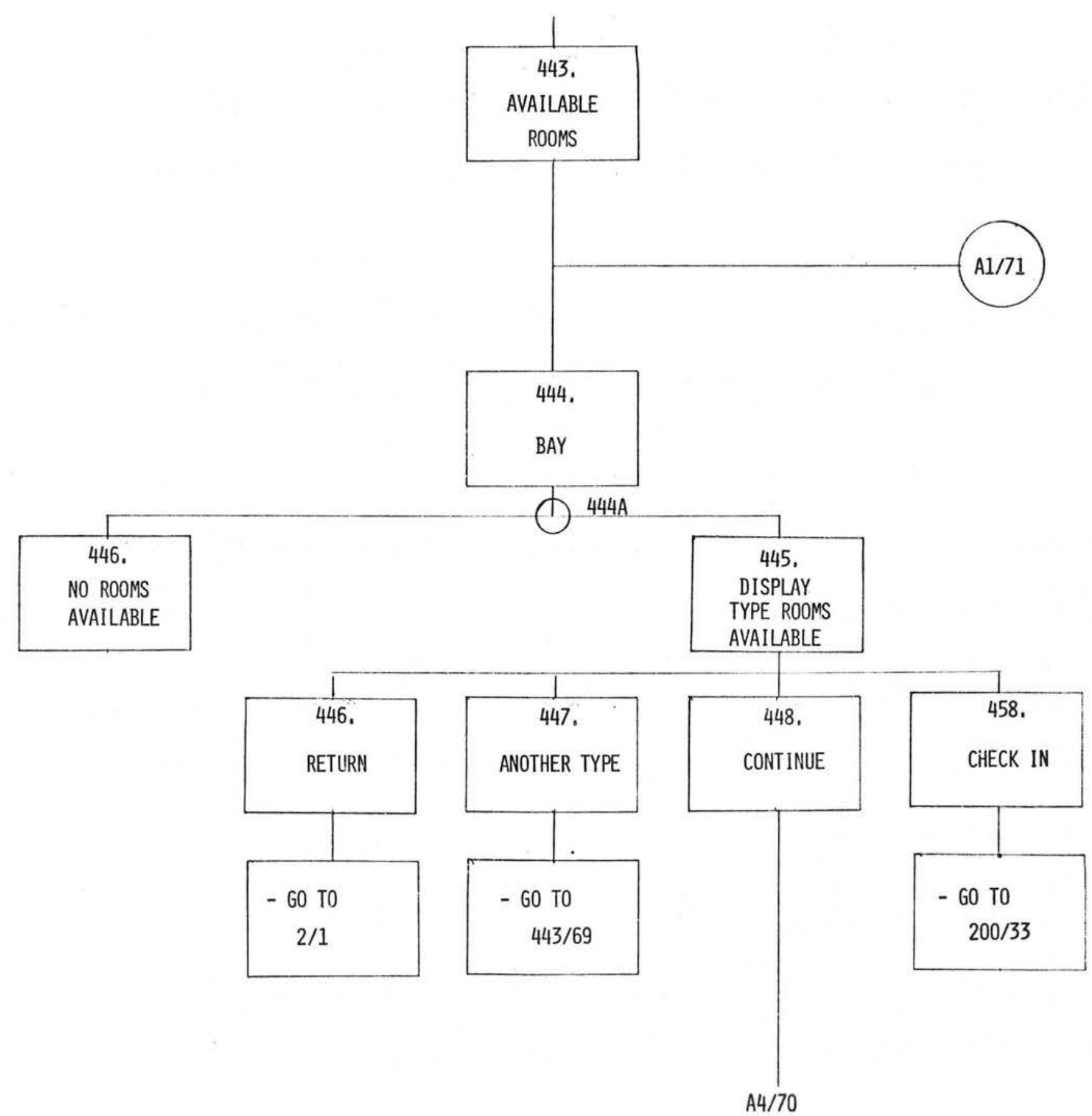




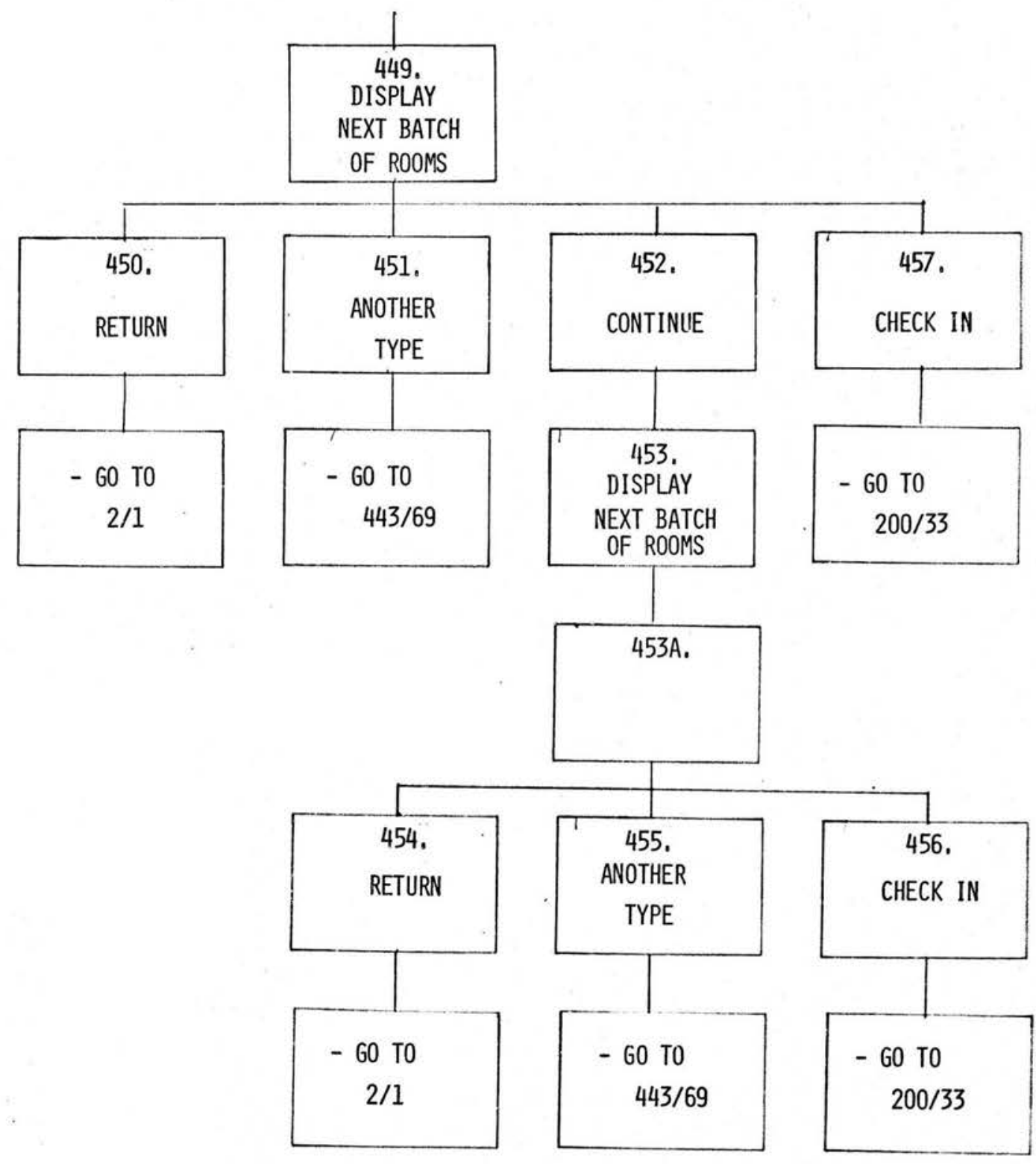




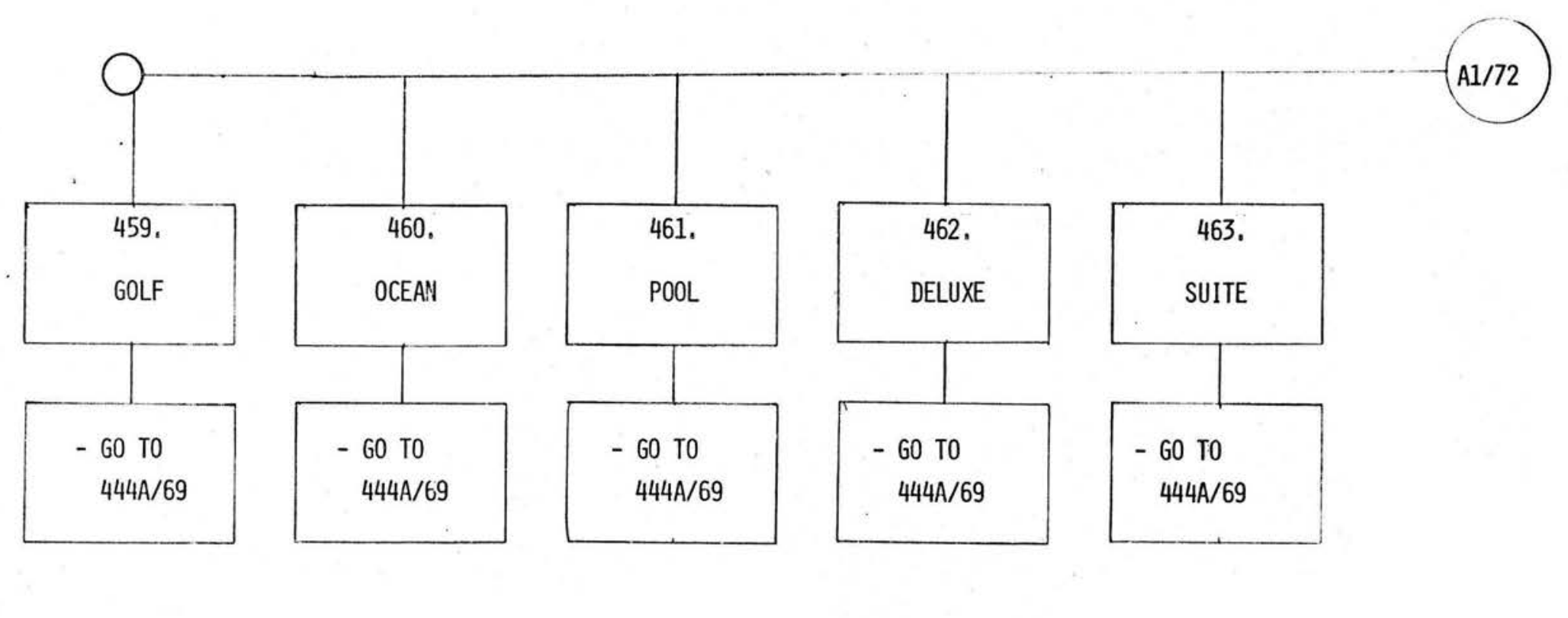




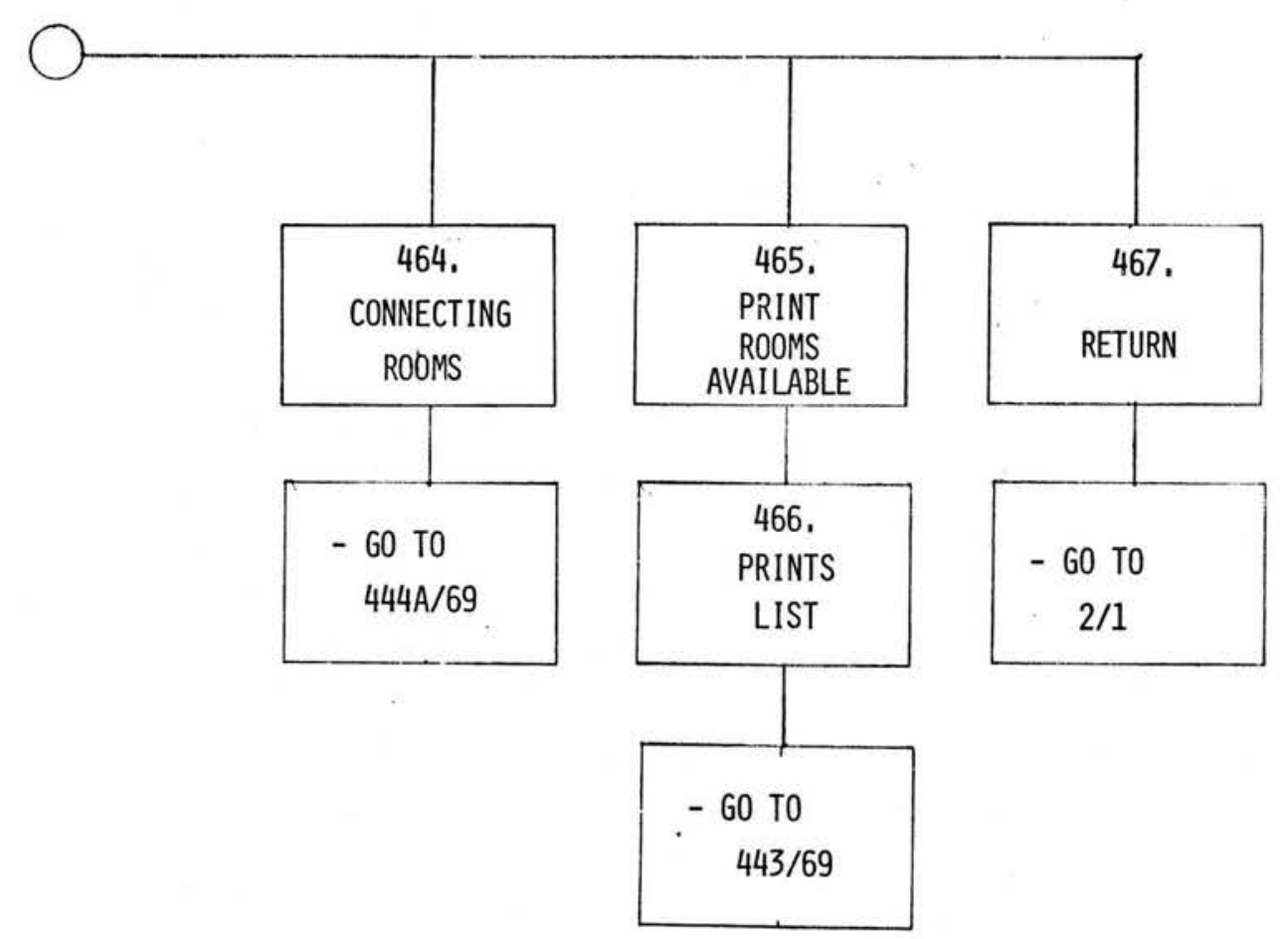




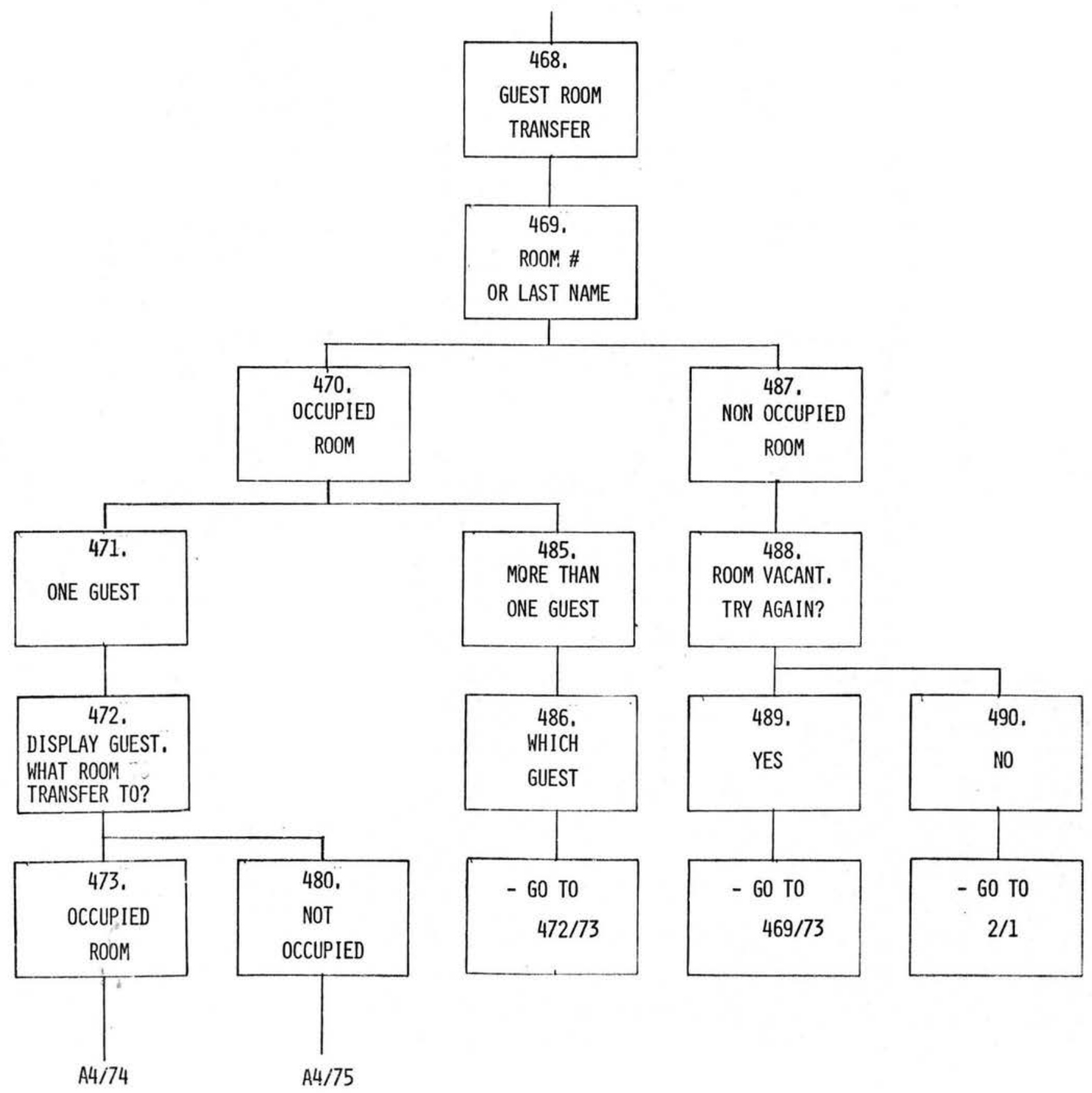




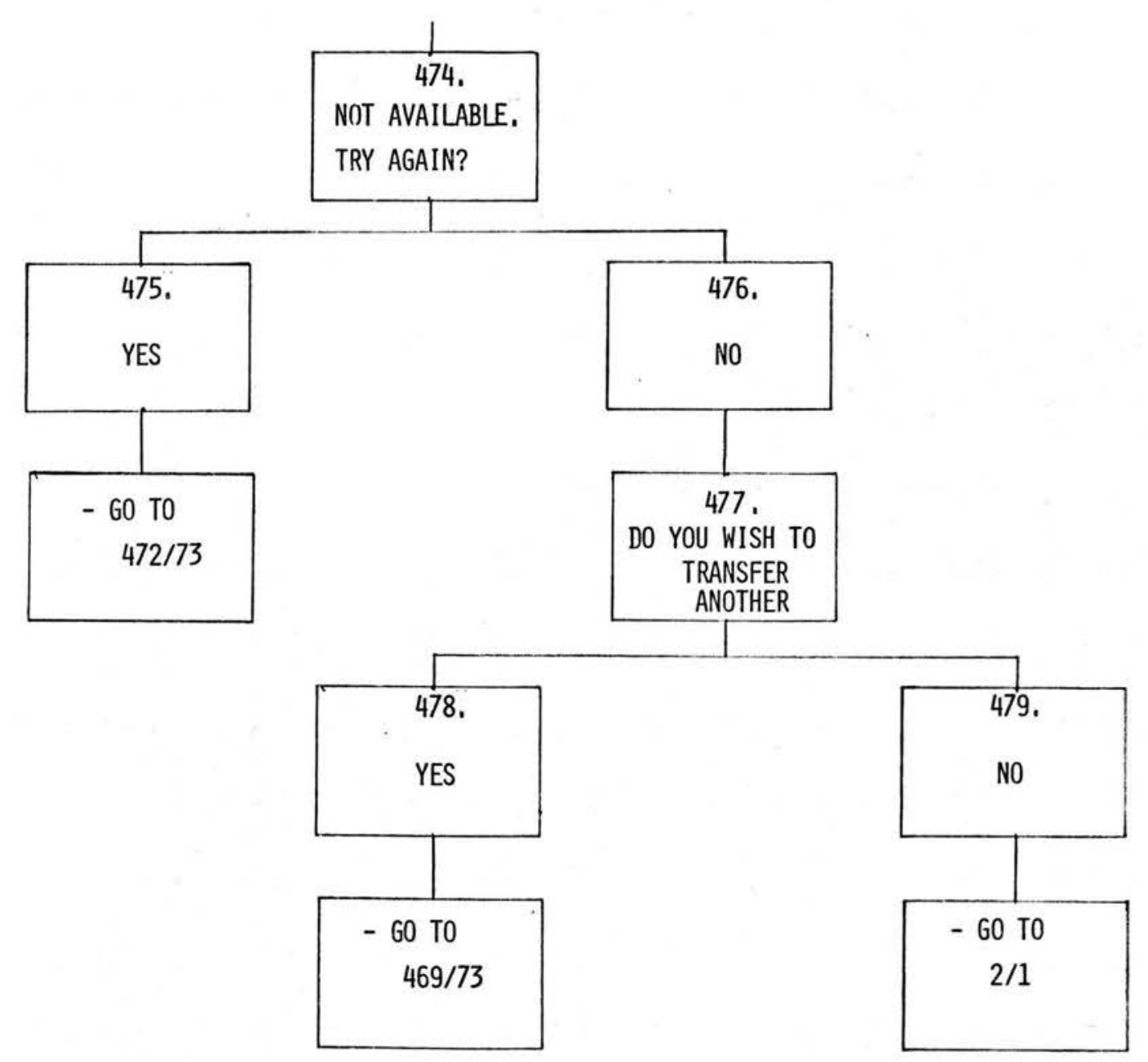




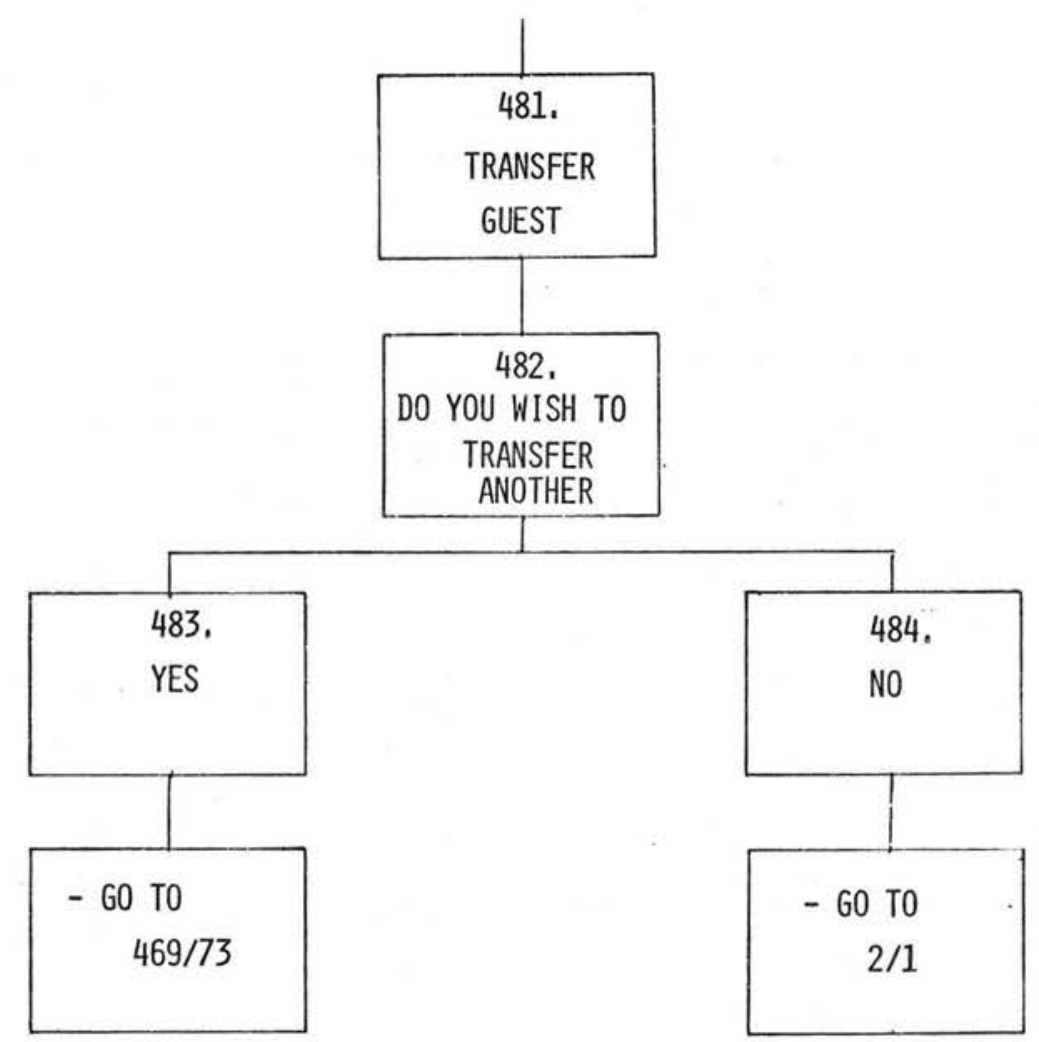




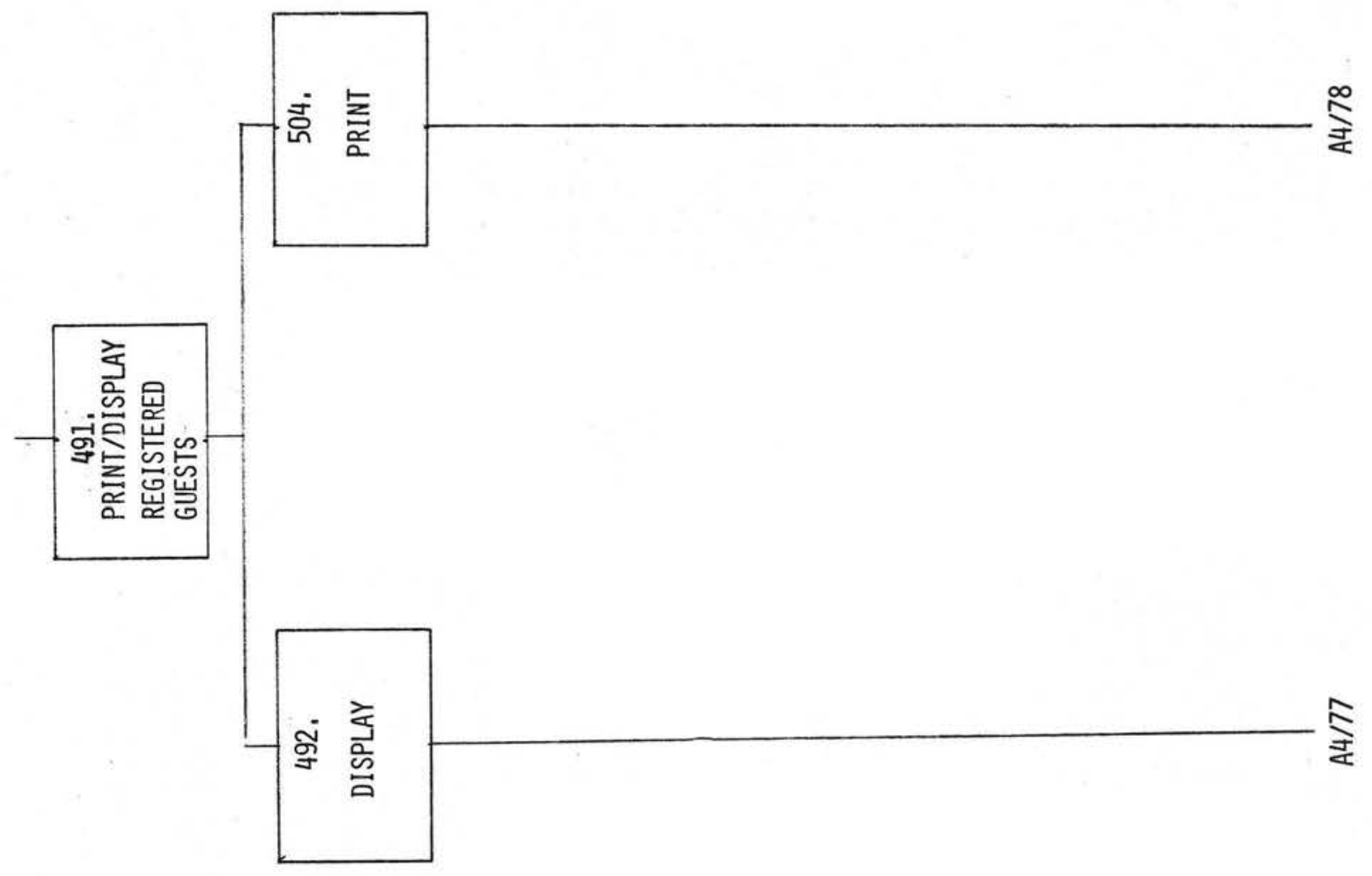




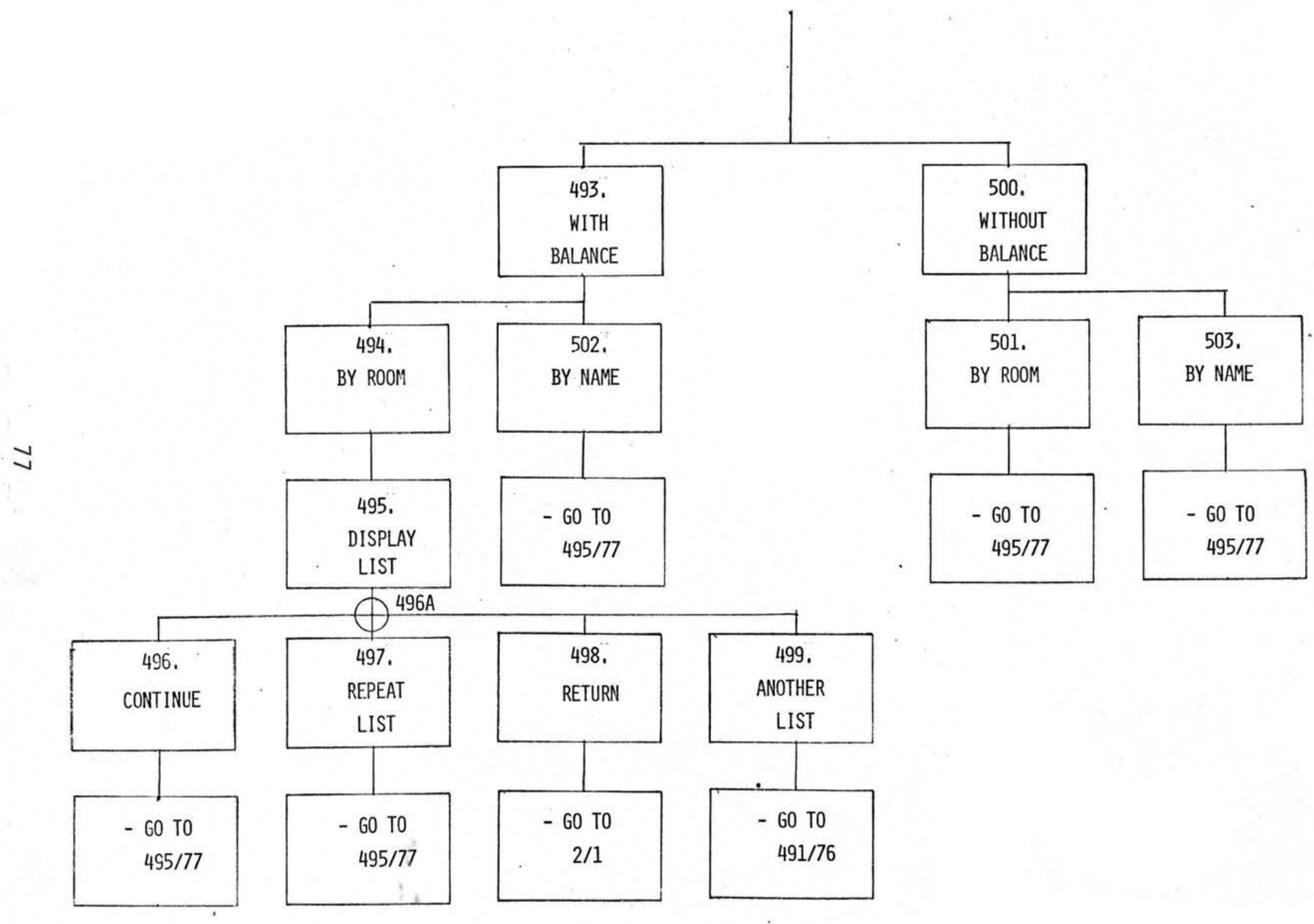




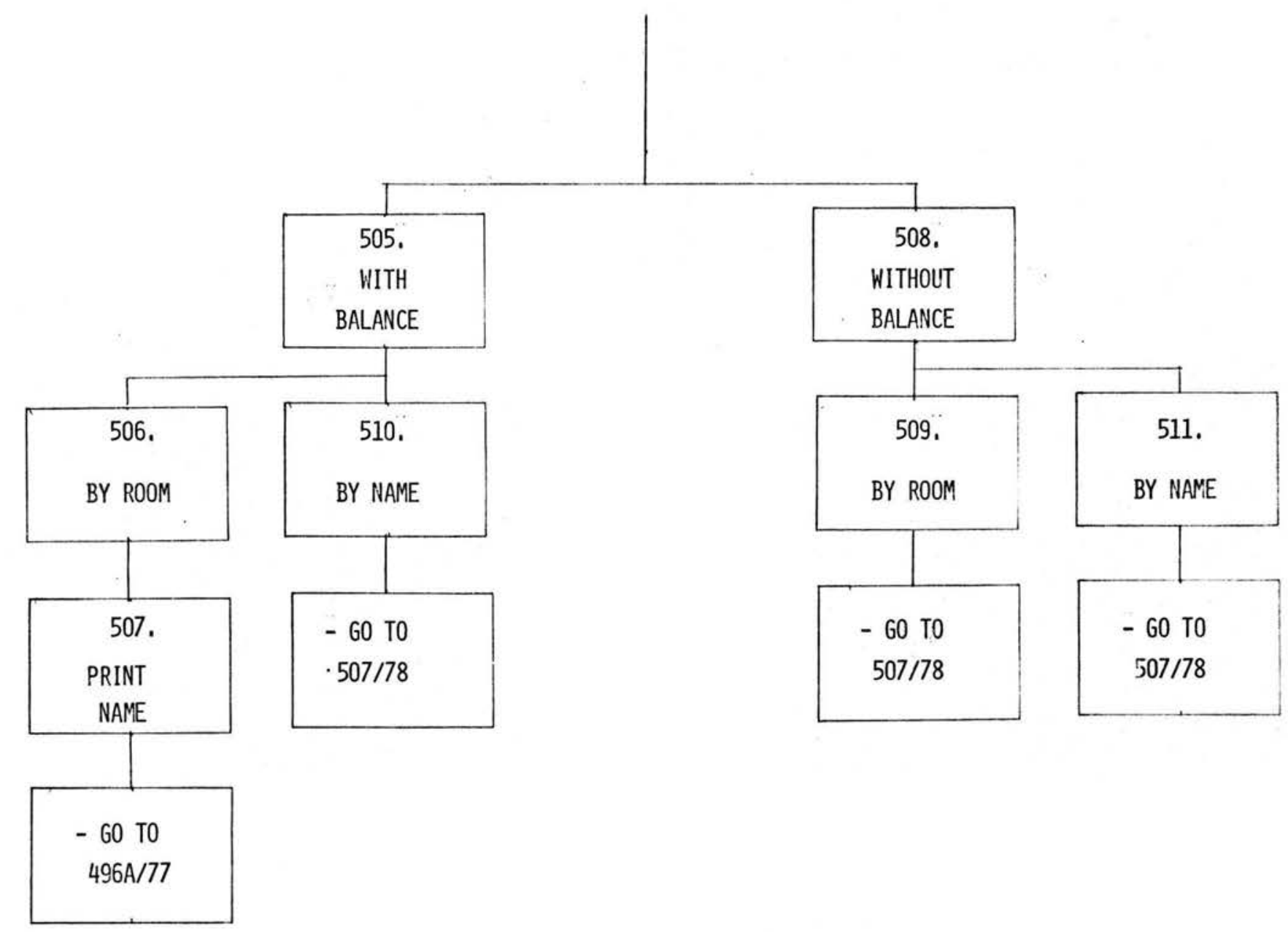




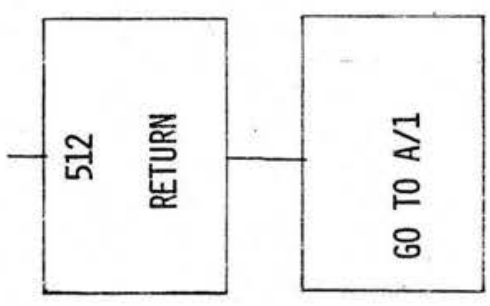

